\title{
Estudo Teórico de Propriedades Químicas de Sistemas Hetero- Macrocíclos que Complexam Metais de Transição Divalentes da Primeira e Segunda Filas
}

Tese apresentada ao Instituto de Química de São Carlos, da Universidade de São Paulo para obtenção do título de Doutor em Ciências.

Área de Concentração: Físico-Química

Orientador: Prof. Dr. Albérico Borges Ferreira da Silva 


\section{DEDICATÓRIA}

Dedico este trabalho às pessoas mais importantes e àqueles a quem mais amo: à minha mãe Francisca das Chagas Alves Lima, ao meu pai José da Costa Lima, à minha esposa Cleonice Lima Barrozo, aos meus filhos Malcon Ricardo Barrozo Lima e Matheus Henrique Barrozo Lima, e aos meus irmãos Maria da Conceição Alves Lima, Ana Paula Alves Lima, Cristiane Alves Lima, João Paulo Alves Lima e Jose Roberto Alves Lima. 


\section{AGRADECIMENTOS}

A Deus, por ter dado força nos momentos mais difíceis.

Ao Instituto de Química de São Carlos/USP, pelo apoio institucional e pelas facilidades oferecidas.

Ao Prof. Dr. Albérico Borges F. da Silva e Prof. Dr. José Walkimar de M. Carneiro, pela orientação e oportunidade de realização deste trabalho.

Aos meus avós, Emilia, Maria Gonçala, João Cheiroso e Raimundo Alves, aos tios, tias, primas e primos, que por serem muitos não citei seus nomes, pelo apoio e incentivo à realização deste trabalho.

Aos meus amigos de trabalho e do futebol, por terem ajudado em todos os momentos durante a realização deste trabalho.

Às pessoas da Química Estrutural (alunos, professores e funcionários) pela amizade demonstrada.

A CAPES, pelo suporte financeiro.

Enfim, a todos que, de alguma forma, colaboraram para a realização deste trabalho, os nossos mais sinceros agradecimentos. 


\section{ÍNDICE}

\section{CAPITULO I}

I-1. Introdução

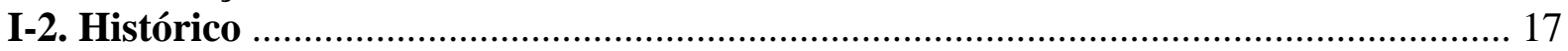

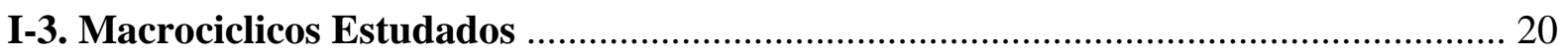

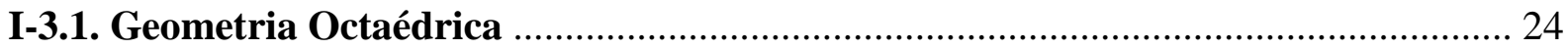

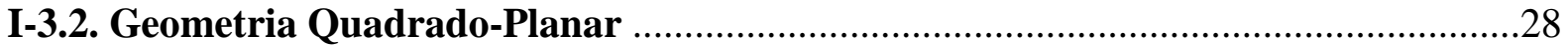

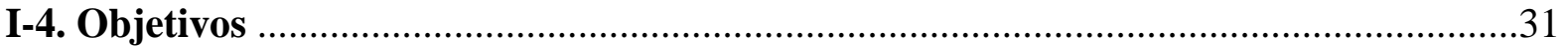

\section{CAPITULO II}

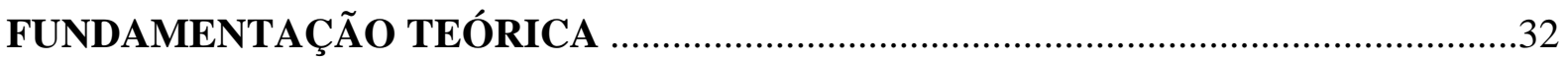

II-1. Introdução

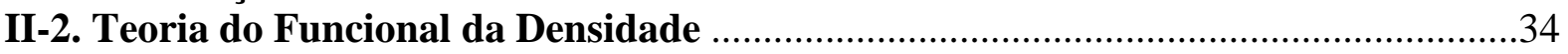

II-2.1. Formalismo Moderno da Teoria do Funcional da Densidade ...........................35

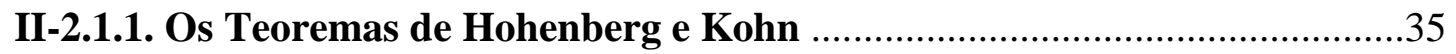

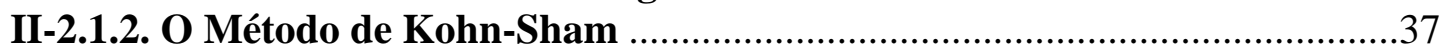

II-2.1.3. Aproximação LDA (Local-Density Approximation) …...........................39

II-2.1.4. Aproximação GGA (Generalized-Gradiente Approximation)................40

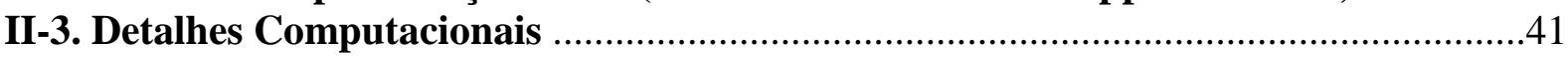

\section{CAPITULO III}

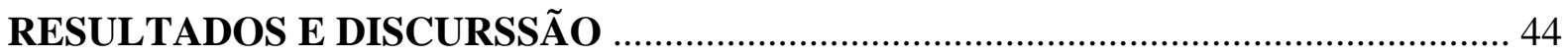

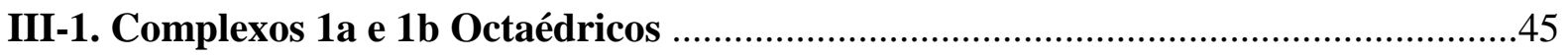

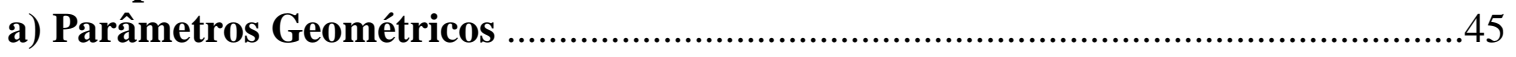

b) Energias Eletrônicas, Estabilidade Relativa dos Complexos e Energia de

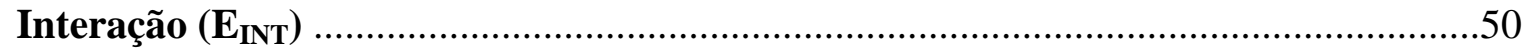

c) Análise dos Espectros Vibracionais de Infravermelho para os Complexos (1a) e

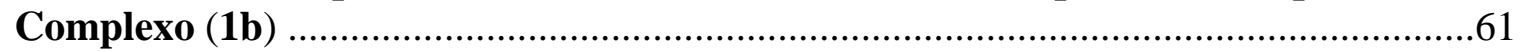

d) Análise das Ligações Químicas com CDA e Análise dos Orbitais Moleculares de

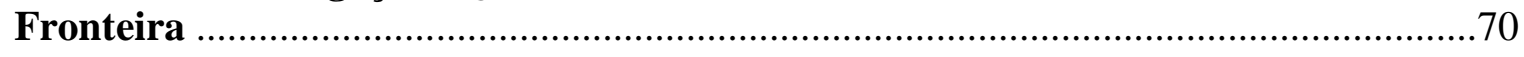

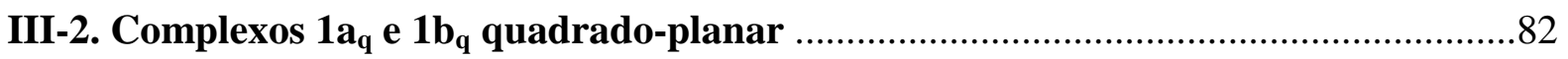

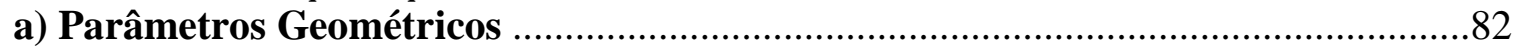

b) Energias Eletrônicas, Estabilidade Relativa dos Complexos e Energia de

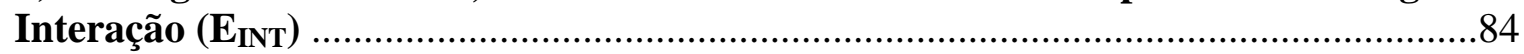

c) Análise dos Espectros Vibracionais de Infravermelho para os Complexos $\left(1 a_{q}\right)$ e

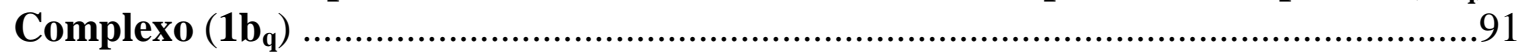

d) Análise dos Orbitais Moleculares nos Complexos $\left(\mathbf{1 a}_{\mathbf{q}}\right)$ e Complexos $\left(1 \mathbf{b}_{\mathbf{q}}\right) \ldots \ldots \ldots . . .95$

III-3. Complexos [20]aneL4(Oct) (Octaédricos) e [20]aneL4(qp) (Quadrado-Planar) 105

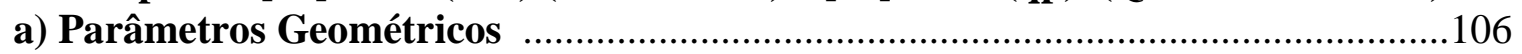

b) Energias Eletrônicas e Energia de Interação $\left(\mathbf{E}_{\mathrm{INT}}\right)$ dos Complexos ...................110

c) Energia de Perturbação de Segunda Ordem (E(2) ..........................................115 


\section{CAPITULO IV}

IV - CONCLUSÃO 123

Referências Bibliográficas 128

Apêndice A

ESTRUTURAS OCTAÉDRICAS DOS COMPLEXOS 1a e 1b 136

Apêndice B

ESTRUTURAS QUADRADO-PLANARES DOS COMPLEXOS $1 a_{q}$ e $1 b_{q}$ 142

Apêndice C: Análise da população natural (NPA- Natural Population Analysis) 148 Apêndice D

ESTRUTURAS OCTAÉDRICAS DOS COMPLEXOS [20]aneL4(Oct) 149

Apêndice E

ESTRUTURAS QUADRADO-PLANARES DOS COMPLEXOS [20]aneL4(qp)...155 


\section{LISTA DE FIGURAS}

Figura 1. Figura do macrocíclico [20] $\mathrm{aneN}_{4} \mathrm{O}_{4}$ com os átomos de nitrogênios como doadores. $\mathrm{Na}$ Figura as cores para os átomos de carbono (cinza), nitrogênio (azul), oxigênio (vermelho) e hidrogênio (branco)

Figura 2. Figura do macrocíclico [20] $\mathrm{aneO}_{4} \mathrm{~N}_{4}$ com os átomos de oxigênios como doadores. Na Figura as cores para os átomos de carbono (cinza), nitrogênio (azul), oxigênio (vermelho) e hidrogênio (branco)

Figura 3. Figura dos macrociclos com os átomos de nitrogênio e oxigênio como doadores: a) [20]aneN $\mathrm{N}_{4}$ e b) [20]ane $\mathrm{N}_{4}$. Na Figura as cores para os átomos de carbono (cinza), nitrogênio (azul), oxigênio (vermelho) e hidrogênio (branco)

Figura 4. Diagrama dos níveis de energia dos orbitais d num arranjo octaédrico ...................24 Figura 5. Possibilidades de (a) spin alto e (b) spin baixo para os complexos octaédricos de $\mathrm{d}^{4}$ $\mathrm{d}^{7}$ elétrons .26

Figura 6. Distorção tetragonal num complexo quadrado planar com íon de configuração $d^{8}$ : a) orbitais $e_{g}$ com quebra de degenerescência entre os orbitais $d_{x} 2-y 2$ e $d_{z} 2$. b) orbitais $d_{x y}$ com

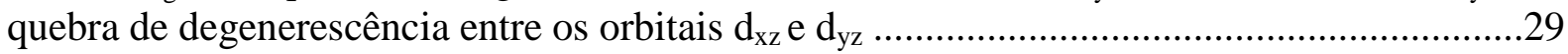

Figura 7. Forte distorção tetragonal provocada nos orbitais d do metal ..................................30 Figura 8. Distância média calculada para as ligações metal-nitrogênio (complexos 1a) e matel-oxigênio (complexos 1b)

Figura 9. Estruturas otimizadas e parâmetros geométricos dos ligantes macrociclos livres [20]aneN4O4 e [20]aneO4N4 calculadas com o modelo teórico B3LYP/Lanl2DZ. Os átomos de hidrogênios foram removidos pra melhor visualizar as estruturas

Figura 10. Energia de interação ( $\left.\mathrm{E}_{\mathrm{INT}}\right)$, em Kcal.mol ${ }^{-1}$, calculada para os complexos 1a e $\mathbf{1 b}$ formado pelo os elementos da primeira e segunda fila dos metais de transição ......................58 Figura 11. Distância média calculada teoricamente entre os átomos de nitrogênio do macrociclo [20]aneN4O4 (1a) ou do oxigênio do macrociclo [29]aneO4N4 (1b) com o íon metálico

Figura 12. Ordem de ligação de Mayer calculada para os complexos 1a e 1b com o programa AOMix-L

Figura 13. Espectros de teóricos de infravermelhos dos complexos 1a .68

Figura 14. Espectros de teóricos de infravermelhos dos complexos $\mathbf{1 b}$

Figura 15. Cargas NBO calculadas para os cátions $\mathrm{M}^{2+}$ da primeira e segunda fila e soma das cargas sobre os ligantes, oxigênio da água e nitrogênio do complexo 1a .............................75

Figura 16. Cargas NBO calculadas para os cátions $\mathrm{M}^{2+}$ da primeira e segunda fila e soma das cargas sobre os ligantes, oxigênio da água e nitrogênio do complexo $\mathbf{1 b}$...............................75

Figura 17. Diagrama dos orbitais moleculares dos complexos $1 \mathbf{a}$ formados pelos os íons

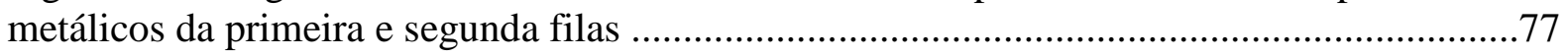

Figura 18. Diagrama dos orbitais moleculares dos complexos $\mathbf{1 b}$ formados pelos os íons metálicos da primeira e segunda filas .77

Figure 19. Orbitais moleculares de fronteira de spin $\alpha$ e $\beta$ calculados para os complexos $1 \mathbf{a}$ e 1b, de camada aberta, em nível de teoria DFT/B3LYP. Na figura as cores para os átomos de carbono (cinza), nitrogênio (azul), oxigênio (vermelho) e hidrogênio (branco) .....................79 Figure 20. Orbitais moleculares de fronteira calculados para os complexos 1a e 1b, de camada fechada, em nível de teoria DFT/B3LYP. Na figura as cores para os átomos de carbono (cinza), nitrogênio (azul), oxigênio (vermelho) e hidrogênio (branco) .80 Figura 21. Estruturas otimizadas dos complexos $\mathbf{1 a}_{\mathbf{q}}$ e $\mathbf{1 b}_{\mathbf{q}}$ com o íon $\mathrm{Fe}^{2+}$ calculadas em nível de teoria DFT/B3LYP 
Figura 22. Estrutura otimizada para complexo $\mathbf{1 b}_{\mathbf{q}}$ com íon de ferro de spin alto. Os átomos de hidrogênio foram removidos para melhor visualização da molécula

Figura 23. Energia de interação ( $\left.\mathrm{E}_{\mathrm{INT}}\right)$, em Kcal.mol ${ }^{-1}$, calculada para os complexos $\mathbf{1 a}_{\mathbf{q}}$ e $\mathbf{1 b}_{\mathbf{q}}$ formado pelo os íons da primeira e segunda fila dos metais de transição ...............................90 Figura 24. Espectro teórico de infravermelho calculado em nível de teoria DFT para o

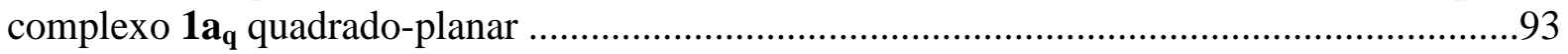
Figura 25. Espectro teórico de infravermelho calculado em nível de teoria DFT para o complexo $\mathbf{1} \mathbf{b}_{\mathbf{q}}$ quadrado-planar .94

Figura 26. Cargas NBO sobre o metal e os ligantes $(\mathrm{N})$ calculadas com B3LYP/Lanl2DZ para os complexos $1 \mathbf{a}_{\mathbf{q}}$ quadrado-planar .98

Figura 27. Cargas NBO sobre o metal e os ligantes $(\mathrm{N})$ calculadas com B3LYP/Lanl2DZ para os complexos $1 \mathbf{a}_{\mathbf{q}}$ quadrado-planar . .99 Figura 28. Diagrama dos orbitais moleculares dos complexos $\mathbf{1} \mathbf{a}_{\mathbf{q}}$ de arranjo quadrado-planar formados pelos os íons metálicos da primeira e segunda fila 100 Figura 29. Diagrama dos orbitais moleculares dos complexos $\mathbf{1} \mathbf{b}_{\mathbf{q}}$ de arranjo quadrado-planar formados pelos os íons metálicos da primeira e segunda fila ..............................................101 Figure 30. Orbitais moleculares de fronteira calculados para os complexos $\mathbf{1 a}_{\mathbf{q}}$ e $\mathbf{1 b}_{\mathbf{q}}$, de camada fechada, em nível de teoria DFT/B3LYP. Na figura as cores para os átomos de carbono (cinza), nitrogênio (azul), oxigênio (vermelho) e hidrogênio

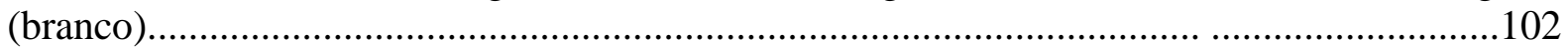

Figure 31. Orbitais moleculares de fronteira calculados para os complexos $\mathbf{1 a}_{\mathbf{q}}$ e $\mathbf{1 b}_{\mathbf{q}}$, de

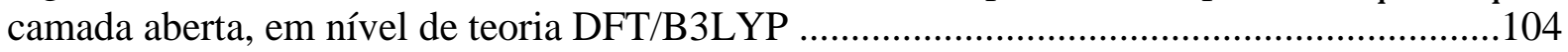
Figura 32. Estruturas otimizadas para os complexos octaédrico e quadrado-planar e ferro e paládio 106

Figura 33. Estruturas otimizadas e parâmetros geométricos dos ligantes macrociclos livres [20]aneN4 e [20]aneO4 calculadas com o modelo teórico B3LYP/Lanl2DZ. Os átomos de hidrogênios foram removidos pra melhor visualizar as estruturas 110 


\section{LISTA DE TABELAS}

Tabela 1. Distâncias de ligações $(\AA)$ e ângulos de ligações $\left(^{\circ}\right)$ calculados para o complexo de $\mathrm{Ni}^{2+}$ (1a) comparado com os valores experimentais obtidos por raios-X ................................45 Tabela 2. Parâmetros geométricos calculados em nível de teoria DFT/B3LYP com o conjunto de base Lanl2DZ para o complexo 1a

Tabela 3. Parâmetros geométricos calculados em nível de teoria DFT/B3LYP com o conjunto de base Lanl2DZ para o complexo 1b

Tabela 4. Energia Eletrônica, em Hartree, e cargas atômica NBO sobre os heteroátomos calculadas em nível de teoria DFT/B3LYP com o conjunto de base Lanl2DZ para os ligantes livre [20]aneN4O4 e [20]aneO4N4

Tabela 5. Energia absoluta e energia relativa calculadas com B3LYP/Lanl2DZ para os

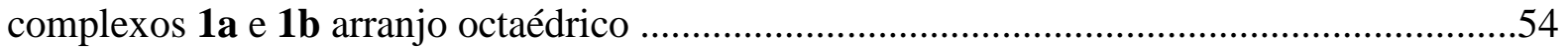

Tabela 6. Energia de interação entre os macrociclos [20]ane $\mathrm{N}_{4} \mathrm{O}_{4}$ e [20]ane $\mathrm{O}_{4} \mathrm{~N}_{4}$ e duas moléculas de água com íons dos metais de transição calculadas com B3LYP/Lanl2DZ para os complexos 1a e 1b

Tabela 7. Distância metal-ligante selecionada, em $\AA$, para os complexos 1a e Complexo 1b calculadas em nível de teoria B3LYP com o conjunto de base Lanl2DZ

Tabela 8. Freqüências vibracionais calculadas em nível de teoria B3LYP/LanL2DZ para os complexos 1a, de arranjo octaédrico

Tabela 9. Freqüências vibracionais calculadas em nível de teoria B3LYP/Lanl2DZ para os complexos $\mathbf{1 b}$ de arranjo octaédrico

Tabela 10. Análise de decomposição de cargas obtida para os complexos 1a e 1b, de camada fechada, calculados com o modelo B3LYP/Lanl2DZ

Tabela 11. Análise de decomposição de cargas obtida para os complexos 1a e 1b, de camada aberta, calculados com o modelo B3LYP/Lanl2DZ

Tabela 12. Parâmetros geométricos calculados em nível de teoria DFT/B3LYP com o

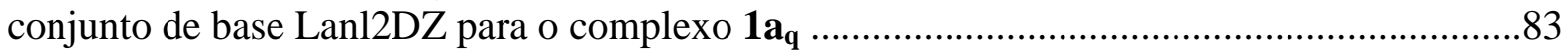
Tabela 13. Parâmetros geométricos calculados em nível de teoria DFT/B3LYP com o

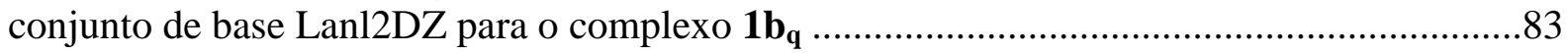
Tabela 14. Energia absoluta e energia relativa calculadas com B3LYP/Lanl2DZ para os

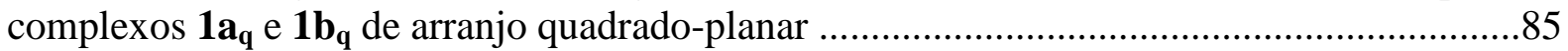
Tabela 15. Parâmetros geométricos selecionados do complexo $\mathbf{1 b}_{\mathbf{q}}$ com íon de ferro de spin alto .....

Tabela 16. Energia de interação ( $\left.\mathrm{E}_{\mathrm{INT}}\right)$ entre os macrociclos [20]ane $\mathrm{N}_{4} \mathrm{O}_{4}$ e [20]ane $\mathrm{O}_{4} \mathrm{~N}_{4}$ com íons dos metais de transição calculadas com B3LYP/Lanl2DZ para os complexos $\mathbf{1 a}_{\mathbf{q}}$ e $\mathbf{1 b}_{\mathbf{q}}$

Tabela 17. Freqüência vibracional teórico calculado em nível de teoria DFT para os complexos 1a e 1b de arranjo quadrado-planar ................................................................91 Tabela 18. Análise de decomposição de cargas obtida para os complexos $\mathbf{1 a}_{\mathbf{q}}$ e $\mathbf{1 b}_{\mathbf{q}}$, de camada fechada, calculados com o modelo B3LYP/Lanl2DZ

Tabela 19. Análise de decomposição de cargas obtida para os complexos $\mathbf{1 a}_{\mathbf{q}}$ e $\mathbf{1 b}_{\mathbf{q}}$, de camada aberta, calculados com o modelo B3LYP/Lanl2DZ

Tabela 20. Parâmetros geométricos calculados em nível de teoria DFT/B3LYP com o conjunto de base Lanl2DZ para o complexo [20]aneN4(Oct).... 
Tabela 21. Parâmetros geométricos calculados em nível de teoria DFT/B3LYP com o conjunto de base Lanl2DZ para o complexo [20]aneO4(Oct)

Tabela 22. Parâmetros geométricos calculados em nível de teoria DFT/B3LYP com o conjunto de base Lanl2DZ para o complexo [20]aneN4(qp)

Tabela 23. Parâmetros geométricos calculados em nível de teoria DFT/B3LYP com o conjunto de base Lanl2DZ para o complexo [20]aneO4(qp)

Tabela 24. Energia eletrônica total calculada em nível de teoria DFT para os macrociclos [20]aneN4 e [20]aneO4

Tabela 25. Energia absoluta e energia relativa calculadas com B3LYP/Lanl2DZ para os complexos [20]aneN4(Oct) e [20]aneO4(Oct) de arranjo octaédrico

Tabela 26. Energia absoluta e energia relativa calculadas com B3LYP/Lanl2DZ para os complexos [20]aneN4(qp) e [20]aneO4(qp) de arranjo quadrado-planar

Tabela 27. Energia de interação ( $\mathrm{E}_{\mathrm{INT}}$ ), em Kcal.mol ${ }^{-1}$, calculada para os complexos [20]aneN4(Oct) e [20]aneO4(Oct) em nível de teoria DFT

Tabela 28. Energia de interação $\left(\mathrm{E}_{\mathrm{INT}}\right)$, em Kcal.mol ${ }^{-1}$, calculada para os complexos [20]aneN4(qp) e [20]aneO4(qp) em nível de teoria DFT

Tabela 29. Energia de perturbação de seguanda ordem E(2), em Kcal.mol ${ }^{-1}$, e carga NBO sobre o íon metálico e os ligantes calculados para os complexos [20]aneO4(Oct) e [20]aneO4(Oct)

Tabela 30. Energia de perturbação de seguanda ordem E(2), em Kcal.mol ${ }^{-1}$, e carga NBO sobre o íon metálico e os ligantes calculados para os complexos [20]aneO4(qp) e [20]aneO4(qp) 118 


\section{LISTA DE ABREVIATURAS}

HK - Hohenberg-Kohn

KS - Kohn-Sham

LDA - Local-Density Approximation

GGA - Generalized-Gradiente Approximation

B3LYP - Funcional que possui três parâmetros hibrido de Lee-Yang-Parr

DFT - Density Functional Theory

ZPVE - Zero Point Vibration Energy

BSSE - Basis Set Superposition Error

POL - Polarização

TC - Transferência de Cargas

1a - complexos octaédricos tendo átomos de nitrogênio como doadores

1b - complexos octaédricos tendo átomos de oxigênio como doadores

$\mathbf{1 a}_{\mathbf{q}}$ - complexos quadrado-planares tendo átomos de nitrogênio como doadores

$\mathbf{1} \mathbf{b}_{\mathbf{q}}$ - complexos quadrado-planares tendo átomos de oxigênio como doadores

NPA - Natural Population Analysis 


\section{RESUMO}

Um estudo teórico detalhado das estruturas e energias do ligante 1, 7, 11, 17-tetraoxa2, 6, 12, 16-trazaocicloocsano ([20]aneN4O4) coordenado com íons metálicos de transição $\mathrm{Fe}^{2+}, \mathrm{Co}^{2+}, \mathrm{Ni}^{2+}, \mathrm{Ru}^{2+}, \mathrm{Rh}^{2+}$ e $\mathrm{Pd}^{2+}$ foi realizado em nível de teoria B3LYP/Lanl2DZ. As geometrias dos complexos foram totalmente otimizados em simetria $\mathrm{C}_{\mathrm{s}}$ com os íons metálicos coordenados com quatro átomos de nitrogênio (complexos $\mathbf{1 a}$ e $\mathbf{1} \mathbf{a}_{\mathbf{q}}$ ) ou quatro átomos de oxigênios (complexos $\mathbf{1 b}$ e $\mathbf{1} \mathbf{b}_{\mathbf{q}}$ ) e duas moléculas de água. Os arranjos octaédricos (1a e 1b) e quadrado-planares $\left(\mathbf{1}_{\mathbf{q}}\right.$ e $\left.\mathbf{1 b}_{\mathbf{q}}\right)$ foram consideremos neste trabalho. A estrutura teórica está em excelente acordo com a estrutura de difração de raio-x experimental determinada para 0 complexo octaédrico de $\mathrm{Ni}^{2+}$ de [20] $\mathrm{AneN}_{4} \mathrm{O}_{4}$. Os cátions $\mathrm{M}^{2+}$ ligam-se preferencialmente aos átomos de nitrogênios com energia de ligação que aumenta na ordem $\mathrm{Fe}^{2+}<\mathrm{Ru}^{2+}<\mathrm{Co}^{2+}<$ $\mathrm{Ni}^{2+}<\mathrm{Rh}^{2+}<\mathrm{Pd}^{2+}$. Para os metais de transição da primeira fila, os complexos de spin alto são mais estáveis que os complexos de spin baixo. Em contraste, para os metais de transição da segunda fila, os estados de spin baixo mostraram-se mais estáveis que os estados de spin alto. As ligações metal-ligante nos complexos foram analisadas em termo das interações covalentes e iônicas e ajudaram a entender porque os complexos (1a e $\mathbf{1 a}_{\mathbf{q}}$ ) são mais estáveis que os complexos $\left(\mathbf{1 b}\right.$ e $\left.\mathbf{1} \mathbf{b}_{\mathbf{q}}\right)$.

Os complexos poliaminas [20]aneN4 e poliéteres [20]aneO4 foram obtidos substituindo os átomos de nitrogênio e oxigênio da posição alfa dos macrociclos [20]aneN4O4 e [20]aneO4N4, respectivamente. O macrociclo [20]aneO4 tem preferência em complexar íons metálicos da primeira fila, enquanto o macrociclo [20]aneN4 prefere complexar os íons metálicos da segunda fila. 


\begin{abstract}
A detailed theoretical study of structures and energies of the 1,7,11,17-tetraoxa2,6,12,16-tetraaza-cycloeicosane ligand ([20]AneN $\mathrm{A}_{4}$ ) coordinated to $\mathrm{Fe}^{2+}, \mathrm{Co}^{2+}, \mathrm{Ni}^{2+}, \mathrm{Ru}^{2+}$, $\mathrm{Rh}^{2+}$, and $\mathrm{Pd}^{2+}$ transition metals ions was carried out with the B3LYP/Lanl2DZ method. The geometries of the complexes were fully optimized in $\mathrm{C}_{\mathrm{s}}$ symmetry with the metal ions coordinated either to four atoms nitrogen (complexes 1a e 1b) or to the four atoms oxygen (complexes $1 \mathbf{a}_{\mathbf{q}}$ e $\mathbf{1 b}_{\mathbf{q}}$ ). The octahedral and square planar arrangements were considered in this work. The theoretical structure is in excellent agreement with the experimental X-ray diffraction structure determination for the [20]AneN $\mathrm{N}_{4} \mathrm{O}_{4}$ octahedral $\mathrm{Ni}^{2+}$ complex. The $\mathrm{M}^{2+}$ cations bind preferentially to the nitrogen atoms with binding energies that increase in the order $\mathrm{Fe}^{2+}<\mathrm{Ru}^{2+}<\mathrm{Co}^{2+}<\mathrm{Ni}^{2+}<\mathrm{Rh}^{2+}<\mathrm{Pd}^{2+}$. For the first-row transition metals, the highspin complexes are more stable than the low-spin complexes. In contrast, for the second-row of transition metals, the low-spin states were found more stable than the high spin states. The metal-ligand bonds in the complexes were analyzed in terms of the covalent and ionic interactions and helped to understand why complexes (1a e $\mathbf{1 a}_{\mathbf{q}}$ ) are more stable than complexes $\left(\mathbf{1 b}\right.$ e $\left.\mathbf{1} \mathbf{b}_{\mathbf{q}}\right)$.
\end{abstract}

The polyamines [20]aneN4 and polyethers [20]aneO4 complexes were obtained substituting the atoms $\mathrm{N}$ or $\mathrm{O}$ of the alfa position of the macrocycles [20]aneN4O4 and [20]aneO4N4, respectively. The macrocycle [20]aneO4 prefers to complex first-row transition metals; however, the macrocycle [20]aneN4 prefers to complex second-row transition metals. 


\section{CAPITULO I}

INTRODUÇÃO 


\section{I-1. Introdução}

Os compostos macrocíclicos contendo heteroátomos com pares de elétrons livres têm despertado grande interesse em vários campos de aplicação, destacando-se seu uso como agentes complexantes de cátions metálicos [1-3], na medicina [4-8], agentes terapêuticos [9] e em tratamento de resíduos [10-12].

A aplicação dos macrocíclicos na área da medicina e como agentes terapêuticos podem ser destacados no uso desses compostos na imagem de ressonância magnética (MRI Magnetics Resonance Imaging), uma vez que eles possuem um grande potencial na produção de radio-fármacos para diagnósticos e terapia de tumores [13]. Rádio-fármacos são moléculas radioativas projetadas para transportar doses limites de radiação no local específico da doença, tais como tumores, permitindo, assim, imagens ou tratamento das doenças [8]. Por esse efeito, o farmaco chega à célula afetada em quantidade suficiente para tratamento, minimizando assim, os danos da radiação nos tecidos normais.

Como a maioria das aplicações dos compostos macrocíclicos está associada à sua habilidade em complexar íons metálicos, torna-se fundamental o desenho e síntese de ligantes macrocíclicos que sejam capazes de discriminar entre os diferentes íons. A habilidade do ligante em controlar a seletividade do íon metálico é claramente de grande interesse em muitas áreas. Esta seletividade é comumente influenciada pela natureza e arranjo dos átomos doadores de pares de elétrons do ligante macrocíclico e também pelo tamanho do anel disponível para o cátion metálico [14-17]. Existe, portanto, uma contínua necessidade de investigação das propriedades de coordenação seletiva de novos agentes ligantes macrocíclicos.

São dois os fatores principais que controlam a estabilidade termodinâmica de um complexo entre um ligante macrocíclico e um cátion metálico e que, portanto, determinam à 
capacidade seletiva do ligante. Estes fatores são os requerimentos estéricos e as interações eletrônicas.

Do ponto de vista estérico, são relevantes os seguintes aspectos: tamanho do cátion, tamanho da cavidade do anel macrocíclico e a densidade de cargas sobre os ligantes do anel macrocíclico. Em alguns trabalhos, foi mostrado que a estabilidade termodinâmica relativa de um complexo é função direta do tamanho do cátion que participa do complexo [18]. Cátions menores são complexados preferencialmente por agentes ligantes contendo um pequeno número de sítios de coordenação. Os cátions maiores, por sua vez, são complexados de forma mais intensa por agentes que possuam vários átomos para coordenação [12]. O tamanho do anel do macrociclo é também um fator relevante. Os anéis menores têm dificuldade em acomodar os cátions de maior raio e, adicionalmente, possuem menor mobilidade conformacional. Os anéis maiores, por sua vez, têm baixa capacidade em coordenar cátions pequenos que formam complexos com número de coordenação baixo. Finalmente, são também importantes as interações que acontecem no próprio ligante. Estas se intensificam com a presença de substituintes ou com o aumento do número de sítios de coordenação [12].

Quanto às interações eletrônicas, estas podem ser essencialmente de dois tipos: interações puramente eletrostáticas e interações por superposição de orbitais. A primeira é observada principalmente entre as espécies duras (ligantes contendo átomos muito eletronegativos, tal como oxigênio) e cátions com orbital d com alta energia, tal como os cátions dos metais alcalinos e alcalinos terrosos. Observa-se, por exemplo, que ligantes onde os heteroátomos são átomos de oxigênio, como os éteres de coroa, complexam principalmente com os metais alcalinos e alcalinos terrosos. As interações por superposição de orbital envolvem principalmente ligantes básicos, contendo átomos de nitrogênio, e metais de transição com orbitais d disponíveis de baixa energia. 
Os fatores mencionados acima, sejam de natureza estérica ou de natureza eletrônica, são freqüentemente objetos de estudos na área da química teórica. No entanto, cálculos teóricos em sistemas hetero-macrocíclicos têm sido pouco estudados. Desta forma, neste trabalho propõe-se empregar métodos sofisticados de química teórica computacional para estudar propriedades químicas e físico-químicas dos sistemas macrociclos e seus complexos, tendo como referência o oxa-azamacrociclo, conforme será detalhado na seção dos objetivos desta tese.

\section{I-2. Histórico}

A química de coordenação de macrociclos com oxigênio ou nitrogênio como heteroátomo complexando íons metálicos tem sido muito estudada teoricamente e experimentalmente nas ultimas décadas [18-25]. O primeiro tem grande habilidade em complexar fortemente metais alcalinos e alcalinos terrosos [26]. Por outro lado, eles coordenam apenas fracamente com os cátions dos metais de transição com orbitais d e f de baixa energia [27-30]. Os macrociclos com átomos de nitrogênio como doadores são melhores complexantes para esses cátions. Também têm sido estudados os macrociclos mistos, isto é, sistemas contendo átomos de nitrogênio e oxigênio como doadores, separados por grupos metilenos. Esses sistemas apresentam grande capacidade em complexar mais de um íon metálico quando introduzi-se na cavidade dos macrociclos átomos de enxofre como doadores [18]. Estes macrociclos apresentam comportamento muito similar àquele observado para os macrociclos comuns com os átomos mais moles de nitrogênio na cavidade de complexação do macrociclo. 
Um caso ainda pouco conhecido são os oxa-azamacrociclicos, ou seja, sistema onde o macrociclo apresenta átomos de nitrogênio ou oxigênio complexando o íon metálico e com átomos de nitrogênio ou oxigênio colocados na posição $\alpha$ do sistema macrociclo. Desta forma, espera-se que a capacidade de coordenação desses sistemas seja consideravelmente modificada em razão da influência recíproca entre os átomos de nitrogênio e oxigênio (ver Figura 1).

O primeiro trabalho experimental onde se fez síntese do sistema com oxaazamacrociclico (Figura 1), foi desenvolvido pro Kuksa et al. em 1999 [11]. Em 2000, as estruturas de raios- $\mathrm{X}$ de dois complexos de $\mathrm{Ni}^{+2}$ e $\mathrm{Zn}^{+2}$ com características bem distintas foram obtidas [12]. O complexo de $\mathrm{Ni}^{+2}$ tem geometria octaédrica com quatro átomos de nitrogênio no plano equatorial (xy) e duas moléculas de água no plano axial (z). No complexo de $\mathrm{Zn}^{+2}$, a coordenação ocorre com os átomos de oxigênio em um arranjo tetraédrico com a camada de coordenação sendo completada pelos átomos do contra-íon, $\mathrm{Cl}^{-}$. Os átomos de nitrogênio do ligante não são coordenados. Este comportamento é contrário àquele observado em outros macrociclos contendo oxigênio e nitrogênio como doadores, onde o átomo de zinco complexa-se apenas ao nitrogênio. 


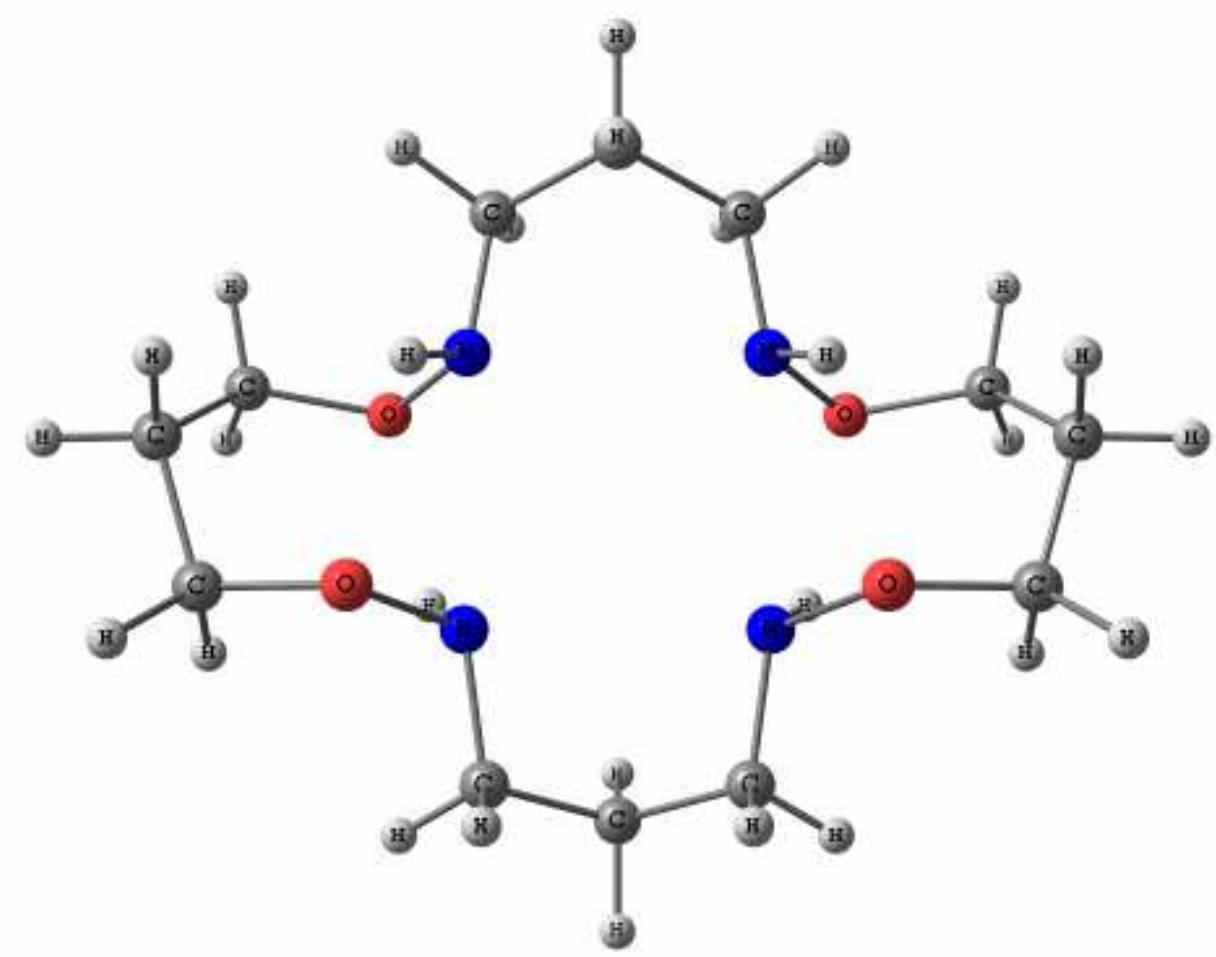

Figura 1. Figura do macrocíclico [20] $\mathrm{aneN}_{4} \mathrm{O}_{4}$ com os átomos de nitrogênios como doadores. $\mathrm{Na}$ figura as cores para os átomos de carbono (cinza), nitrogênio (azul), oxigênio (vermelho) e hidrogênio (branco).

Estudos comparativos entre macrociclos com doadores do tipo $\mathrm{N}_{4}$ e $\mathrm{N}_{2} \mathrm{O}_{2}$ mostraram que a presença de oxigênio do tipo éter no ligante tende a baixar a estabilidade cinética e termodinâmica nos complexos de níquel. Estudos sobre a relação entre o tamanho do anel e a estabilidade termodinâmica dos complexos de níquel, onde o macrociclo tem grupos $\mathrm{N}_{2} \mathrm{O}_{2}$ como doadores, revelam que o macrociclo com 16anel produz complexos mais estáveis, tanto do ponto de vista cinético quanto do ponto de vista termodinâmico. Adicionalmente, o macrociclo de 16anel apresenta uma menor tensão [11]. No caso do macrociclo da Figura 1, a presença dos átomos de oxigênio na posição alfa $(\alpha)$ aos átomos de nitrogênio parece favorecer a formação de um complexo mais estável [11]. Também tem sido mostrado que os macrociclos poliaminas e polieteres apresentam considerável diferença na estabilidade termodinâmica. Em outras palavras, quando substituímos os quatros nitrogênios dos 
macrociclos de 12anel, 14anel, 16anel, etc., por quatro átomos de oxigênio, a complexação dos íons metálicos tornam-se muito mais favorável [31-32] Esse favorecimento energético tem sido atribuído ao "efeito do macrociclo" [33]. Este efeito refere-se ao aumento da estabilidade termodinâmica de um complexo formado entre um íon metálico e um ligante macrociclo polidentado quando comparado com um complexo formado por o mesmo íon e um correspondente ligante monodentado. O efeito do macrociclo tem uma origem entrópica, isto é, ele é resultado de uma pré-organização dos átomos doadores sobre o átomo do centro metálico [33].

A alta estabilidade termodinâmica e cinética dos compostos mencionados acima devese basicamente a cavidade dos macrociclos, a densidade de carga incidida sobre a cavidade dos macrociclos e o tamanho do íon metálico [23]. Desta forma, para melhor entender as interações entre os ligantes macrociclicos e os íons metálicos, cálculos teóricos em nível de teoria DFT (Density Functional Theory) faz-se necessário.

\section{I-3. Macrociclicos Estudados}

O sistema que serviu como referência para a presente tese de doutorado foi o 1, 7, 11, 17-tetraoxa-2, 6, 12, 16-tetraazacicloicosano (ver Figura 1). Nesse sistema, os átomos de oxigênio estão posicionados na posição $\alpha$ dos átomos de nitrogênio. A simetria geométrica obtida neste sistema foi $\mathrm{C}_{\mathrm{S}}$. Nesta tese, tal sistema será reconhecido pela sigla [20]ane $\mathrm{N}_{4} \mathrm{O}_{4}$. O sistema 1, 7, 11, 17-tetraaza-2, 6, 12, 16-tetraoxa-cicloicosano também foi estudado. Como pode ser observado, foram substituídos os átomos de oxigênio por nitrogênio, colocando os átomos de oxigênio na cavidade de coordenação do macrociclo e os átomos de nitrogênio na posição $\alpha$. O sistema macrociclico [20]ane $\mathrm{O}_{4} \mathrm{~N}_{4}$ é mostrado na Figura 2. 


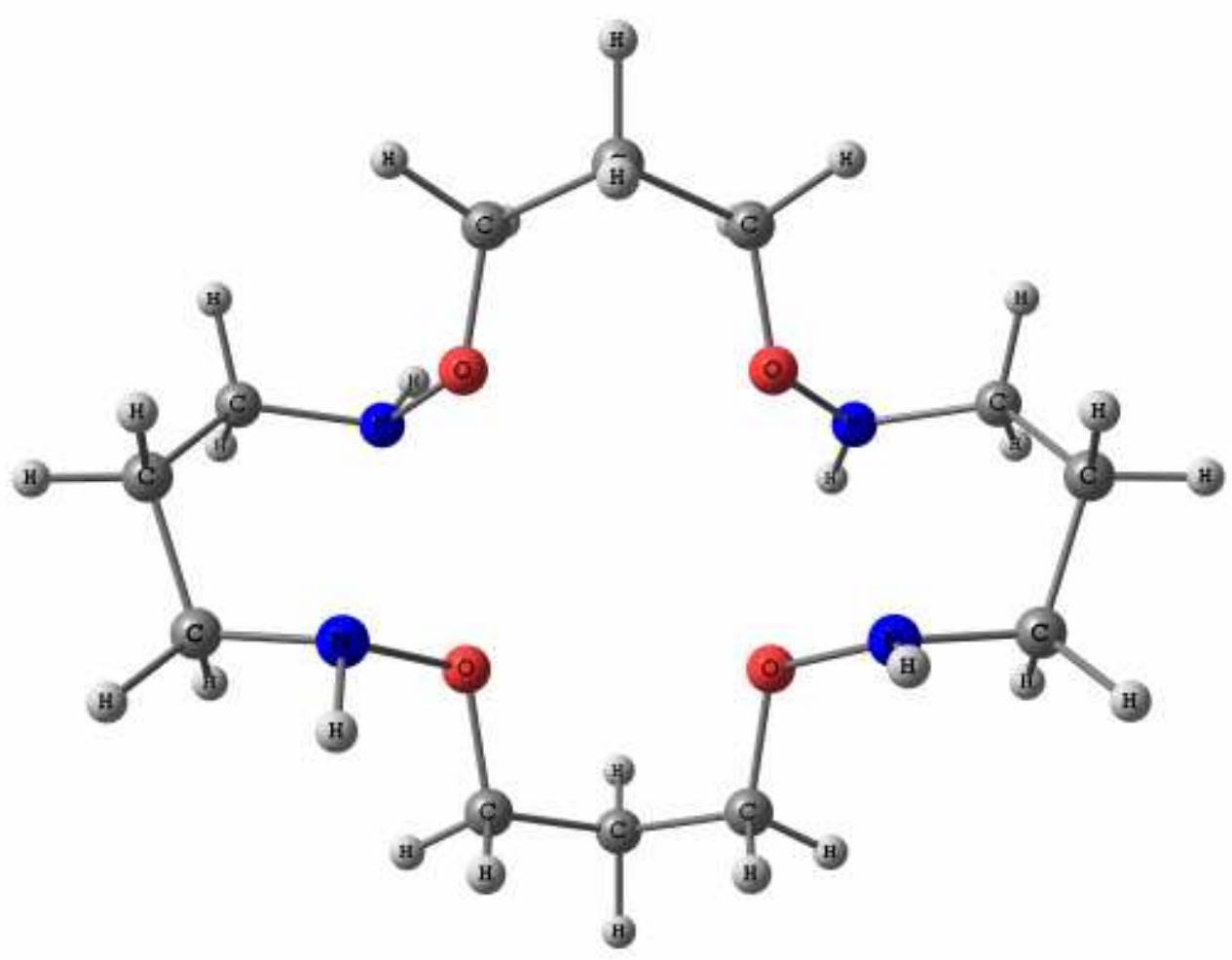

Figura 2. Figura do macrocíclico [20]ane $\mathrm{O}_{4} \mathrm{~N}_{4}$ com os átomos de oxigênios como doadores. $\mathrm{Na}$ figura as cores para os átomos de carbono (cinza), nitrogênio (azul), oxigênio (vermelho) e hidrogênio (branco).

Para verificar o efeito dos átomos na posição $\alpha$ dos macrociclos, foram substituídos os átomos de oxigênio ou nitrogênio por grupos $-\mathrm{CH}_{2}$. Desta forma, os sistemas $1,5,11,15$ tetraaza-cicloicosano $\left([20] \mathrm{aneN}_{4}\right)$ e $1,5,11,15$-tetraoxa-cicloicosano ([20]aneO 4 ) foram obtidos. Esses macrociclos poliaminas e polieteres são mostrados na Figura 3. 


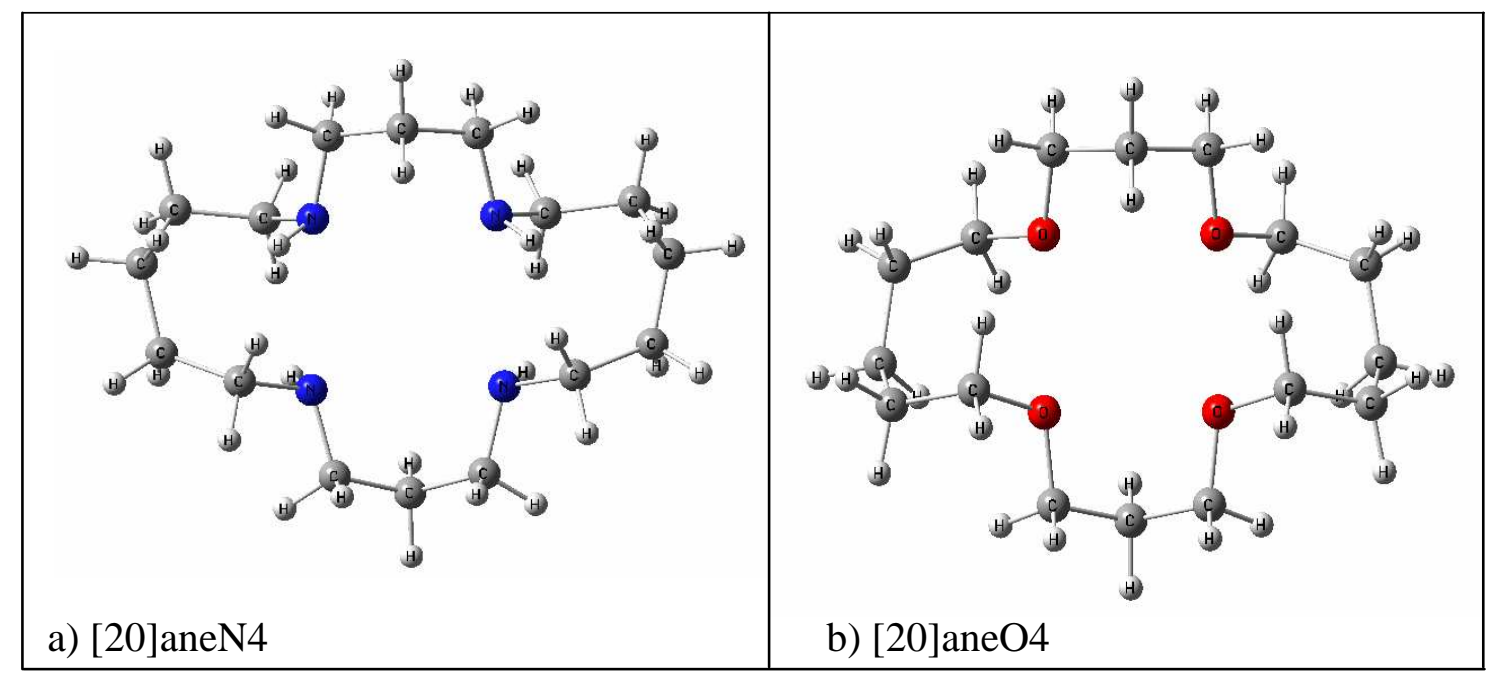

Figura 3. Figura dos macrociclos com os átomos de nitrogênio e oxigênio como doadores: a) [20]ane $\mathrm{N}_{4}$ e b) [20] $\operatorname{aneN}_{4}$. Na figura as cores para os átomos de carbono (cinza), nitrogênio (azul), oxigênio (vermelho) e hidrogênio (branco).

Os arranjos octaédrico e quadrado-planar foram considerados para todos os complexos estudados. Nos complexos de arranjo octaédrico, os quatro átomos de nitrogênio ou oxigênio, que estão coordenando diretamente com os íons metálicos, são colocados no plano axial e as duas moléculas de água estão colocadas na posição equatorial, como mencionado anteriormente. Os complexos $\mathbf{1 a}$ e $\mathbf{1 b}$ de arranjo octaédrico, obtidos na complexação dos íons metálicos $\left(\mathrm{M}^{2+}\right)$ pelo os macrociclos [20]ane $\mathrm{N}_{4} \mathrm{O}_{4}(\mathbf{1 a})$ e [20]aneO $\mathrm{O}_{4} \mathrm{~N}_{4}$ (1b) e as duas moléculas de água $\left(\mathrm{O}_{\mathrm{W}}\right)$ são mostrados no Esquema 1. Os complexos $\mathbf{1 a}_{\mathrm{q}}$ e $\mathbf{1} \mathbf{b}_{\mathrm{q}}$, com arranjo geométrico quadrado planar, foram obtidos removendo-se as moléculas de água da posição equatorial, como pode ser verificado no Esquema 2. 


\section{Esquema 1}
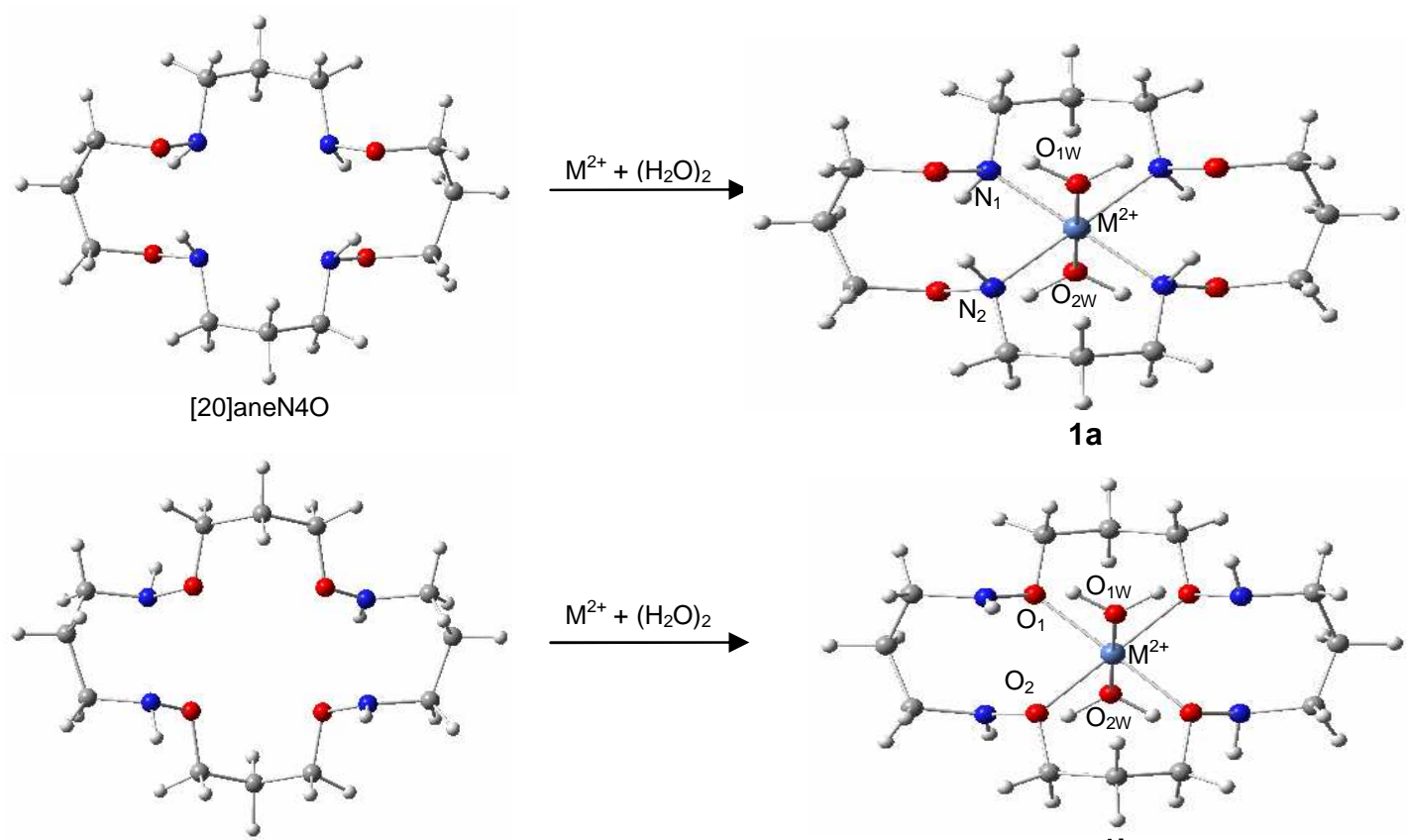

[20]aneO4N

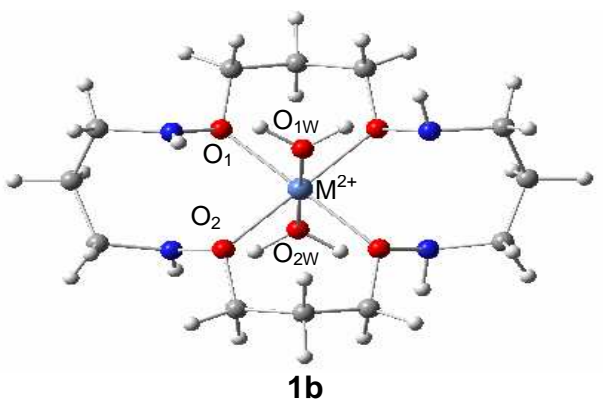

Esquema 2

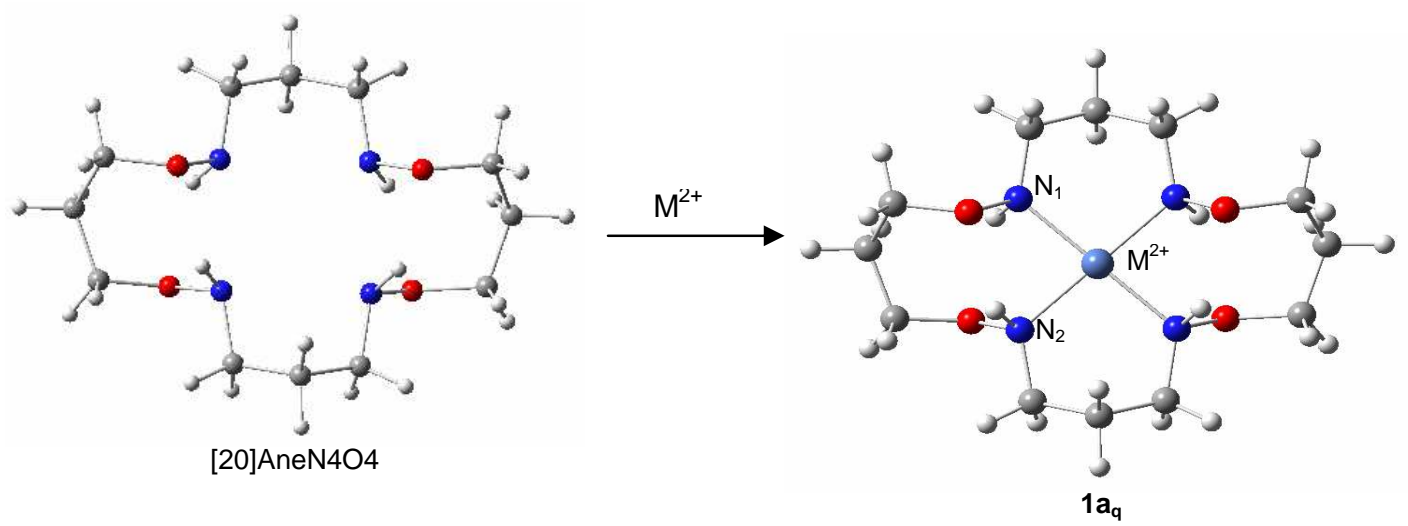

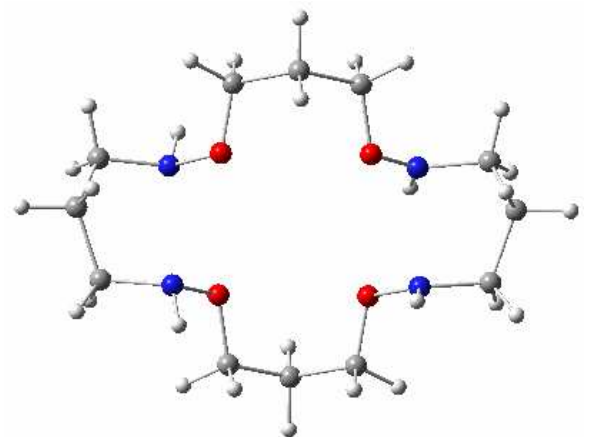

[20]aneO4N4

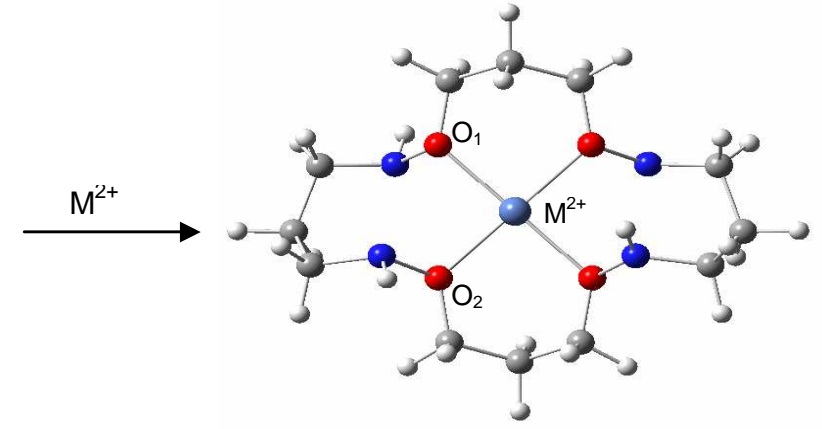

$1 b_{q}$ 
Os complexos derivados da complexação dos íons metálicos nos macrociclos poliaminas ([20]ane $\mathrm{N}_{4}$ ) e polieteres ([20]aneO $\mathrm{O}_{4}$ ) foram obtidos da mesma forma como mostrado nos esquemas 1 e 2. Os arranjos geométricos octaédrico e quadrado planar foram também aqui considerados.

Um breve comentário sobre a teoria do campo ligante aplicada a complexos octaédricos e quadrado planares será apresentado a seguir.

\section{I-3.1. Geometria Octaédrica}

Na teoria do campo ligante, um complexo é definedo como um cátion metálico central cercado por íons ou ligantes dipolares que são atraídos eletrostaticamente pelo cátion [34]. A ligação dentro do complexo é devido à atração eletrostática entre o núcleo do cátion metálico e os elétrons dos ligantes. As interações entre os elétrons do cátion e dos ligantes são inteiramente repulsivas [34]. Nos metais de transição, essa repulsão entre os elétrons causa o desdobramento do orbital d em $t_{2 g}$ e e $e_{g}$, como mostra o diagrama da Figura 4.

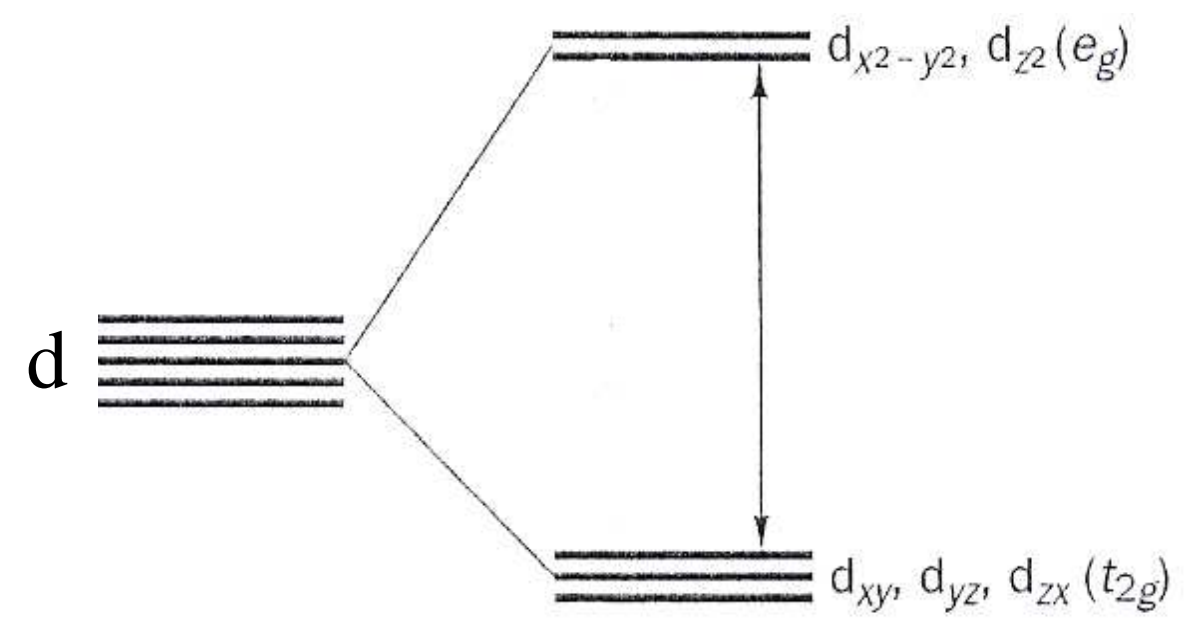

Figura 4. Diagrama dos níveis de energia dos orbitais d num arranjo octaédrico. 
A divisão entre os grupos $t_{2 g}$ e $e_{g}$ dos elétrons d é chamada de desdobramento do campo cristalino, $\Delta_{\mathrm{o}}$ (onde o subscrito (o) significa um campo cristalino octaédrico). Para os elementos da primeira fila dos metais de transição, $\Delta_{\mathrm{o}}$ tem um valor em torno de $10.000 \mathrm{~cm}^{-1}$. Para os íons de metais de transição dicátions esse valor é usualmente entre $5.000-15.000 \mathrm{~cm}^{-1}$; e para os íons tricátions $10.000-30.000 \mathrm{~cm}^{-1}$ [35]. A variação desse valor aumenta aproximadamente em relação à proporção da carga do cátion, sendo mais dependente do tipo de ligantes que estão interagindo com o centro metálico do que do metal, ou seja, o desdobramento do campo cristalino depende principalmente do tipo de ligante no complexo. Para os complexos com metais de transição da segunda e terceira filas, o valor do $\Delta_{o}$ é duas vezes maior que os dos metais da primeira fila [35].

Num complexo octaédrico, os elétrons do ligante podem ser considerados para preencher todos os seis orbitais moleculares ligantes e qualquer elétron do íon metálico ocupa os orbitais não ligantes $t_{2 g}$ e antiligante $e_{g}$. Ligantes cujos orbitais interajam fortemente com os orbitais do metal são chamados ligantes de campo forte. Esses ligantes causam uma grande divisão dos orbitais $t_{2 g}$ e $e_{g}$. Ligantes com uma pequena interação entre sues orbitais e os orbitais do metal são chamados de ligantes de campo fraco e a divisão dos orbitais $t_{2 \mathrm{~g}}$ e $\mathrm{e}_{\mathrm{g}}$ é pequena.

Nos complexos de coordenação, a multiplicidade do estado fundamental depende do tipo de campo do ligante, isto é, ligantes de campo forte apresentam estados espectroscópicos de spin alto e ligantes de campo fraco exibem estados espectroscópicos de spin baixo (ver Figura 5). No arranjo de spin alto, a repulsão intereletrônica entre os elétrons d é pequena. Desta forma, os elétrons estão espacialmente menos concentrados e a estabilização da troca intereletrônica é maior, tendo como conseqüência o emparelhamento de spin como estado de energia mais baixo. Já o arranjo de spin baixo, difere do spin alto porque um ou mais elétrons 
são transferidos do orbital mais estável $t_{2 g}$ para o orbital menos estável e $e_{g}$, causando assim um desemparelhamento de spin com estado de energia mais baixo.

Como podemos observar na Figura 5, para os íons com $\mathrm{d}^{1}, \mathrm{~d}^{2}, \mathrm{~d}^{3}, \mathrm{~d}^{8}, \mathrm{~d}^{9}$ e $\mathrm{d}^{10}$ elétrons no orbital d, existe somente uma possível configuração eletrônica, portanto não há diferença de spin dos elétrons para os casos de campo forte ou fraco. No entanto, para os íons de $\mathrm{d}^{4} \mathrm{a} \mathrm{d}^{7}$, os elétrons possuem ambos os estados de spin alto e spin baixo. Por exemplo, o íon $\mathrm{d}^{6}$ pode ter estado de multiplicidade quinteto (spin alto) e singleto (spin baixo), como mostrado na Figura 5. Nesses íons também pode ocorre o estado tripleto (estado intermediário), sendo que o estado de mais baixa energia para esse sistema é o de spin alto, seguindo a regra de Hund. Dessa forma, ligantes de campo forte originam complexo de spin baixo e ligantes de campo fraco formam complexo de spin alto.
$\Delta_{o} \quad \uparrow-$
$\uparrow \frac{\uparrow}{d^{2}}-$
$\uparrow \frac{\uparrow}{d^{3}} \uparrow$
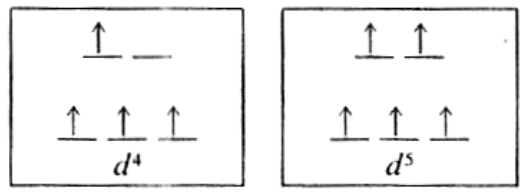

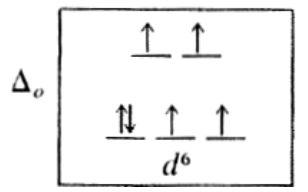

$\uparrow \uparrow$
$\stackrel{\uparrow}{\uparrow} \frac{\uparrow}{d^{7}} \Perp$
$\uparrow \uparrow$
$\stackrel{\uparrow}{1}$
$\underline{11} \underline{\mathbb{N}}$

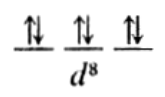
$\stackrel{\uparrow}{\uparrow} \frac{\Uparrow}{d^{9}} \stackrel{\uparrow}{ }$
$\stackrel{\uparrow}{i \downarrow} \frac{\Uparrow}{d^{10}}$

a) Complexos com ligantes do campo fraco (spin alto)
$\Delta_{o} \quad \stackrel{-}{-}-$
$\stackrel{\uparrow}{\uparrow}-$
$\uparrow \frac{\uparrow}{d^{3}} \Perp$
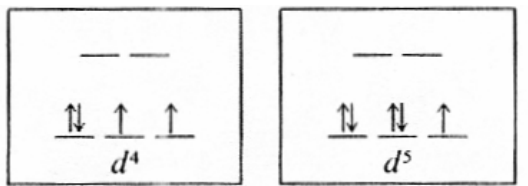
\begin{tabular}{|l}
\hline-- \\
$\mathbb{N} \frac{\mathbb{N}}{d^{6}} \frac{\mathbb{N}}{}$
\end{tabular}
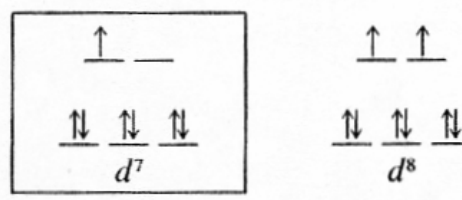
$\underline{1} \perp$
$\underline{\mathbb{1}} \stackrel{\mathbb{1}}{2}$

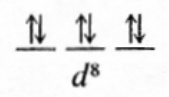
$\stackrel{\Uparrow \downarrow}{d^{9}} \stackrel{\Uparrow \downarrow}{-}$

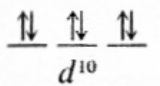

b) Complexos com ligantes do campo forte (spin baixo)

Figura 5. Possibilidades de (a) spin alto e (b) spin baixo para os complexos octaédricos de $\mathrm{d}^{4}$ $\mathrm{d}^{7}$ elétrons. 
No modelo do campo cristalino, os ligantes são aproximados por cargas pontuais ou dipolos. O valor de $\Delta_{\mathrm{o}}$ para um particular complexo depende da magnitude de carga que está sobre o metal. Isso sugere que pode ser possível colocar os ligantes em ordem crescente de carga efetiva, e, portanto, do aumento do $\Delta_{\mathrm{o}}$. Alem disso, essa ordem pode ser a mesma para todos os metais. A ordem dos ligantes é conhecida por série espectroquimica [36] e a ordem crescente do $\Delta_{\mathrm{o}}$ na serie é:

$$
\begin{gathered}
\mathrm{I}^{-}<\mathrm{Br}^{-}<\underline{\mathrm{SCN}^{-}}<\mathrm{Cl}^{-}<\mathrm{NO}_{3}{ }^{-}<\mathrm{N}_{3}{ }^{-}<\mathrm{F}^{-}<\mathrm{OH}^{-}<\mathrm{C}_{2} \mathrm{O}_{4}{ }^{2-}<\mathrm{H}_{2} \mathrm{O}<\underline{\mathrm{NCS}}^{-}<\mathrm{CH}_{3} \mathrm{CN}<\text { py }<\mathrm{NH}_{3} \\
<\text { en }<\text { bipy }<\text { phen }<\mathrm{SO}_{3}{ }^{2-}<\text { bpy }<\mathrm{NC}_{2}{ }^{-}<\underline{\mathrm{CN}}^{-}<\mathrm{CO}
\end{gathered}
$$

(O átomo doador em um ligante ambidentado está sublinhado). Por exemplo, a série indica que a absorção de um complexo hexaciano ocorrerá em uma energia muito mais alta do que aquela de um complexo hexacloro do mesmo metal. Uma serie similar de variação existe para os íons metálicos. O $\Delta_{\mathrm{o}}$ aumenta com o aumento da carga formal sobre o íon e para baixo do grupo na tabela periódica [36].

$\mathrm{Mn}^{\mathrm{II}}<\mathrm{Ni}^{\mathrm{II}}<\mathrm{Co}^{\mathrm{II}}<\mathrm{Fe}^{\mathrm{II}}<\mathrm{V}^{\mathrm{II}}<\mathrm{Fe}^{\mathrm{III}}<\mathrm{Cr}^{\mathrm{II}}<\mathrm{V}^{\mathrm{III}}<\mathrm{Co}^{\mathrm{III}}<\mathrm{Mn}^{\mathrm{IV}}<\mathrm{Rh}^{\mathrm{III}}<\mathrm{Pd}^{\mathrm{IV}}<\mathrm{Ir}^{\mathrm{III}}<\mathrm{Pt}^{\mathrm{IV}}$

A força do campo cristalino depende da identidade do metal e do ligante; assim, não é possível especificar um ponto universal na série espectroquímica onde um complexo muda de spin alto para spin baixo. Entretanto, complexos de spin baixo normalmente ocorrem para ligantes que estão no final da série espectroquímica (tal como o $\mathrm{CN}^{-}$) em combinação com os íons metálicos 3d. Complexos de spin alto são comuns em ligantes que estão no início da série (tal como o $\mathrm{Cl}^{-}$) em combinação com os íons metálicos 3d. Agora, considerando os 
complexos dos metais $4 \mathrm{~d}$ e $5 \mathrm{~d}$, os valores do $\Delta_{\mathrm{o}}$ são mais altos do que para os metais $3 \mathrm{~d}$. Conseqüentemente, os complexos desses metais geralmente possuem configurações eletrônicas que são características de campos cristalinos fortes e tipicamente têm spin baixo.

\section{I-3.2. Geometria Quadrado-Planar}

É conveniente considerar o octaédro regular como um ponto de partida para compostos hexacoordenados com geometrias que são distorcidas para o quadrado-planar. A distorção tetragonal, correspondendo à extensão ao longo do eixo z, e a compressão dos eixos $x$ e y reduz a energia do orbital $e_{g}\left(d_{z^{2}}\right)$ e aumenta a energia do orbital $e_{g}\left(d_{x^{2}-y^{2}}\right)$ (Figura 6) [37]. Deste modo, se um, dois ou três elétrons ocuparem os orbitais e $e_{\mathrm{g}}$ (como nos complexos $d^{7}, d^{8}$ e $d^{9}$ ) uma distorção tetragonal pode ser energeticamente vantajosa. Por exemplo, em um complexo $\mathrm{d}^{9}$, tal distorção deixa dois elétrons estabilizados e um desestabilizado. Uma distorção similar pode ser esperada quando há um, dois ou três elétrons $e_{\mathrm{g}}$ no complexo; em cada caso a distorção abaixa a energia total. A distorção de um complexo $\mathrm{d}^{8}$ de spin alto pode ser grande o suficiente para permitir que os dois elétrons $e_{\mathrm{g}}$ emparelhem-se no orbital $\mathrm{d}_{\mathrm{z}^{2}}$. Está distorção pode ir até a perda total dos ligantes no eixo $\mathrm{z}$ com formação do complexo quadrado-planar $\mathrm{d}^{8}$, tal como encontrado para os complexos de $\operatorname{Rh}(\mathrm{I}), \operatorname{Ir}(\mathrm{I}), \operatorname{Pt}(\mathrm{I}), \operatorname{Pd}(\mathrm{II})$ e $\mathrm{Au}(\mathrm{III})$ [37]. A ocorrência é comum para complexos quadrado-planares de configuração $4 \mathrm{~d}^{8} \mathrm{e}$ $5 \mathrm{~d}^{8}$, correlacionando-se com os valores altos do parâmetro de desdobramento do campo ligante nestas duas séries, dando origem à estabilização do campo ligante em complexos quadrado-planares de spin baixo (Figura 6). 

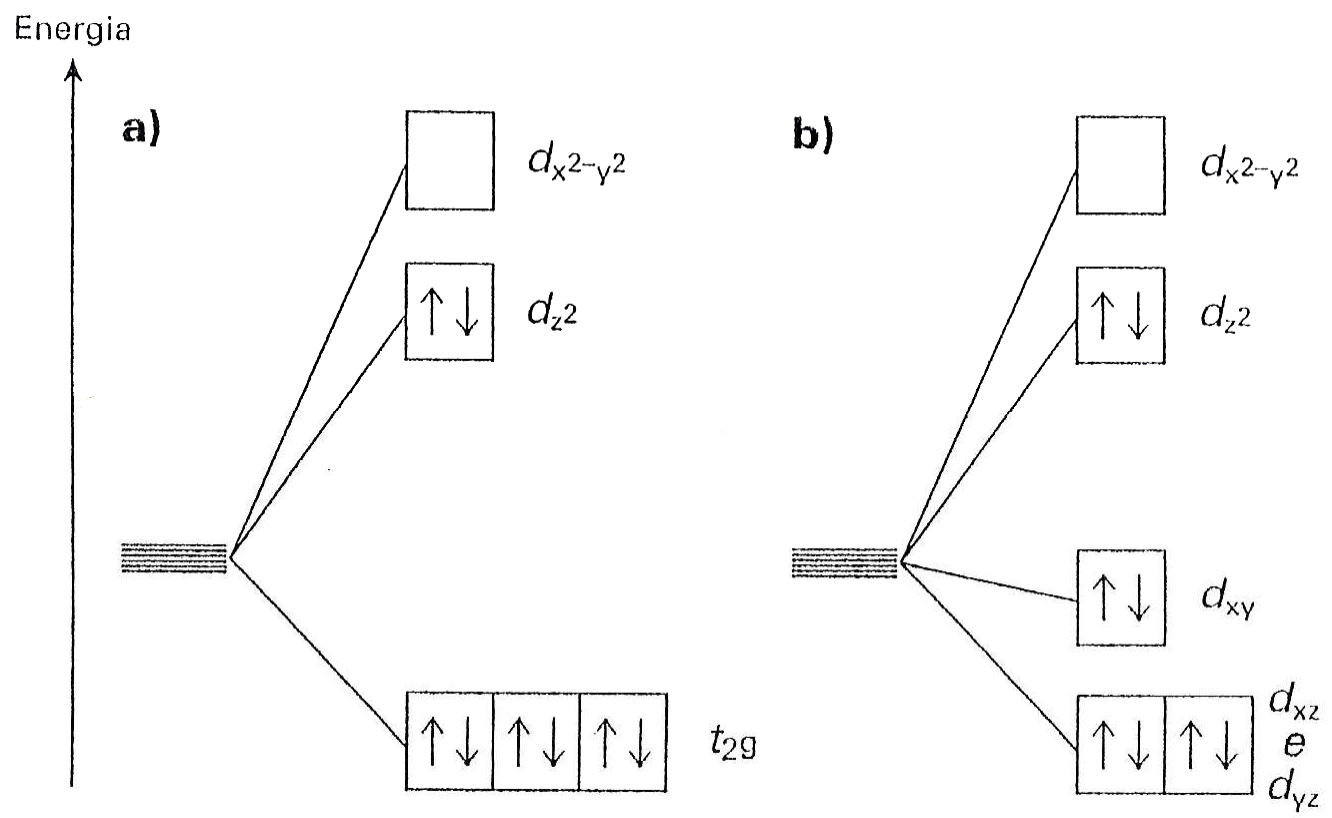

Figura 6. Distorção tetragonal num complexo quadrado planar com íon de configuração $d^{8}$ : a) orbitais e $\mathrm{g}$ com quebra de degenerescência entre os orbitais $d_{x^{2}-y^{2}}$ e $d_{z^{2}}$. b) orbitais $d_{x y}$ com quebra de degenerescência entre os orbitais $d_{x z}$ e $d_{y z}$.

Em alguns casos, a distorção tetragonal pode se tornar tão grande que o orbital $\mathrm{d}_{\mathrm{z}^{2}}$ passa a ter menor energia que o orbital $d_{x y}$, como mostra a Figura 7. $O$ grau dessa distorção depende do íon metálico e dos ligantes. 


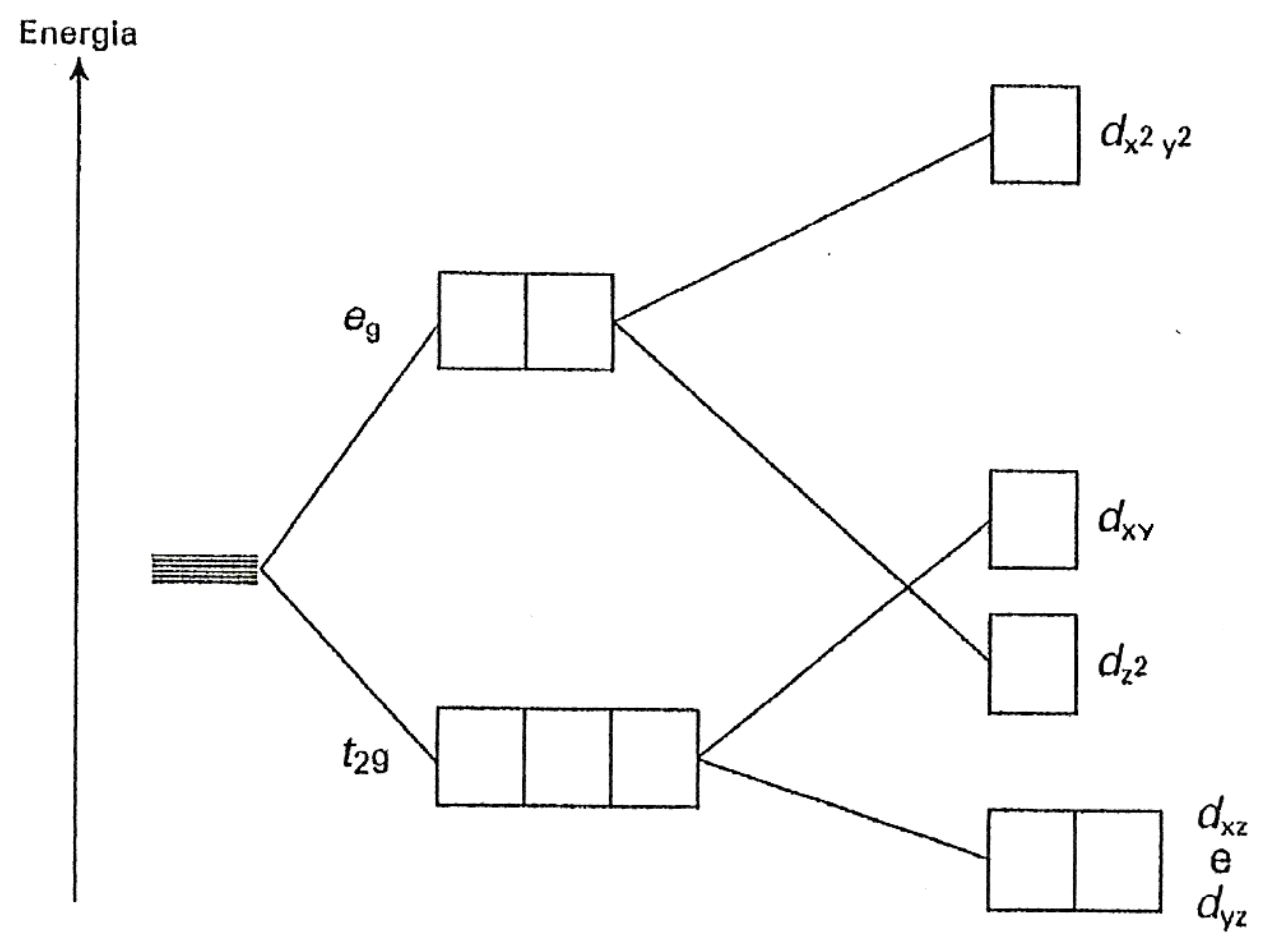

Figura 7. Forte distorção tetragonal provocada nos orbitais d do metal.

Complexos quadrado-planares são formados por íons de configuração $\mathrm{d}^{8}$ com ligantes de campo forte, como por exemplo $\left[\mathrm{Ni}(\mathrm{CN})_{4}\right]^{2-}$. O desdobramento do campo cristalino $\Delta_{\mathrm{o}}$ é maior para os elementos da segunda e terceira filas dos metais de transição, resultado em complexos de spin baixo. Íons metálicos com configuração $\mathrm{d}^{4}$ num campo de ligante fraco formam complexos quadrado-planares [37]. 


\section{I-4. Objetivos}

No presente trabalho, o método ab initio DFT foi empregado para estudar a natureza das ligações químicas existentes entre os átomos complexantes (nitrogênio ou oxigênio) e os íons metálicos da primeira e segunda fila dos metais de transição, assim como estudar as propriedades químicas e físico-químicas dos sistemas macrocíclicos contendo nitrogênio e oxigênio como hetero-átomos, ou seja:

1- Estudar os sistemas tetra-éter macrociclos, tetra-aminas macrociclos e oxa-azamacrociclos complexando os íons metálicos da primeira e segunda filas dos metais de transição.

2- Entender a natureza das ligações através da interação doador-aceptor entre os fragmentos ligantes e metal, respectivamente. Essas interações serão quantificadas através das cargas doadas do ligante $(\mathrm{N}, \mathrm{O})$ para o metal (responsáveis pelas ligações $\sigma$ ) e da retrodoação do metal para o ligante (responsáveis pelas ligações $\pi$ ).

3- Desenvolver cálculos de freqüências para obter os espectros vibracionais dos complexos, a fim de caracterizar as atribuições dos modos vibracionais nesses sistemas.

4- Calcular propriedades termodinâmicas, como a energia de interação, com o intuito de estabelecer uma ordem de estabilidade entre os íons complexos, isto é, qual o ligante $(\mathrm{N}, \mathrm{O})$ que melhor coordena com os metais de transição. Essa estabilidade será comparada com a série de Irving-Williams para metais de transição da primeira fila, bem como atribuir uma série de estabilidade para os metais da segunda fila nos diferentes sistemas estudados. 


\section{CAPITULO II}

FUNDAMENTAÇÃO TEÓRICA 


\section{II-1. Introdução}

Para que as predições através de modelos de simulações das propriedades dos sólidos e moléculas tenham um razoável nível de confiança, é indispensável uma excelente representação do comportamento dos componentes de tais sistemas. Potencial interatômico [38] ou modelos de cargas - ligação [39] são aproximações clássicas que foram usadas para estudar problemas envolvendo conjunto de átomos com algum sucesso. Atualmente, sistemas constituídos de milhares de átomos são simulados usando esses métodos clássicos [40]. Nas últimas décadas, os modelos da mecânica quântica tornaram-se bastante adequados para os estudos de sistemas constituídos por um número de átomos relativamente grande.

Estudos computacionais das propriedades eletrônicas e estruturais de sistemas com um grande número de átomos tornaram-se comuns na última década. No entanto, para tais sistemas, a equação de Schrödinger requer uma solução precisa. Essa equação é facilmente construída para sistemas de muitos corpos. Entretanto, torna-se impossível a solução dessa equação sem fazer alguma aproximação. Na presente tese, apenas o método da teoria do funcional da densidade (DFT - Density Functional Theory) com o funcional hibrido B3LYP foi utilizado. Sendo assim, uma breve discussão sobre a teoria do DFT será relatada neste capitulo. 


\section{II-2. Teoria do Funcional da Densidade}

A equação de Schrödinger só é possível resolver exatamente para sistemas monoeletrônicos conhecidos como hidrogenóides. No entanto, para sistemas poli-eletrônicos, a solução dessa equação torna-se impossível sem fazer aproximações, como por exemplo a aproximação de Born e Oppenheimer [41]. Essas aproximações permitem resolver a equação de Schrödinger desacoplando o movimento eletrônico do movimento nuclear, reduzindo, assim, o problema de muitos corpos a um problema de partícula independente. Entretanto, essa solução ainda só é possível e exata para sistemas pequenos de átomos e moléculas. Para sistemas grandes, como sólidos, a solução torna-se fora de alcance.

Thomas e Fermi [42,43] propuseram um novo esquema baseado na densidade eletrônica dos sistemas, $\rho(r)$. Com isso, torna-se mais simples a solução da equação de Schrödinger para sistemas grandes, uma vez que a complicada função de onda de N elétrons na equação de Schrödinger é substituída pela densidade eletrônica, que é muito mais simples. Esse modelo assume que as propriedades eletrônicas dos sistemas reais sejam similares àquelas dos gases de férmions, isto é, um ensemble clássico de partículas não interagentes. Apesar do limitado sucesso em reproduzir as propriedades dos sistemas reais, esse modelo foi o protótipo da teoria do funcional da densidade, que focaliza a densidade eletrônica como variável fundamental. 


\section{II-2.1. Formalismo Moderno da Teoria do Funcional da Densidade}

Um sistema eletrônico descrito pelo Hamiltoniano:

$$
\hat{\mathrm{H}} \equiv-\frac{1}{2} \nabla_{\mathrm{i}}^{2}+\frac{1}{2} \sum_{\mathbf{j} \neq \mathrm{i}}^{\mathrm{N}} \frac{1}{\left|\mathrm{r}_{\mathbf{i}}-\mathrm{r}_{\mathbf{j}}\right|}+v\left(\mathrm{r}_{\mathbf{i}}\right)
$$

onde $v(r)$ representa algum potencial externo, tanto a energia do estado fundamental como a função de onda do estado fundamental podem ser determinadas minimizando o funcional da energia. A partir da forma do operador do Hamiltoniano total, fica óbvio que duas quantidades fixam completamente o referido Hamiltoniano. Essas quantidades dizem respeito ao número $N$ de elétrons do sistema e o potencial externo, $v$, que determinam todas as propriedades do sistema no estado fundamental.

Hohenberg e Kohn [44] mostraram que pode-se usar a densidade eletrônica $\rho$ como variável básica ao invés de $N$ e v.

\section{II-2.1.1. Os Teoremas de Hohenberg e Kohn}

Os primeiros cientistas que consideram a densidade eletrônica, $\rho$, como variável básica foram Hohenberg e Kohn [45]. Essa consideração faz parte do primeiro teorema de Hohenberg e Kohn (HK). Essa afirmação possui conseqüências de grande alcance. Desde que $\rho(\mathrm{r})$ determina $v$, e trivialmente $\mathrm{N}$, conseqüentemente $\rho(\mathrm{r})$ determina o Hamiltoniano $\hat{\mathrm{H}}$, daí, implicitamente, todas propriedades deriváveis do $\hat{\mathrm{H}}$. 
A prova desse teorema é consideravelmente simples. Para isso, basta reduzir ao absurdo (reductio ad absurdum), tendo como proposição o fato de que dois potenciais externos diferentes, $v$ e v', levam a mesma densidade de cargas $\rho$, ou seja, um sistema de potencial externo $v$ com $\mathrm{N}$ elétrons, definido como $\int \rho(\mathrm{r}) \mathrm{dr}$, associado a um estado fundamental de densidade $\rho(r)$, Hamiltoniano $\hat{H}$, com função de onda e energia do estado fundamental $\Psi$ e E, respectivamente. Um segundo sistema, com $\mathrm{N}$ partículas, será caracterizado por: v', $\mathrm{N}, \rho(\mathrm{r})^{\prime}, \hat{H}^{\prime}, \Psi^{\prime}, \mathrm{E}^{\prime}$. Onde $v^{\prime} \neq v+\mathrm{C}$, e conseqüientemente $\Psi^{\prime} \neq \Psi$.

Pelo princípio variacional de Rayleigh-Ritz,

$$
\mathrm{E}<E^{\prime}+\int\left[v(r)-v^{\prime}(r)\right] \rho(r) d r
$$

A desigualdade acima segue do fato de que $\Psi^{\prime} \neq \Psi$. Desse modo,

$$
\mathrm{E}^{\prime}<E+\int\left[v^{\prime}(r)-v(r)\right] \rho^{\prime}(r) d r
$$

na qual as equações II.2 e II.3 podem ser somadas. Assim, qualquer potencial v', exceto $v^{\prime} \neq v$ $+\mathrm{C}$, leva a $\rho^{\prime} \neq \rho$. A energia do estado fundamental do sistema pode ser escrita como:

$$
\mathrm{E}=\langle\psi|\hat{V}| \psi\rangle+\left\langle\Psi\left|\hat{\mathrm{T}}+\hat{V}_{e e}\right| \Psi\right\rangle,
$$

onde os termos do segundo membro são os valores esperados dos operadores do potencial externo, energia cinética e energia de interação. Obviamente,

$$
\begin{aligned}
& \left\langle\Psi\left|\hat{V_{e x t}}\right| \Psi\right\rangle=\left\langle\Psi\left|\sum_{i=1}^{N} v\left(r_{i}\right)\right| \Psi\right\rangle=\int v(r) \rho(r) \\
& F_{H F}[\rho] \equiv\left\langle\Psi\left|\hat{\mathrm{T}}+\hat{V}_{e e}\right| \Psi\right\rangle,
\end{aligned}
$$


são funcionais de $\rho$. $F_{H F}$ é universal, no sentido em que realmente não depende do potencial externo. Usando as equações II.4 e II.5, pode-se escrever explicitamente o funcional da energia total do sistema como:

$$
\mathrm{E} \equiv \mathrm{E}_{\nu}[\rho(r)]=\int v(r) \rho(r) d r+F_{H F}[\rho(r)]
$$

O segundo teorema diz respeito ao princípio variacional da densidade, no qual para uma densidade tentativa $\rho^{\prime}(r)$, tal que $\rho^{\prime}(r) \geq 0$ e $\int \rho^{\prime}(r) d r=N$, tem-se que:

$$
\mathrm{E}_{v}[\rho(' r)] \geq \mathrm{E}_{0}
$$

onde $E_{v}\left[\rho^{\prime}(r)\right]$ é o funcional da energia da densidade.

Em conclusão, Hohenberg e Kohn mostraram que todos os termos na expressão da energia total podem ser avaliados como uma soma de funcionais da densidade de cargas. Os termos da energia cinética, de troca e correlação são mais difíceis de serem expressos como funcionais da densidade.

\section{II-2.1.2. O Método de Kohn-Sham}

O método de Hohenberg e Kohn não desenvolve um procedimento prático para a construção do funcional $\mathrm{F}_{\mathrm{HF}}[\rho]$. Uma importante questão ainda precisa ser respondida: as propriedades do gás homogêneo de elétrons podem ser usadas no estudo de sistemas não homogêneos, como sólidos? A principal falha dos funcionais nos modelos de Thomas-Fermi, Thomas-Fermi-Dirac e $X_{\alpha}$ de Slater era a deficiência em descrever a contribuição cinética $\mathrm{T}[\rho]$.

O método Kohn-Sham (KS) mudou essa situação drasticamente [45]. Ele introduziu a idéia dos orbitais monoeletrônicos, os quais podem ser construídos de modo rigoroso. Com 
essa idéia, a descrição da contribuição da energia cinética pode ser representada mais apropriadamente.

O esquema de KS tem suas raízes nos métodos de Hartree e $X_{\alpha}$ de Slater, porém, o método de Kohn-Sham inclui os efeitos de troca e correlação eletrônica explicitamente.

De acordo com o primeiro teorema de Hohenberg e Kohn, existe um único funcional da energia para o qual o princípio variacional produz a densidade $\rho(r)$ exata do então estado fundamental, correspondendo ao Hamiltoniano do sistema. $\mathrm{O} \mathrm{T}_{\mathrm{s}}[\rho]$ denota o funcional universal (no sentido que não depende do potencial externo) da energia cinética para o sistema de partículas não interagente.

O esquema de KS afirma que para qualquer sistema de partículas interagentes, existe um potencial monoeletrônico local $v_{\mathrm{s}}(\mathrm{r})$ (potencial fictício), tal que a exata densidade do estado fundamental $\rho(r)$ do sistema não interagente é:

$$
\rho(r)=\rho_{s}(r)
$$

onde $\rho(r)$ representa a densidade de carga real do gás de elétrons não homogêneo.

A energia de troca e correlação, $E_{x c}[\rho]$, pode ser decomposta nas componentes de troca e de correlação como segue abaixo:

$$
E_{x c}[\rho]=E_{x}[\rho]+E_{c}[\rho]
$$

onde:

$$
E_{x}[\rho]=\left\langle\phi_{\rho}\left|V_{e}-\mathrm{e}\right| \phi_{\rho}\right\rangle-U_{H}[\rho]
$$

e

$$
E c[\rho]=F[\rho]-\left\{T_{s}[\rho]+U_{H}[\rho]+E x\right\} .
$$




\section{II-2.1.3. Aproximação LDA (Local-Density Approximation)}

Apesar das equações KS incorporarem a energia cinética $T_{s}[\rho]$, elas ainda deixam o termo de correlação e troca indeterminado. É necessário, portanto, encontrar uma maneira de contornar esta dificuldade. A mais simples aproximação para $T_{s}[\rho]$ foi apresentada por Kohn e Sham em 1965. Esta aproximação é conhecida como Aproximação Local da Densidade (LDA - Local-Density Approximation) para a energia de troca e correlação. Esses autores mostraram que se $\rho$ varia extremamente lento com a posição, então a energia $E_{x c}[\rho]$ pode ser dada por:

$$
\operatorname{ExC}_{\mathrm{XC}}^{\mathrm{LDA}}[\rho]=\int \rho(\mathrm{r}) \varepsilon_{\mathrm{Xc}}(\rho) \mathrm{dr}
$$

onde $\epsilon_{x c}$ é a energia de troca-correlação por partícula do gás de elétrons de densidade $\rho$ associada ao potencial LDA

$$
\mathrm{V}_{\mathrm{xc}}^{\mathrm{LDA}}=\frac{\delta \mathrm{E}_{\mathrm{xc}}^{\mathrm{LDA}}}{\delta \rho}=\varepsilon_{\mathrm{xc}}(\rho(\mathrm{r}))+\rho(\mathrm{r}) \frac{\delta \varepsilon_{\mathrm{xc}}(\rho)}{\delta \rho} .
$$

As equações II.13 e II.14 são usadas para resolver as equações de KS. O funcional $E_{x c}[\rho]$ pode ser escrito como a equação II.10. Para um gás homogêneo de elétrons [46], o termo $E_{x}$ é denominado funcional de Dirac. Esse funcional pode ser escrita como:

$$
\varepsilon_{\mathrm{x}}[\rho]=-\frac{3}{4}\left(\frac{3}{\pi} \rho(\mathrm{r})\right)^{1 / 3}
$$

Em termos práticos, os cálculos de moléculas usando $\mathrm{E}_{\mathrm{Xc}}^{\mathrm{LDA}}$, ou qualquer outro funcional, são desenvolvidos do seguinte modo: faz-se, inicialmente, uma suposição para a densidade $\rho$, a qual é geralmente feita usando a densidade eletrônica dos átomos individuais em uma dada geometria molecular. A partir desta densidade inicial, calcula-se o potencial 
$\mathrm{V}_{\mathrm{xc}}(\mathrm{r})$ usando as equações da derivada do funcional $\mathrm{E}_{\mathrm{Xc}}^{\mathrm{LDA}}$ e as partes de soma, de troca e correlação.

O funcional LDA pode sofrer sérios problemas quando aplicado a sistemas reais de interesse que não se comportam como um gás homogêneo. Um exemplo disso é que ele superestima a energia de correlação. Assim, para melhorar os resultados da aproximação LDA têm-se introduzido as chamadas "correlações não-locais". Essa correção é importante, por exemplo, para predizer a energia das reações químicas [46].

A equação a seguir apresenta a forma geral para a correção não-local na LDA, dada em função do gradiente da densidade eletrônica.

$$
\mathrm{E}_{\mathrm{X}}^{\mathrm{NL}}-\mathrm{LDA} \quad[\rho]=\mathrm{E}_{\mathrm{X}}^{\mathrm{LDA}}[\rho]+\mathrm{F}_{\mathrm{x}}\left[\rho^{\alpha}, \rho^{\beta}, \nabla \rho^{\alpha}, \nabla \rho^{\beta}, \ldots\right]
$$

onde o segundo termo do segundo membro é um funcional apropriado, conhecido como componente não-homogêneo da energia de troca. Para um gás homogêneo, a correlação nãolocal é nula, $\mathrm{F}_{\mathrm{x}}=0$.

\section{II-2.1.4. Aproximação GGA (Generalized-Gradiente Approximation)}

Outra aproximação que procura corrigir o potencial LDA e que fornece erros menores que $1 \%$ [46] para energia de troca, aparece no trabalho de Perdew e Yue [47] e utiliza uma expressão simples e precisa para o gradiente:

$$
\mathrm{E}_{\mathrm{X}}^{\mathrm{GGA}}[\rho]=-\frac{3}{4}\left(\frac{3}{\pi}\right)^{1 / 3} \int \rho(\mathrm{r})^{4 / 3} \mathrm{~F}(\mathrm{~s}) \mathrm{dr}
$$

onde 
$\mathrm{s}=\frac{|\nabla \rho(\mathrm{r})|}{2 \mathrm{~K}_{\mathrm{F}} \rho(\mathrm{r})}, \mathrm{K}_{\mathrm{F}}=\left[3 \pi^{2} \rho(\mathrm{r})\right]^{1 / 3}, \mathrm{~F}(\mathrm{~s})=\left(1+1,296 \mathrm{~s}^{2}+14 \mathrm{~s}^{6}\right)^{1 / 15}$

$\mathrm{Na}$ LDA, F(s) é igual a 1.

Os funcionais de correlação pelo gradiente de uso mais comum incluem o de LeeYang-Parr (LYP), o funcional de correlação de Perdew (P86 ou Pc86), o funcional de correlação de Perdew-Wang 1991 (PW91 ou PWc91) e os funcionais de Becke, conhecidos como Bc96 ou B96.

O funcional híbrido B3LYP [48-50] (o numero 3 indica que esse funcional possui três parâmetros) é uma das aproximações mais populares aplicadas a grandes sistemas contendo metais de transição e foi utilizado nesta tese para os cálculos com DFT .

\section{II-3. Detalhes Computacionais}

No presente trabalho, a análise conformacional de todas as estruturas iniciais dos macrociclos [20]aneN4O4, [20]aneO4N4, [20]aneN4 e [20]aneO4 foram realizadas utilizando o programa HyperChem. Após obtermos a conformação mais favorável dos macrociclos, foram realizados cálculos de otimização de geometria e análise de frequiência em nível da teoria DFT (Desnity Functional Theory) com o funcional hibrido B3LYP [48-50], juntamente com o conjunto de base não relativística LANL2DZ [51-53]. Os complexos foram obtidos complexando nos macrociclos seguintes íons metálicos da primeira e segunda filas: $\mathrm{Fe}^{2+}$, $\mathrm{Co}^{2+}, \mathrm{Ni}^{2+}, \mathrm{Ru}^{2+}, \mathrm{Rh}^{2+}$ e $\mathrm{Pd}^{2+}$. Todas as possíveis multiplicidades de spin dos complexos foram consideradas, no intuito de verificar a diferença energética entre as diferentes multiplicidades. Também foram considerados estados intermediários, como por exemplo, o estado tripleto para o íon de $\mathrm{Fe}^{2+}$, que num sistema octaédrico é esperado ter estado de spin 
alto (quinteto) ou estado de spin baixo (singleto), dependendo do tipo de ligante que está diretamente ligado ao metal. Os arranjos octaédrico e quadrado-planar foram considerados em todos os complexos. Todas as estruturas foram otimizadas no programa Gaussian 03 [54]. Cálculos de freqüências foram realizados para verificar se todas as estruturas otimizadas estavam no mínimo de energia, ou seja, todas as frequiências calculadas como valores reais.

Para verificar o efeito dos átomos colocados na posição $\alpha$ dos macrociclos, foram realizadas substituições dos átomos de nitrogênio no macrociclo [20]aneN4O4 e dos átomos de oxigênio no macrociclo [20]aneO4N4 por grupos $-\mathrm{CH}_{2}$. Desta forma, foram obtidos macrociclos denominados poliaminas [20]aneN4 e poliéteres [20]aneO4, com vinte membros, respectivamente.

A natureza das ligações entre os macrociclos e os íons metálicos foram estudadas pelo programa AOMix [55,56]. O programa AOMix é uma poderosa ferramenta que ajuda quantificar a quantidade de carga transferida do metal para o ligante (retrodoação) e do ligante para o metal (doação). Essas transferências de cargas são obtidas pela análise de decomposição de carga (CDA - Charge Decomposition Analysis) [57,58]. Onde, no CDA, o complexo é fragmentado em dois ou mais fragmentos sendo que para os complexos octraédricos nós consideramos como um fragmento o íon metálico e o outro fragmento o ligante macrociclico e as duas moléculas de água. A ordem de ligação de Mayer [59-62] foi obtida pelo programa AOMix-L [56], como implementado no programa AOMix. O calculo da energia de perturbação de segunda ordem $(\mathrm{E}(2))$ foi realizado para estimar a interação doadorreceptor nos complexos derivados da complexação dos íons metálicos pelos macrociclos [20]aneN4 e [20]aneO4. As cargas dos macrociclos e dos complexos foram calculadas pelo método NBO [63], como implementado no programa Gaussian 03 [54].

Com os resultados das freqüências calculadas para os complexos no programa Gaussian 03 [54], o programa Swizard [64] foi usado para obter os espectros vibracionais de 
infravermelho para os sistemas estudados. Dependendo do modelo químico usado nos cálculos, isto é, o método de cálculo escolhido e o conjunto de base utilizado, os valores das frequiências vibracionais podem ser superestimados. Várias estratégias de escalamento têm sido empregadas para tornar as freqüências harmônicas em melhor concordância com as freqüências fundamentais medidas experimentalmente [65]. Nesta tese, utilizou-se uma estratégia simples de escalamento homogêneo das freqüências harmônicas determinada por Scott \& Radom [66]. Neste caso, para o conjunto de base Lanl2DZ, o fator de escala utilizado foi de 0,9614, segundo Li et al. [67]. 


\section{CAPITULO III}

RESULTADOS E DISCURSSÃO 


\section{III-1. Complexos 1a e 1b Octaédricos}

\section{a) Parâmetros Geométricos}

Tendo o complexo 1, 7, 11, 17-tetraoxa-2, 6, 12, 16-tetraazacicloicosano de níquel (II), desenvolvido por kuksa et al. [11] como base, será mostrado os resultados teórico e experimental dos parâmetros geométricos obtidos para esse complexo. Essa molécula tem grupo pontual $\mathrm{C}_{\mathrm{s}}$ com os quatro átomos de nitrogênio situados no plano $\mathrm{xy}$ e as duas moléculas de águas ao longo do eixo z do complexo. Na Tabela 1 são mostrados os resultados teóricos comparados com os valores experimentais obtidos por raios-X para esse complexo.

Tabela 1. Distâncias de ligação $(\AA)$ e ângulos de ligação $\left(^{\circ}\right)$ calculados para o complexo de $\mathrm{Ni}^{2+}$ (1a) comparado com os valores experimentais obtidos por raios-X

\begin{tabular}{ccc}
\cline { 2 - 3 } & B3LYP/Lanl2DZ & Experimental $^{\mathrm{a}}$ \\
\hline $\mathrm{N} 1-\mathrm{Ni}$ & $2,134(\AA)$ & $2,098(\AA)$ \\
$\mathrm{N} 2-\mathrm{Ni}$ & $2,127(\AA)$ & $2,111(\AA)$ \\
$\mathrm{Ni}-\mathrm{O}_{2 \mathrm{~W}}$ & $2,110(\AA)$ & $2,110(\AA)$ \\
$\mathrm{Ni}-\mathrm{O}_{1 \mathrm{~W}}$ & $2,100(\AA)$ & $2,120(\AA)$ \\
$\mathrm{N} 1-\mathrm{Ni}-\mathrm{N} 2$ & $87,0\left(^{\circ}\right)$ & $93,10\left(^{\circ}\right)$ \\
$\mathrm{N} 1-\mathrm{Ni}-\mathrm{O}_{2 \mathrm{~W}}$ & $88,2\left(^{\circ}\right)$ & $89,72\left(^{\circ}\right)$ \\
$\mathrm{N} 2-\mathrm{Ni}-\mathrm{O}_{1 \mathrm{w}}$ & $88,1\left(^{\circ}\right)$ & $88,56\left(^{\circ}\right)$ \\
$\mathrm{O}_{1 \mathrm{w}}-\mathrm{Ni}-\mathrm{O}_{2 \mathrm{~W}}$ & $180,0\left(^{\circ}\right)$ & $179,96\left(^{\circ}\right)$ \\
\hline
\end{tabular}

${ }^{\mathrm{a}}$ Ref. 11. 
Os parâmetros geométricos calculados em nível de teoria DFT estão em bom acordo com os resultados experimentais. A distância N1-Ni calculada teoricamente é de 2,134 A, sendo que o valor experimental observado para essa ligação é de 2,098 Å. A distância teórica superestima a experimental em 0,036 ̊. Para a ligação N2-Ni, os valores teórico e experimental são de 2,127 e 2,111 A, respectivamente. Nesse comprimento de ligação, a diferencia entre os valores teórico e experimental é de apenas 0,016 ̊̊. Em relação às distâncias $\mathrm{Ni}-\mathrm{O}_{1 \mathrm{~W}}$ (oxigênio da água) a diferença entre os valores teórico e experimental é de apenas $0,020 \AA$, e para o comprimento de ligação $\mathrm{Ni}-\mathrm{O}_{2 \mathrm{~W}}$ (oxigênio da água) observa-se o mesmo valor $(2,110 \AA$ A). A maior diferença entre as distâncias do nitrogênio com o metal resulta num maior desvio entre o ângulo de ligação N1-Ni-N2. Nesse complexo, a diferença entre o valor teórico e experimental é de aproximadamente $6^{\circ}$. Os valores teóricos dos ângulos de ligação $\mathrm{N} 1-\mathrm{Ni}-\mathrm{O}_{2 \mathrm{~W}}$ e $\mathrm{N} 2-\mathrm{Ni}-\mathrm{O}_{1 \mathrm{w}}$ são de $88,19^{\circ}$ e $88,13^{\circ}$, respectivamente. Enquanto os valores experimentais são de $89,72\left(^{\circ}\right)$ e $88,56\left({ }^{\circ}\right)$, respectivamente. O ângulo formado pelas moléculas de água, que estão ao longo do eixo z, e o metal central é exatamente o mesmo. Os parâmetros geométricos obtidos, tanto experimentalmente quanto teoricamente, sugerem um sistema de arranjo octaédrico levemente distorcido.

Por falta de informações experimentais para os complexos de $\mathrm{Fe}^{2+}, \mathrm{Co}^{2+}, \mathrm{Ru}^{2+}, \mathrm{Rh}^{+2} \mathrm{e}$ $\mathrm{Pd}^{2+}$, na Tabela 2, são mostrados apenas os valores dos parâmetros geométricos calculados em nível de teoria DFT para esses íons no complexo 1a. Os valores teóricos do complexo de níquel são mostrados apenas para efeito de comparação com os outros íons metálicos. 
Tabela 2. Parâmetros geométricos calculados em nível de teoria DFT/B3LYP com o conjunto de base Lanl2DZ para o complexo 1a

\begin{tabular}{ccccccc}
\cline { 2 - 6 } & $\mathrm{Fe}^{2+}$ & $\mathrm{Co}^{2+}$ & $\mathrm{Ni}^{2+}$ & $\mathrm{Ru}^{2+}$ & $\mathrm{Rh}^{2+}$ & $\mathrm{Pd}^{2+}$ \\
\hline $\mathrm{N} 1-\mathrm{M}^{2+}$ & $2,201(\AA)$ & $2,173(\AA)$ & $2,134(\AA)$ & $2,137(\AA)$ & $2,123(\AA)$ & $2,110(\AA)$ \\
$\mathrm{N} 2-\mathrm{M}^{2+}$ & $2,205(\AA)$ & $2,167(\AA)$ & $2,127(\AA)$ & $2,139(\AA)$ & $2,142(\AA)$ & $2,112(\AA)$ \\
$\mathrm{M}^{2+}-\mathrm{O}_{2 \mathrm{~W}}$ & $2,144(\AA)$ & $2,115(\AA)$ & $2,110(\AA)$ & $2,149(\AA)$ & $2,510(\AA)$ & $3,860(\AA)$ \\
$\mathrm{M}^{2+}-\mathrm{O}_{1 \mathrm{~W}}$ & $2,162(\AA)$ & $2,125(\AA)$ & $2,100(\AA)$ & $2,167(\AA)$ & $2,510(\AA)$ & $3,685(\AA)$ \\
$\mathrm{N} 1-\mathrm{M}^{2+}-\mathrm{N} 2$ & $92,8\left(^{\circ}\right)$ & $84,9\left(^{\circ}\right)$ & $86,0\left(^{\circ}\right)$ & $95,2\left(^{\circ}\right)$ & $85,3\left(^{\circ}\right)$ & $84,9\left(^{\circ}\right)$ \\
$\mathrm{N} 1-\mathrm{M}^{2+}-\mathrm{O}_{2 \mathrm{~W}}$ & $94,1\left(^{\circ}\right)$ & $91,1\left(^{\circ}\right)$ & $88,1\left(^{\circ}\right)$ & $91,1\left(^{\circ}\right)$ & $96,1\left(^{\circ}\right)$ & $48,2\left(^{\circ}\right)$ \\
$\mathrm{N} 2-\mathrm{M}^{2+}-\mathrm{O}_{1 \mathrm{~W}}$ & $85,5\left(^{\circ}\right)$ & $89,0\left(^{\circ}\right)$ & $88,1\left(^{\circ}\right)$ & $88,4\left(^{\circ}\right)$ & $77,6\left(^{\circ}\right)$ & $102,0\left(^{\circ}\right)$ \\
$\mathrm{O}_{1 \mathrm{~W}}-\mathrm{M}^{2+}-\mathrm{O}_{2 \mathrm{~W}}$ & $179,3\left(^{\circ}\right)$ & $179,8\left(^{\circ}\right)$ & $180,0\left(^{\circ}\right)$ & $179,2\left(^{\circ}\right)$ & $178,0\left(^{\circ}\right)$ & $175,8\left(^{\circ}\right)$
\end{tabular}

Como pode ser observado na tabela acima, a distância da ligação $\mathrm{N}-\mathrm{M}^{2+}$ diminui a medida que o número atômico $(\mathrm{Z})$ dos íons metálicos aumenta. O comprimento de ligação para os íons da primeira fila diminui na seguinte ordem: $\mathrm{Fe}^{2+}>\mathrm{Co}^{2+}>\mathrm{Ni}^{2+}$. A mesma tendência é observado nos íons da segunda fila $\mathrm{Ru}^{2+}>\mathrm{Rh}^{2+}>\mathrm{Pd}^{2+}$. Isso se deve ao fato que, indo da esquerda pra direita, na tabela periódica, os raios iônicos tende a diminuir, e, conseqüentemente, as distâncias metal-ligante também tendem a diminuir. Na Tabela 2, uma importante informação é obtida sobre os arranjos geométricos desses complexos. Essa informação é referente às ligações metal- $\mathrm{O}_{\mathrm{W}}$ (oxigênio da água). Como pode ser observado nessas ligações, o comprimento de ligação nos complexos de $\mathrm{Fe}^{2+}, \mathrm{Co}^{2+}, \mathrm{Ni}^{2+}$ e $\mathrm{Ru}^{2+}$ variam em média de 2,110 a 2,170 A, ou seja, para esses íons metálicos, o arranjo octaédrico permanece inalterado. No entanto, quando observamos os complexos formados pelos íons da segunda fila, exceto o complexo de $\mathrm{Ru}^{2+}$, o arranjo octaédrico não é mais mantido, uma vez que a distância metal- $\mathrm{O}_{\mathrm{W}}$ varia de 2,510 a $3,773 \AA$ para os íons de $\mathrm{Rh}^{2+}$ e $\mathrm{Pd}^{2+}$, respectivamente. Uma explicação para a grande distorção nesses complexos é a distorção tetragonal (ou efeito Jahn-Teller) que é responsável pelo alongamento do eixo z e a 
compressão dos eixos x e y, levando a uma redução na energia do orbital $e_{g}\left(d_{z}^{2}\right)$ e aumentando a energia do orbital $e_{g}\left(d_{x^{2}-y^{2}}\right)$ (ver Figura 6). Como conseqüência, nos complexos de $\mathrm{Rh}^{2+}$ e $\mathrm{Pd}^{2+}$ são observadas quatro ligações mais curtas e duas ligações mais longas. Como no complexo 1a, os ligantes aminas são de campo forte e os elétrons nos complexos $4 d^{7}$ e $4 d^{8}$ são arranjados com um elétron e dois elétrons emparelhados no orbital $\left(\mathrm{d}_{\mathrm{z}}{ }^{2}\right)$, respectivamente, resultando assim em complexo de spin baixo. Entretanto, tal distorção não é observada para o complexo formado pelo íon $\mathrm{Ru}^{2+}\left(4 \mathrm{~d}^{6}\right)$. Nesse sistema, como os ligantes são de campo forte, é impossível que um ou mais elétrons ocupem um orbital $e_{\mathrm{g}}$, e, desta forma, mantém-se um arranjo octaédrico como observado pelos cálculos teóricos, uma vez que nesse complexo a distância metal-O $\mathrm{W}_{\mathrm{W}}$ é em média de 2,158 ̊̊. Todas as estruturas otimizadas para os complexos formados pelos íons metálicos da primeira e segunda fila estão no Apêndice A.

É importante ressaltar que só mantemos a discursão dos complexos formados pelos íons $\mathrm{Rh}^{2+}$ e $\mathrm{Pd}^{2+}$, em virtude de termos inicialmente calculados tais sistemas com as duas moléculas de água no eixo z.

Na Tabela 3, estão os resultados geométricos obtidos para os complexos $\mathbf{1 b}$ formados pelos íons metálicos da primeira e segunda filas: $\mathrm{M}^{2+}=\mathrm{Fe}^{2+}, \mathrm{Co}^{2+}, \mathrm{Ni}^{2+}, \mathrm{Ru}^{2+}, \mathrm{Rh}^{2+}, \mathrm{Pd}^{2+}$.

Tabela 3. Parâmetros geométricos calculados em nível de teoria DFT/B3LYP com o conjunto de base Lanl2DZ para o complexo $\mathbf{1 b}$

\begin{tabular}{ccccccc} 
& $\mathrm{Fe}^{2+}$ & $\mathrm{Co}^{2+}$ & $\mathrm{Ni}^{2+}$ & $\mathrm{Ru}^{2+}$ & $\mathrm{Rh}^{2+}$ & $\mathrm{Pd}^{2+}$ \\
\hline $\mathrm{O} 1-\mathrm{M}^{2+}$ & $2,105(\AA)$ & $2,085(\AA)$ & $2,075(\AA)$ & $2,133(\AA)$ & $2,114(\AA)$ & $2,086(\AA)$ \\
$\mathrm{O} 2-\mathrm{M}^{2+}$ & $2,131(\AA)$ & $2,151(\AA)$ & $2,114(\AA)$ & $2,162(\AA)$ & $2,502(\AA)$ & $3,073(\AA)$ \\
$\mathrm{M}^{2+}-\mathrm{O}_{2 \mathrm{~W}}$ & $2,151(\AA)$ & $2,098(\AA)$ & $2,069(\AA)$ & $2,168(\AA)$ & $2,079(\AA)$ & $2,018(\AA)$ \\
$\mathrm{M}^{2+}-\mathrm{O}_{1 \mathrm{~W}}$ & $2,052(\AA)$ & $2,043(\AA)$ & $2,016(\AA)$ & $2,117(\AA)$ & $2,111(\AA)$ & $2,051\left(^{\AA}\right)$ \\
$\mathrm{O} 1-\mathrm{M}^{2+}-\mathrm{N} 2$ & $97,8\left(^{\circ}\right)$ & $88,0\left(^{\circ}\right)$ & $96,7\left(^{\circ}\right)$ & $94,3\left(^{\circ}\right)$ & $89,2\left(^{\circ}\right)$ & $82,3\left(^{\circ}\right)$ \\
$\mathrm{O} 1-\mathrm{M}^{2+}-\mathrm{O}_{2 \mathrm{~W}}$ & $80,5\left(^{\circ}\right)$ & $85,8\left(^{\circ}\right)$ & $94,3\left(^{\circ}\right)$ & $85,0\left(^{\circ}\right)$ & $97,4\left(^{\circ}\right)$ & $117,1\left(^{\circ}\right)$ \\
$\mathrm{N} 2-\mathrm{M}^{2+}-\mathrm{O}_{1 \mathrm{~W}}$ & $76,2\left(^{\circ}\right)$ & $98,5\left(^{\circ}\right)$ & $85,7\left(^{\circ}\right)$ & $79,9\left(^{\circ}\right)$ & $75,8\left(^{\circ}\right)$ & $88,7\left(^{\circ}\right)$ \\
$\mathrm{O}_{1 \mathrm{~W}}-\mathrm{M}^{2+}-\mathrm{O}_{2 \mathrm{~W}}$ & $151,1\left(^{\circ}\right)$ & $176,5\left(^{\circ}\right)$ & $173,2\left(^{\circ}\right)$ & $174,5\left(^{\circ}\right)$ & $176,5\left(^{\circ}\right)$ & $177,7\left(^{\circ}\right)$ \\
\hline
\end{tabular}


O comprimento de ligação $\mathrm{O}-\mathrm{M}^{2+}$, onde $\mathrm{O}$ são os átomos de oxigênio colocados diretamente na cavidade de complexação do macrociclo [20]aneO4N4, diminuem de acordo com os complexos 1a, isto é, $\mathrm{Fe}^{2+}>\mathrm{Co}^{2+}>\mathrm{Ni}^{2+}$ para os íons metálicos da primeira fila e $\mathrm{Ru}^{2+}>$ $\mathrm{Rh}^{2+}>\mathrm{Pd}^{2+}$ para os íons metálicos da segunda fila. Entretanto, três fatores diferentes podem ser observados: (1) Os comprimentos de ligação O- $\mathrm{M}^{2+}$, para maioria dos complexos 1b, com exceção dos íons $\mathrm{Rh}^{2+}$ e $\mathrm{Pd}^{2+}$, são relativamente menores quando comparados com o comprimento de ligação N-M ${ }^{2+}$ (complexo 1a). Por exemplo, para o complexo $\mathbf{1 b}$ de $\mathrm{Fe}^{2+}$ a distância de ligação é em média 2,118 ̊̊, enquanto no complexo $1 \mathbf{a}$ de $\mathrm{Fe}^{2+}$ essa distância é de 2,203 $\AA$, ou seja, o complexo $\mathbf{1 b}$ de $\mathrm{Fe}^{2+}$ apresenta um ligação de $0,085 \AA$ menor que o complexo 1a. No entanto, essa tendência não é mais observada quando comparamos os

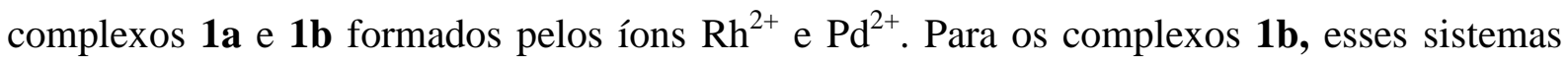
apresentam uma maior deformação na cavidade de complexação (ver Tabela 3). As geometrias otimizadas de todos os complexos $\mathbf{1 b}$ estão colocadas no Apêndice A. (2) A ligação $\mathrm{M}^{2+}-\mathrm{O}_{\mathrm{W}}$ foi mantida em todos os complexos, garantindo assim um sistema hexacoordenado. Isso se deve ao fato que os grupos complexantes da cavidade do macrociclo são éteres. Esse ligante não provoca uma distorção tetragonal significativa nos complexos, deixando os orbitais $\mathrm{e}_{\mathrm{g}}$ praticamente degenerados. A análise das energias dos orbitais serão analisadas na seção "d". 3- Na Tabela 3, os sistemas hexacoordenados apresentam arranjo octaédrico distorcido, haja a vista os valores calculados para os ângulos de ligação O1-M-O2, $\mathrm{O}-\mathrm{M}-\mathrm{O}_{\mathrm{W}}$ e $\mathrm{O}_{\mathrm{W} 1}-\mathrm{M}-\mathrm{O}_{\mathrm{W} 2}$. Como podemos observar, os valores para os ângulos O1-M-O2 e O$\mathrm{M}-\mathrm{O}_{\mathrm{W}}$ variam de 75,8 a $117,1^{\circ}$, sendo que o valor do ângulo equatorial $\mathrm{O}_{\mathrm{W} 1}-\mathrm{M}-\mathrm{O}_{\mathrm{W} 2}$ tem uma variação de 151,1 a $177,7^{\circ}$, mostrando assim uma tendência de complexos octaédricos bem distorcidos. Essa distorção faz com que a simetria desses complexos tenha simetria pontual reduzida $\left(C_{1}\right)$. 
A Figura 8 mostra a variação média da distância metal-nitrogênio (complexos 1a) e matel-oxigênio (complexos 1b).

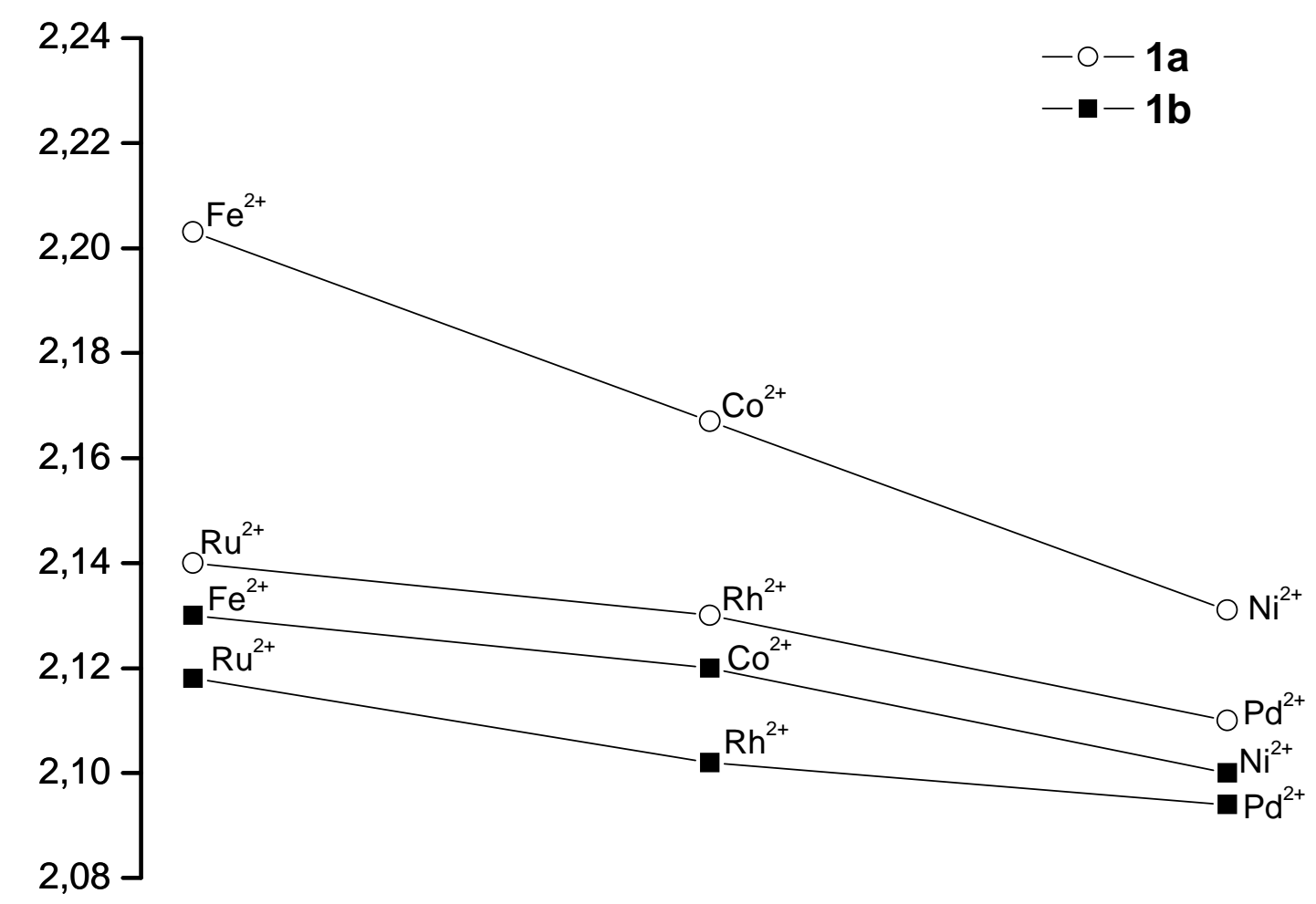

Figura 8. Distância média calculada para as ligações metal-nitrogênio (complexos 1a) e matel-oxigênio (complexos 1b).

Os complexos $\mathbf{1 b}$ formados pelos íons metálicos da primeira e segunda filas dos metais de transição apresentam uma variação de distância bem similar, enquanto que para os complexos 1a essa variação é bem significativa. 


\section{b) Energias Eletrônicas, Estabilidade Relativa dos Complexos e Energia de Interação ( $\left.\mathbf{E}_{\text {INT }}\right)$}

As estruturas otimizadas mais estáveis obtidas pela análise conformacional, juntamente com alguns parâmetros geométricos dos ligantes macrociclos [20]aneN4O4 e [20]aneO4N4, são mostrados na Figura 9.

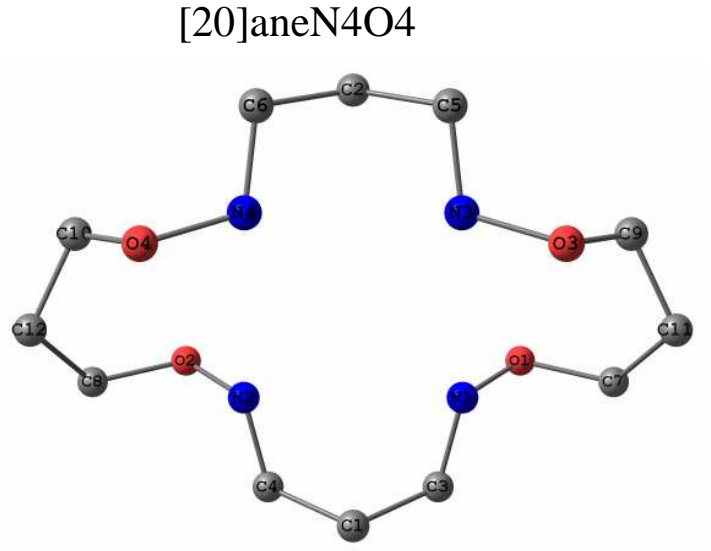

N4-N2: $2,947(\AA)$

N3-N1: $2,947(\AA)$

N4-N3: 2,963 (A)

N2-N1: 3,306 (̊)

N4-N1: 4,299 (̊)

N3-N2: 4,299 (̊)
[20]AneO4N4

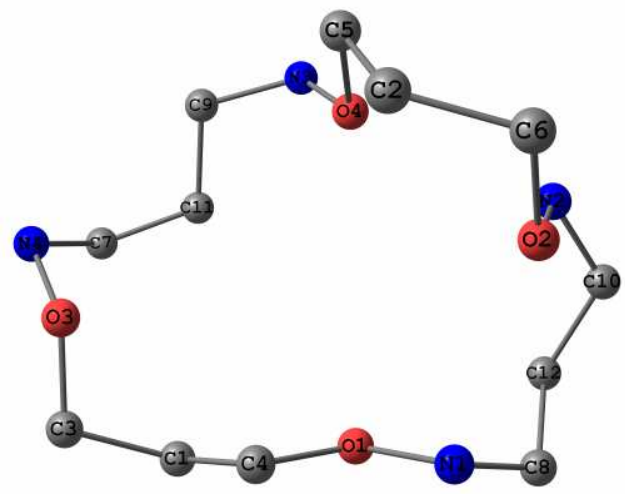

O3-O2: 5,824 (A)

O4-O1: 4,377 (̊)

O3-O4: 4,504 (̊)

O2-O1: 3,679 $(\AA)$

O2-O4: 3,090 (̊)

O3-O1: 4,098 (̊)

Figura 9. Estruturas otimizadas e parâmetros geométricos dos ligantes macrociclos livres [20]aneN4O4 e [20]aneO4N4 calculadas com o modelo teórico B3LYP/Lanl2DZ. Os átomos de hidrogênios foram removidos para melhor visualizar as estruturas.

Em 2004, Castro-Soto et al. [23] mostrou que pode existir uma relação direta entre o tamanho da cavidade do macrociclo antes da complexação e a estabilidade do complexo formado. Como podemos observar na Figura 9, a conformação mais estável adotada pelos macrociclos livres e as distâncias cruzadas entre os heteroátomos $(\mathrm{N}, \mathrm{O})$, dá uma indicação do espaço avaliado dentro da cavidade do macrociclo para complexação de um íon metálico. O macrociclo [20]aneN4O4 é mais simétrico que o alternativo [20]aneO4N4. Uma alta simetria e uma apropriada dimensão da cavidade [23] do macrociclo são requisitos importantes para a 
complexação do íon metálico pelo macrociclo. Tais requisitos reduzem o custo energético para a reorganização do macrociclo quando ele interagir com os íons metálicos [68]. Desta forma, um dos prováveis indícios do macrociclo [20]aneN4O4 resultar em complexos mais estáveis que o macrociclo [20]aneO4N4 é em virtude da energia de reorganização para o formação do complexo. Tal evidência ficará mais elucidada quando discutirmos as energias de interação.

As energias eletrônicas, em Hartree, dos ligantes livres [20]aneN4O4 e [20]aneO4N4, juntamente com as cargas atômicas média dos heteroátomos obtidas pela análise NBO, são apresentadas na Tabela 4.

Tabela 4. Energia eletrônica, em Hartree, e cargas atômica NBO sobre os heteroátomos calculadas em nível de teoria DFT/B3LYP com o conjunto de base Lanl2DZ para os ligantes livre [20]aneN4O4 e [20]aneO4N4

\begin{tabular}{ccc}
\hline Heteroatomo & Cargas $\left(\mathrm{e}^{-}\right)$ & Energia (Hartree) \\
\hline \multicolumn{3}{c}{$[20]$ aneN4O4 } \\
\hline nitrogênio & $-1,611$ & $-993,193589$ \\
oxigênio & $-1,888$ & \\
\hline \multicolumn{3}{c}{$[20]$ aneO4N4 } \\
\hline nitrogênio & $-1,975$ & $-993,214836$ \\
oxigênio & $-1,609$ & \\
\hline
\end{tabular}

Como observado na Tabela 4, as cargas sobre heteroátomos que estão colocados diretamente na cavidade de complexação dos ligantes livres são relativamente semelhantes. Por exemplo, a carga média sobre os átomos de nitrogênio, no ligante [20]aneN4O4, é de -1,611 eletron (e`). Já nos átomos de oxigênios do ligante [20]aneO4N4, a carga NBO é de -1,609 (e`). Porém, as cargas sobre o heteroátomo que estão na posição $\alpha$ são relativamente bem diferentes, ou seja, -1,888 e -1,975 ( (⿱一土) $)$ para os átomos de oxigênio e nitrogênio, respectivamente, nos ligantes [20]aneN4O4 e [20]aneO4N4. Analisando as energias 
eletrônicas, podemos verificar que o macrociclo [20]aneO4N4 é aproximadamente 7,2 $\mathrm{Kcal}_{\mathrm{mol}}{ }^{-1}$ mais estável que o macrociclo [20]aneN4O4. Porém, a maior estabilidade eletrônica observada para o macrociclo [20]aneN4O4 não é suficiente para que este sistema resulte em complexos mais estáveis, uma vez que a simetria do macrociclo [20]aneN4O4 é bastante distorcida.

Os cátions $\mathrm{M}^{2+}$ da primeira e segunda filas dos metais de transição têm a subcamada $3 \mathrm{~d}$ e $4 \mathrm{~d}$, respectivamente, parcialmente preenchida, o que pode levar à uma variedade de estados eletrônicos para cada cátion. Múltiplas multiplicidades $(n+1)$, onde n é o número de elétrons desemparelhados, podem ser encontradas nos complexos formados por esses cátions. Os arranjos dos spins nos orbitais $t_{2 g}$ e $e_{g}$ dependem, dentre outros fatores, do tipo de ligante que está ligado ao metal, ou seja, se o ligante for de campo forte, o complexo terá multiplicidade de spin baixo. Caso o ligante seja de campo fraco, o estado eletrônico do complexo é de spin alto. Por exemplo, $\mathrm{O}$ cátion metálico $\mathrm{Fe}^{2+}$, de configuração eletrônica $\mathrm{d}^{6}$, poderá ter nenhum ou quatro elétrons desemparelhados, resultando em complexos de spin baixo ou spin alto, respectivamente. O estado eletrônico intermediário tripleto, para os cátions $\mathrm{d}^{6}$, também foi considerado. Esse estado foi obtido teoricamente considerando uma quebra de degenerescência do orbital $t_{2 g}$, obtendo, assim, uma configuração eletrônica $t_{2 g}{ }^{5} e_{g}^{1}$ com um elétron desemparelhado em cada orbital $\mathrm{d}_{\mathrm{xy}}$ e $\mathrm{d}_{\mathrm{z}}{ }^{2}$.

Na Tabela 5 estão apresentados os valores das energias eletrônicas absoluta para todos os possíveis estados eletrônicos (multiplicidade de spin) dos complexos 1a e 1b, assim como as energias relativas entre esses complexos. Esses valores de energia foram obtidos com a correção da energia vibracional do ponto zero. 
Tabela 5. Energia absoluta e energia relativa calculadas com B3LYP/Lanl2DZ para os complexos 1a e 1b arranjo octaédrico

\begin{tabular}{|c|c|c|c|c|c|c|}
\hline $\begin{array}{c}\text { Cátion } \\
\mathrm{M}^{2+}\end{array}$ & Multipli. & $\begin{array}{c}\text { Energia abs. } \\
\text { (a.u.) }\end{array}$ & $\begin{array}{c}\Delta \mathrm{E}^{\mathrm{a}} \\
\left(\mathrm{kcal} . \mathrm{mol}^{-1}\right)\end{array}$ & $\begin{array}{c}\text { Energia abs. } \\
\text { (a.u.) }\end{array}$ & $\begin{array}{c}\Delta \mathrm{E}^{\mathrm{a}} \\
\left(\mathrm{kcal} . \mathrm{mol}^{-1}\right)\end{array}$ & 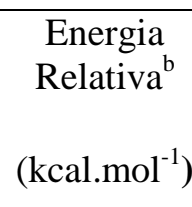 \\
\hline & & \multicolumn{2}{|c|}{$1 \mathbf{a}$} & \multicolumn{2}{|c|}{ 1b } & $1 b-1 a$ \\
\hline \multirow[t]{3}{*}{$\mathrm{Fe}^{2+}$} & Quinteto & $-1269,12043$ & 0,00 & $-1269,10241$ & 0,00 & 11,31 \\
\hline & Tripleto & $-1269,10812$ & 9,99 & $-1269,06582$ & 22,96 & 26,54 \\
\hline & Singleto & $-1269,11386$ & 6,38 & $-1269,05778$ & 28,00 & 35,19 \\
\hline \multirow[t]{2}{*}{$\mathrm{Co}^{2+}$} & Quadupleto & $-1290,76032$ & 0,00 & $-1290,72953$ & 0,00 & 19,32 \\
\hline & Dubleto & $-1290,75248$ & 4,92 & $-1290,70062$ & 18,15 & 32,54 \\
\hline \multirow[t]{2}{*}{$\mathrm{Ni}^{2+}$} & Tripleto & $-1314,98938$ & 0,00 & $-1314,94938$ & 0,00 & 25,10 \\
\hline & Singleto & $-1314,95251$ & 23,14 & $-1314,89998$ & 31,00 & 32,96 \\
\hline \multirow[t]{3}{*}{$\mathrm{Ru}^{2+}$} & Quinteto & $-1239,46233$ & 55,50 & $-1239,44882$ & 13,53 & 8,48 \\
\hline & Tripleto & $-1239,50641$ & 27,84 & $-1239,45335$ & 10,69 & 33,30 \\
\hline & Singleto & $-1239,55077$ & 0,00 & $-1239,47038$ & 0,00 & 50,44 \\
\hline \multirow[t]{2}{*}{$\mathrm{Rh}^{2+}$} & Quad. & $-1255,09091$ & 41,87 & $-1255,06258$ & 13,10 & 17,78 \\
\hline & Dubleto & $-1255,15763$ & 0,00 & $-1255,08346$ & 0,00 & 46,54 \\
\hline \multirow[t]{2}{*}{$\mathrm{Pd}^{2+}$} & Tripleto & $-1272,33689$ & 26,72 & $-1272,28612$ & 5,82 & 31,86 \\
\hline & Singleto & $-1272,37948$ & 0,00 & $-1272,29538$ & 0,00 & 52,77 \\
\hline
\end{tabular}

${ }^{\mathrm{a}}$ Energia relativa calculada tendo como referencia o cátion com estado de spin mais estável.

${ }^{b}$ Energia relativa entre os complexos de [20]AneN $\mathrm{N}_{4} \mathrm{O}_{4}(\mathbf{1 a})$ e [20] $\mathrm{AneO}_{4} \mathrm{~N}_{4}(\mathbf{1 b})$.

No caso do íon $\mathrm{Fe}^{2+}$, com a configuração eletrônica d $\mathrm{d}^{6}$, é bem diferente. A princípio, os complexos de $\mathrm{Fe}^{2+}$ podem existir nos estados singleto, tripleto e quinteto. No presente trabalho, os complexos 1a, devido à presença dos átomos de nitrogênio, tem uma variação de estabilidade entre os estados de aproximadamente $10 \mathrm{Kcal}_{\mathrm{mol}}{ }^{-1}$. Entretanto, o estado quinteto é mais estável que os estados singleto e tripleto em cerca de 6,4 e $10 \mathrm{Kcal}_{\mathrm{mol}}{ }^{-1}$, 
respectivamente. Em contraste, no complexo 1b, devido aos átomos de oxigênio, o estado de spin alto quinteto é consideravelmente mais estável que os estados singleto e tripleto (mais que $20 \mathrm{Kcal}_{\mathrm{mol}}{ }^{-1}$ ). Portanto, o campo ligante tem uma forte influência sobre a estabilidade relativa dos diferentes estados eletrônicos. O campo fraco promovido pelo os átomos de oxigênio não é suficiente para estabilizar os estados de multiplicidade baixa, tornando os estados singleto e tripleto menos estáveis que o estado fundamental quinteto. Sendo que para o complexo 1a, as ligantes aminas, de campo forte, promovem uma menor diferença de energia entre os estados de multiplicidade.

Analisando os complexos formados por íons metálicos da segunda fila $\left(\mathrm{Ru}^{2+}, \mathrm{Rh}^{2+} \mathrm{e}\right.$ $\mathrm{Pd}^{2+}$ ), podemos observar duas mudanças significativas em relação aos complexos da primeira fila. Primeiramente, nesses complexos os estados de spin baixo são mais estáveis. Podemos pegar como exemplo o complexo de $\mathrm{Pd}^{2+}(\mathbf{1 a})$ na qual a diferença entre o spin baixo e o spin alto é aproximadamente $27 \mathrm{Kcal}_{\mathrm{mol}}{ }^{-1}$, enquanto em complexos dos cátions $\mathrm{Rh}^{2+}$ e $\mathrm{Ru}^{2+}$ essa diferença aumenta de 42 e $56 \mathrm{Kcal}_{\mathrm{mol}}{ }^{-1}$, respectivamente. A mesma tendência pode ser observada para os complexos $\mathbf{1 b}$, onde a diferença entre os estados de spin baixo e spin alto aumenta de 6, 13 e $14 \mathrm{Kcal}_{\mathrm{mol}}{ }^{-1}$ para os complexos de $\mathrm{Pd}^{2+}, \mathrm{Rh}^{2+}$ e $\mathrm{Ru}^{2+}$, respectivamente. A segunda mudança importante que podemos notar é que os complexos $\mathbf{1 b}$ possuem menor diferença de energia quando comparado aos complexos 1a. Essa menor diferença é devido aos átomos de oxigênio, no complexo $\mathbf{1 b}$, que são ligantes de campo fraco, estabilizarem melhor o estado de spin baixo.

Os cátions $\mathrm{M}^{2+}$ da primeira fila mostraram ter uma preferência pelo os estado de spin alto, em ambos os complexos aqui estudados. Entretanto, para os cátions $\mathrm{M}^{2+}$ da segunda fila, os estados de spin baixo foram os mais estáveis. Tal preferência pode ser atribuída a dois efeitos de cooperação: (a) a forte sobreposição entre os orbitais 4 d e os orbitais do ligante, (b) 
a diminuição da energia de emparelhamento devido ao largo volume disponível para os elétrons no orbital 4d quando comparado com o orbital 3d. Ambos efeitos podem contribuir para a estabilidade do complexo de spin baixo [35].

A capacidade de ligantes macrociclicos contendo átomos de nitrogênio ou oxigênio para complexar íons metálicos é bem conhecida [18,25]. Entretanto, usualmente, devido à baixa basicidade dos átomos de oxigênio quando comparados a átomos de nitrogênio, este último pode formar complexo mais forte que os ligantes com átomos de oxigênio. Como exemplo primordial, nós podemos citar os complexos $\left[\mathrm{M}\left(\mathrm{H}_{2} \mathrm{O}\right)_{6}\right]^{2+}$ versus $\left[\mathrm{M}\left(\mathrm{NH}_{3}\right)_{6}\right]^{2+}[69]$. É bem conhecido que o complexo hexaamima é mais estável que o complexo hexa-aquo, embora a diferença de energia diminua quando usamos metais com raio atômico menor [69].

Os presentes ligantes macrociclos ([20] $\mathrm{aneN}_{4} \mathrm{O}_{4}$ e [20]aneO $\left.\mathrm{O}_{4} \mathrm{~N}_{4}\right)$ proporcionam uma ferramenta poderosa para testar a capacidade relativa de complexação de íons metálicos por átomos de nitrogênio ou oxigênio. Os cálculos indicam que a complexação por átomos de nitrogênio ([20]ane $\mathrm{N}_{4} \mathrm{O}_{4}$ ) é a opção preferencial para todos os cátions estudados. Como os complexos 1a e 1b são isômeros, uma comparação diretamente entre suas energias relativas pode ser feita. Quando comparamos as energias absolutas dadas na Tabela 5, observa-se que os complexos 1a são sempre mais estáveis que os correspondentes complexos 1b com energia relativa de 8,5 a $53 \mathrm{Kcal}_{\mathrm{mol}}{ }^{-1}$. A diferença de energia entre os dois complexos formados por íons da segunda fila aumenta com o número atômico (Z). Para um dado íon metálico da primeira fila, a diferença de energia entre os complexos 1a e 1b diminui quando aumenta a multiplicidade (Tabela 5).

Uma das principais metas desse estudo é quantificar a capacidade do ligante macrociclo em selecionar diferentes cátions. Isso pode ser feito em termo da energia de interação $\left(\mathrm{E}_{\mathrm{INT}}\right)$ entre o íon metálico e o ligante. Essa energia pode ser obtida pela Equação 1. 


$$
\mathrm{E}_{\mathrm{INT}}=\mathrm{E}_{\text {complexo }}-\left(\mathrm{E}_{\mathrm{A}}+\mathrm{E}_{\mathrm{B}}\right),
$$

onde, $\mathrm{E}_{\mathrm{A}}$ é a energia do íon metálico e $\mathrm{E}_{\mathrm{B}}$ é a energia do macrociclo e das duas moléculas de água. $\mathrm{E}_{\text {complexo }}$ é a energia dos complexos formados por diferentes íons metálicos. É importante ressaltar que o Erro de Superposição de Base não foi considerado em virtude da complexidade do sistema.

As energias de interação para ambos os complexos 1a e 1b são dadas na Tabela 6. As interações para nitrogênio (1a) é sempre mais forte que para oxigênio (1b), como já indicado acima pela comparação das diferentes energias entre os complexos $\mathbf{1 a}$ e $\mathbf{1 b}$.

Tabela 6. Energia de interação entre os macrociclos [20]ane $\mathrm{N}_{4} \mathrm{O}_{4}$ e [20]ane $\mathrm{O}_{4} \mathrm{~N}_{4}$ e duas moléculas de água com íons dos metais de transição calculadas com B3LYP/Lanl2DZ para os complexos 1a e 1b

\begin{tabular}{ccc}
\hline Cátion $\mathrm{M}^{2+}$ & $\mathrm{E}_{\mathrm{INT}}\left(\mathrm{Kcal}_{\mathrm{mol}}{ }^{-1}\right) \mathbf{1 a}$ & $\mathrm{E}_{\mathrm{INT}}\left(\mathrm{Kcal}^{\mathrm{mol}}{ }^{-1}\right) \mathbf{1 b}$ \\
\hline $\mathrm{Fe}^{2+}$ & $-415,6$ & $-394,9$ \\
$\mathrm{Co}^{2+}$ & $-442,4$ & $-415,9$ \\
$\mathrm{Ni}^{2+}$ & $-458,2$ & $-425,9$ \\
$\mathrm{Ru}^{2+}$ & $-432,1$ & $-374,5$ \\
$\mathrm{Rh}^{2+}$ & $-486,0$ & $-432,3$ \\
$\mathrm{Pd}^{2+}$ & $-516,5$ & $-456,5$ \\
\hline
\end{tabular}

A Figura 10 mostra que, em uma fila, a força da interação aumenta com o aumento do

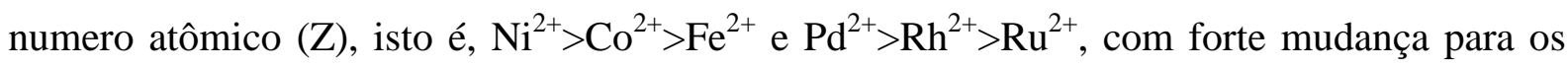
cátions no segundo grupo $\left(\mathrm{Ru}^{2+}, \mathrm{Rh}^{2+}\right.$ e $\left.\mathrm{Pd}^{2+}\right)$ que para os cátions do primeiro grupo $\left(\mathrm{Fe}^{2+}\right.$, $\mathrm{Co}^{2+}$ e $\mathrm{Ni}^{2+}$ ). Quando comparado um par no mesmo grupo, nos complexos 1a, os íons metálicos da segunda fila ligam-se mais fortemente que os correspondentes íons metálicos da 
primeira fila, i.e., $\mathrm{Ru}^{2+}>\mathrm{Fe}^{2+}, \mathrm{Rh}^{2+}>\mathrm{Co}^{2+}$ e $\mathrm{Pd}^{2+}>\mathrm{Ni}^{2+}$. Para os complexos $\mathbf{1 b}$, o mesmo comportamento é observado, exceto para o par $\mathrm{Fe}^{2+} / \mathrm{Ru}^{2+}$, onde para o complexo de $\mathrm{Fe}^{2+}$ a energia de interação é aproximadamente $16 \mathrm{Kcal}_{\mathrm{mol}}{ }^{-1}$ mais alta que para o complexo de $\mathrm{Ru}^{2+}$. Em geral, a diferença de energia entre um par do complexo é sempre maior para complexos com [20]aneN4O4 que com [29]aneO4N4.

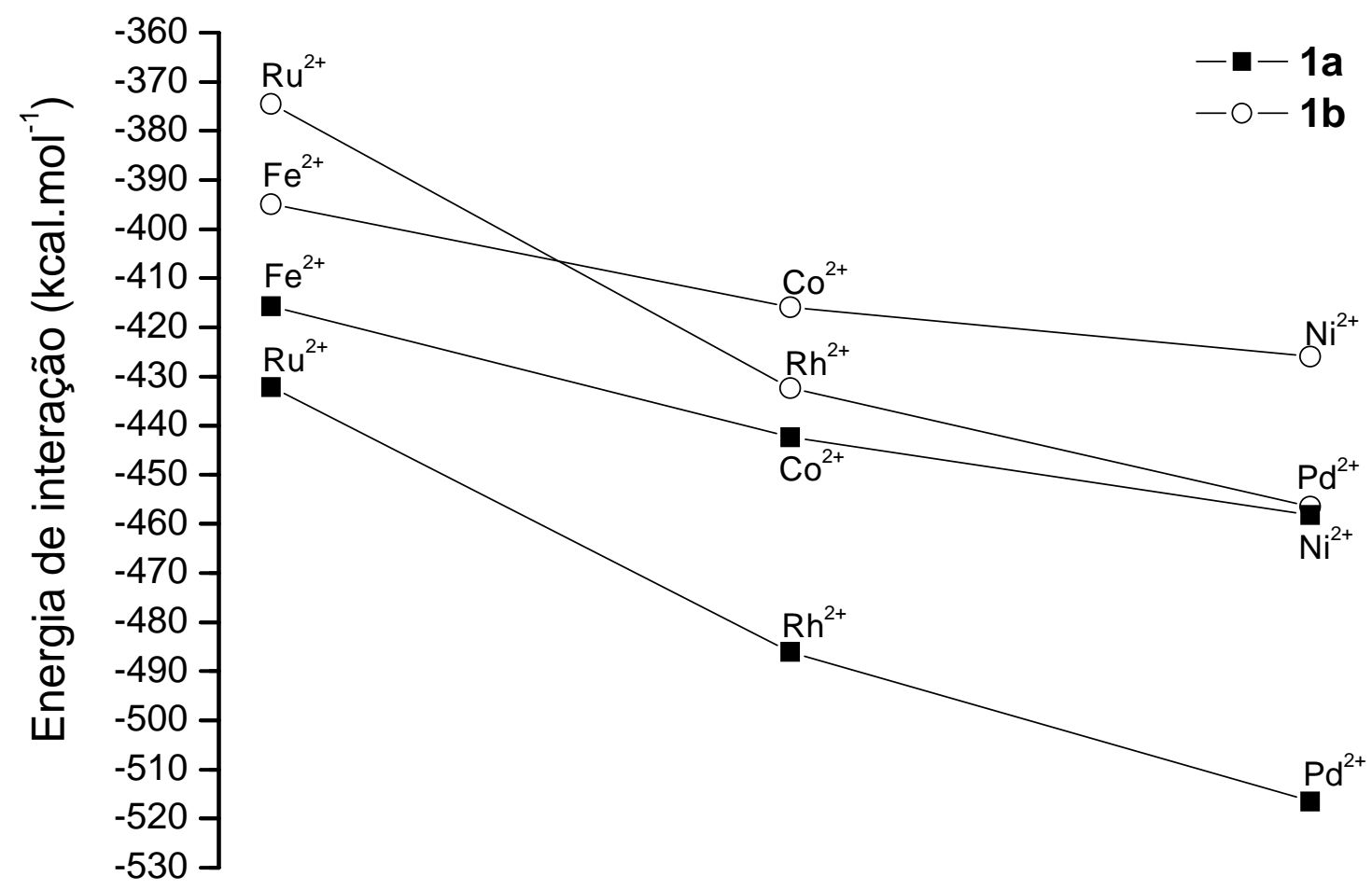

Figura 10. Energia de interação ( $\mathrm{E}_{\mathrm{INT}}$ ), em Kcal.mol ${ }^{-1}$, calculada para os complexos 1a e $\mathbf{1 b}$ formado pelo os elementos da primeira e segunda fila dos metais de transição.

Em resumo, nossos resultados indicam que esses ligantes macrociclicos ligam-se mais fortemente com metais de maior número atômico, quando comparados com qualquer metal de uma fila ou grupo da tabela periódica. Esses resultados estão de acordo com os resultados de outros ligantes discutidos na literatura $[8,18,21,23]$. Outra observação que pode ser feita é em relação da distância média entre os átomos de nitrogênio do macrociclo [20]aneN4O4, ou dos 
átomos de oxigênio do macrociclo [20]aneO4N4, com o íon metálico. Quanto menor for a distância $\mathrm{M}-\mathrm{L}(\mathrm{L}=\mathrm{N}, \mathrm{O})$, maior será a energia de interação. Esses resultados são mostrados na Figura 11.

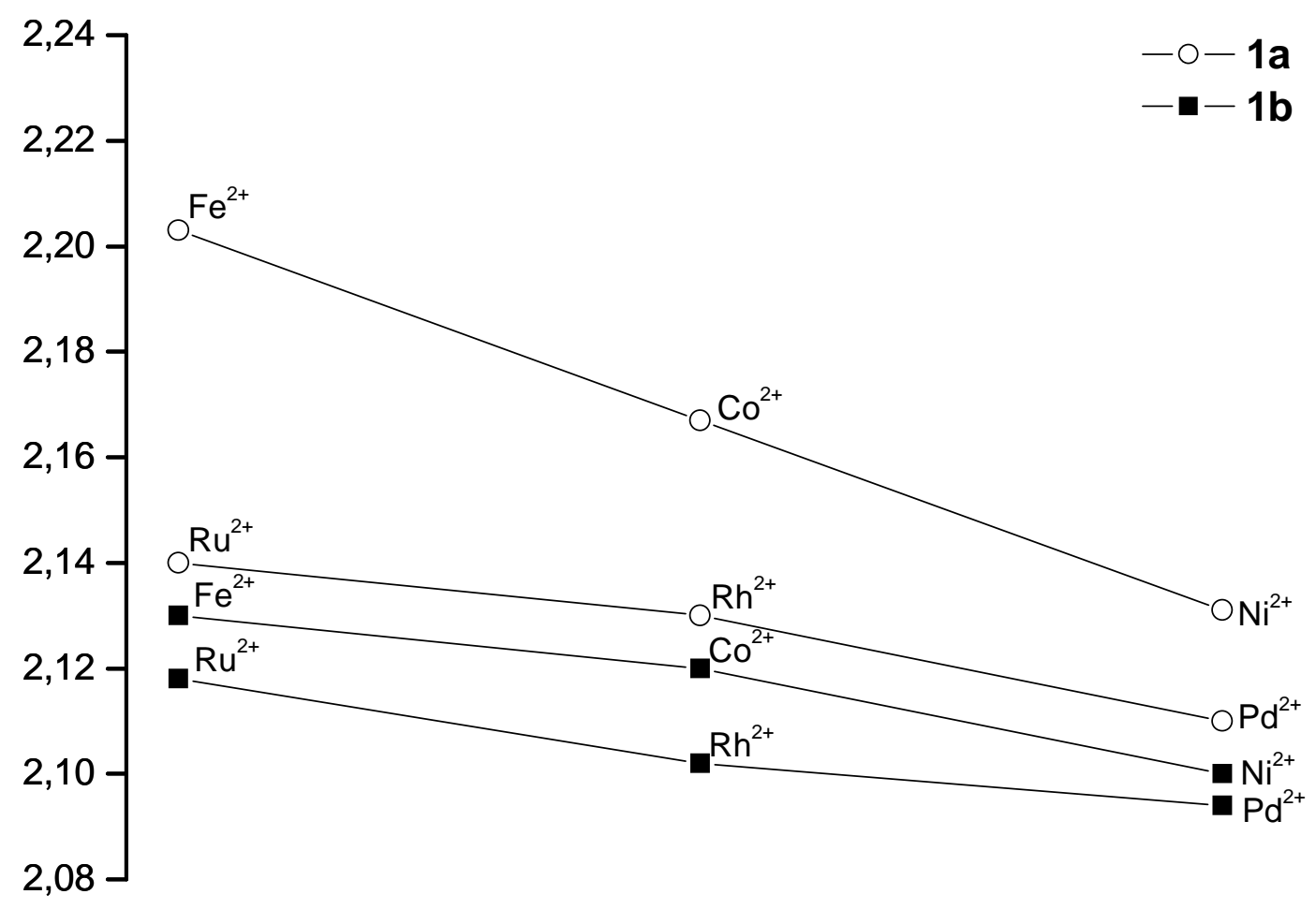

Figura 11. Distância média calculada teoricamente entre os átomos de nitrogênio do macrociclo [20]aneN4O4 (1a), ou do oxigênio do macrociclo [29]aneO4N4 (1b), com o íon metálico.

Entretanto, como o átomo de oxigênio é menor que o átomo de nitrogênio, a distância metal-oxigênio é menor que a correspondente distância metal-nitrogênio. Adicionalmente, pode ser visto que a distância metal-ligante (ligante: $\mathrm{N}$ ou $\mathrm{O}$ ) diminui com o aumento do número atômico em uma dada fila. $\mathrm{Na}$ Tabela 7, alguns parâmetros geométricos para a distância metal-ligante são apresentados. 
Tabela 7. Distância metal-ligante $(\AA ̊)$ para os complexos 1a e 1b calculada em nível de teoria B3LYP com o conjunto de base Lanl2DZ

\begin{tabular}{lllllllll}
\hline \multicolumn{4}{c}{ Complexo 1a } & \multicolumn{5}{c}{ Complexo 1b } \\
\hline & $\mathrm{N}_{1} \mathrm{M}$ & $\mathrm{N}_{2} \mathrm{M}$ & $\mathrm{O}_{1 \mathrm{w}} \mathrm{M}$ & $\mathrm{O}_{2 \mathrm{w}} \mathrm{M}$ & $\mathrm{O}_{1} \mathrm{M}$ & $\mathrm{O}_{2} \mathrm{M}$ & $\mathrm{O}_{1 \mathrm{w}} \mathrm{M}$ & $\mathrm{O}_{2 \mathrm{w}} \mathrm{M}$ \\
$\mathrm{Fe}^{2+}$ & 2,201 & 2,205 & 2,162 & 2,144 & 2,105 & 2,131 & 2,151 & 2,052 \\
$\mathrm{Co}^{2+}$ & 2,173 & 2,167 & 2,115 & 2,125 & 2,085 & 2,151 & 2,098 & 2,043 \\
$\mathrm{Ni}^{2+}$ & 2,134 & 2,127 & 2,110 & 2,100 & 2,074 & 2,114 & 2,016 & 2,069 \\
$\mathrm{Ru}^{2+}$ & 2,137 & 2,139 & 2,149 & 2,167 & 2,133 & 2,162 & 2,167 & 2,129 \\
$\mathrm{Rh}^{2+}$ & 2,123 & 2,142 & 2,509 & 2,509 & 2,114 & 2,130 & 2,079 & 2,109 \\
$\mathrm{Pd}^{2+}$ & 2,110 & 2,112 & 2,106 & 2,106 & 2,100 & 2,104 & 2,018 & 2,051 \\
\hline
\end{tabular}

O macrociclo [20]aneN4O4 mostra-se mais rígido, portanto com menos conformações envolvidas e levando a um nível de menor preorganização, aumentando, assim, a força do campo do macrociclo como ligante e aumentando o overlap da ligação metal-ligante, como será discutido na seção da análise das ligações químicas entre o metal e o ligante.

A ordem de ligação de Mayer [59-62] foi estimada para todos os complexos 1a a $\mathbf{1 b}$, visando relacionar a força da ligação nos complexos $\mathbf{1 a}$ a $\mathbf{1 b}$ com a ordem de ligação de Mayer. Esse resultado foi obtido pelo programa AOMix-L [55] e mostrado na Figura 12.

De um modo geral, os resultados da ordem ligação demonstram a mesma tendência dos parâmetros geométricos, ou seja, os complexos com maior ordem de ligação possuem maior energia de interação. Como resultado adicional, os complexos 1a apresentam, tanto em uma determina fila quanto num determinado grupo, uma ordem superior quando comparado com os complexos 1b. Por exemplo, os complexos de paládio, que têm maior energia de interação, apresentam os seguintes valores de ordem de ligação: 0,46 e 0,44 para os complexos 1a e 1b, respectivamente. 


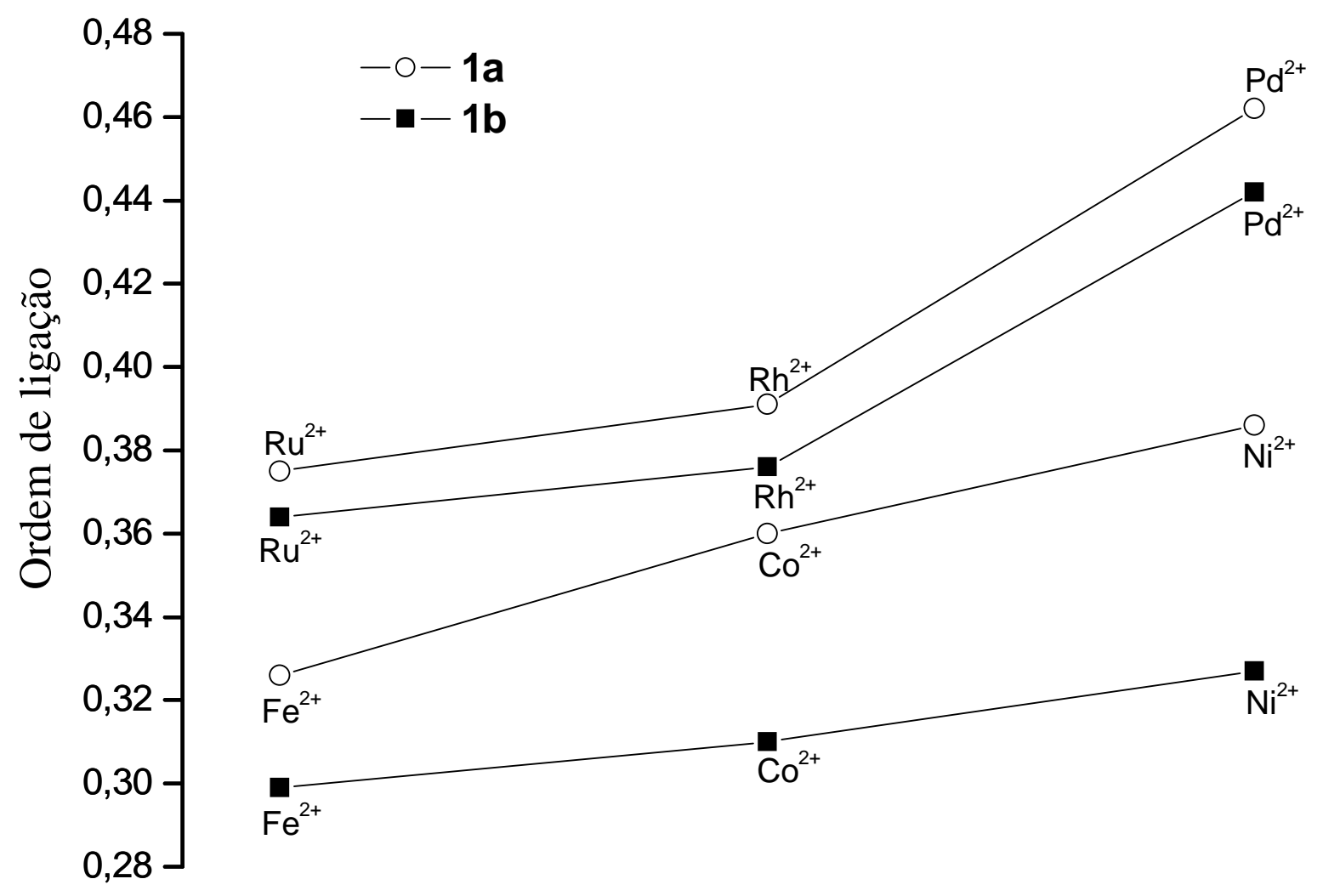

Figura 12. Ordem de ligação de Mayer calculada para os complexos 1a e 1b com o programa AOMix-L.

\section{c) Análise dos Espectros Vibracionais de Infravermelho para os Complexos}

(1a) e (1b)

Todos os complexos 1a estudados têm grupo pontual $\mathrm{C}_{\mathrm{s}}$, com exceção do complexo de $\mathrm{Pd}^{2+}$, onde as moléculas de água deslocam-se totalmente para fora do eixo axial (ver Apêndice A). Esses sistemas possuem uma representação irredutível $\left(\Gamma_{\text {vib }}\right)$ de 159 modos vibracionais (3N-6) para moléculas não lineares, onde $\mathrm{N}$ é o número de átomos na molécula. Na região de 100 a $4000 \mathrm{~cm}^{-1}$, basicamente quase todos esses modos são ativos no infravermelho. 
A Tabela 8 lista os resultados das frequiências calculadas, bem como as atribuições das bandas para o ligante [20]aneN4O4 e para todos os complexos 1a de arranjo octaédrico.

Tabela 8. Freqüências vibracionais calculadas em nível de teoria B3LYP/LanL2DZ para os complexos 1a de arranjo octaédrico

\begin{tabular}{|c|c|c|c|c|c|c|c|}
\hline \multicolumn{8}{|c|}{ complexos 1a } \\
\hline [20]aneN4O4 & $\mathrm{Fe}^{2+}$ & $\mathrm{Co}^{2+}$ & $\mathrm{Ni}^{2+}$ & $\mathrm{Ru}^{2+}$ & $\mathrm{Rh}^{2+}$ & $\mathrm{Pd}^{2+}$ & $\begin{array}{c}\text { Atribuição dos modos } \\
\text { vibracionais }\end{array}$ \\
\hline- & 3662 & 3675 & 3646 & 3677 & 3648 & 3699 & $\mathrm{v}_{\mathrm{as}}\left(\mathrm{OH}_{2}\right)$ \\
\hline- & 3534 & 3514 & 3505 & 3537 & 3423 & 3547 & $v_{\mathrm{s}}\left(\mathrm{OH}_{2}\right)$ \\
\hline 3324 & 3293 & 3308 & 3297 & 3280 & 3269 & 3260 & $v_{\mathrm{s}}(\mathrm{N}-\mathrm{H})$ \\
\hline $3021-2950$ & $\begin{array}{l}3043- \\
2985\end{array}$ & $\begin{array}{l}3045- \\
2986\end{array}$ & $\begin{array}{l}3047- \\
2987\end{array}$ & $\begin{array}{l}3044- \\
2985\end{array}$ & $\begin{array}{l}3048- \\
2990\end{array}$ & $\begin{array}{l}3055- \\
2981\end{array}$ & $v_{\text {as }}\left(\mathrm{CH}_{2}\right)$ \\
\hline $2942-2828$ & $\begin{array}{l}2970- \\
2937\end{array}$ & $\begin{array}{l}2973- \\
2938\end{array}$ & $\begin{array}{l}2975- \\
2939\end{array}$ & $\begin{array}{l}2972- \\
2938\end{array}$ & $\begin{array}{l}2976- \\
2942\end{array}$ & $\begin{array}{l}2978- \\
2942\end{array}$ & $v_{\mathrm{s}}\left(\mathrm{CH}_{2}\right)$ \\
\hline- & 1538 & 1534 & 1539 & 1538 & 1514 & 1550 & $\sigma\left(\mathrm{OH}_{2}\right)$ \\
\hline $1488-1435$ & $\begin{array}{l}1476- \\
1439\end{array}$ & $\begin{array}{l}1476- \\
1444\end{array}$ & $\begin{array}{l}1477- \\
1445\end{array}$ & $\begin{array}{l}1473- \\
1442\end{array}$ & $\begin{array}{l}1471- \\
1442\end{array}$ & $\begin{array}{l}1473- \\
1436\end{array}$ & $\sigma\left(\mathrm{CH}_{2}\right)$ \\
\hline $1431-1325$ & $\begin{array}{l}1382- \\
1306\end{array}$ & $\begin{array}{l}1384- \\
1327\end{array}$ & $\begin{array}{l}1386- \\
1327\end{array}$ & $\begin{array}{c}1378- \\
1326\end{array}$ & $\begin{array}{l}1392- \\
1325\end{array}$ & $\begin{array}{c}1375- \\
1323\end{array}$ & $\delta_{\mathrm{s}}\left(\mathrm{CH}_{2}\right), \delta_{\mathrm{s}}(\mathrm{NH})$ \\
\hline $1243-1170$ & $\begin{array}{l}1272- \\
1144\end{array}$ & $\begin{array}{l}1275- \\
1145\end{array}$ & $\begin{array}{l}1278- \\
1152\end{array}$ & $\begin{array}{c}1284- \\
1160\end{array}$ & $\begin{array}{l}1284- \\
1160\end{array}$ & $\begin{array}{c}1306- \\
1184\end{array}$ & $\delta_{\mathrm{d}}\left(\mathrm{CH}_{2}\right)$ \\
\hline $1130-975$ & $\begin{array}{c}1104- \\
986\end{array}$ & $\begin{array}{c}1103- \\
954\end{array}$ & $\begin{array}{c}1104- \\
955\end{array}$ & $\begin{array}{c}1102- \\
1020\end{array}$ & $\begin{array}{l}1105- \\
1028\end{array}$ & $\begin{array}{l}1133- \\
1038\end{array}$ & $\begin{array}{c}\delta_{\mathrm{s}}(\mathrm{C}-\mathrm{C}) ; \mathrm{v}_{\mathrm{s}}(\mathrm{C}-\mathrm{C}), \mathrm{v}_{\mathrm{s}}(\mathrm{C}- \\
\mathrm{N}) ; \mathrm{v}_{\mathrm{s}}(\mathrm{C}-\mathrm{O}-\mathrm{N})\end{array}$ \\
\hline $967-660$ & $\begin{array}{l}960- \\
716\end{array}$ & $\begin{array}{l}938- \\
720\end{array}$ & $\begin{array}{l}935- \\
723\end{array}$ & $\begin{array}{l}955- \\
699\end{array}$ & $\begin{array}{l}960- \\
724\end{array}$ & $\begin{array}{l}963- \\
726\end{array}$ & $\begin{array}{c}\delta_{\mathrm{d}}(\mathrm{C}-\mathrm{C}) ; \mathrm{v}_{\text {as }}(\mathrm{C}-\mathrm{N}) ; \mathrm{v}_{\mathrm{as}}(\mathrm{C}- \\
\mathrm{O}-\mathrm{N}) ; \delta_{\mathrm{d}}\left(\mathrm{OH}_{2}\right)\end{array}$ \\
\hline- & 546 & 573 & 591 & 618 & 663 & - & $\delta_{\mathrm{s}}\left(\mathrm{OH}_{2}\right)$ \\
\hline $556-200$ & $\begin{array}{l}539- \\
200\end{array}$ & $\begin{array}{l}548- \\
200\end{array}$ & $\begin{array}{l}563- \\
200\end{array}$ & $\begin{array}{l}568- \\
200\end{array}$ & $\begin{array}{l}577- \\
200\end{array}$ & $\begin{array}{l}572- \\
200\end{array}$ & $\begin{array}{l}\delta_{\mathrm{d}}\left(\mathrm{OH}_{2}\right) ; \delta_{\mathrm{d}}(\mathrm{C}-\mathrm{C}-\mathrm{C}) ; \delta_{\mathrm{d}} \\
(\mathrm{C}-\mathrm{C}-\mathrm{N}) ; \quad \delta_{\mathrm{d}} \quad(\mathrm{C}-\mathrm{N}-\mathrm{O}) ; \\
\text { deformação do macrociclo }\end{array}$ \\
\hline- & $\begin{array}{l}435 \\
338 \\
272\end{array}$ & $\begin{array}{l}441, \\
339,276\end{array}$ & $\begin{array}{l}450 \\
353 \\
290\end{array}$ & $\begin{array}{l}548, \\
404 \\
367\end{array}$ & 551 & 562 & $\begin{array}{l}v_{\mathrm{s}}(\mathrm{M}-\mathrm{N}), \quad \mathrm{v}_{\mathrm{as}}\left(\mathrm{M}-\mathrm{OH}_{2}\right) \\
\mathrm{v}_{\mathrm{s}}\left(\mathrm{M}-\mathrm{OH}_{2}\right),\end{array}$ \\
\hline
\end{tabular}

$v_{\mathrm{s}}=$ estiramento simétrico; $\delta_{\mathrm{d}}=$ deformação angular fora do plano; $\sigma=$ tesoura; $\delta_{\mathrm{s}}=$ deformação angular no plano; $v_{\mathrm{as}}=$ estiramento assimétrico.

Para os complexos 1a, os modos vibracionais atribuídos aos estiramentos assimétricos $\left(v_{\mathrm{as}}\right)$ e simétricos $\left(\mathrm{v}_{\mathrm{s}}\right)$ da $\mathrm{H}_{2} \mathrm{O}$ foram calculados na região de 3699 a $3646 \mathrm{~cm}^{-1}$ (estiramento assimétrico) e entre 3547 e $3423 \mathrm{~cm}^{-1}$ (estiramento simétrico). Diaz e seus colaboradores [70] 
observaram o estiramento simétrico da água, para o complexo de $\mathrm{Cu}^{2+}$ formado pelo macrociclo [12]aneN4, em $3450 \mathrm{~cm}^{-1}$. De um modo geral, os resultados teóricos estão em um razoável entendimento com o valor observado experimentalmente [70], tendo uma variação máxima de aproximadamente $100 \mathrm{~cm}^{-1}$ (Tabela 8).

As bandas atribuídas aos estiramentos simétricos N-H são observadas em $3324 \mathrm{~cm}^{-1}$, para o ligante livre. Nos complexos 1a, a região de surgimento dessa banda fica entre 3308 a $3260 \mathrm{~cm}^{-1}$. Esses resultados estão de acordo com o observado na literatura para os complexos macrociclos com 12,16, 18 e 21 membros [70-73]. Os modos vibracionais de estiramentos assimétricos e simétricos, referentes ao grupo $\mathrm{CH}_{2}$, aparecem na região de 3055 a $2981 \mathrm{~cm}^{-1}$ (modo assimétrico) e 2978 a $2828 \mathrm{~cm}^{-1}$ (modo simétrico). No ligante livre foi observado o maior deslocamento no modo simétrico, em $2828 \mathrm{~cm}^{-1}$, quando comparado com os complexos (ver Tabela 8).

O movimento vibracional de tesoura $(\sigma)$ da água e do grupo $\mathrm{CH}_{2}$ foi observado na região de $1500 \mathrm{~cm}^{-1}\left(\sigma\left(\mathrm{H}_{2} \mathrm{O}\right)\right)$ e em $1440 \mathrm{~cm}^{-1}$ para $\sigma\left(\mathrm{CH}_{2}\right)$. Os modos de deformação no plano $\left(\delta_{\mathrm{s}}\right)$ para os grupos $\mathrm{CH}_{2}$ e $\mathrm{NH}$, tanto do ligante livre quanto dos complexos, são calculados na região de 1400 a $1300 \mathrm{~cm}^{-1}$, respectivamente. As freqüências abaixo de 1300 $\mathrm{cm}^{-1}$ e acima $1140 \mathrm{~cm}^{-1}$ foram atribuídos ao modo vibracional de deformação fora do plano $\left(\delta_{\mathrm{d}}\right)$ do grupo $\mathrm{CH}_{2}$ (Tabela 8). Esse modo foi observado experimentalmente por CamposVallette et al. [71] entre 1280 a $1260 \mathrm{~cm}^{-1}$, tanto para o ligante livre quanto para os complexos de $\mathrm{Ni}^{2+}, \mathrm{Cu}^{2+}$ e $\mathrm{Zn}^{2+}$ por ele estudados.

Na região de 1130 a $955 \mathrm{~cm}^{-1}$ são observados os modos de deformação no plano C-C e os modos vibracionais simétricos $\mathrm{C}-\mathrm{C}, \mathrm{C}-\mathrm{N}$ e $\mathrm{C}-\mathrm{O}-\mathrm{N}$ do macrociclo no complexo e no ligante livre. Entretanto, segundo Diaz et al. [72], esses modos vibracionais para o macrociclo de 12 membros são observados na região de $1300 \mathrm{~cm}^{-1}$. No entanto, no presente trabalho, esses modos vibracionais foram atribuídos na região de 1130 a $955 \mathrm{~cm}^{-1}$, como mencionado acima. 
Os modos vibracionais de deformação fora do plano C-C e $\mathrm{H}_{2} \mathrm{O}$, bem como estiramentos assimétricos C-C, C-N e C-O-N foram calculadas na região de 970 e $720 \mathrm{~cm}^{-1}$ (Tabela 8). A deformação no plano $\mathrm{H}_{2} \mathrm{O}$ foi observada na região de 660 a $540 \mathrm{~cm}^{-1}$. Sendo que essa freqüência, referente a esse modo vibracional aumenta de $\mathrm{Fe}^{2+}$ para $\mathrm{Ni}^{2+}$ para os metais da primeira fila e de $\mathrm{Ru}^{2+}$ para $\mathrm{Rh}^{2+}$ nos metais da segunda fila, não sendo observado esse modo vibracional no complexo de $\mathrm{Pd}^{2+}$.

Os modos vibracionais referentes à deformação fora do plano do macrociclo [20]aneN4O4 foram calculadas na região de 570 a $200 \mathrm{~cm}^{-1}$. Essa atribuição está em boa concordância com os resultados experimentais discutidos na literatura [70-74].

De acordo com Nakamoto [75], os modos referentes ao estiramento metal-nitrogênio (M-N) em complexos metálicos, de um modo geral, ocorre na região abaixo de $500 \mathrm{~cm}^{-1}$. Estudos de espectroscopia vibracional teórico e experimental em outros sistemas macrociclos com 12, 16, 18, e 21 membros mostraram que os modos vibracionais abaixo de $500 \mathrm{~cm}^{-1}$, estão diretamente relacionados ao metal [70-74]. Experimentalmente, essa é uma importante região que pode dar informação da formação do complexo pelo surgimento da banda metalligante.

Para formação de um complexo octaédrico 1a, são esperados três picos que podem ser atribuídos ao estiramento simétrico metal-ligante do plano equatorial, estiramento simétrico metal-ligante do plano axial (no presente caso a água) e o estiramento assimétrico metalligante também no plano axial. No complexo de $\mathrm{Fe}^{2+}$, por exemplo, o estiramento simétrico Fe-N foi calculado em $452 \mathrm{~cm}^{-1}$. Os modos de estiramentos assimétrico e simétrico $\mathrm{H}_{2} \mathrm{O}$ foram calculadas em 338 e 272, respectivamente. No caso do complexo formado pelo íon $\mathrm{Co}^{2+}$, o estiramento Co-N foi observado em $450 \mathrm{~cm}^{-1}$ e os estiramentos da água foram calculados em 353 e $290 \mathrm{~cm}^{-1}$ para os modos assimétrico e simétrico, respectivamente. Para o complexo de $\mathrm{Ni}^{2+}$, o $v_{\mathrm{s}}(\mathrm{Ni}-\mathrm{N}), \mathrm{v}_{\text {as }}\left(\mathrm{Ni}-\mathrm{OH}_{2}\right)$ e $v_{\mathrm{s}}\left(\mathrm{Ni}-\mathrm{OH}_{2}\right)$ foram calculados em 450, 353 e 290 
$\mathrm{cm}^{-1}$, respectivamente. Estes resultados estão de acordo com os resultados experimentais observados por Campos-Vallette et al. [71] para essas vibrações. Em seu trabalho [71], o estiramento simétrico Ni-N foi observado em $426 \mathrm{~cm}^{-1}$ e de baixa intensidade. Analisando as freqüências vibracionais do estiramento metal-ligante, podemos observar que essa frequiência torna-se mais forte para $\mathrm{Fe}^{2+}<\mathrm{Co}^{2+}<\mathrm{Ni}^{2+}$. Esse aumento da freqüência faz com que a ligação M-N torne-se mais forte nos respectivos íons (ver Tabela 2, pág. 47). Essa mesma tendência pode ser observada para as ligações $\mathrm{M}-\mathrm{OH}_{2}$.

Para os íons da segunda fila dos metais de transição, similar tendência foi observada para o $v_{\mathrm{s}}(\mathrm{M}-\mathrm{N})$, ou seja, à medida que nos deslocamos para a esquerda da tabela periódica, no mesmo período, a freqüência vibracional aumenta, tornando-se mais forte a ligação metalnitrogênio. No entanto, apenas no complexo $\mathbf{1 a}$ de $\mathrm{Ru}^{2+}$, os estiramentos assimétrico e simétrico da água foram calculadas em 404 e $367 \mathrm{~cm}^{-1}$, respectivamente. Nos complexos 1a, formados pelos os íons $\mathrm{Rh}^{2+}$ e $\mathrm{Pd}^{2+}$, a ligação do metal com as duas moléculas de $\mathrm{H}_{2} \mathrm{O}$ não foi verificada (ver Tabela 2 e figuras do Apêndice A). A não formação de ligação metal-oxigênio da água ratifica a idéia que esses íons têm necessariamente preferências à formação de complexos quadrado-planar, principalmente o íon $\mathrm{Pd}^{2+}$, como será discutido mais adiante.

Na Tabela 9, são apresentados os resultados das freqüências vibracionais calculadas para o ligante livre [20]aneO4N4 e para os complexos $\mathbf{1 b}$. 
Tabela 9. Freqüências vibracionais calculadas em nível de teoria B3LYP/Lanl2DZ para os complexos 1b de arranjo octaédrico

\begin{tabular}{|c|c|c|c|c|c|c|c|}
\hline \multicolumn{8}{|c|}{ complexos $\mathbf{1 b}$} \\
\hline [20]aneN4O4 & $\mathrm{Fe}^{2+}$ & $\mathrm{Co}^{2+}$ & $\mathrm{Ni}^{2+}$ & $\mathrm{Ru}^{2+}$ & $\mathrm{Rh}^{2+}$ & $\mathrm{Pd}^{2+}$ & modos vibracionais \\
\hline- & 3624 & 3639 & 3630,3151 & 3616 & 3627 & 3653 & $v_{\text {as }}\left(\mathrm{OH}_{2}\right)$ \\
\hline- & - & - & - & - & - & - & $v_{\mathrm{s}}\left(\mathrm{OH}_{2}\right)$ \\
\hline 3237 & 3258 & 3257 & 3255 & 3252 & 3270 & 3266 & $v_{\mathrm{s}}(\mathrm{N}-\mathrm{H})$ \\
\hline $3020-2950$ & $3041-2889$ & $3046-2989$ & $3049-2988$ & $3045-2988$ & $3049-2997$ & $3064-2996$ & $\mathrm{v}_{\mathrm{as}}\left(\mathrm{CH}_{2}\right)$ \\
\hline 2944-2858 & $2972-2920$ & $2972-2911$ & $2971-2928$ & $2970-2927$ & $2975-2936$ & $2977-2934$ & $v_{\mathrm{s}}\left(\mathrm{CH}_{2}\right)$ \\
\hline- & 1535 & 1542 & 1541 & 1545 & 1568 & $1771-1524$ & $\sigma\left(\mathrm{OH}_{2}\right)$ \\
\hline $1476-1422$ & $1474-1429$ & $1475-1434$ & $1476-1433$ & $1476-1437$ & $1469-1432$ & $1468-1430$ & $\sigma\left(\mathrm{CH}_{2}\right)$ \\
\hline $1417-1318$ & $1427-1383$ & $1427-1331$ & $1427-1330$ & $1429-1331$ & $1420-1326$ & $1420-1320$ & $\delta_{\mathrm{s}}\left(\mathrm{CH}_{2}\right), \delta_{\mathrm{s}}(\mathrm{NH})$ \\
\hline $1309-1160$ & $1285-1171$ & $1281-1179$ & $1283-1179$ & $1284-1181$ & $1280-1173$ & $1276-1170$ & $\delta_{\mathrm{d}}\left(\mathrm{CH}_{2}\right)$ \\
\hline $1116-980$ & $1118-1013$ & $1120-975$ & $1125-971$ & $1126-971$ & $1126-969$ & $1123-961$ & $\delta_{\mathrm{s}}(\mathrm{C}-\mathrm{C}), v_{\mathrm{s}}(\mathrm{C}-\mathrm{N}), v_{\mathrm{s}}(\mathrm{C}-\mathrm{C}), v_{\mathrm{s}}(\mathrm{C}-\mathrm{O}-\mathrm{N})$ \\
\hline $955-668$ & $1004-660$ & $948-676$ & $940-670$ & $940-670$ & $932-668$ & $930-643$ & $\delta_{\mathrm{d}}(\mathrm{C}-\mathrm{C}), \nu_{\text {as }}(\mathrm{C}-\mathrm{N}), \nu_{\text {as }}(\mathrm{C}-\mathrm{O}-\mathrm{N}), \delta_{\mathrm{d}}\left(\mathrm{OH}_{2}\right)$ \\
\hline- & - & - & - & - & - & - & $\delta_{\mathrm{s}}\left(\mathrm{OH}_{2}\right)$ \\
\hline \multirow[t]{2}{*}{$561-200$} & $542-100$ & $549-100$ & $559-100$ & $552-100$ & $536-100$ & $529-100$ & $\begin{array}{c}\delta_{\mathrm{d}}\left(\mathrm{OH}_{2}\right), \delta_{\mathrm{d}}(\mathrm{C}-\mathrm{C}-\mathrm{C}), \delta_{\mathrm{d}}(\mathrm{C}-\mathrm{C}-\mathrm{N}), \delta_{\mathrm{d}}(\mathrm{C}- \\
\mathrm{N}-\mathrm{O}), \text { Deformação do macrociclo }\end{array}$ \\
\hline & $\begin{array}{l}306,260 \\
156\end{array}$ & $\begin{array}{l}412,385 \\
312\end{array}$ & $\begin{array}{l}427,340 \\
324\end{array}$ & $\begin{array}{l}428,410 \\
372\end{array}$ & $\begin{array}{l}436,408 \\
370\end{array}$ & $(499,447)^{*}$ & $v_{\mathrm{s}}(\mathrm{M}-\mathrm{O}), \mathrm{v}_{\mathrm{as}}\left(\mathrm{M}-\mathrm{OH}_{2}\right), v_{\mathrm{s}}\left(\mathrm{M}-\mathrm{OH}_{2}\right)$ \\
\hline
\end{tabular}

$v_{\mathrm{s}}=$ estiramento simétrico; $\delta_{\mathrm{d}}=$ deformação angular fora do plano; $\sigma=$ tesoura; $\delta_{\mathrm{s}}=$ deformação angular no plano; $v_{\mathrm{as}}=$ estiramento assimétrico.

* No complexo com o íon paládio não foi observado o estiramento Pd-O no macrociclo. 
$\mathrm{O}$ estiramento assimétrico $\mathrm{v}_{\mathrm{as}}\left(\mathrm{M}-\mathrm{OH}_{2}\right)$ para os complexos $\mathbf{1 b}$ foram calculados na região entre 3600 e $3660 \mathrm{~cm}^{-1}$. Porém, em nenhum dos complexos estudados foi observado o estiramento simétrico $v_{\mathrm{s}}\left(\mathrm{M}-\mathrm{OH}_{2}\right)$. Possivelmente uma explicação para a não observação de modo vibracional para os complexos $\mathbf{1 b}$ deve-se a interação do íon metálico com o macrociclo estar ligados por átomos de oxigênio. Os modos vibracionais referentes ao estiramento simétrico $v_{\mathrm{s}}(\mathrm{N}-\mathrm{H})$ e deformação no plano $\delta_{\mathrm{s}}(\mathrm{N}-\mathrm{H})$ foram calculados na região de 3200 a $1300 \mathrm{~cm}^{-1}$, respectivamente, em todos os complexos estudados e no ligante macrocíclico livre [20]aneO4N4. A região de 3000 a $2900 \mathrm{~cm}^{-1}$ pode ser atribuída aos estiramentos simétricos e assimétricos $\mathrm{CH}_{2}$ nos complexos $\mathbf{1 b}$, assim como no ligante [20]aneO4N4. Os modos de deformação no plano $\left(\delta_{s}\right)$ e deformação fora do plano $\left(\delta_{d}\right)$ podem ser observados na região de 1400 a $1160 \mathrm{~cm}^{-1}$ (Tabela 9).

As frequiências vibracionais observadas abaixo de $1120 \mathrm{~cm}^{-1}$ são referentes a vários modos vibracionais tais como $v_{\mathrm{s}}(\mathrm{C}-\mathrm{N}), \mathrm{v}_{\mathrm{s}}(\mathrm{C}-\mathrm{C}), \mathrm{v}_{\mathrm{as}}(\mathrm{C}-\mathrm{N}), \mathrm{v}_{\mathrm{as}}(\mathrm{C}-\mathrm{C})$ e os modos de deformação do macrociclo [20]aneO4N4. No entanto, a região que evidencia a formação do complexo pode ser observada abaixo de $450 \mathrm{~cm}^{-1}$. Em todos os complexos $\mathbf{1 b}$, exceto o complexo $\mathbf{1 b}$ de paládio, foram observados os modos de estiramento simétrico metal-oxigênio (M-O), sendo "O”" os átomos de oxigênio colocados diretamente na cavidade de complexação do macrociclo. Os modos de estiramento assimétrico $v_{\text {as }}\left(\mathrm{M}-\mathrm{OH}_{2}\right)$ e estiramento simétrico $v_{\mathrm{s}}$ $\left(\mathrm{M}-\mathrm{OH}_{2}\right)$ foram observados em todos os complexos. Semelhante ao comportamento observado nos complexos 1a, formados por íons metálicos da primeira e segunda filas, nos complexos $\mathbf{1 b}$ desses mesmos grupos, com exceção do íon $\mathrm{Pd}^{2+}$, o estiramento metal-oxigênio aumenta na seguinte ordem: $\mathrm{Fe}^{2+}<\mathrm{Co}^{2+}<\mathrm{Ni}^{2+}$, com os seguintes valores de freqüências calculadas: 306,412 e $427 \mathrm{~cm}^{-1}$, respectivamente, e de 428 e $436 \mathrm{~cm}^{-1}$ para os íons $\mathrm{Ru}^{2+}$ e $\mathrm{Rh}^{2+}$, respectivamente. Esse modo vibracional (metal-ligante) contribui diretamente na diminuição do comprimento de ligação metal-oxigênio (M-O), tanto na primeira fila quanto 
na segunda fila dos metais de transição. Porém, o estiramento $\mathrm{M}-\mathrm{O}$ não foi observado no complexo de $\mathrm{Pd}^{2+}$. Isso explica o fato que neste complexo não foi observado a formação de quatro ligações M-O (ver Tabela 3, pág. 48), uma vez que a distância média M-O foi calculada acima de $3 \AA$.

Ao contrario do observado nos complexos 1 a com o íon de $\mathrm{Pd}^{2+}$, em todos complexos 1 b estudados foram observados os modos de estiramentos simétrico e assimétrico $\mathrm{M}-\mathrm{OH}_{2}$.

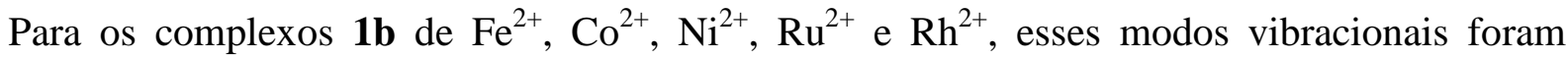
observados na região de 170 a $410 \mathrm{~cm}^{-1}$. Para o complexo $\mathbf{1 b}$ com o íon de $\mathrm{Pd}^{2+}$, esses modos freqüências foram observados em $447 \mathrm{e} 499 \mathrm{~cm}^{-1}$, respectivamente.

Os espectros teóricos de infravermelho obtidos pelos cálculos DFT e simulados pelo programa Swizard [64], para os complexos 1a e 1b, são mostrados nas Figuras 13 e 14.
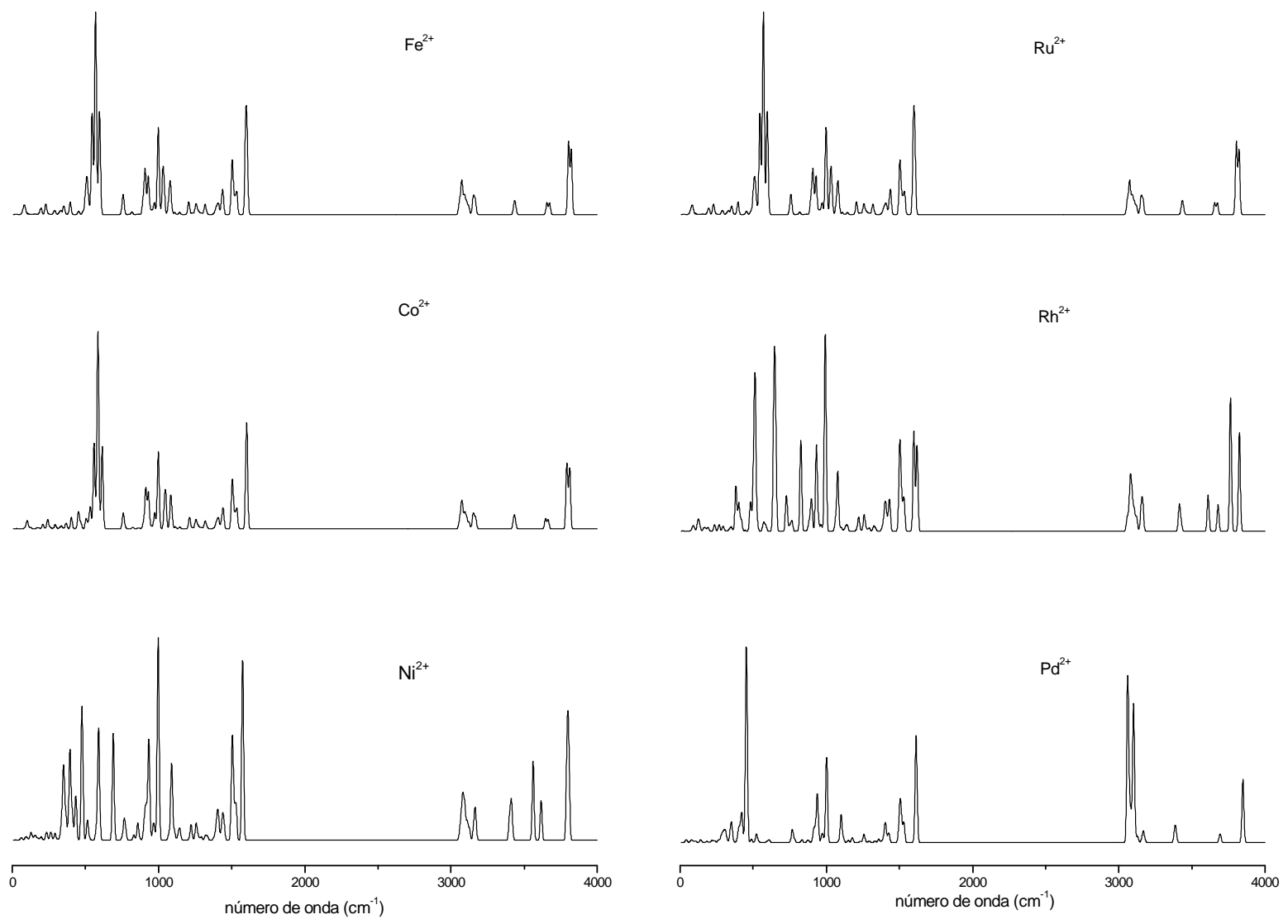

Figura 13. Espectros teóricos de infravermelho dos complexos 1a. 

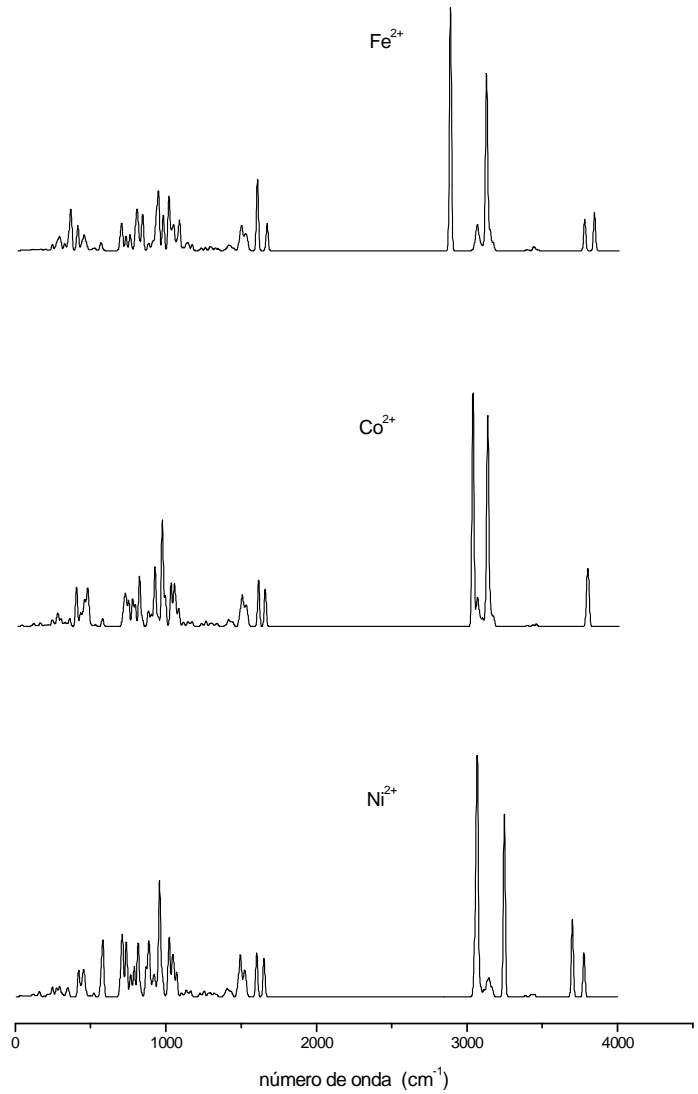
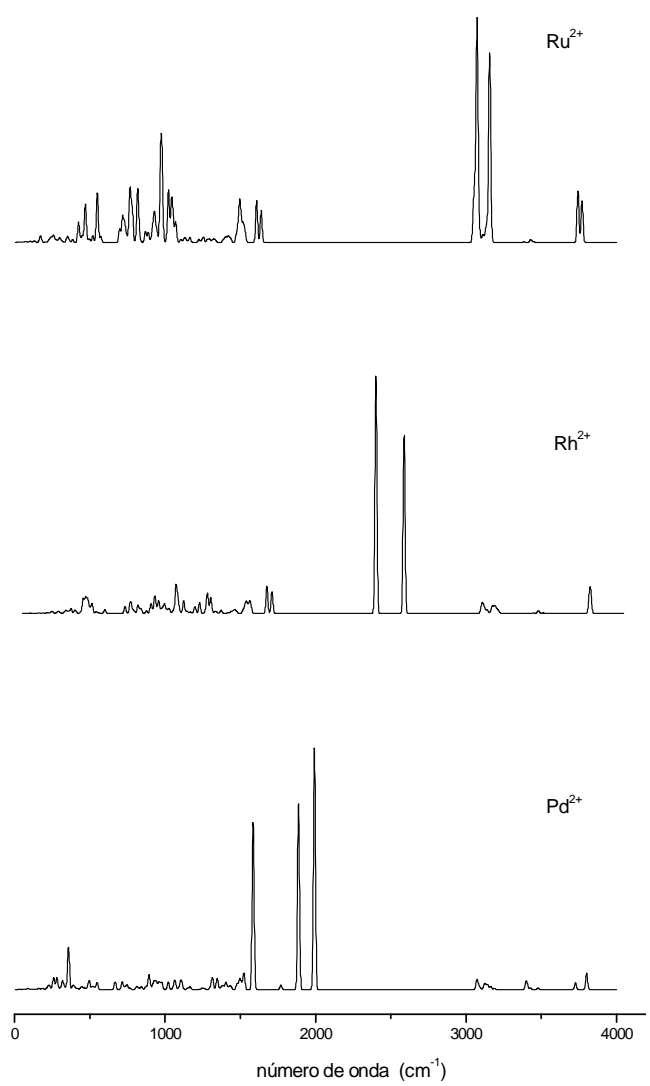

Figura 14. Espectros teóricos de infravermelho dos complexos $\mathbf{1 b .}$

Na Figura 14, nos complexos $\mathbf{1 b}$ de $\mathrm{Rh}^{2+}$, aparecem duas bandas intensas, em 2444 e $2264 \mathrm{~cm}^{-1}$, que são atribuídas as interações dos hidrogênios das duas águas, colocadas no eixo z, com o nitrogênio do grupo amina. Essa interação provoca o estiramento $\mathrm{N}-\mathrm{H}_{\text {água }}$ observado na Figura 13. No complexo de $\mathrm{Pd}^{2+}$ também foi observado o surgimento dessas bandas, porém, deslocada para a região abaixo de $2000 \mathrm{~cm}^{-1}$. Essas bandas não são observadas nos complexos 1a, uma vez que as moléculas de água encontram-se posicionadas bem mais afastadas do grupo NH no macrociclo [20]aneN4O4. O Apêndice A mostra as estruturas otimizadas desses complexos. 


\section{d) Análise das Ligações Químicas com CDA e Análise dos Orbitais}

\section{Moleculares de Fronteira}

A ligação química em um complexo metálico é usualmente descrita em termos das interações covalente e iônica entre o metal e os ligantes. Em muitos metais de transição, especialmente em complexos formados por metais de transição da primeira fila, a contribuição iônica é donimante [76].

A análise de decomposição de cargas (CDA - Charges Decomposition Analysis) [56] foi usada para investigar as interações doador-receptor entre o metal-ligante. O CDA é uma excelente ferramenta na análise das ligações químicas entre os fragmentos do metal e do ligante em termos da doação do ligante para o metal (responsáveis pelas ligações $\sigma$ (sigma) e $\pi$ (pi)) e da retrodoação do metal para o ligante (responsáveis pelas ligações $\pi$ (pi)). No presente trabalho, a contribuição dos orbitais nos complexos 1a e $\mathbf{1 b}$ foi dividida em três partes: 1) doação $\sigma$ e $\pi$ do ligante para o metal; 2) retrodoação $\pi$ do metal para o ligante; 3) a polarização eletrônica do metal para o ligante. A polarização de um fragmento é o efeito da distorção da nuvem eletrônica de um fragmento por outro e inclue as interações entre todas as cargas permanentes, cargas multipolares e multipolos induzidos [77-78].

A análise CDA fornece estimativas razoáveis das interações de doação e retrodoação, se a polarização eletrônica estiver ausente ou se ela for suficientemente pequena [21 58]. Neste trabalho usou-se o método de análise de decomposição de cargas estendida (ECDA Extented Charge Decomposition Analysis) para verificar a transferência de cargas (TC) e a contribuição da polarização individual de cada fragmento (POL). Os resultados de doação, retrodoação (rd), transferência de cargas (TC), polarização (POL) e cargas obtidas pela análise do NBO ( $\left.\mathrm{q}_{\mathrm{NBO}}\right)$ sobre o metal e os átomos de nitrogênio no macrociclo [20]aneN4O4 
ou os átomos de oxigênio no macrociclo [20]aneO4N4 e as moléculas de água nos complexos $\mathbf{1 a}$ e 1b, formados pelos íons metálicos $\mathrm{Pd}^{2+}, \mathrm{Ru}^{2+}, \mathrm{Fe}^{2+}, \mathrm{Co}^{2+}, \mathrm{Ni}^{2+}$ e $\mathrm{Rh}^{2+}$ de camada fechada (singleto) e camada aberta (quinteto, quarteto, tripleto e dubleto), respectivamente, são mostradas nas Tabelas 10 e 11. Como é sabido, o sistema de camada aberta, em outras palavras, sistemas com spins desemparelhados, geram spins alfa $(\alpha)$ e spins beta $(\beta)$. Desta forma, os resultados apresentados na Tabela 11 mostram as contribuições individuais de cada spin, assim como a soma de ambos os spins na doação, retrodoação, transferência de cargas, polarização e cargas NBO. Para fazer essa análise foi necessário dividir o complexo em dois fragmentos, sendo que nos resultados apresentados nas tabelas a seguir. O número 1 representa o fragmento dos íons metálicos e o número 2 representa os fragmentos dos macrociclos [20]aneN4O4 ou [20]aneO4N4 e as moléculas de água. 
Tabela 10. Análise de decomposição de cargas obtida para os complexos 1a e 1b, de camada fechada, calculados com o modelo B3LYP/Lanl2DZ

\begin{tabular}{|c|c|c|c|c|}
\hline Complexo & $\begin{array}{c}\mathrm{Ru}- \\
\text { Nitrogênio }\end{array}$ & $\begin{array}{c}\text { Ru- } \\
\text { Oxigênio }\end{array}$ & $\begin{array}{c}\text { Pd- } \\
\text { Nitrogênio }\end{array}$ & $\begin{array}{c}\text { Pd- } \\
\text { Oxigênio }\end{array}$ \\
\hline Doação (a.u) $^{1}$ & 0,664 & 1,054 & 0,903 & 1,200 \\
\hline $\operatorname{rd}(\mathrm{a} . \mathrm{u})^{\mathrm{II}}$ & $-0,020$ & $-0,020$ & 0,037 & 0,004 \\
\hline $\operatorname{POL}(\mathrm{M})-\operatorname{POL}(\mathrm{L})^{\mathrm{III}}$ & 78,7 & 68,9 & 51,3 & 38,0 \\
\hline $\mathrm{TC}(2 \rightarrow 1)-\mathrm{TC}(1 \rightarrow 2)^{\mathrm{IV}}$ & 1,284 & 1,392 & 1,513 & 1,567 \\
\hline Metal q $\mathrm{NBO}_{\mathrm{N}}$ (a.u.) & 0,686 & 0,961 & 0,865 & 1,122 \\
\hline Ligante $\mathrm{q}_{\mathrm{NBO}}(\text { a.u. })^{\mathrm{V}}$ & $-0,344$ & $-0,477$ & $-0,382$ & $-0,477$ \\
\hline $\mathrm{O}_{\text {água }} \mathrm{q}_{\mathrm{NBO}}$ (a.u.) $)^{\mathrm{VI}}$ & $-0,929$ & $-0,960$ & $-0,998$ & $-1,039$ \\
\hline
\end{tabular}

I- Doação de cargas do ligante para o metal;

II- retrodoação de cargas (rd) do metal para o ligante;

III- Polarização (POL) do metal e polarização do ligante, respectivamente;

IV- Transferência de cargas (TC) dos ligante para o metal e transferência de cargas do metal para o ligante, respectivamente.

V- média das cargas sobre os ligantes nitrogênio ou oxigênio.

VI- média das cargas do oxigênio da água. 
Tabela 11. Análise de decomposição de cargas obtida para os complexos 1a e 1b, de camada aberta, calculados com o modelo B3LYP/Lanl2DZ

\begin{tabular}{|c|c|c|c|c|}
\hline \multirow[t]{2}{*}{ Complexo } & \multicolumn{4}{|c|}{ 1a } \\
\hline & $\mathrm{Fe}$ & Co & $\mathrm{Ni}$ & $\mathrm{Rh}$ \\
\hline Doação $^{\alpha}$ (a.u.) & 0,602 & 0,650 & 0,663 & 0,244 \\
\hline $\operatorname{rd}^{\alpha}(\mathrm{a} . \mathrm{u})$ & $-0,044$ & $-0,020$ & $-0,017$ & 0,011 \\
\hline $\operatorname{Doação~}^{\beta}$ (a.u) & 0,793 & 0,792 & 0,804 & 0,617 \\
\hline $\mathrm{rd}^{\beta}(\mathrm{a} . \mathrm{u})$ & 0,004 & 0,011 & 0,011 & 0,022 \\
\hline$* \Sigma^{\alpha+\beta}$ da Doação & 1,395 & 1,442 & 1,467 & 0,963 \\
\hline$\Sigma^{\alpha+\beta}$ da rd & $-0,040$ & $-0,009$ & $-0,006$ & 0,033 \\
\hline $\mathrm{POL}^{\alpha}(\mathrm{M})-\mathrm{POL}(\mathrm{L})$ & $-6,7$ & $-6,9$ & $-7,0$ & 58,8 \\
\hline $\mathrm{POL}^{\beta}(\mathrm{M})-\mathrm{POL}(\mathrm{L})$ & 80,2 & 99,7 & 76,2 & $-0,1$ \\
\hline$\Sigma^{\alpha+\beta}$ da POL & 73,5 & 92,8 & 69,2 & 58,7 \\
\hline $\mathrm{TC}^{\alpha}(2 \rightarrow 1)-\mathrm{TC}(1 \rightarrow 2)$ & 1,007 & 1,043 & 1,065 & 1,247 \\
\hline $\mathrm{TC}^{\beta}(2 \rightarrow 1)-\mathrm{TC}(1 \rightarrow 2)$ & 1,446 & 1,598 & 1,793 & 1,469 \\
\hline$\Sigma^{\alpha+\beta} \mathrm{da} \mathrm{TC}$ & 2,453 & 2,641 & 2,858 & 2,716 \\
\hline Metal $\mathrm{q}_{\mathrm{NBO}}(\mathrm{a} . . \mathrm{u})$ & 1,516 & 1,476 & 1,406 & 0,889 \\
\hline Nitrogen $\mathrm{q}_{\mathrm{NBO}}(\mathrm{a} . . \mathrm{u})$ & $-0,478$ & $-0,475$ & $-0,434$ & $-0,374$ \\
\hline \multirow[t]{3}{*}{$\mathrm{O}_{\text {água }} \mathrm{q}_{\mathrm{NBO}}(\mathrm{a} . . \mathrm{u})$} & $-1,035$ & $-1,029$ & $-1,026$ & $-1,006$ \\
\hline & \multicolumn{4}{|c|}{$\mathbf{1 b}$} \\
\hline & $\mathrm{Fe}$ & $\mathrm{Co}$ & $\mathrm{Ni}$ & $\mathrm{Rh}$ \\
\hline $\operatorname{Doação~}^{\alpha}$ (a.u.) & 0,628 & 0,684 & 0,710 & 0,568 \\
\hline $\mathrm{rd}^{\alpha}(\mathrm{a} . \mathrm{u})$ & $-0,046$ & $-0,028$ & $-0,025$ & $-0,016$ \\
\hline $\operatorname{Doação~}^{\beta}(\mathrm{a} . \mathrm{u})$ & 0,800 & 0,812 & 0,801 & 0,696 \\
\hline $\mathrm{rd}^{\beta}(\mathrm{a} . \mathrm{u})$ & 0,007 & 0,005 & 0,005 & 0,000 \\
\hline$\Sigma^{\alpha+\beta}$ da Doação & 1,428 & 1,496 & 1,511 & 1,264 \\
\hline$\Sigma^{\alpha+\beta}$ da rd & $-0,039$ & $-0,023$ & $-0,020$ & $-0,016$ \\
\hline $\mathrm{POL}^{\alpha}(\mathrm{M})-\mathrm{POL}(\mathrm{L})$ & $-6,8$ & $-6,8$ & $-6,9$ & 27,7 \\
\hline $\mathrm{POL}^{\beta}(\mathrm{M})-\mathrm{POL}(\mathrm{L})$ & 80,1 & 121,1 & 108,6 & 29,9 \\
\hline
\end{tabular}


Continuação Tabela 11

\begin{tabular}{ccccc}
\hline$\Sigma^{\alpha+\beta}$ da POL & 83,3 & 114,3 & 101,7 & 57,6 \\
$\mathrm{TC}^{\alpha}(2 \rightarrow 1)-\mathrm{TC}(1 \rightarrow 2)$ & 0,987 & 1,046 & 1,009 & 1,316 \\
$\mathrm{TC}^{\beta}(2 \rightarrow 1)-\mathrm{TC}(1 \rightarrow 2)$ & 1,402 & 1,514 & 1,656 & 1,533 \\
$\Sigma^{\alpha+\beta}$ da TC & 2,387 & 2,560 & 2,665 & 2,849 \\
Metal q & 1,581 & 1,559 & 1,522 & 1,041 \\
Oxigênio q $(\mathrm{a} . . \mathrm{u})$ & $-0,560$ & $-0,563$ & $-0,562$ & $-0,501$ \\
Oágua $_{\text {án }}$ (a..u) & $-1,071$ & $-1,065$ & $-1,055$ & $-0,987$ \\
\hline
\end{tabular}

. $* \Sigma^{\alpha+\beta}$ Somatório da contribuição dos spins alfa $(\alpha)$ e beta $(\beta)$.

A mesma nomenclatura para as abreviações usadas na Tabela 8 foram adotadas para a Tabela 11, sendo que nesta última temos o símbolo de somatório $\Sigma$ que representa a soma das contribuições dos spins $\alpha$ e $\beta$.

Em todos os casos, a retrodoação é muito pequena, com contribuição de somente 0,01 0,04 (a.u), isto é, a retrodoação é negligenciada como já era esperado, pois os ligantes são ligantes do tipo $\sigma$.

Os complexos dos metais de transição da primeira fila mostraram significativa contribuição covalente. A interação covalente metal-ligante envolve doação de cargas do ligante para o metal (ver Tabela 10 e 11). A intensidade da interação covalente aumenta de $\mathrm{Fe}^{2+}<\mathrm{Co}^{2+}<\mathrm{Ni}^{2+}$. Esse aumento ocorre simultaneamente com a diminuição da contribuição iônica, como observado nas Figuras 15 e 16, respectivamente. 


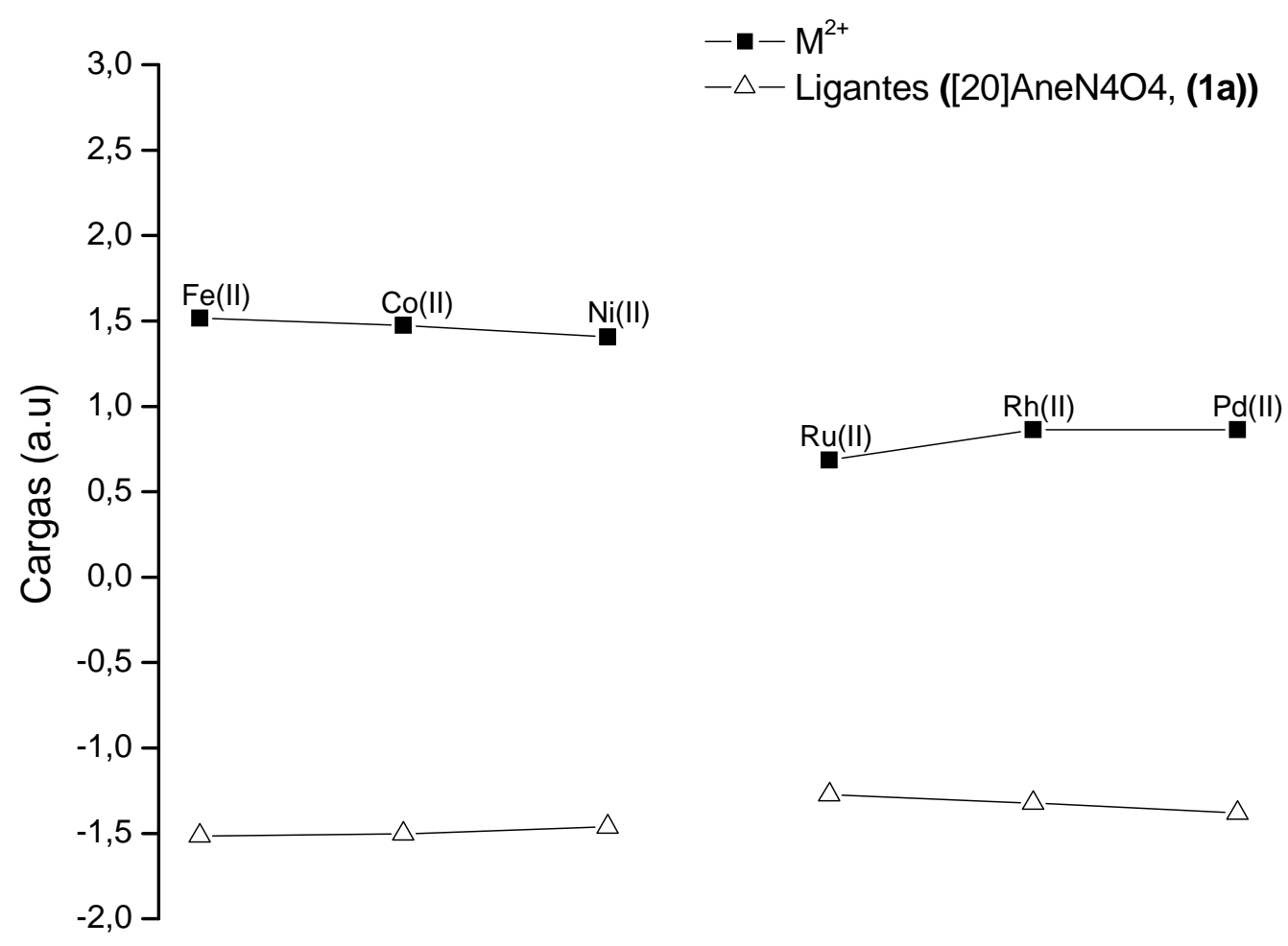

Figura 15. Cargas NBO calculadas para os cátions $\mathrm{M}^{2+}$ da primeira e segunda filas e soma das cargas sobre os ligantes, oxigênio da água e nitrogênio do complexo 1a.

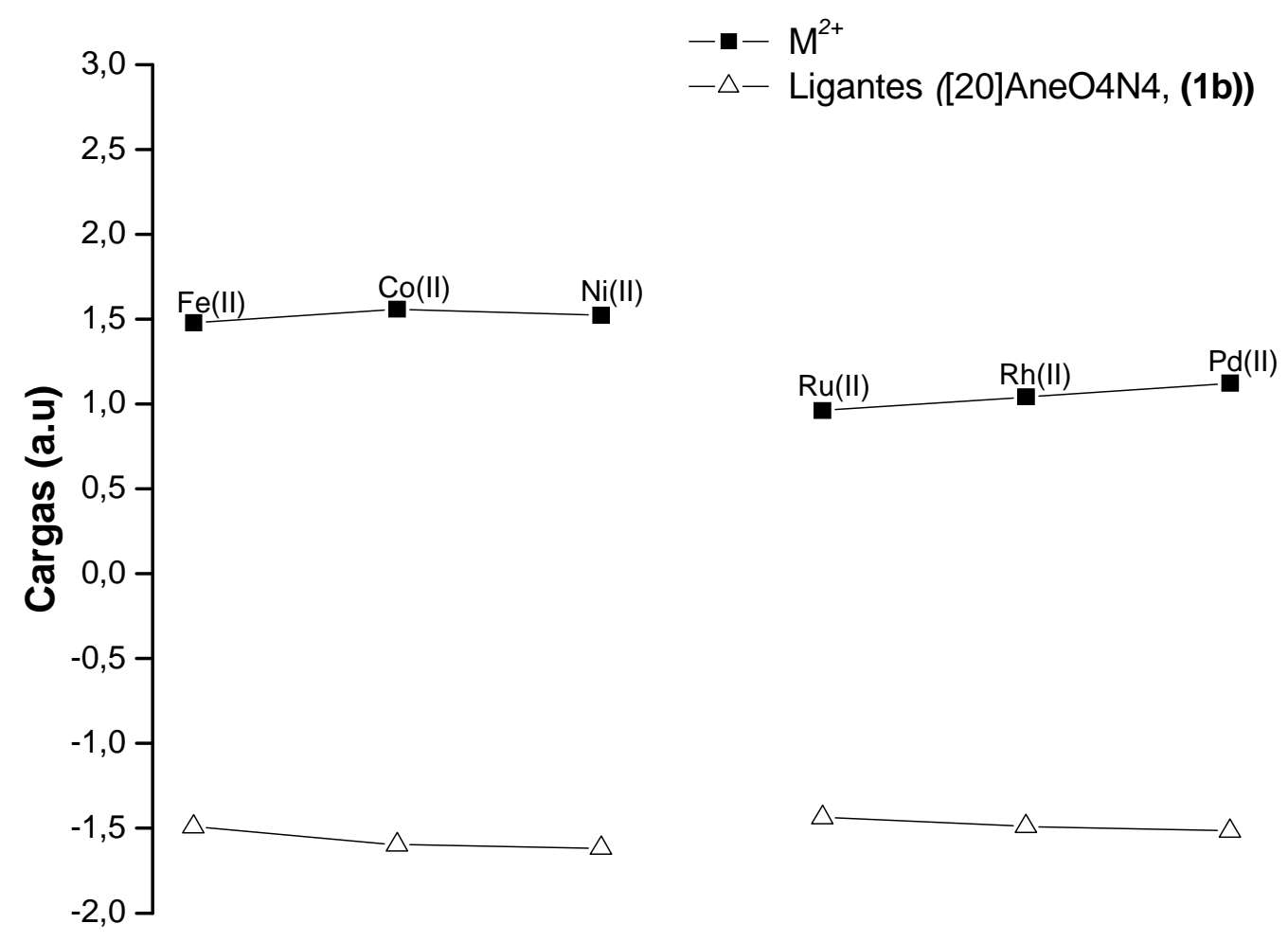

Figura 16. Cargas NBO calculadas para os cátions $\mathrm{M}^{2+}$ da primeira e segunda filas e soma das cargas sobre os ligantes, oxigênio da água e nitrogênio do complexo $\mathbf{1 b .}$ 
A contribuição iônica está relacionada com as cargas do metal e dos átomos de nitrogênio e oxigênio da água (complexo 1a), e as cargas do metal e dos átomos de oxigênio do macrociclo e oxigênio da água (complexo 1b). Como pode ser observado para os complexos 1a, o valor absoluto das cargas do metal e do ligante são maiores no complexo de $\mathrm{Fe}^{2+}$ e diminuído no complexo de $\mathrm{Ni}^{2+}$. Desta forma, as interações iônicas aumentam de $\mathrm{Ni}^{2+}>$ $\mathrm{Co}^{2+}>\mathrm{Fe}^{2+}$. Em ambos os complexos 1a e 1b, as cargas sobre as moléculas de água são similares (Tabelas 10 e 11). Como observado anteriormente, a contribuição iônica é predominante para os complexos dos metais de transição da primeira fila.

A análise de cargas NBO para os complexos com metais de transição da segunda fila mostra que a contribuição covalente torna-se mais forte quando comparada com os correspondentes complexos dos metais da primeira fila (Figuras 15 e 16). Aqui, pode ser observado que o alto efeito da carga nuclear efetiva dos metais desfavorece a interação covalente metal-ligante, ou seja, a forte interação covalente é calculada para o complexo de $\mathrm{Ru}^{2+}$, enquanto a interação covalente mais fraca é calculada para o complexo de $\mathrm{Pd}^{2+}$. No complexo de $\mathrm{Pd}^{2+}$, a alta carga nuclear efetiva reduz o gap entre o orbital molecular mais alto ocupado (HOMO) e o orbital molecular mais baixo ocupado (LUMO), portanto tornando a contribuição iônica mais forte. Por exemplo, o complexo $\mathbf{1 a}$ de $\mathrm{Ru}^{2+}$ tem um gap (LUMOHOMO) de 4,9 eV; enquanto que para o complexo de $\mathrm{Pd}^{2+}$, o gap é de 4,27 eV. O contrário é observado para os complexos 1a e 1b formados por íons metálicas da primeira fila. Para mostrar a variação no gap de energia entre os orbitais moleculares (LUMO-HOMO), o diagrama dos orbitais moleculares com os cinco últimos orbitais ocupados (HOMOs) e os cinco primeiros orbitais virtuais (LUMO), para os complexos 1a e 1b, foram plotados e são mostrados nas Figuras 17 e 18, respectivamente. 


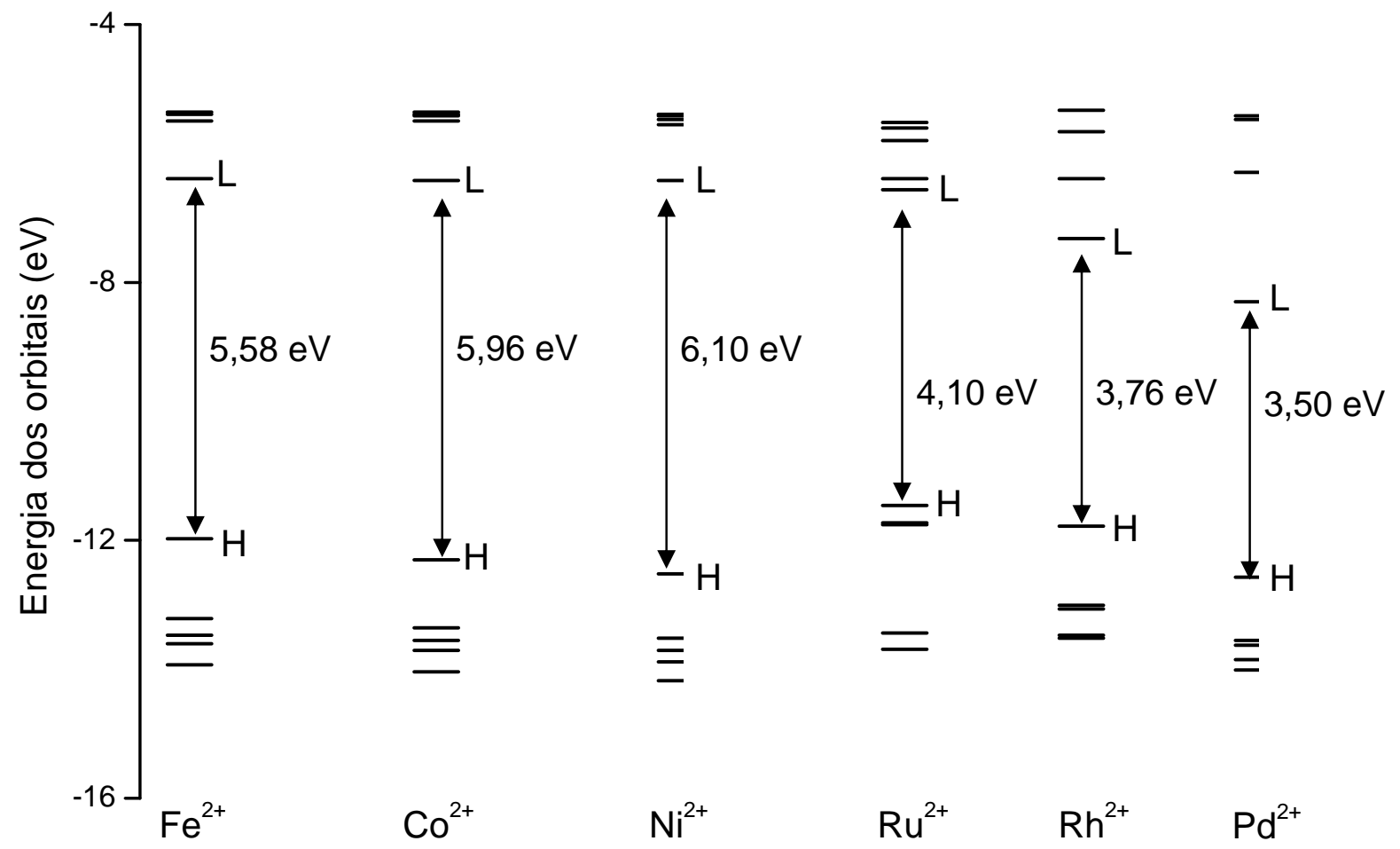

Figura 17. Diagrama dos orbitais moleculares dos complexos 1a formados pelos íons metálicos da primeira e segunda filas.

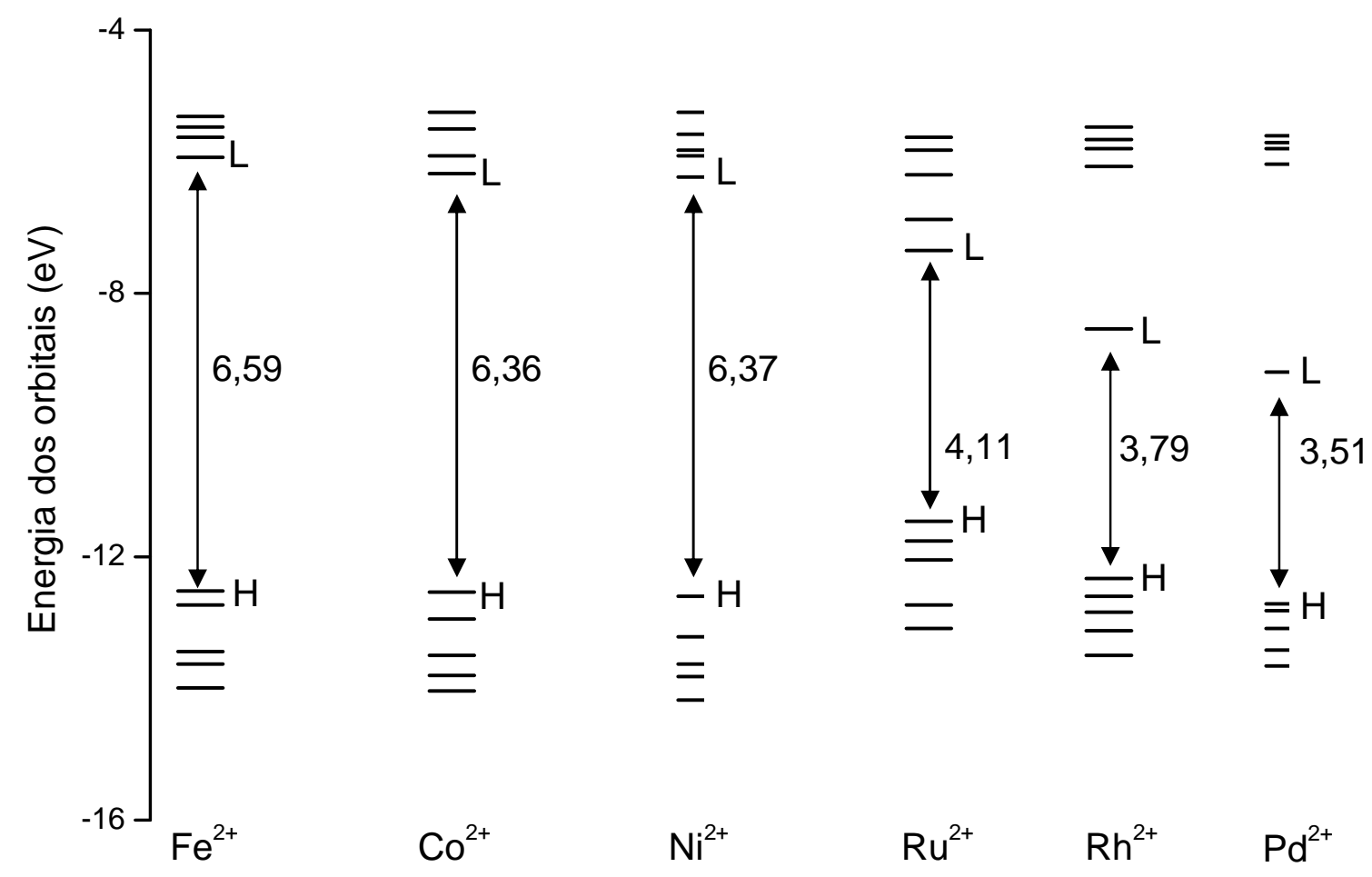

Figura 18. Diagrama dos orbitais moleculares dos complexos $\mathbf{1 b}$ formados pelos íons metálicos da primeira e segunda filas. 
Nas Figuras 17 e 18, assim como em toda a tese, $\mathrm{H}$ refere-se ao orbital mais alto ocupado (HOMO) e L ao orbital mais baixo desocupado (LUMO). Nas Figuras 17 e 18, para os sistemas de camada aberta, apenas as energias dos orbitais alfa foram consideradas em virtude desses orbitais contribuírem significamente para a formação mais estável dos complexos 1a e 1b, respectivamente (ver Figuras 17 e 18).

A análise dos orbitais moleculares de fronteira também pode ser outra ferramenta favorável para o entendimento das ligações químicas entre os ligantes e os íons metálicos, assim como ajudar a entender o por quê dos complexos 1a apresentarem maior estabilidade eletrônica quando comparados com os complexos 1b. Alguns orbitais moleculares relevantes para as ligações químicas nos complexos, e que podem ser usados para justificar a maior estabilidade dos complexos 1a em relação aos complexos 1b, são mostrados nas Figuras 19 e 20 para os complexos de camadas aberta e fechada, respectivamente. 

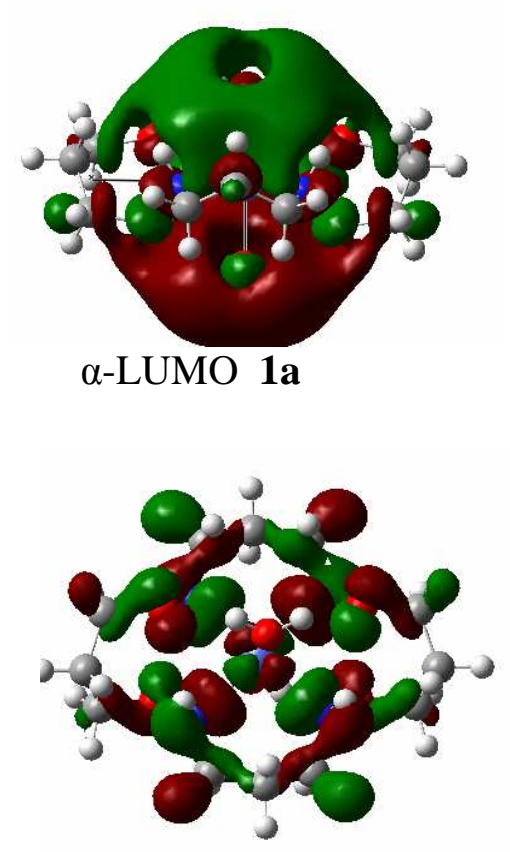

$\alpha-\mathrm{HOMO} 1 \mathrm{a}$

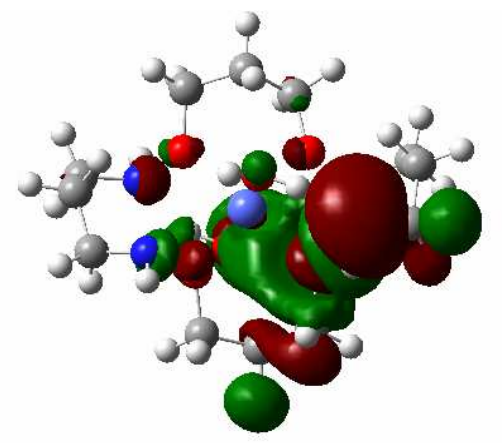

$\alpha$-LUMO 1b

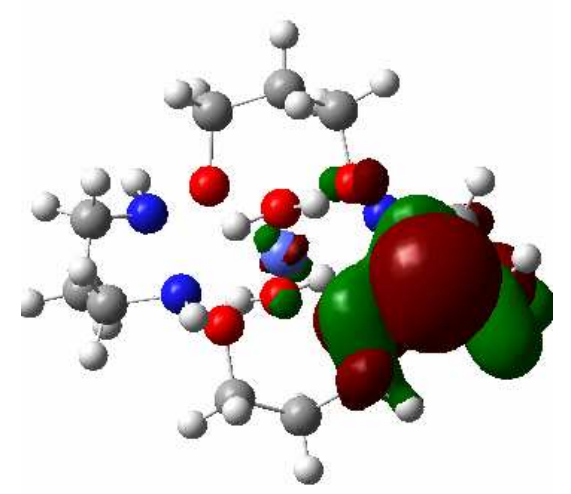

$\alpha-H O M O ~ 1 b$

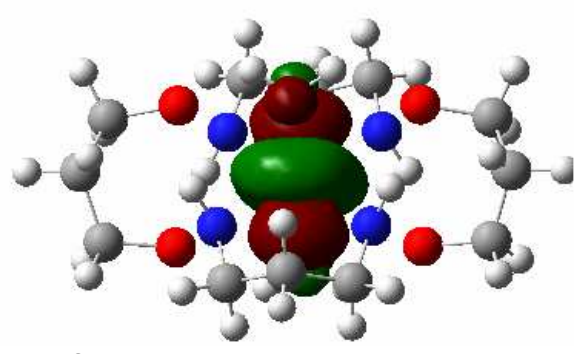

$\beta$-LUMO 1a

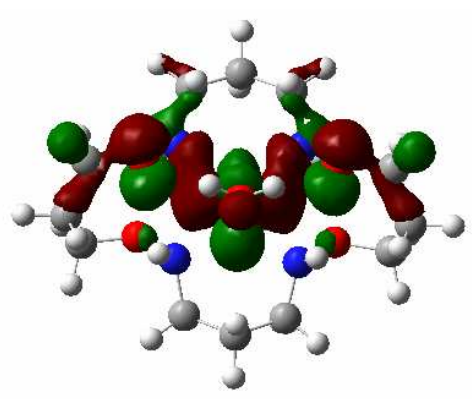

$\beta$-HOMO 1a

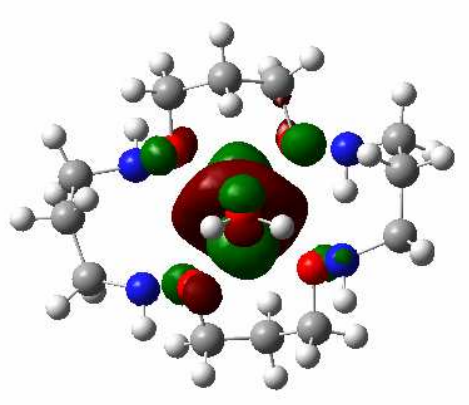

$\beta$-LUMO 1b

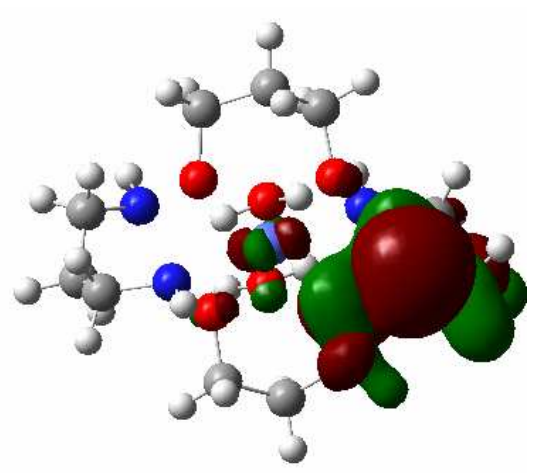

$\beta$-HOMO 1b

Figure 19. Orbitais moleculares de fronteira de spins $\alpha$ e $\beta$ calculados para os complexos 1a e 1b, de camada aberta, em nível de teoria DFT/B3LYP. Na figura as cores para os átomos de carbono (cinza), nitrogênio (azul), oxigênio (vermelho) e hidrogênio (branco). 


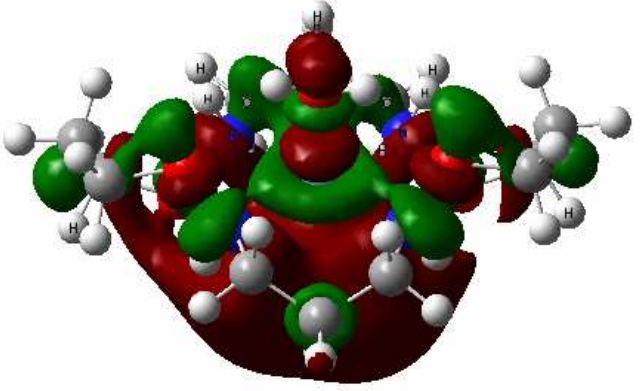

LUMO 1a

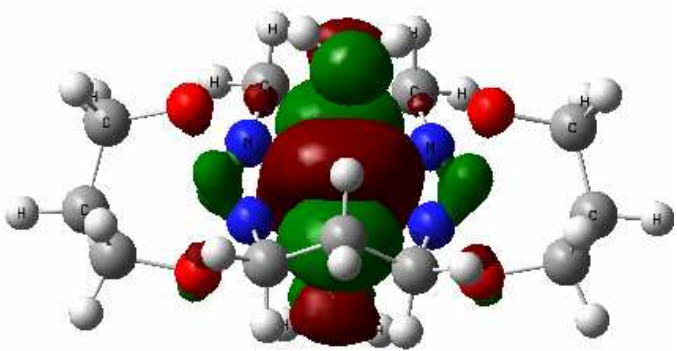

HOMO 1a

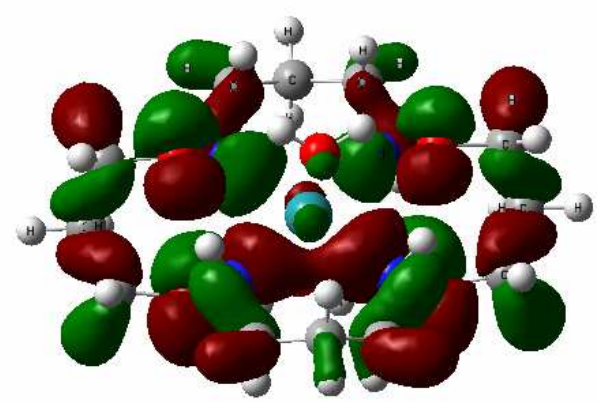

HOMO-3 1a

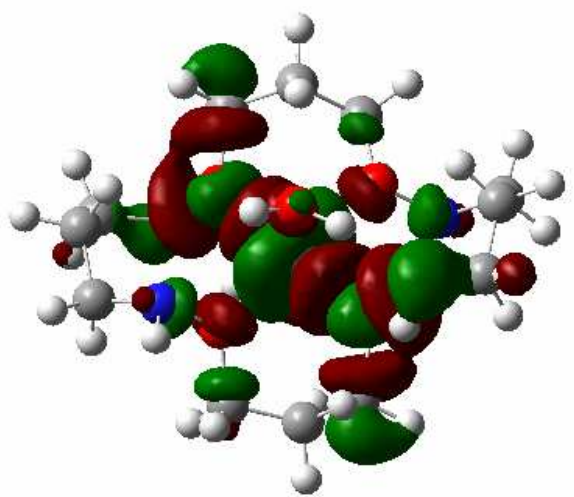

LUMO 1b

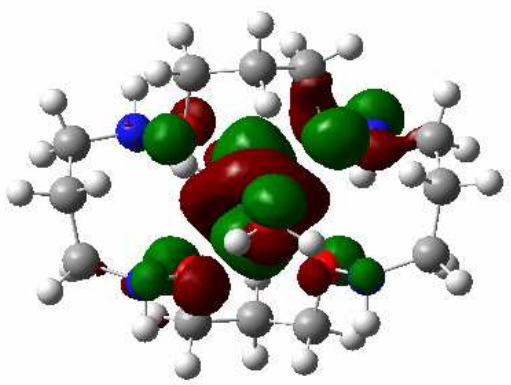

HOMO 1b

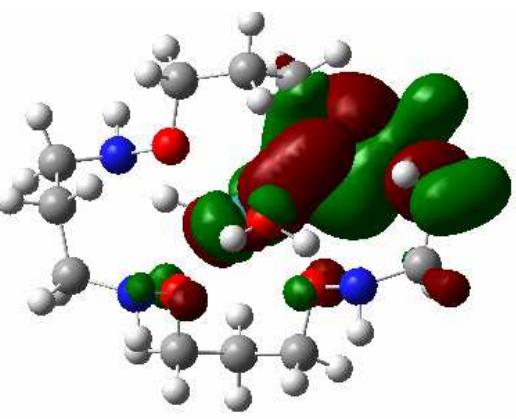

HOMO-3 1b

Figure 20. Orbitais moleculares de fronteira calculados para os complexos 1a e 1b, de camada fechada, em nível de teoria DFT/B3LYP. Na figura as cores para os átomos de carbono (cinza), nitrogênio (azul), oxigênio (vermelho) e hidrogênio (branco). 
No caso dos complexos 1a e 1b de camada aberta, ambos orbitais de fronteira $\alpha$ e $\beta$ foram analisados. Os orbitais moleculares para esses complexos mostraram ordem similar para os metais da primeira e segunda filas. O HOMO- $\alpha$ nos complexos 1a é altamente simétrico, isto é, delocalizado sobre o complexo (Figura 17). A composição desse orbital é de $30 \%$ de caráter $n d^{\mathrm{x}}$ do metal (onde, $\mathrm{n}=3$ ou 4 para os íons metálicos da primeira ou segunda fila, respectivamente, e $x=6,7$ ou 8 , onde $\mathrm{x}$ é o número de elétrons na camada de valência) e $70 \%$ é de caráter p do ligante macrociclo [20]aneN4O4. O LUMO- $\alpha$ é caracterizado por um orbital $\mathrm{p}$ do metal e sp do macrociclo. Nos orbitais moleculares $\beta$, o HOMO tem a mesma composição do HOMO- $\alpha$, porém, o orbital HOMO- $\beta$ apresenta ser mais localizado. Uma diferença significativa é observada quando se compara os orbitais LUMO- $\alpha$ e LUMO- $\beta$, uma vez que, neste último, o orbital é essencialmente de caráter d do metal. A análise dos orbitais de fronteira nos complexos $\mathbf{1 b}$ revelou que os orbitais HOMO- $\alpha$, LUMO- $\alpha$ e HOMO- $\beta$ são totalmente assimétricos, ou seja, estes orbitais são localizados em uma determinada região do complexo. O orbital LUMO- $\beta$ (1b) mostrou formato semelhante ao observado para o orbital LUMO- $\alpha(\mathbf{1 a})$.

Os orbitais moleculares mais relevantes para os sistemas (1a) e (1b) de camada fechada estão representados na Figura 20. Nesses sistemas, os orbitais HOMO, HOMO-1 e HOMO-2 têm um caráter $\mathrm{nd}^{\mathrm{x}}$ do metal. O orbital HOMO-3 mostrou a mesma característica do orbital HOMO- $\alpha$ (1a). Todos os orbitais dos complexos 1b são assimétricos, isto é, são mais localizados em uma determinada região do complexo. Portanto, a orientação favorável dos orbitais dos heteroátomos para os íons metálicos, e vice-versa, como encontrado nos complexos 1a, ajudam a estabilizar os complexos 1a comparados com os correspondentes complexos $\mathbf{1 b}$. 


\section{III-1. Complexos $1 a_{q}$ e $1 b_{q}$ quadrado-planar}

\section{a) Parâmetros Geométricos}

Os complexos $\mathbf{1} \mathbf{a}_{\mathbf{q}}$ e $\mathbf{1} \mathbf{b}_{\mathbf{q}}$ com arranjo quadrado-planar foram obtidos removendo as moléculas de água do eixo axial como mostrado no Esquema 2. Para todos os complexos 1a $\mathbf{a}_{\mathbf{q}}$, o grupo pontual usado foi de simetria $C_{s}$. No entanto, para os complexos $\mathbf{1 b}_{\mathbf{q}}$, devido a grande distorção na geometria do macrociclo [20]aneO4N4, esses complexos apresentaram grupo pontual $\left(C_{1}\right)$. A Figura 21 mostra as estruturas otimizadas para os complexos $\mathbf{1 a}_{\mathbf{q}}$ e $\mathbf{1 b}_{\mathbf{q}}$ com o íon $\mathrm{Co}^{2+}$.

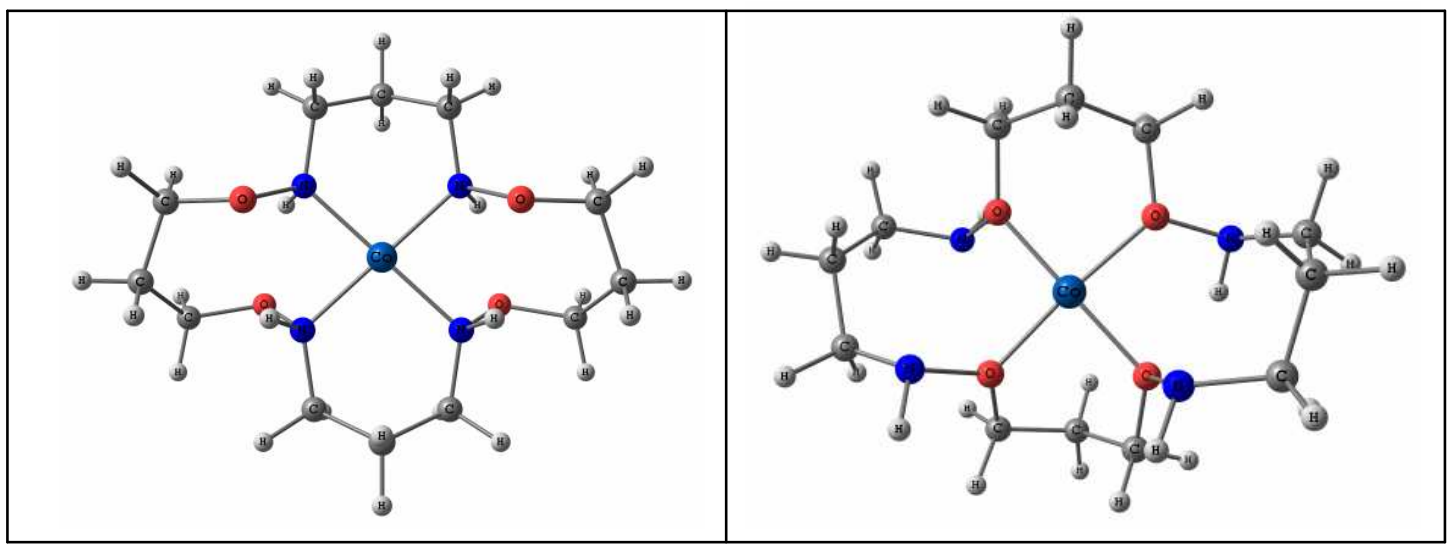

Figura 21. Estruturas otimizadas dos complexos $\mathbf{1 a}_{\mathbf{q}}$ e $\mathbf{1} \mathbf{b}_{\mathbf{q}}$ com o íon $\mathrm{Fe}^{2+}$ calculadas em nível de teoria DFT/B3LYP.

Alguns parâmetros geométricos para os complexos $\mathbf{1 a}_{\mathbf{q}}$ e $\mathbf{1 b}_{\mathbf{q}}$ são mostrados nas Tabelas 12 e 13, respectivamente. 
Tabela 12. Parâmetros geométricos calculados em nível de teoria DFT/B3LYP com o conjunto de base Lanl2DZ para os complexos $\mathbf{1 a}_{\mathbf{q}}$

\begin{tabular}{ccccccc} 
& $\mathrm{Fe}^{2+}$ & $\mathrm{Co}^{2+}$ & $\mathrm{Ni}^{2+}$ & $\mathrm{Ru}^{2+}$ & $\mathrm{Rh}^{2+}$ & $\mathrm{Pd}^{2+}$ \\
\hline $\mathrm{N} 1-\mathrm{M}^{2+}$ & $2,046(\AA)$ & $2,016(\AA)$ & $2,101(\AA)$ & $2,158(\AA)$ & $2,126(\AA)$ & $2,114(\AA)$ \\
$\mathrm{N} 2-\mathrm{M}^{2+}$ & $2,037(\AA)$ & $2,013(\AA)$ & $2,091(\AA)$ & $2,143(\AA)$ & $2,115(\AA)$ & $2,105(\AA)$ \\
$\mathrm{N} 1-\mathrm{M}^{2+}-\mathrm{N} 2$ & $86,4\left(^{\circ}\right)$ & $85,2\left(^{\circ}\right)$ & $86,3\left(^{\circ}\right)$ & $87,5\left(^{\circ}\right)$ & $84,9\left(^{\circ}\right)$ & $84,3\left(^{\circ}\right)$ \\
$\mathrm{N} 2-\mathrm{M}^{2+}-\mathrm{N} 3$ & $179,6\left(^{\circ}\right)$ & $179,6\left(^{\circ}\right)$ & $179,6\left(^{\circ}\right)$ & $179,4\left(^{\circ}\right)$ & $179,9\left(^{\circ}\right)$ & $179,7\left(^{\circ}\right)$ \\
\hline
\end{tabular}

Tabela 13. Parâmetros geométricos calculados em nível de teoria DFT/B3LYP com o conjunto de base Lanl2DZ para os complexos $\mathbf{1 b}_{\mathbf{q}}$

\begin{tabular}{ccccccc} 
& $\mathrm{Fe}^{2+}$ & $\mathrm{Co}^{2+}$ & $\mathrm{Ni}^{2+}$ & $\mathrm{Ru}^{2+}$ & $\mathrm{Rh}^{2+}$ & $\mathrm{Pd}^{2+}$ \\
\hline $\mathrm{O} 1-\mathrm{M}^{2+}$ & $2,177(\AA)$ & $1,944(\AA)$ & $2,173(\AA)$ & $2,453(\AA)$ & $2,090(\AA)$ & $2,483(\AA)$ \\
$\mathrm{O} 2-\mathrm{M}^{2+}$ & $2,375(\AA)$ & $1,905(\AA)$ & $2,139(\AA)$ & $2,412(\AA)$ & $2,080(\AA)$ & $2,484(\AA)$ \\
$\mathrm{O} 1-\mathrm{M}^{2+}-\mathrm{O} 2$ & $83,3\left(^{\circ}\right)$ & $88,6\left(^{\circ}\right)$ & $89,1\left(^{\circ}\right)$ & $88,3\left(^{\circ}\right)$ & $89,7\left(^{\circ}\right)$ & $80,2\left(^{\circ}\right)$ \\
$\mathrm{O} 2-\mathrm{M}^{2+}-\mathrm{O} 3$ & $147,7\left(^{\circ}\right)$ & $174,8\left(^{\circ}\right)$ & $170,7\left(^{\circ}\right)$ & $171,1\left(^{\circ}\right)$ & $173,3\left(^{\circ}\right)$ & $167,1\left(^{\circ}\right)$ \\
\hline
\end{tabular}

Analisando inicialmente os parâmetros geométricos para os complexos $\mathbf{1 a}_{\mathbf{q}}$, podemos observar que a distância nitrogênio-metal $\left(\mathrm{N}-\mathrm{M}^{2+}\right)$ é em média 2,015 a 2,096 ̊̊, para os metais da primeira fila, enquanto nos metais da segunda fila essa distância varia de 2,110 a 2,151 Å. Estes valores estão em excelente concordância com os resultados experimentais de distância M-N obtidos na literatura [6]. Uma fato interessante pode ser observado em relação a distância M-N no complexo $\mathbf{1} \mathbf{a}_{\mathbf{q}}$, formado pelo íon $\mathrm{Co}^{2+}$. Nesse complexo, a distância M-N é a menor da série (em torno de 2,015 $\mathrm{A}$ ), bem diferente do que é observado para os complexos octaédricos 1a, onde a distância tem a tendência de diminuir com o aumento do número atômico. Quando analisado, os complexos formados pelos íons metálicos da segunda fila apresentam resultados semelhantes aos obtidos pelos complexos octaédricos 1a, ou seja, uma tendência da distância metal-ligante diminuir com o aumento do número atômico. 
Semelhante comportamento pode ser observado para os complexos quadrado-planares $\mathbf{1 b}_{\mathbf{q}}$ formados pelos metais de transição da primeira e segunda filas quando comparados com os complexos quadrado-planares $\mathbf{1} \mathbf{a}_{\mathbf{q}}$, ou seja, os complexos formados pelo os íons $\mathrm{Co}^{2+} \mathrm{e}$ $\mathrm{Rh}^{2+}$ apresentam em média uma menor distância metal-oxigênio $(1,925$ e 2,085 ̊, respectivamente). Com exceção dos íons mencionados anteriormente, a distância metalnitrogênio $\left(\mathbf{1 a}_{\mathbf{q}}\right)$ é sempre menor que a distância metal-oxigênio $\left(\mathbf{1}_{\mathbf{q}}\right)$. Tal diferença se deve a grande distorção geométrica sofrida nos complexos $\mathbf{1}_{\mathbf{q}}$. Esta distorção pode ser verificada quando comparamos o ângulo O2-M ${ }^{2+}-\mathrm{O} 3\left(\mathbf{1}_{\mathbf{q}}\right)$ e N2-M ${ }^{2+}-\mathrm{N} 3\left(\mathbf{1 a}_{\mathbf{q}}\right)$. Nos complexos $\mathbf{1} \mathbf{a}_{\mathbf{q}}$, esse ângulo é de aproximadamente $180^{\circ}$, enquanto que para os complexos $\left(\mathbf{1 b}_{\mathbf{q}}\right)$ esse ângulo varia de 145 a $175^{\circ}$, sendo que a maior distorção é observada para os íons de $\mathrm{Fe}^{2+}$ e $\mathrm{Pd}^{2+}$ (Tabela 12 e 13). Todas as estruturas otimizadas dos complexos $\mathbf{1 a}_{\mathbf{q}}$ e $\mathbf{1} \mathbf{b}_{\mathbf{q}}$ são mostradas no Apêndice B.

\section{b) Energias Eletrônicas, Estabilidade Relativa dos Complexos e Energia de Interação $\left(\mathbf{E}_{\mathbf{I N T}}\right)$}

As energias eletrônicas dos diferentes estados de spin para os complexos $\mathbf{1 a}_{\mathbf{q}}$ e $\mathbf{1 b}_{\mathbf{q}}$ de arranjo quadrado-planar são mostrados na Tabela 12. As mesmas considerações adotadas para os cálculos dos diferentes estados de spin, nos complexos octaédricos, foram consideradas para os complexos quadrado-planares. 
Tabela 14. Energia absoluta e energia relativa calculadas com B3LYP/Lanl2DZ para os complexos $\mathbf{1} \mathbf{a}_{\mathbf{q}}$ e $\mathbf{1} \mathbf{b}_{\mathbf{q}}$ de arranjo quadrado-planar

\begin{tabular}{|c|c|c|c|c|c|c|}
\hline $\begin{array}{c}\text { Cátion } \\
\mathrm{M}^{2+}\end{array}$ & Multipli. & $\begin{array}{c}\text { Energia abs. } \\
\text { (a.u.) }\end{array}$ & $\begin{array}{c}\Delta \mathrm{E}^{\mathrm{a}} \\
\left(\mathrm{kcal} . \mathrm{mol}^{-1}\right)\end{array}$ & $\begin{array}{c}\text { Energia abs. } \\
\text { (a.u.) }\end{array}$ & $\begin{array}{c}\Delta \mathrm{E}^{\mathrm{a}} \\
\left(\mathrm{kcal} . \mathrm{mol}^{-1}\right)\end{array}$ & $\begin{array}{c}\text { Energia } \\
\text { relativa }^{\mathrm{b}}\end{array}$ \\
\hline & & \multicolumn{2}{|c|}{ 1a } & \multicolumn{2}{|c|}{ 1b } & $1 \mathrm{~b}-1 \mathrm{a}$ \\
\hline \multirow[t]{3}{*}{$\mathrm{Fe}^{2+}$} & Singleto & $-1116,204177$ & 26,3 & $-1116,185988$ & 33,8 & 11,4 \\
\hline & Quinpleto & $-1116,246132$ & 2,4 & $-1116,23991$ & 0,0 & 3,9 \\
\hline & Tripleto & $-1116,249923$ & 0,0 & $-1116,215587$ & 15,3 & 21,6 \\
\hline \multirow[t]{2}{*}{$\mathrm{Co}^{2+}$} & Quadrupleto & $-1137,877466$ & 8,5 & $-1137,839389$ & 11,8 & 23,9 \\
\hline & Dubleto & $-1137,89096$ & 0,0 & $-1137,820645$ & 0,0 & 44,1 \\
\hline \multirow[t]{2}{*}{$\mathrm{Ni}^{2+}$} & Tripleto & $-1162,102309$ & 7,4 & $-1162,082001$ & 11,1 & 12,7 \\
\hline & Singleto & $-1162,114088$ & 0,0 & $-1162,064264$ & 0,0 & 31,3 \\
\hline \multirow[t]{3}{*}{$\mathrm{Ru}^{2+}$} & Quinpleto & $-1086,603656$ & 22,1 & $-1086,592755$ & 17,5 & 6,8 \\
\hline & Singleto & $-1086,638846$ & 16,6 & $-1086,609423$ & 7,0 & 18,5 \\
\hline & Tripleto & $-1086,665272$ & 0,0 & $-1086,620589$ & 0,0 & 28,0 \\
\hline \multirow[t]{2}{*}{$\mathrm{Rh}^{2+}$} & Quadrupleto & $-1102,242524$ & 41,5 & $-1102,216779$ & 3,5 & 16,2 \\
\hline & Dubleto & $-1102,308651$ & 0,0 & $-1102,222417$ & 0,0 & 54,1 \\
\hline \multirow[t]{2}{*}{$\mathrm{Pd}^{2+}$} & Tripleto & $-1119,46638$ & 44,6 & $-1119,447334$ & 17,22 & 12,0 \\
\hline & Singleto & $-1119,537423$ & 0,0 & $-1119,474781$ & 0,0 & 39,3 \\
\hline
\end{tabular}

Nos complexos quadrado-planares é esperando uma grande distorção tetragonal devido à ausência de ligante no eixo z da molécula. Em outras palavras, espera-se que nesses complexos os estados de spin baixo sejam predominantes. Entretanto, quando a Tabela 14 é analisada, pode-se observar uma estranha anomalia para ambos os complexos com configuração $d^{6}$. Como falado anteriormente, só era esperado que o estado de spin baixo (singleto) tivesse menor energia. Porém, esse não foi o caso. O estado de menor energia eletrônica calculado para o complexo $\mathbf{1 a}_{\mathbf{q}}$ formado pelo íon $\mathrm{Fe}^{2+}$ foi o estado tripleto; sendo 
que a diferença de energia entre o estado tripleto e quinteto é inferior a $3 \mathrm{Kcal}_{\mathrm{mol}}{ }^{-1}$. Ou seja, estes estados podem coexistir simultaneamente num determinado meio. A diferença de energia entre o estado esperado singleto e o estado observado tripleto é bem alta, cerca de 26 $\mathrm{Kcal}_{\mathrm{mol}}{ }^{-1}$. Sendo assim, o estado fundamental que era esperado ser singleto torna inviável devido a sua alta energia eletrônica. A explicação para tal anomalia está na análise dos orbitais naturais (NPA - Natural Population Analysis) obtida pele método NBO, como implementado no programa Guassian 03 [54). Esse resultado mostrou que a distorção tetragonal sofrida pelos os orbitais $\mathrm{d}_{\mathrm{z}}{ }^{2}$ e $\mathrm{d}_{\mathrm{xy}}$ era menor do que o esperado, isto é, esses orbitais possuem uma relativa degenerescência que favorece o estado tripleto. Os resultados obtidos pela análise NPA estão no Apêndice C. Ao descermos no mesmo grupo de configuração eletrônica $d^{6}$, observamos que o estado tripleto apresenta menor energia eletrônica que os respectivos singleto e quinteto. Porém, a diferença de energia entre os pares de estados

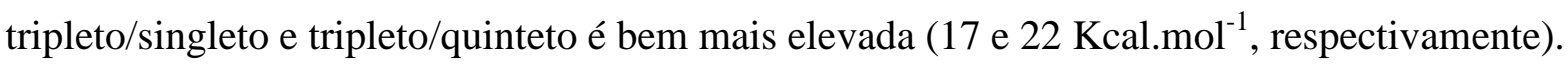

As energias eletrônicas calculadas para os complexos $\mathbf{1} \mathbf{a}_{\mathbf{q}}$ com íons da primeira e segunda filas dos metais de transição de configuração $\mathrm{d}^{7}$ e $\mathrm{d}^{8}$ apresentaram o estado de spin baixo de menor energia, como esperado. Nesses complexos, podemos observar que para os íons da primeira fila a diferença entre os estados de spin baixo e spin alto é de

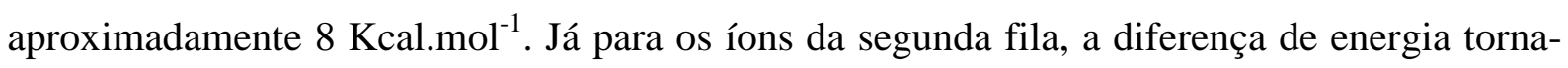
se bastante significativa (superior a $40 \mathrm{Kcal}_{\mathrm{mol}}{ }^{-1}$ ). Tal diferença é o esperado, uma vez que esses íons tem preferência por complexos de spin baixo em virtude do maior desdobramento do campo cristalino que é provocado nos orbitais.

A análise das energias eletrônicas para o complexo $\mathbf{1 b}_{\mathbf{q}}$ com o íon $\mathrm{Fe}^{2+}$ mostrou um resultado ainda mais surpreendente. Nesse sistema, o estado de spin quinteto apresentou menor energia eletrônica. A resposta para esse comportamento se deve ao fato que o arranjo quadrado-planar, inicialmente proposto para esse complexo e com quatro ligações metal- 
oxigênio, foi totalmente distinto após a otimização. Ao analisarmos a estrutura do complexo, observa-se três interações metal-oxigênio e três interações metal-nitrogênio; sendo que os átomos $\mathrm{O} 38$ e N44 estavam situados em uma posição pseudo-axial do centro metálico e os átomos O40, O41, N43 e N45 num plano pseudo-equatorial bem distorcido, em outras palavras, o complexo adquiri um arranjo pseudo-octraédrico altamente distorcido como mostra a Figura 22 e a Tabela 15.

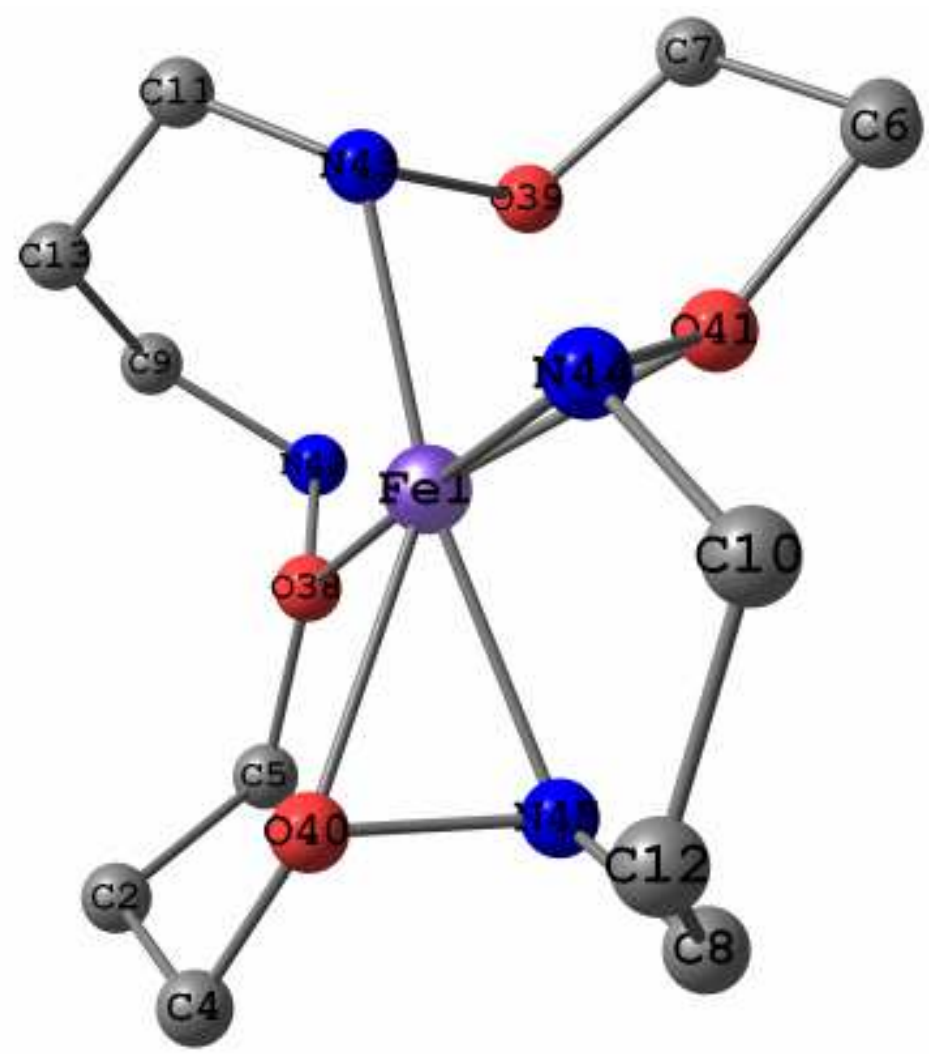

Figura 22. Estrutura otimizada para o complexo $\mathbf{1 b}_{\mathbf{q}}$ com íon de ferro de spin alto. Os átomos de hidrogênio foram removidos para melhor visualização da molécula. 
Tabela 15. Parâmetros geométricos selecionados do complexo $\mathbf{1 b}_{\mathbf{q}}$ com íon de ferro de spin alto

\begin{tabular}{cc|cc}
\hline \multicolumn{2}{c|}{ Comprimento de ligação $(\AA)$} & \multicolumn{2}{|c}{ Ângulo de ligação $\left(^{\circ}\right)$} \\
\hline O38-Fe & 2,124 & O38-Fe-N44 & 173,6 \\
O41-Fe & 2,124 & O40-Fe-N45 & 39,8 \\
N43-Fe & 2,173 & N43-Fe-O41 & 81,1 \\
N45-Fe & 2,182 & N43-Fe-O38 & 92,9 \\
N44-Fe & 2,386 & O40-Fe-O41 & 119,3 \\
O40-Fe & 2,230 & O38-Fe-O40 & 80,5 \\
O-N* & 1,500 & N44-Fe-N45 & 84,3 \\
\hline
\end{tabular}

*Distância média das quatro ligações O-N no complexo.

As ligações metal-nitrogênio e metal-oxigênio são mostradas na Figura 14. Podemos observar que no plano pseudo-equatorial os átomos O40, O41, N43 e N45 estão ligados ao

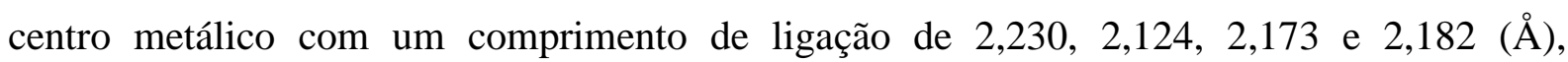
respectivamente, e no plano pseudos-axial os átomos $\mathrm{O} 38$ e N44 apresentam comprimento de ligação na ordem de 2,124 e 2,386 (̊̊), respectivamente. O ângulo de ligação O38-Fe-N44, do eixo pseudo-axial, foi estimado em $173,6^{\circ}$. No plano pseudo-equatorial, os ângulos de ligação variam de 39,8 a $119,3^{\circ}$. O pequeno ângulo O40-Fe-N45 de 39, $8^{\circ}$ deve ser conseqüência dos átomos N45 e O40 estarem diretamente ligados (ver a Figura 22). O alongamento de 119,3 do ângulo O40-Fe-O41 está relacionado à maior distância calculada metal-O40 neste complexo.

As energias de interação $\left(E_{\mathrm{INT}}\right)$ para os complexos quadrado-planares $\mathbf{1 a}_{\mathbf{q}}$ e $\mathbf{1 b}_{\mathbf{q}}$ são mostradas na Tabela 16. Essas energias foram obtidas pela Equação 1, exceto para o termo $\mathrm{E}_{\mathrm{B}}$, onde as duas moléculas de água foram desconsideradas. 
Tabela 16. Energia de interação ( $\mathrm{E}_{\mathrm{INT}}$ ) entre os macrociclos [20]ane $\mathrm{N}_{4} \mathrm{O}_{4}$ e [20]ane $\mathrm{O}_{4} \mathrm{~N}_{4}$ com íons dos metais de transição calculada com B3LYP/Lanl2DZ para os complexos $\mathbf{1 a}_{\mathbf{q}}$ e $\mathbf{1 b}_{\mathbf{q}}$

\begin{tabular}{ccc}
\hline Cátion $\mathrm{M}^{2+}$ & $\mathrm{E}_{\mathrm{INT}}(\mathrm{Kcal} / \mathrm{mol}) \mathbf{1 a}_{\mathbf{q}}$ & $\mathrm{E}_{\mathrm{INT}}(\mathrm{Kcal} / \mathrm{mol}) \mathbf{1 b}_{\mathbf{q}}$ \\
\hline $\mathrm{Fe}^{2+}$ & $-358,7$ & $-341,4$ \\
$\mathrm{Co}^{2+}$ & $-390,8$ & $-345,1$ \\
$\mathrm{Ni}^{2+}$ & $-402,8$ & $-369,4$ \\
$\mathrm{Ru}^{2+}$ & $-370,4$ & $-329,0$ \\
$\mathrm{Rh}^{2+}$ & $-447,2$ & $-379,8$ \\
$\mathrm{Pd}^{2+}$ & $-482,0$ & $-429,3$ \\
\hline
\end{tabular}

Nos complexos quadrado-planar, assim como nos complexos octaédricos, o macrociclo ([20]ane $\mathrm{N}_{4} \mathrm{O}_{4}$ ) com átomos de nitrogênio resultou em complexos com maior energia de interação ( $\left.\mathrm{E}_{\mathrm{INT}}\right)$, quando comparados aos complexos derivados do macrociclo ([20]ane $\mathrm{O}_{4} \mathrm{~N}_{4}$ ) com átomos de oxigênio. A diferença de energia calculada para os complexos $\mathbf{1} \mathbf{a}_{\mathbf{q}}$ e $\mathbf{1} \mathbf{b}_{\mathbf{q}}$ aumentam do $\mathrm{Fe}^{2+}<\mathrm{Co}^{2+}<\mathrm{Ni}^{2+}$. Nos íons metálicos da segunda fila, observamos a mesma tendência, porém com uma variação de energia bem mais significativa. Por exemplo, quando comparamos íons do mesmo grupo $\mathrm{d}^{8}\left(\mathrm{Ni}^{2+} / \mathrm{Pd}^{2+}\right)$, a diferença de energia entre os

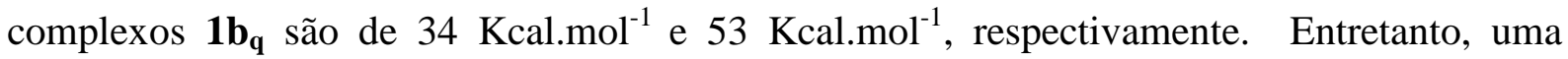
mudança dessa tendência ocorre com os íons $\mathrm{Fe}^{2+} / \mathrm{Ru}^{2+}$ nos complexos $\mathbf{1 a}_{\mathbf{q}}$ e $\mathbf{1 b}_{\mathbf{q}}$, onde o primeiro possui um energia de interação estimada em $-341 \mathrm{Kcal}_{\mathrm{mol}}{ }^{-1}$, enquanto que para o segundo íon essa energia é estimada em -329 Kcal.mol ${ }^{-1}$, isto é, uma diferença de energia de 51 Kcal.mol ${ }^{-1}$. Esses resultados são mostrados na Figura 23. 


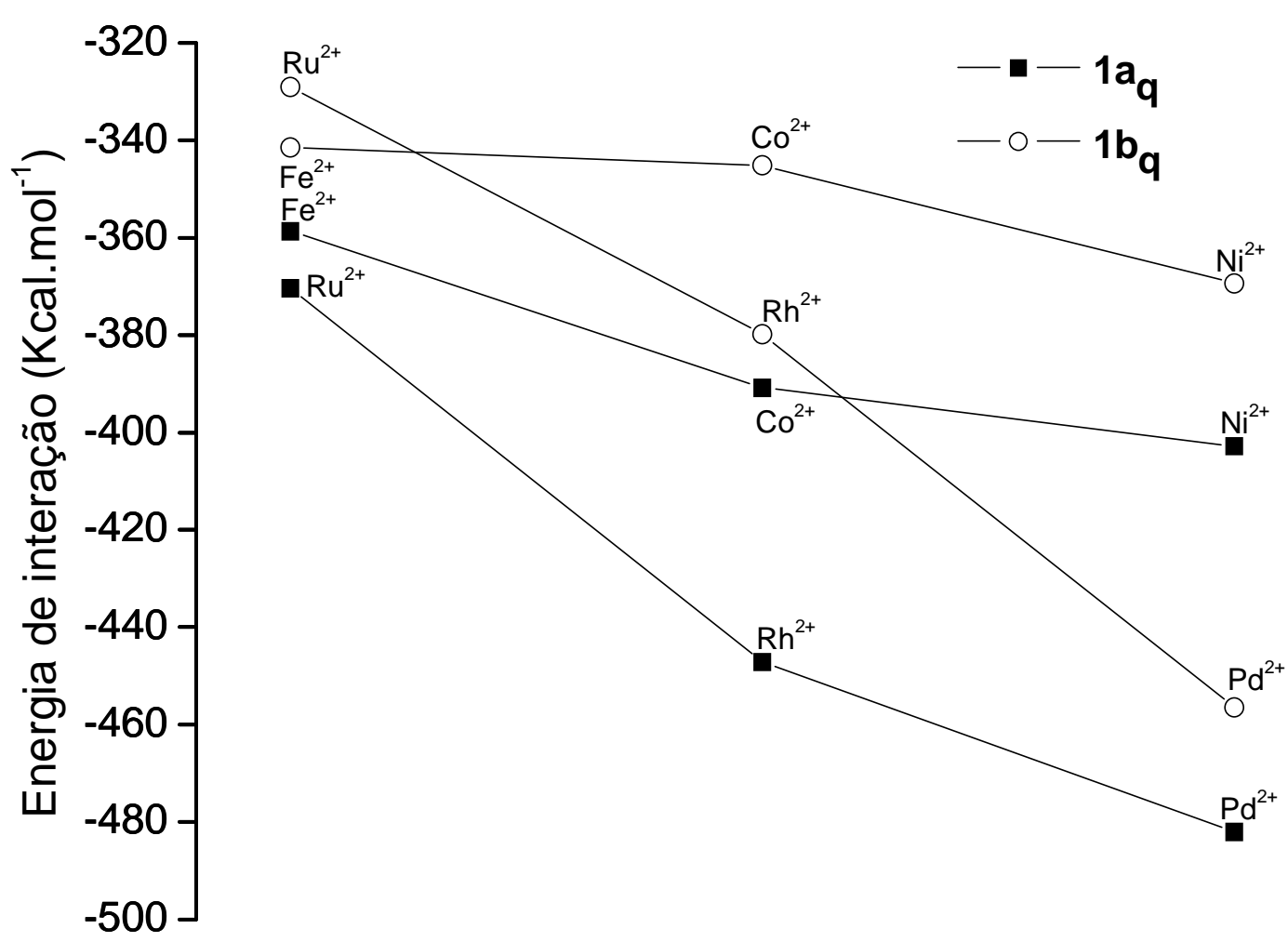

Figura 23. Energia de interação ( $E_{\text {INT }}$ ), em Kcal.mol ${ }^{-1}$, calculada para os complexos $\mathbf{1 a}_{\mathbf{q}}$ e $\mathbf{1 b}_{\mathbf{q}}$ formados pelos íons da primeira e segunda fila dos metais de transição.

Analisando a Figura 23, observamos o mesmo comportamento entre os complexos $\mathbf{1} \mathbf{a}_{\mathbf{q}}$ e $\mathbf{1 b}_{\mathbf{q}}$ de arranjo geométrico octaédrico e quadrado-planar (ver Figura 10, pág. 57). Porém, neste último, a energia de interação calculada para o complexo $\left(\mathbf{1 b}_{\mathbf{q}}\right)$, formado pelo íon paládio, é superior à calculada para o complexo $\left(\mathbf{1 a}_{\mathbf{q}}\right)$, formado pelo íon níquel. 


\section{c) Análise dos Espectros Vibracionais de Infravermelho para os Complexos}

$\left(1 \mathbf{a}_{\mathbf{q}}\right) \mathbf{e}\left(\mathbf{1} \mathbf{b}_{\mathbf{q}}\right)$

De um modo geral, os modos atribuídos aos estiramentos simétricos $\left(v_{\mathrm{s}}\right)$ e assimétricos $\left(v_{\mathrm{as}}\right)$, bem como os modos de deformação no plano $\left(\delta_{\mathrm{s}}\right)$, fora do plano $\left(\delta_{\mathrm{d}}\right)$ e de tesoura $(\sigma)$, observados nos complexos 1a e $\mathbf{1 b}$ de arranjo octaédrico, foram também observados na mesma região para os complexos $\mathbf{1 a}_{\mathbf{q}}$ e $\mathbf{1 b}_{\mathbf{q}}$ de arranjo quadrado-planar. Porém, na região abaixo de $600 \mathrm{~cm}^{-1}$, que é importante para verificação da formação do complexo, por ser bastante sensível à presença do metal, foi observado mudanças significativas. Desta forma, será discutido apenas os modos vibracionais observado nessa região para os complexos quadrado-planares $\mathbf{1 a}_{\mathbf{q}}$ e $\mathbf{1} \mathbf{b}_{\mathbf{q}}$, formados por íons metálicos da primeira e segunda filas.

Os modos vibracionais de estiramento simétrico e assimétrico metal-ligante, e os modos referentes às deformações no plano e fora do plano, são mostrados na Tabela 17.

Tabela 17. Frequiência vibracional teórica calculada em nível de teoria DFT para os complexos $\mathbf{1} \mathbf{a}_{\mathbf{q}}$ e $\mathbf{1} \mathbf{b}_{\mathbf{q}}$ de arranjo quadrado-planar

\begin{tabular}{|c|c|c|c|c|c|c|}
\hline \multicolumn{7}{|c|}{ complexo $\mathbf{1} \mathbf{a}_{\mathbf{q}}$} \\
\hline $\mathrm{Fe}^{2+}$ & $\mathrm{Co}^{2+}$ & $\mathrm{Ni}^{2+}$ & $\mathrm{Ru}^{2+}$ & $\mathrm{Rh}^{2+}$ & $\mathrm{Pd}^{2+}$ & modos vibracionais \\
\hline 546 & 472 & 539 & 443 & 558 & 559 & $v_{\mathrm{s}}(\mathrm{M}-\mathrm{N})$ \\
\hline 573 & 562 & 564 & 488 & 567 & 569 & $\mathrm{v}_{\mathrm{as}}(\mathrm{M}-\mathrm{N})$ \\
\hline 351 & 350 & 422 & 343 & 323 & 300 & $\delta_{\mathrm{s}}(\mathrm{M}-\mathrm{N})$ \\
\hline 139 & 245 & 244 & 275 & 258 & 257 & $\delta_{\mathrm{d}}(\mathrm{M}-\mathrm{N})$ \\
\hline \multicolumn{7}{|c|}{ complexo $\mathbf{1} \mathbf{b}_{\mathbf{q}}$} \\
\hline $\mathrm{Fe}^{2+}$ & $\mathrm{Co}^{2+}$ & $\mathrm{Ni}^{2+}$ & $\mathrm{Ru}^{2+}$ & $\mathrm{Rh}^{2+}$ & $\mathrm{Pd}^{2+}$ & modos vibracionais \\
\hline 440 & 468 & 488 & 486 & 488 & 496 & $\mathrm{v}_{\mathrm{s}}(\mathrm{M}-\mathrm{O})$ \\
\hline 514 & 523 & 498 & 522 & 480 & 431 & $\mathrm{v}_{\mathrm{as}}(\mathrm{M}-\mathrm{O})$ \\
\hline 339 & 328 & 271 & 319 & 286 & 318 & $\delta_{\mathrm{s}}(\mathrm{M}-\mathrm{O})$ \\
\hline 135 & 220 & 172 & 235 & 212 & 243 & $\delta_{\mathrm{d}}(\mathrm{M}-\mathrm{O})$ \\
\hline
\end{tabular}


Os estiramentos assimétricos e simétricos, metal-ligante, em todos os complexos $\mathbf{1 a}_{\mathbf{q}} \mathrm{e}$ $\mathbf{1 b}_{\mathbf{q}}$, são observados na região de 560 a $440 \mathrm{~cm}^{-1}$. Nesses sistemas, observa-se um aumento gradativo dos estiramentos simétrico à medida que aumenta o número atômico, com exceção dos complexos $\mathbf{1} \mathbf{a}_{\mathbf{q}}$ formados por íons da primeira fila. Por exemplo, para os complexos $\mathbf{1 a}_{\mathbf{q}}$ dos íons $\mathrm{Fe}^{2+}, \mathrm{Co}^{2+} \mathrm{e} \mathrm{Ni}^{2+}$, os estiramentos simétricos foram calculados em 546,472 e $539 \mathrm{~cm}^{-}$ ${ }^{1}$, respectivamente. Enquanto nos complexos $\mathbf{1} \mathbf{a}_{\mathbf{q}}$ com íon da segunda fila, os estiramentos simétricos observados foram de 443, 558 e $559 \mathrm{~cm}^{-1}$ para os íons $\mathrm{Ru}^{2+}, \mathrm{Rh}^{2+}$ e $\mathrm{Pd}^{2+}$, respectivamente. A mesma tendência foi observada nos estiramentos assimétricos dos complexos $\mathbf{1 a}_{\mathbf{q}}$ formados por íons metálicos da segunda fila, ou seja, o aumento do estiramento assimétrico é proporcional ao aumento do número atômico, como mostrado na Tabela 17. Já nos complexos $\mathbf{1}_{\mathbf{q}}$, a freqüência vibracional referente aos estiramentos simétricos aumenta à medida que se desloca para a direta da tabela periódica. Nesses complexos, esse modo vibracional foi calculado numa região abaixo de $500 \mathrm{~cm}^{-1}$.

Os modos vibracionais referentes à deformação no plano e fora do plano são observados na região de 430 a $130 \mathrm{~cm}^{-1}$. Como pode ser observado na Tabela 17 , os complexos $\mathbf{1} \mathbf{a}_{\mathbf{q}}$ e $\mathbf{1} \mathbf{b}_{\mathbf{q}}$, formados pelo íon $\mathrm{Fe}^{2+}$, apresentam a menor freqüência vibracional de deformação fora do plano em relação aos outros íons. De um modo geral, para os complexos $\mathbf{1} \mathbf{a}_{\mathbf{q}}$ e $\mathbf{1} \mathbf{b}_{\mathbf{q}}$ de geometria quadrado-planar, especificamente para esses modos vibracionais, a variação das freqüências não demonstrou ter um comportamento uniforme, em outras palavras, a frequiência vibracional não aumentou com o aumento do número atômico, diferentemente do que foi observado para os complexos $\mathbf{1 a}$ e $\mathbf{1 b}$ de geometria octaédrica.

Os espectros de infravermelho calculados em nível de teoria DFT são mostrados nas Figuras 24 e 25. 

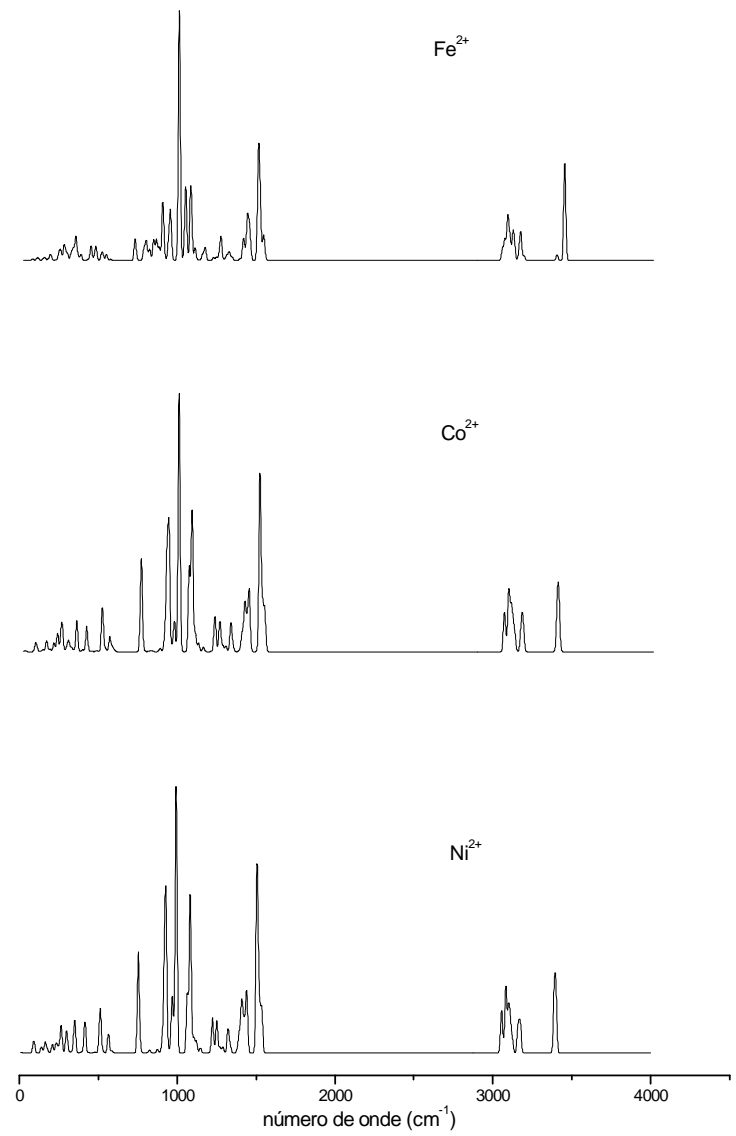
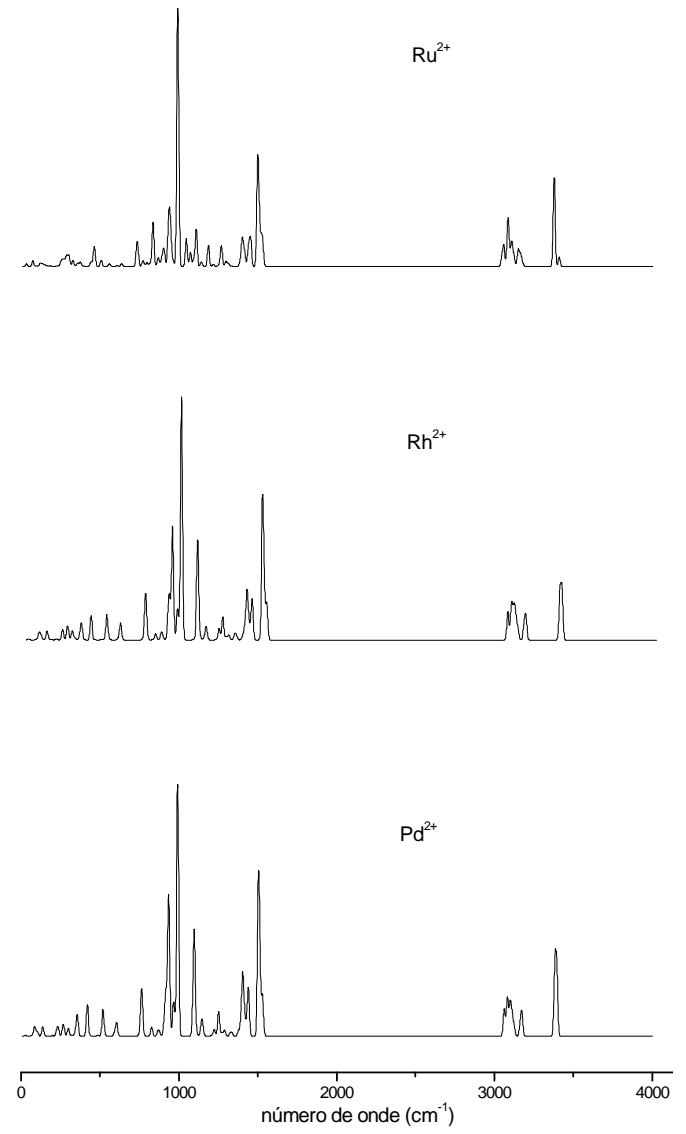

Figura 24. Espectro teórico de infravermelho calculado em nível de teoria DFT para os complexos quadrado-planar $\mathbf{1} \mathbf{a}_{\mathbf{q}}$. 

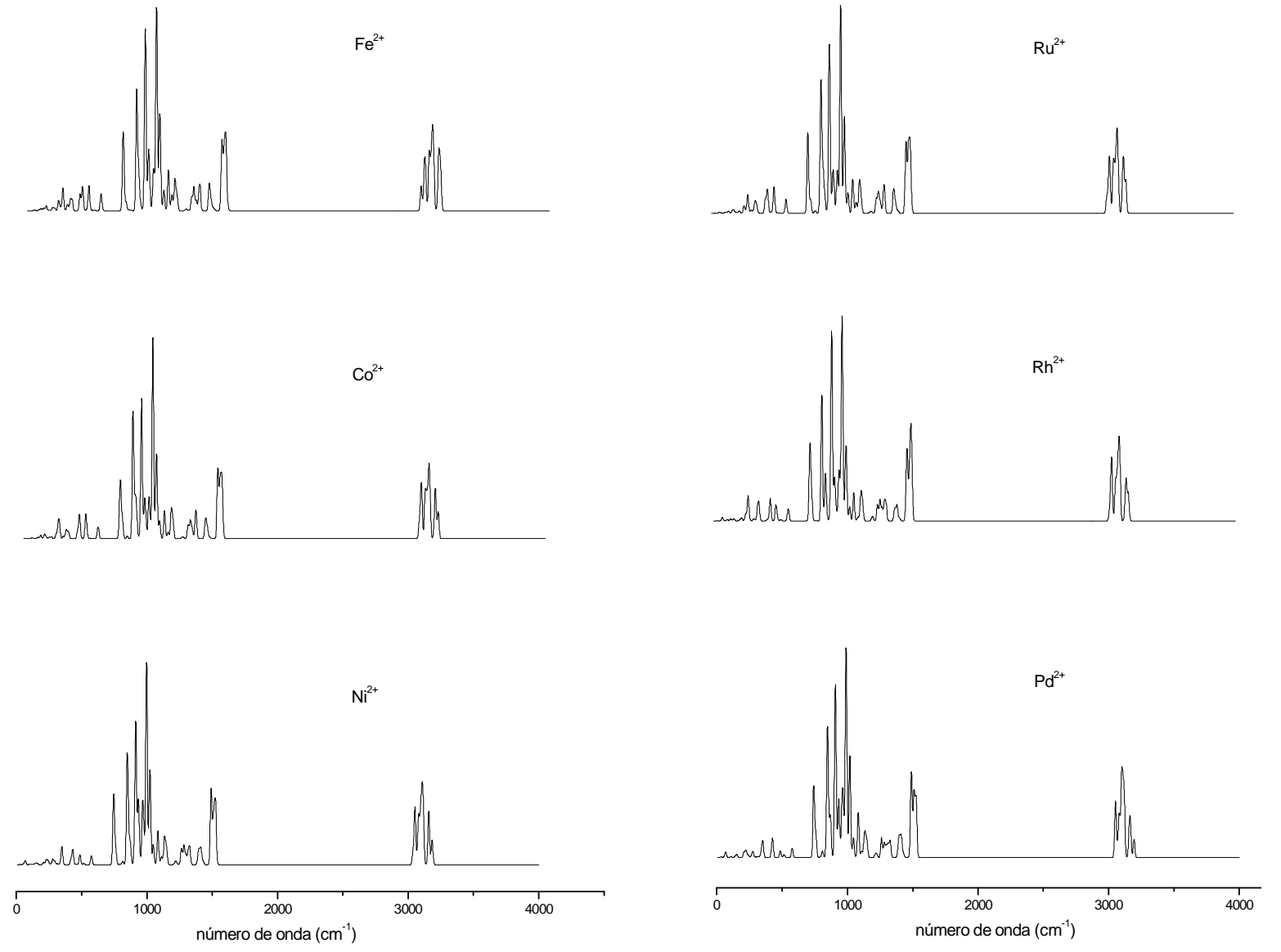

Figura 25. Espectro teórico de infravermelho calculado em nível de teoria DFT para os complexos quadrado-planar $\mathbf{1} \mathbf{b}_{\mathbf{q}}$. 


\section{c) Análise dos Orbitais Moleculares nos Complexos $\left(1 \mathbf{a}_{\mathbf{q}}\right)$ e Complexos $\left(1 \mathbf{b}_{\mathbf{q}}\right)$}

Os resultados obtidos pela análise CDA, para os complexos $\mathbf{1 a}_{\mathbf{q}}$ e $\mathbf{1} \mathbf{b}_{\mathbf{q}}$ com geométrica quadrado-planar, são mostrados nas Tabelas 18 e 19 para os sistemas de camada fechada e aberta, respectivamente.

Tabela 18. Análise de decomposição de cargas obtida para os complexos $\mathbf{1 a}_{\mathbf{q}}$ e $\mathbf{1 b}_{\mathbf{q}}$, de camada fechada, calculados com o método B3LYP/Lanl2DZ

\begin{tabular}{|c|c|c|c|c|}
\hline Complexo & Ni-Nitrogênio & Ni-Oxigênio & Pd-Nitrogênio & $\begin{array}{c}\text { Pd- } \\
\text { Oxigênio }\end{array}$ \\
\hline Doação (a.u $)^{I}$ & 0,580 & 0,895 & 0,721 & 1,111 \\
\hline rd (a.u) ${ }^{\mathrm{II}}$ & $-0,010$ & 0,020 & 0,011 & 0,000 \\
\hline $\operatorname{POL}(\mathrm{M})-\operatorname{POL}(\mathrm{L})^{\mathrm{III}}$ & 66,9 & 50,9 & 40,0 & 45,0 \\
\hline $\mathrm{TC}(2 \rightarrow 1)-\mathrm{TC}(1 \rightarrow 2)^{\mathrm{IV}}$ & 1,137 & 1,203 & 1,315 & 1,460 \\
\hline Metal qNBO (a.u.) & 0,946 & 1,078 & 0,814 & 0,926 \\
\hline Ligante $\mathrm{q}_{\mathrm{NBO}}$ (a.u.) $^{\mathrm{V}}$ & $-0,412$ & $-0,528$ & $-0,385$ & $-0,485$ \\
\hline
\end{tabular}

I- Doação de cargas do ligante para o metal;

II- retrodoação de cargas (rd) do metal para o ligante;

III- Polarização (POL) do metal e polarização do ligante, respectivamente;

IV- Transferência de cargas (TC) dos ligantes para o metal e transferência de cargas do metal para o ligante, respectivamente.

V- média das cargas sobre os ligantes nitrogênio ou oxigênio. 
Tabela 19. Análise de decomposição de cargas obtida para os complexos $\mathbf{1 a}_{\mathbf{q}}$ e $\mathbf{1 b}_{\mathbf{q}}$, de camada aberta, calculados com o método B3LYP/Lanl2DZ

\begin{tabular}{|c|c|c|c|c|}
\hline \multirow[t]{2}{*}{ Complexo } & \multicolumn{4}{|c|}{$1 a_{q}$} \\
\hline & $\mathrm{Fe}$ & $\mathrm{Co}$ & $\mathrm{Ru}$ & $\mathrm{Rh}$ \\
\hline $\mathrm{d}^{\alpha}$ (a.u.) & 0,535 & 0,552 & 0,549 & 0,116 \\
\hline $\operatorname{rd}^{\alpha}(\mathrm{a} . \mathrm{u})$ & 0,044 & 0,008 & 0,017 & 0,003 \\
\hline$d^{\beta}($ a.u $)$ & 0,602 & 0,636 & 0,701 & 0,581 \\
\hline $\mathrm{rd}^{\beta}(\mathrm{a} . \mathrm{u})$ & 0,000 & 0,001 & 0,008 & 0,013 \\
\hline$\Sigma^{\alpha+\beta} \mathrm{da} \mathrm{d}$ & 1,137 & 1,188 & 1,250 & 0,697 \\
\hline$\Sigma^{\alpha+\beta}$ da rd & 0,044 & 0,009 & 0,025 & 0,016 \\
\hline $\mathrm{P}^{\alpha}(\mathrm{M})-\mathrm{P}(\mathrm{L})$ & $-3,1$ & $-5,8$ & $-4,0$ & 49,6 \\
\hline $\mathrm{P}^{\beta}(\mathrm{M})-\mathrm{P}(\mathrm{L})$ & 71,8 & 80,2 & 65,9 & 0,2 \\
\hline da $P$ & 68,7 & 74,4 & 61,9 & 49,8 \\
\hline $\mathrm{TC}^{\alpha}(2 \rightarrow 1)-\mathrm{TC}(1 \rightarrow 2)$ & 0,935 & 0,943 & 0,861 & 1,109 \\
\hline $\mathrm{TC}^{\beta}(2 \rightarrow 1)-\mathrm{TC}(1 \rightarrow 2)$ & 1,246 & 1,385 & 1,599 & 1,209 \\
\hline$\Sigma^{\alpha+\beta} \mathrm{da} \mathrm{TC}$ & 2,181 & 2,328 & 2,460 & 2,318 \\
\hline Metal q $\mathrm{q}_{\mathrm{NBO}}(\mathrm{a} . . \mathrm{u})$ & 1,119 & 1,077 & 0,996 & 0,916 \\
\hline \multirow[t]{3}{*}{ Nitrogen $\mathrm{q}_{\mathrm{NBO}}(\mathrm{a} . . \mathrm{u})$} & $-0,435$ & $-0,425$ & $-0,405$ & $-0,385$ \\
\hline & \multicolumn{4}{|c|}{$1 b_{q}$} \\
\hline & $\mathrm{Fe}$ & Co & $\mathrm{Ru}$ & $\mathrm{Rh}$ \\
\hline $\mathrm{d}^{\alpha}$ (a.u.) & 0,536 & 0,588 & 0,601 & 0,569 \\
\hline $\mathrm{rd}^{\alpha}(\mathrm{a} . \mathrm{u})$ & $-0,016$ & $-0,010$ & $-0,011$ & $-0,008$ \\
\hline$d^{\beta}($ a.u $)$ & 0,702 & 0,736 & 0,698 & 0,592 \\
\hline $\mathrm{rd}^{\beta}(\mathrm{a} . \mathrm{u})$ & $-0,003$ & $-0,001$ & 0,003 & $-0,002$ \\
\hline$\Sigma^{\alpha+\beta} \mathrm{da} \mathrm{d}$ & 1,238 & 1,344 & 1,299 & 1,161 \\
\hline$\Sigma^{\alpha+\beta}$ da rd & $-0,019$ & $-0,011$ & $-0,008$ & $-0,010$ \\
\hline $\mathrm{P}^{\alpha}(\mathrm{M})-\mathrm{P}(\mathrm{L})$ & $-3,9$ & $-3,7$ & $-4,1$ & 20,1 \\
\hline $\mathrm{P}^{\beta}(\mathrm{M})-\mathrm{P}(\mathrm{L})$ & 66,0 & 99,1 & 93,5 & 18.8 \\
\hline
\end{tabular}


Continuação da Tabela 19

\begin{tabular}{ccccc}
\hline$\Sigma^{\alpha+\beta}$ da P & 62,1 & 95,4 & 89,4 & 38,9 \\
$\mathrm{TC}^{\alpha}(2 \rightarrow 1)-\mathrm{TC}(1 \rightarrow 2)$ & 0,807 & 0,903 & 0,888 & 1,104 \\
$\mathrm{TC}^{\beta}(2 \rightarrow 1)-\mathrm{TC}(1 \rightarrow 2)$ & 1,218 & 1,328 & 1,356 & 1,399 \\
$\Sigma^{\alpha+\beta}$ da TC & 2,125 & 2,231 & 2,244 & 2,503 \\
Metal q & 1,519 & 1,488 & 1,129 & 1,115 \\
Oxigênio q $($ a..u $)$ & $-0,543$ & $-0,498$ & $-0,513$ & $-0,505$ \\
\hline
\end{tabular}

De modo geral, os resultados da análise CDA para os complexos quadrado-planar foram muito semelhantes aos obtidos para os complexos octaédricos.

Como mencionado anteriormente, na análise CDA para os complexos octaédricos, a retrodoação calculada para esses sistemas foram desprezíveis. Desta forma, a interação doador-receptor nos complexos são predominantemente interações sigmas covalentes. A forte evidência está nos resultados obtidos para a doação de cargas do ligante-metal. A doação de carga do ligante para o metal nos complexos quadrado-planares $\mathbf{1 a}_{\mathbf{q}}$ e $\mathbf{1 b}_{\mathbf{q}}$ formadas pelos

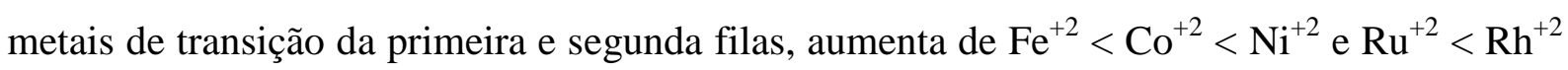
$<\mathrm{Pd}^{+2}$, respectivamente, como mostrado nas Tabelas 18 e 19.

A força da interação covalente aumenta no sentido inverso à interação iônica, como já discutida nos complexos octaédricos. As Figuras 26 e 27 mostram a variação das cargas NBO dos íons metálicos com os ligantes do macrociclos. Como observado nas Figuras 26 e 27, a maior variação entre as cargas do íon metálico da primeira fila e do ligante aparecem no complexo de $\mathrm{Fe}^{2+}$ em ambos os sistemas $\mathbf{1} \mathbf{a}_{\mathbf{q}}$ e $\mathbf{1} \mathbf{b}_{\mathbf{q}}$ aqui estudados. O sistema com menor variação de carga foi observado para o complexo $\mathbf{1 a}_{\mathbf{q}}$ e $\mathbf{1 b}_{\mathbf{q}}$ de $\mathrm{Ni}^{2+}$. Essa mesma tendência foi verificada para os complexos 1a e 1b de arranjo octaédrico (ver Figuras 17 e 18, pág. 75). No entanto, quando analisamos as cargas dos complexos $\mathbf{1 a}_{\mathbf{q}}$ e $\mathbf{1} \mathbf{a}_{\mathbf{q}}$, formado por íons metálicos da 
segunda fila, observa-se um comportamento diferente em relação aos complexos $\mathbf{1 a}$ e $\mathbf{1 b}$ (octaédrico) desses mesmos íons. Enquanto que nos complexos octaédricos, as cargas sobre os íons metálicos e os ligantes $(\mathrm{N}, \mathrm{O})$ aumentam de $\mathrm{Ru}^{2+}$ para $\mathrm{Rh}^{2+}$ e de $\mathrm{Rh}^{2+}$ para $\mathrm{Pd}^{2+}$ (ver Tabelas 10 e 11, pág. 72 e 73), nos complexos quadrado-planar as cargas sobre os íons metálicos e os ligantes $(\mathrm{N}, \mathrm{O})$ diminuem nos complexos de $\mathrm{Ru}^{2+}$ para $\mathrm{Rh}^{2+}$ e de $\mathrm{Rh}^{2+}$ para $\mathrm{Pd}^{2+}$ (Tabelas 18 e 19). Sendo assim, nos complexos formados por íons metálicos da segunda fila, o aumento da contribuição covalente, ou diminuição da contribuição iônica, ocorre no mesmo sentido para os complexos formados por metais da primeira fila.

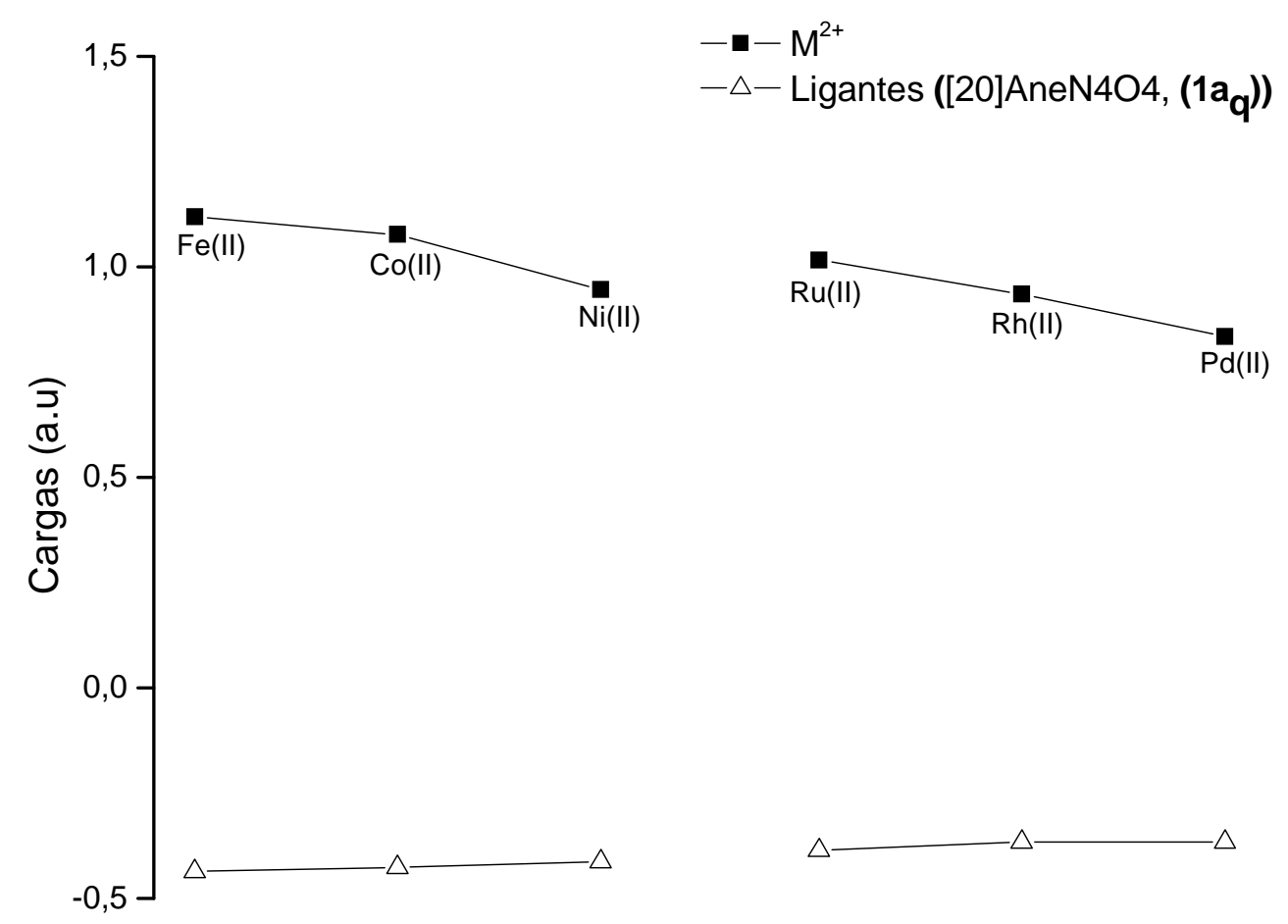

Figura 26. Cargas NBO sobre o metal e os ligantes (N) calculadas com B3LYP/Lanl2DZ para os complexos quadrado-planares $\mathbf{1} \mathbf{a}_{\mathbf{q}}$. 


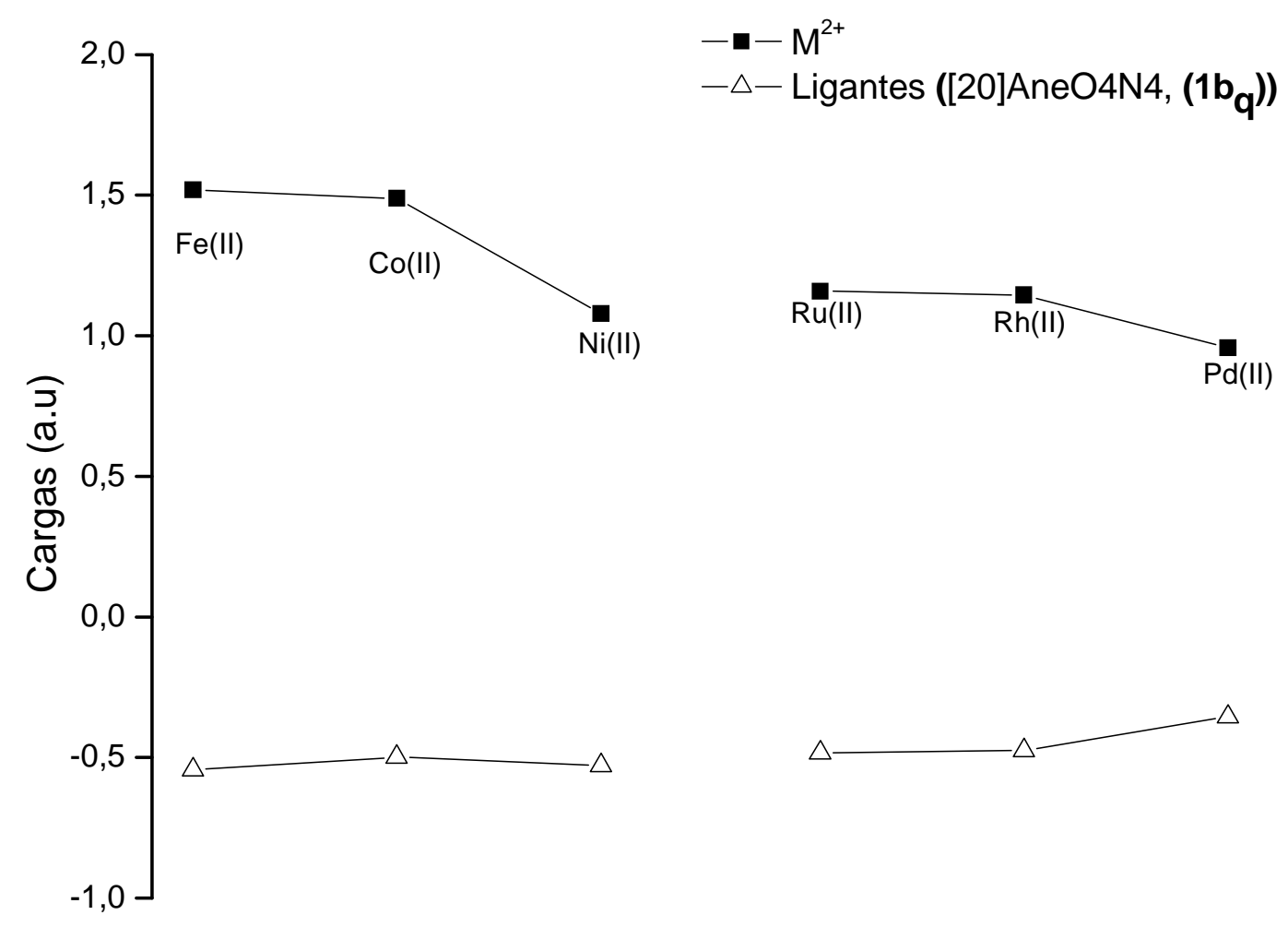

Figura 27. Cargas NBO sobre o metal e os ligantes $(\mathrm{O})$ calculadas com B3LYP/Lanl2DZ para os complexos $\mathbf{1} \mathbf{b}_{\mathbf{q}}$ quadrado-planar.

Os complexos $\mathbf{1} \mathbf{a}_{\mathbf{q}}$ e $\mathbf{1} \mathbf{b}_{\mathbf{q}}$ dos íons da primeira fila mostram ter um maior caráter iônico nas interações metal-ligante quando comparados aos complexos octaédricos. Tal evidência pode ser averiguada analisando o diagrama do orbital molecular mostrado nas Figuras 28 e 29. O caráter iônico torna-se mais pronunciado à medida que o gap de energia (LUMOHOMO) torna-se menor. Por exemplo, no complexo 1a (octaédrico) de $\mathrm{Fe}^{2+}$, o gap de energia calculado foi de 5,58 eV. Já para o complexo $\mathbf{1 a}_{\mathbf{q}}$ (quadrado-planar), desse mesmo íon, o gap foi estimado em 5,45 eV, ou seja, o complexo $\mathbf{1 a}_{\mathbf{q}}$ (quadrado-planar) tem um gap de energia 0,43 eV menor que o complexo 1a (octaédrico). Porém, uma mudança significativa no gap de energia foi observada nos íons $\mathrm{Co}^{2+} \mathrm{e} \mathrm{Ni}^{2+}$ dos complexos $\mathbf{1 b}$. O gap calculado para esses íons, nos complexos octaédricos, foram de 6,36 e 6,37 eV, respectivamente (ver Figura 18, pág. 77). Nos complexos $\mathbf{1 b}_{\mathbf{q}}$ quadrado-planar, o gap de energia calculado foi de 3,21 e 3,11 
eV (Figura 29), para os íons $\mathrm{Co}^{2+} \mathrm{e} \mathrm{Ni}^{2+}$, respectivamente. Nesses íons, a diferença de energia foi superior a $3 \mathrm{eV}$. Conseqüentemente, o caráter iônico tornou-se mais pronunciado para os complexos $\mathbf{1} \mathbf{b}_{\mathbf{q}}$.

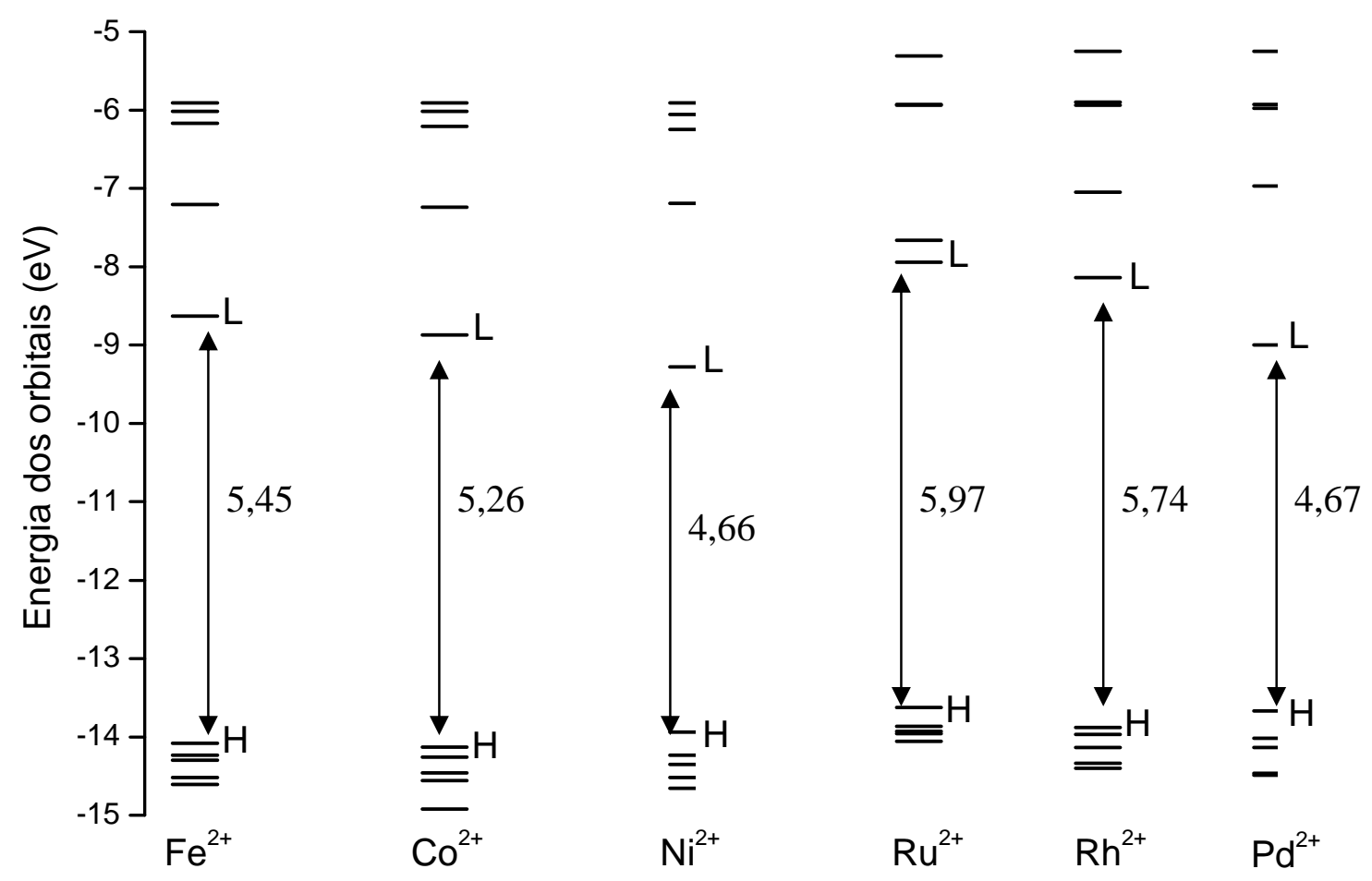

Figura 28. Diagrama dos orbitais moleculares dos complexos $\mathbf{1} \mathbf{a}_{\mathbf{q}}$ de arranjo quadrado-planar formados pelos os íons metálicos da primeira e segunda filas.

Os complexos formados pelos íons metálicos da segunda fila mostraram uma tendência contraria ao observado para os complexos formados por íons da primeira fila, quando comparado à tendência da força iônica nos complexos octaédricos e quadradoplanares. Nos complexos 1a e 1b octaédricos, o caráter iônico demonstrou-se mais pronunciado. Porém, essa não foi uma tendência geral, pois o gap de energia (LUMOHOMO) para os íons metálicos $\mathrm{Rh}^{2+}$ e $\mathrm{Pd}^{2+}$, nos complexo $\mathbf{1} \mathbf{b}_{\mathbf{q}}$ (quadrado-planar), foi menor que o calculado para os complexos $\mathbf{1 b}$ (octaédrico). Sendo assim, nestes últimos complexos, o 
caráter iônico aumentou, uma vez que quanto menor o gap de energia mais predominante são as ligações iônicas. Tal tendência pode ser observa comparando as Tabelas 18 e 19.

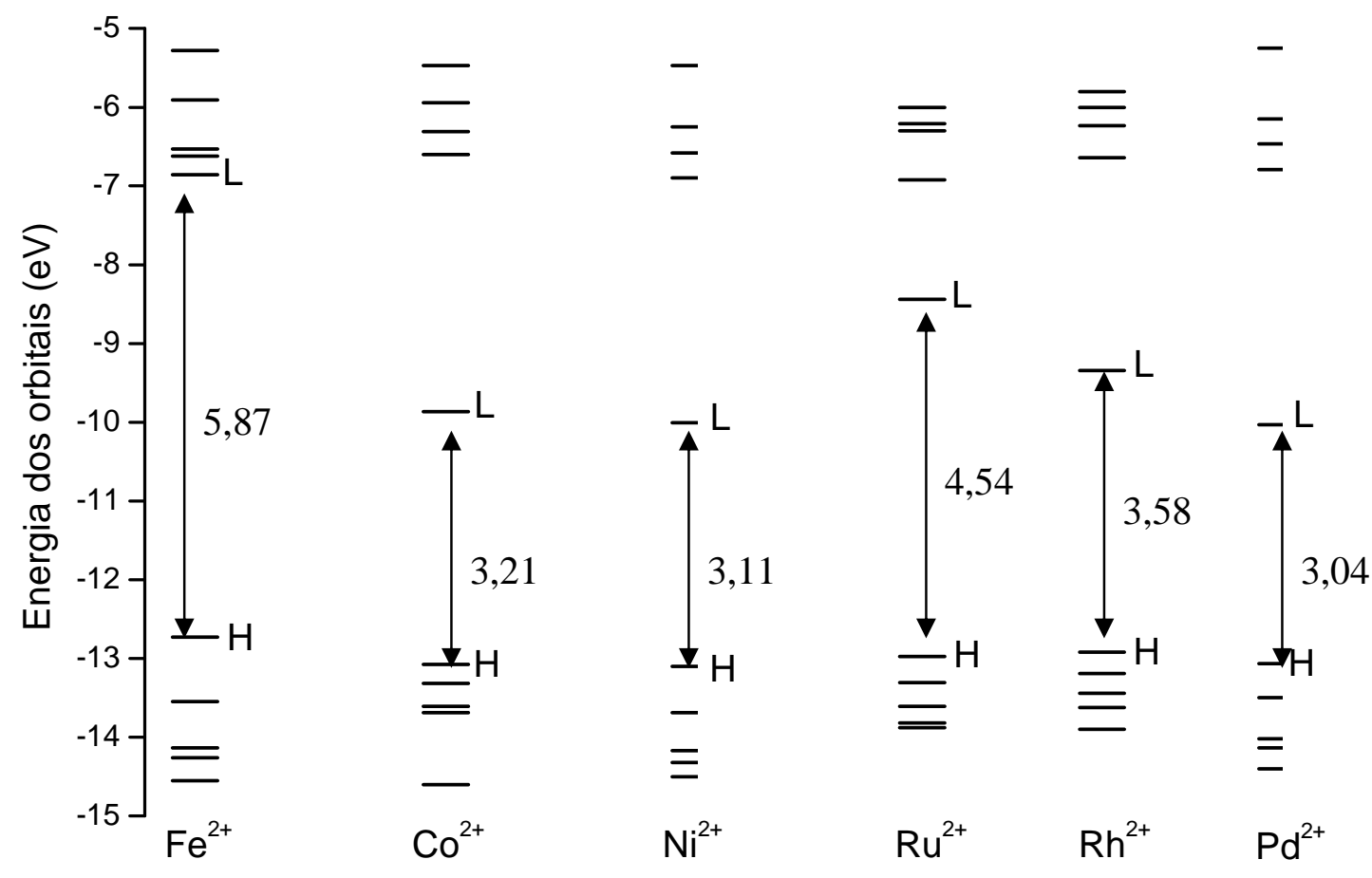

Figura 29. Diagrama dos orbitais moleculares dos complexos $\mathbf{1 b}_{\mathbf{q}}$ de arranjo quadrado-planar formados pelos os íons metálicos da primeira e segunda filas.

Os orbitais moleculares de fronteira (HOMO e LUMO) para os complexos $\mathbf{1 a}_{\mathbf{q}}$ e $\mathbf{1} \mathbf{b}_{\mathbf{q}}$, de camada fechada, são mostrados na Figura 30. Os íons $\mathrm{Ni}^{2+}$ e $\mathrm{Pd}^{2+}$ de configuração eletrônica d ${ }^{8}$ adquiriram uma configuração mais estável no estado singleto.

Semelhante aos sistemas octaédricos, nos complexos quadrado-planar $\mathbf{1 a}_{\mathbf{q}}$ os orbitais HOMO e LUMO são bem delocalizados, ou seja, estão totalmente distribuído sobre todo o complexo. O HOMO $1 \mathbf{a}_{\mathbf{q}}$ tem uma significativa contribuição do metal ( $\cong 38 \%$ do orbital $\mathrm{t}_{2 \mathrm{~g}}$ ) e o restante desse orbital é composto pelo ligante [20]aneN4O4. Já o HOMO do complexo $\mathbf{1 b}_{\mathbf{q}}$ é predominantemente localizado em uma determinada região do macrociclo [20]aneO4N4 (Figura 30). Entretanto, os LUMOs de ambos os complexos apresentaram a mesma composição e formato, ou seja, nesses orbitais pode ser observado uma significativa 
contribuição do metal, bem como dos ligantes. Porém, a maior simetria observada para o orbital mais alto ocupado do complexo $\mathbf{1} \mathbf{a}_{\mathbf{q}}$, torna-o mais estável que no complexo $\mathbf{1 b}_{\mathbf{q}}$.

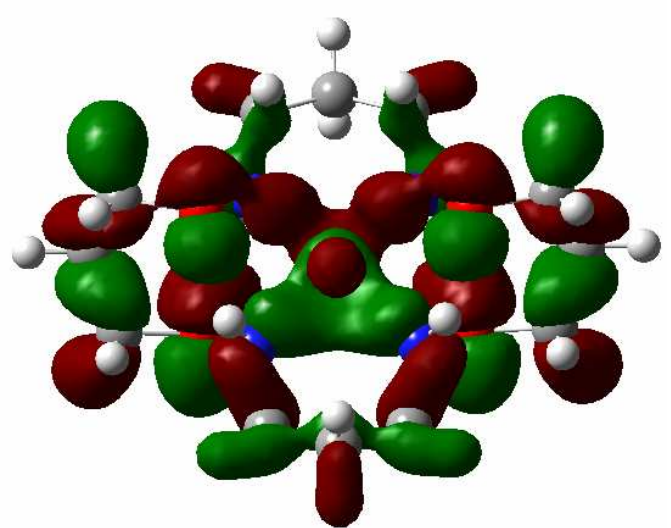

HOMO 1 $\mathbf{a}_{\mathbf{q}}$

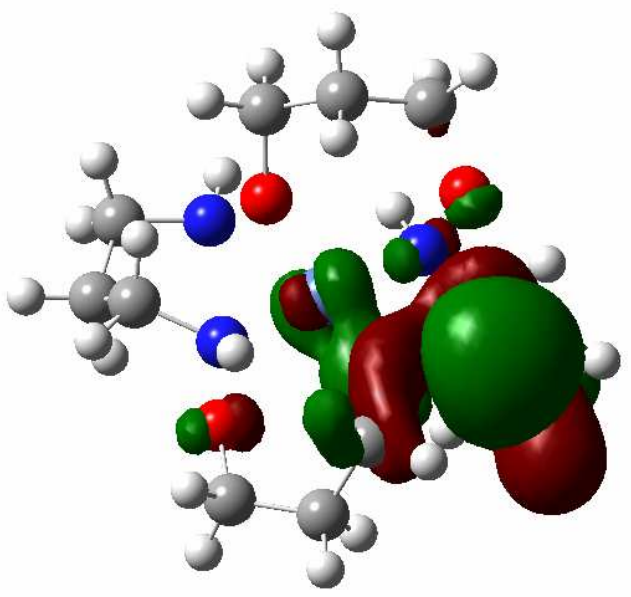

HOMO $\mathbf{1} \mathbf{b}_{\mathbf{q}}$

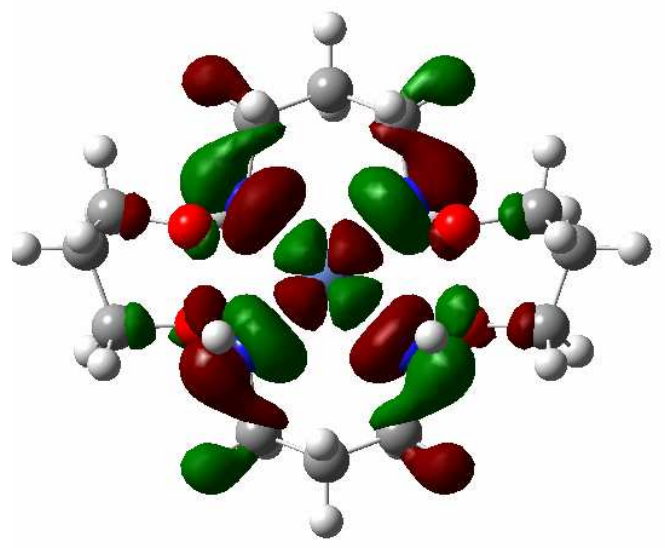

LUMO 1 $1 \mathbf{a}_{\mathbf{q}}$

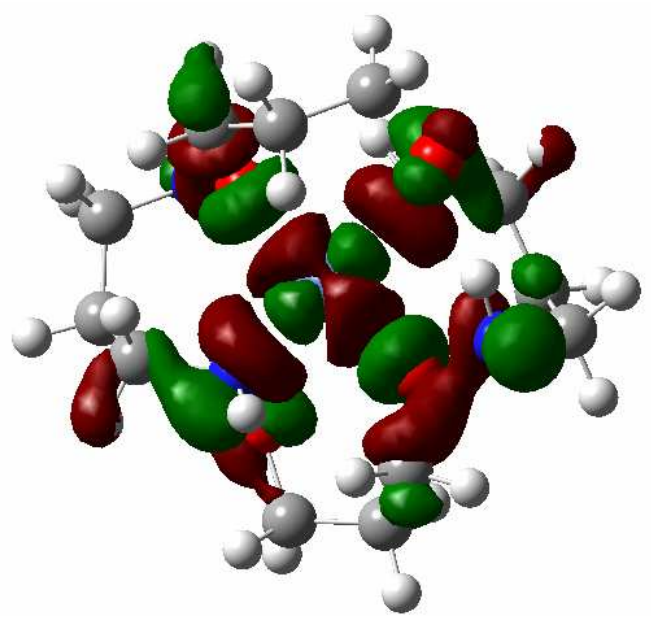

LUMO $\mathbf{1} \mathbf{b}_{\mathbf{q}}$

Figure 30. Orbitais moleculares de fronteira calculados para os complexos $\mathbf{1 a}_{\mathbf{q}}$ e $\mathbf{1 b}_{\mathbf{q}}$, de camada fechada, em nível de teoria DFT/B3LYP. Na figura as cores para os átomos de carbono (cinza), nitrogênio (azul), oxigênio (vermelho) e hidrogênio (branco). 
Os orbitais moleculares dos sistemas de camada aberta são mostrados na Figura 31. Para esses sistemas, podemos observar que os complexos $\mathbf{1} \mathbf{a}_{\mathbf{q}}$ possuem orbitais HOMO, alfa e beta, mais delocalizado, isto é, sobre o metal e parte do ligante. Já os HOMOs dos complexos $\mathbf{1 b}_{\mathbf{q}}$ são predominantemente localizados sobre o ligante com uma pequena contribuição do metal de aproximadamente $10 \%$. Ao analisamos os orbitais $\beta$-LUMO do complexo $1 \mathbf{1}_{\mathbf{q}}$, podemos observar uma forte composição metálica (cerca de $80 \%$ ).

A maior simetria observada para o orbital mais alto ocupado do complexo $\mathbf{1 a}_{\mathbf{q}}$, de camada aberta ou fechada, torna este sistema mais estável que o complexo $\mathbf{1} \mathbf{b}_{\mathbf{q}}$. 


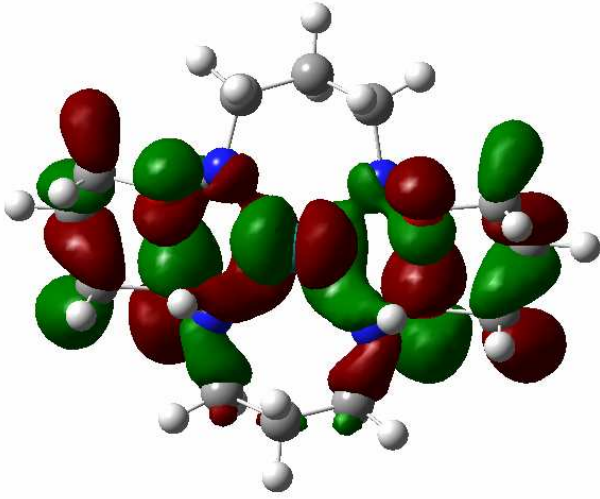

$\alpha$-HOMO 1a

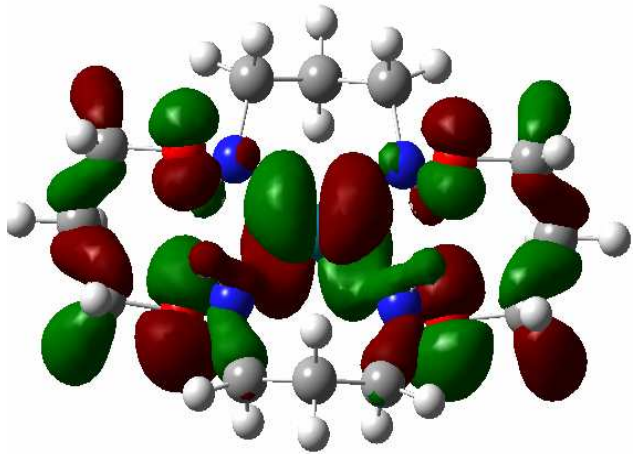

$\beta$-HOMO 1a $\mathbf{a}_{\mathbf{q}}$

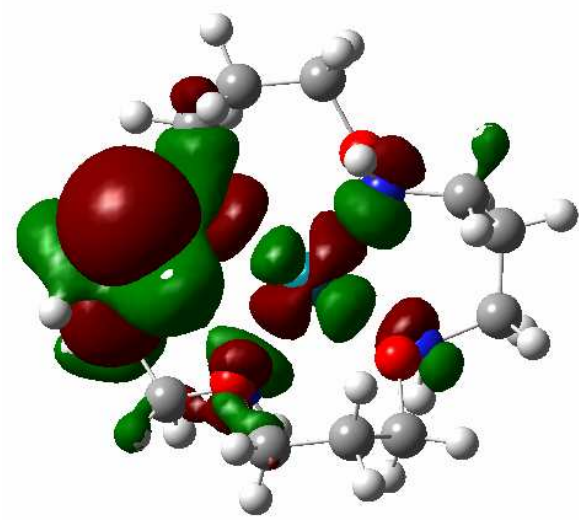

$\alpha-\mathrm{HOMO} \mathbf{1} \mathbf{b}_{\mathbf{q}}$

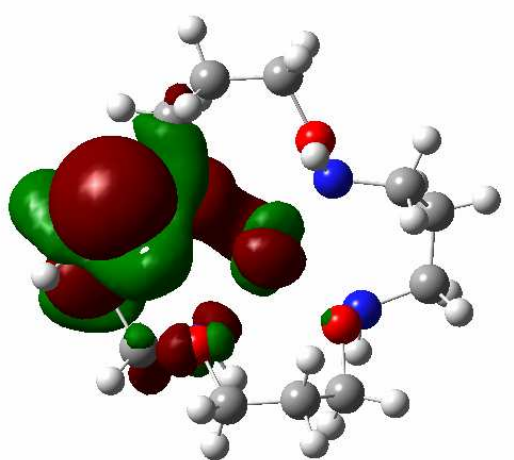

$\beta$-HOMO $1 \mathbf{b}_{\mathbf{q}}$

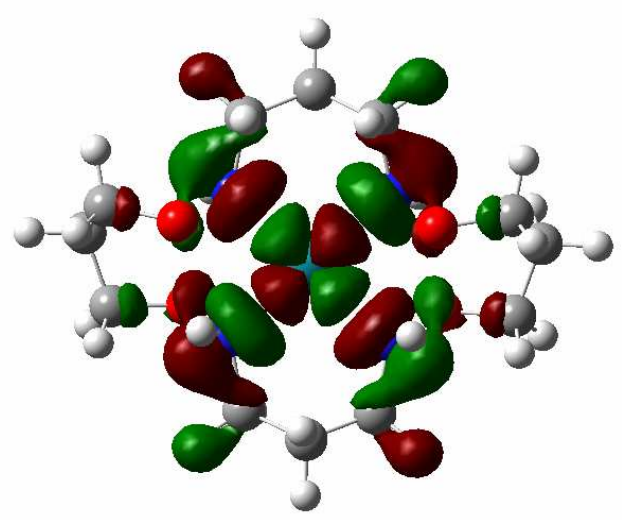

$\alpha$-LUMO 1a
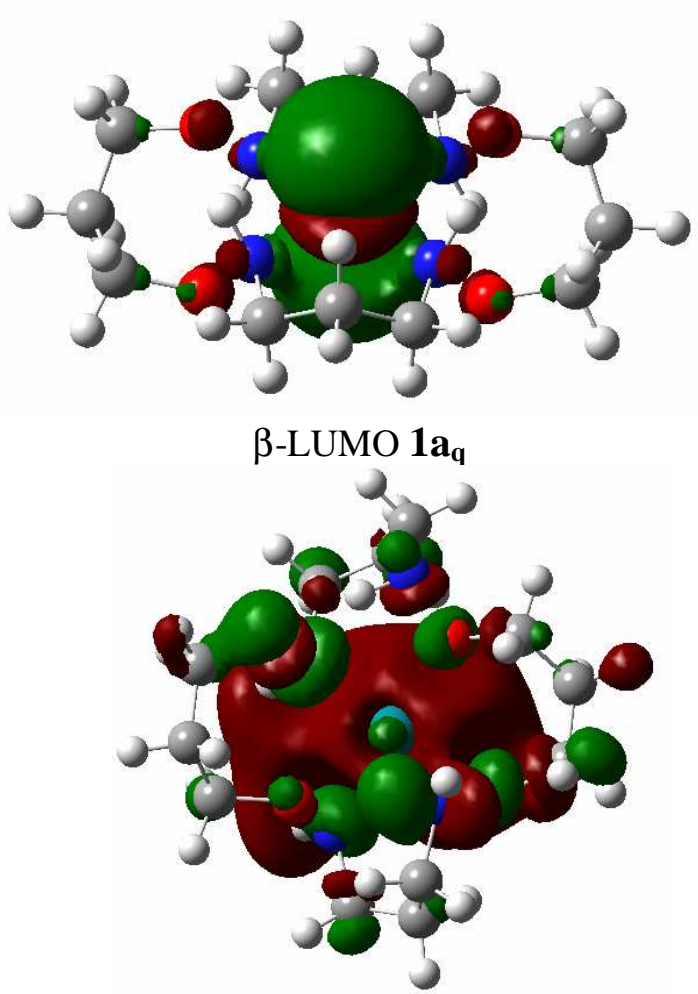

$\alpha$-LUMO $1 \mathbf{b}_{\mathbf{q}}$

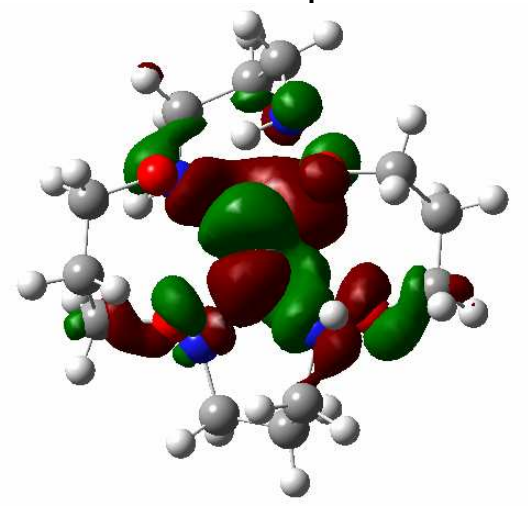

$\beta$-LUMO $1 \mathbf{b}_{\mathbf{q}}$

Figure 31. Orbitais moleculares de fronteira calculados para os complexos $\mathbf{1 a}_{\mathbf{q}}$ e $\mathbf{1 b}_{\mathbf{q}}$, de camada aberta, em nível de teoria DFT/B3LYP. 


\section{III-3. Complexos [20]aneL4(Oct) (Octaédricos) e [20]aneL4(qp)}

\section{(Quadrado-Planar)}

Nesta seção serão discutidos os resultados obtidos dos parâmetros geométricos, energia de interação ( $\left.E_{\mathrm{INT}}\right)$ e energia de perturbação de segunda ordem $(E(2))[79,80]$ para os complexos octaédrico e quadrado-planar. Esses complexos são obtidos substituindo os átomos de nitrogênio ou oxigênio, da posição alfa do macrociclos, por grupos $-\mathrm{CH}_{2}$. A partir dessa substituição, foram obtidos outros macrociclos [20]aneN4 e [20]aneO4, denominados de poliaminas e poliéteres, respectivamente. Essa substituição foi única e exclusivamente para verificar o efeito da posição alfa nos macrociclos na complexação de íons metálicos.

É importante frisar, que apenas os estados mais estáveis derivados dos complexos 1a e 1b de geometrias octaédrico e quadrado-planar foram considerados. Por exemplo, o complexo de $\mathrm{Fe}^{2+}$ obtido na complexação do íon metálico $\mathrm{Fe}^{2+}$ pelo macrociclo [20]aneN4O4 ou [20]aneO4N4, sistema octaédrico, apresentou como estado espectroscópico mais estável um quinteto. Sendo assim, apenas o estado quinteto foi considerado nos cálculos envolvendo esse íon metálico com os macrociclos [20]aneN4 e [20]aneO4.

Para diferenciar os complexos octaédrico e quadrado-planar com a substituição dos átomos da posição alfa por grupo $-\mathrm{CH} 2$ será adotada a seguinte nomenclatura: (a) [20]aneL4(Oct) para os complexos octaédricos e (b) [20]aneL4(qp) para os complexos quadrado-planar. A letra L representa os átomos de nitrogênio ou oxigênio na cavidade de complexação dos macrociclos. 


\section{a) Parâmetros Geométricos}

As estruturas otimizadas para os complexos octaédrico e quadrado-planar, obtidas na complexação dos íons metálicos da primeira e segunda fila dos metais de transição pelos macrociclos [20]aneN4 e [20]aneO4, são mostradas na Figura 32.

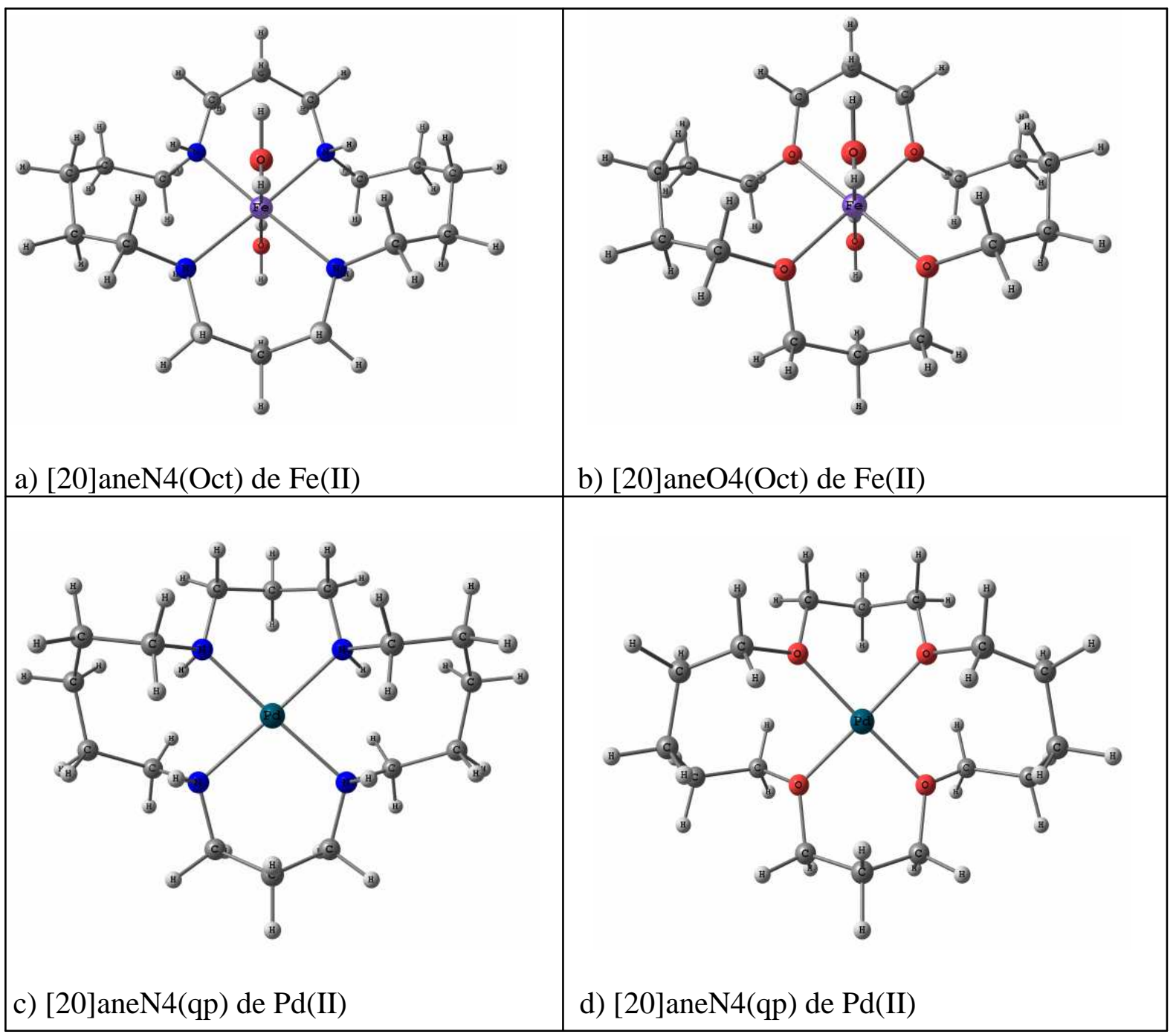

Figura 32. Estruturas otimizadas para os complexos octaédrico e quadrado-planar com ferro e paládio. 
De um modo geral, os complexos derivados dos macrociclos [20]aneN4 ou [20]aneO4 demonstraram ter maior simetria que os complexos derivados do macrociclo [20]aneO4N4. Os parâmetros geométricos obtidos para os complexos octaédricos são mostrados nas Tabelas 20 e 21 e para o arranjo quadrado-planar nas Tabelas 22 e 23.

Tabela 20. Parâmetros geométricos calculados em nível de teoria DFT/B3LYP com o conjunto de base Lanl2DZ para o complexo [20]aneN4(Oct)

\begin{tabular}{ccccccc} 
& $\mathrm{Fe}^{2+}$ & $\mathrm{Co}^{2+}$ & $\mathrm{Ni}^{2+}$ & $\mathrm{Ru}^{2+}$ & $\mathrm{Rh}^{2+}$ & $\mathrm{Pd}^{2+}$ \\
\hline $\mathrm{N} 1-\mathrm{M}^{2+}$ & $2,261(\AA)$ & $2,228(\AA)$ & $2,238(\AA)$ & $2,257(\AA)$ & $2,222(\AA)$ & $2,128(\AA)$ \\
$\mathrm{N} 2-\mathrm{M}^{2+}$ & $2,300(\AA)$ & $2,275(\AA)$ & $2,190(\AA)$ & $2,219(\AA)$ & $2,171(\AA)$ & $2,148(\AA)$ \\
$\mathrm{M}^{2+}-\mathrm{O}_{2 \mathrm{~W}}$ & $2,239(\AA)$ & $2,204(\AA)$ & $2,171(\AA)$ & $2,194(\AA)$ & $2,783(\AA)$ & $3,833(\AA)$ \\
$\mathrm{M}^{2+}-\mathrm{O}_{1 \mathrm{~W}}$ & $2,242(\AA)$ & $2,205(\AA)$ & $2,177(\AA)$ & $2,193(\AA)$ & $2,601(\AA)$ & $4,133(\AA)$ \\
$\mathrm{N} 1-\mathrm{M}^{2+}-\mathrm{N} 2$ & $85,5\left(^{\circ}\right)$ & $87,2\left(^{\circ}\right)$ & $86,0\left(^{\circ}\right)$ & $85,8\left(^{\circ}\right)$ & $85,5\left(^{\circ}\right)$ & $93,2\left(^{\circ}\right)$ \\
$\mathrm{N} 1-\mathrm{M}^{2+}-\mathrm{O}_{2 \mathrm{~W}}$ & $89,8\left(^{\circ}\right)$ & $91,5\left(^{\circ}\right)$ & $89,9\left(^{\circ}\right)$ & $89,6\left(^{\circ}\right)$ & $94,5\left(^{\circ}\right)$ & $127,0\left(^{\circ}\right)$ \\
$\mathrm{N} 2-\mathrm{M}^{2+}-\mathrm{O}_{1 \mathrm{~W}}$ & $91,1\left(^{\circ}\right)$ & $89,9\left(^{\circ}\right)$ & $91,5\left(^{\circ}\right)$ & $90,5\left(^{\circ}\right)$ & $91,4\left(^{\circ}\right)$ & $83,4\left(^{\circ}\right)$ \\
$\mathrm{O}_{1 \mathrm{w}}-\mathrm{M}^{2+}-\mathrm{O}_{2 \mathrm{~W}}$ & $177,9\left(^{\circ}\right)$ & $178,0\left(^{\circ}\right)$ & $177,2\left(^{\circ}\right)$ & $178,3\left(^{\circ}\right)$ & $171,5\left(^{\circ}\right)$ & $113,9\left(^{\circ}\right)$
\end{tabular}

Dois pontos importantes podem ser observados na tabela acima. Primeiro, a substituição dos átomos de oxigênio na posição alfa do macrociclo [20]aneN4O4 por grupos $\left(-\mathrm{CH}_{2}\right)$ faz com que a distância média metal-ligante tivessem uma aumento de aproximadamente 0,1 A. Por exemplo, para o complexo [20]aneN4(Oct) de $\mathrm{Fe}^{2+}$, a distância média N-M ${ }^{2+}$ é de 2,281 $\AA$; enquanto no complexo $\mathbf{1 a}$ de $\mathrm{Fe}^{2+}$ (octaédrico), à distância $\mathrm{M}^{2+}-\mathrm{N}$ foi estimada em 2,203 $\AA$ (ver Tabela 2, pág. 47). Tal fato deve-se a substituição de um elemento altamente eletronegativo, o oxigênio, pelo grupo $-\mathrm{CH}_{2}$. Desta forma, nos complexos poliaminas ([20]aneN4), as ligações metal-ligante tendem a ser maiores se comparadas com os complexos oxa-azo ([20]aneN4O4). O segundo ponto é que nos complexos formados pelos 


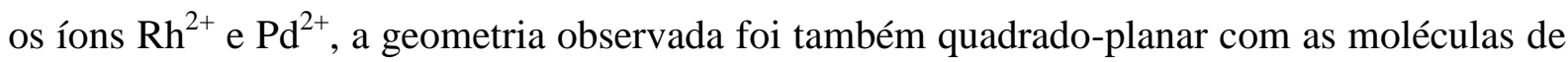
água bem afastadas do centro metálico acima de $3 \AA$ para o ion $\mathrm{Pd}^{2+}$, e em aproximadamente $3 \AA$, para o ion $\mathrm{Rh}^{2+}$. Aqui também podemos observar a importância dos átomos de oxigênio colocados na posição alfa do macrociclo. Esses átomos conduzem a uma estrutura quadradoplanar muito mais simétrica se comparada com o arranjo quadrado-planar obtido pelo macrociclo [20]aneN4 (ver figura do Apêndice D).

O macrociclo poliéteres ([20]aneO4) resultam em complexos octaédricos pouco distorcidos para os íons $\mathrm{Fe}^{2+}, \mathrm{Co}^{2+}, \mathrm{Ni}^{2+}$ e $\mathrm{Ru}^{2+}$, quando comparado com o macrociclo [20]aneO4N4. Os ângulos formados pelos átomos $\mathrm{O} 1-\mathrm{M}^{2+}-\mathrm{O} 2$ nos complexos desses íons são de aproximadamente $90^{\circ}$. O ângulo $\mathrm{O}_{1 \mathrm{~W}}-\mathrm{M}^{2+}-\mathrm{O}_{2 \mathrm{~W}}$ varia de 178 a $179^{\circ}$. A geometria observada para os íons $\mathrm{Rh}^{2+}$ e $\mathrm{Pd}^{2+}$ foi um quadrado-planar distorcido. Porém, nestes complexos, o ângulo médio $\mathrm{O} 1-\mathrm{M}^{2+}-\mathrm{O} 2$ variou de 56 e $93^{\circ}$, para os complexos de $\mathrm{Rh}^{2+}$ e $\mathrm{Pd}^{2+}$, respectivamente. Esses resultados são mostrados na Tabela 21.

Tabela 21. Parâmetros geométricos calculados em nível de teoria DFT/B3LYP com o conjunto de base Lan12DZ para o complexo [20]aneO4(Oct)

\begin{tabular}{ccccccc} 
& $\mathrm{Fe}^{2+}$ & $\mathrm{Co}^{2+}$ & $\mathrm{Ni}^{2+}$ & $\mathrm{Ru}^{2+}$ & $\mathrm{Rh}^{2+}$ & $\mathrm{Pd}^{2+}$ \\
\hline $\mathrm{O} 1-\mathrm{M}^{2+}$ & $2,137(\AA)$ & $2,137(\AA)$ & $2,101(\AA)$ & $2,172(\AA)$ & $2,120(\AA)$ & $2,056(\AA)$ \\
$\mathrm{O} 2-\mathrm{M}^{2+}$ & $2,156(\AA)$ & $2,123(\AA)$ & $2,090(\AA)$ & $2,158(\AA)$ & $2,109(\AA)$ & $2,058(\AA)$ \\
$\mathrm{M}^{2+}-\mathrm{O}_{2 \mathrm{~W}}$ & $2,224(\AA)$ & $2,135(\AA)$ & $2,107(\AA)$ & $2,170(\AA)$ & $2,545(\AA)$ & $3,560(\AA)$ \\
$\mathrm{M}^{2+}-\mathrm{O}_{1 \mathrm{~W}}$ & $2,179(\AA)$ & $2,153(\AA)$ & $2,121(\AA)$ & $2,170(\AA)$ & $2,678(\AA)$ & $3,926(\AA)$ \\
$\mathrm{O} 1-\mathrm{M}^{2+}-\mathrm{O} 2$ & $93,7\left(^{\circ}\right)$ & $93,2\left(^{\circ}\right)$ & $91,6\left(^{\circ}\right)$ & $90,2\left(^{\circ}\right)$ & $90,0\left(^{\circ}\right)$ & $89,0\left(^{\circ}\right)$ \\
$\mathrm{O} 1-\mathrm{M}^{2+}-\mathrm{O}_{2 \mathrm{~W}}$ & $81,2\left(^{\circ}\right)$ & $86,4\left(^{\circ}\right)$ & $86,2\left(^{\circ}\right)$ & $86,6\left(^{\circ}\right)$ & $86,3\left(^{\circ}\right)$ & $81,9\left(^{\circ}\right)$ \\
$\mathrm{O} 2-\mathrm{M}^{2+}-\mathrm{O}_{1 \mathrm{~W}}$ & $84,6\left(^{\circ}\right)$ & $84,3\left(^{\circ}\right)$ & $84,6\left(^{\circ}\right)$ & $84,8\left(^{\circ}\right)$ & $80,8\left(^{\circ}\right)$ & $88,7\left(^{\circ}\right)$ \\
$\mathrm{O}_{1 \mathrm{~W}}-\mathrm{M}^{2+}-\mathrm{O}_{2 \mathrm{~W}}$ & $177,7\left(^{\circ}\right)$ & $178,5\left(^{\circ}\right)$ & $178,8\left(^{\circ}\right)$ & $178,9\left(^{\circ}\right)$ & $175,1\left(^{\circ}\right)$ & $166,9\left(^{\circ}\right)$ \\
\hline
\end{tabular}


As Tabelas 22 e 23 mostram os parâmentos geométricos obtidos para os sistemas quadrado-planar obtidos pelos macrociclo poliamina [20]aneN4 e poliéteres [20]aneO4 complexando os íons $\mathrm{Fe}^{2+}, \mathrm{Co}^{2+}, \mathrm{Ni}^{2+}, \mathrm{Ru}^{2+}, \mathrm{Rh}^{2+} \mathrm{e} \mathrm{Pd}^{2+}$.

Para os complexos [20]aneN4, observa-se uma estrutura quadrado-palnar pouco distorcida, tendo em média a distância $\mathrm{M}^{2+}-\mathrm{N}$ em torno de 2,2 $\AA$ e com o ângulo N1- $\mathrm{M}^{2+}$-N2 variando entre 85 e $87^{\circ}$ (Tabela 22). Praticamente, a mesma variação é observada no complexo [20]aneN4O4 (ver Tabela 2, pág. 47).

Tabela 22. Parâmetros geométricos calculados em nível de teoria DFT/B3LYP com o conjunto de base Lanl2DZ para o complexo [20]aneN4(qp)

\begin{tabular}{ccccccc} 
& $\mathrm{Fe}^{2+}$ & $\mathrm{Co}^{2+}$ & $\mathrm{Ni}^{2+}$ & $\mathrm{Ru}^{2+}$ & $\mathrm{Rh}^{2+}$ & $\mathrm{Pd}^{2+}$ \\
\hline $\mathrm{N} 1-\mathrm{M}^{2+}$ & $2,168(\AA)$ & $2,130(\AA)$ & $2,106(\AA)$ & $2,039(\AA)$ & $2,147(\AA)$ & $2,129(\AA)$ \\
$\mathrm{N} 2-\mathrm{M}^{2+}$ & $2,245(\AA)$ & $2,225(\AA)$ & $2,200(\AA)$ & $2,137(\AA)$ & $2,216(\AA)$ & $2.194(\AA)$ \\
$\mathrm{N} 1-\mathrm{M}^{2+}-\mathrm{N} 2$ & $86,4\left(^{\circ}\right)$ & $86,5\left(^{\circ}\right)$ & $85,4\left(^{\circ}\right)$ & $85,2\left(^{\circ}\right)$ & $85,2\left(^{\circ}\right)$ & $84,8\left(^{\circ}\right)$ \\
$\mathrm{N} 2-\mathrm{M}^{2+}-\mathrm{N} 3$ & $174,3\left(^{\circ}\right)$ & $175,0\left(^{\circ}\right)$ & $174,8\left(^{\circ}\right)$ & $175,5\left(^{\circ}\right)$ & $177,8\left(^{\circ}\right)$ & $177,4\left(^{\circ}\right)$
\end{tabular}

Tabela 23. Parâmetros geométricos calculados em nível de teoria DFT/B3LYP com o conjunto de base Lanl2DZ para o complexo [20]aneO4(qp)

\begin{tabular}{ccccccc} 
& $\mathrm{Fe}^{2+}$ & $\mathrm{Co}^{2+}$ & $\mathrm{Ni}^{2+}$ & $\mathrm{Ru}^{2+}$ & $\mathrm{Rh}^{2+}$ & $\mathrm{Pd}^{2+}$ \\
\hline $\mathrm{O} 1-\mathrm{M}^{2+}$ & $2,050(\AA)$ & $2,021(\AA)$ & $1,999(\AA)$ & $2,063(\AA)$ & $2,080(\AA)$ & $2,061(\AA)$ \\
$\mathrm{O} 2-\mathrm{M}^{2+}$ & $2,037(\AA)$ & $2,005(\AA)$ & $1,983(\AA)$ & $2,054(\AA)$ & $2,070(\AA)$ & $2,050(\AA)$ \\
$\mathrm{O} 1-\mathrm{M}^{2+}-\mathrm{O} 2$ & $90,3\left(^{\circ}\right)$ & $90,5\left(^{\circ}\right)$ & $91,0\left(^{\circ}\right)$ & $90,1\left(^{\circ}\right)$ & $90,2\left(^{\circ}\right)$ & $89,8\left(^{\circ}\right)$ \\
$\mathrm{O} 2-\mathrm{M}^{2+}-\mathrm{O} 3$ & $176,4\left(^{\circ}\right)$ & $177,6\left(^{\circ}\right)$ & $178,0\left(^{\circ}\right)$ & $178,7\left(^{\circ}\right)$ & $178,4\left(^{\circ}\right)$ & $178,3\left(^{\circ}\right)$ \\
\hline
\end{tabular}


Os resultados obtidos para os complexos [20]aneO4 mostraram que o arranjo quadrado-planar é bem mais regular quando comparado com os complexos [20]aneO4N4. Observe na Tabela 23 que os ângulos $\mathrm{O} 1-\mathrm{M}^{2+}-\mathrm{O} 2$ são de aproximadamente $90^{\circ}$, enquanto que nos complexos [20]aneO4N4 esses mesmos ângulos variam de 80 a $90^{\circ}$ (ver Tabela 3, pág. 48). A observação visual pode ser feita olhando a figura do Apêndice E.

\section{b) Energias Eletrônicas e Energia de Interação $\left(E_{I N T}\right)$ dos Complexos}

As estruturas dos macrociclos poliaminas [20]aneN4 e poliéteres [20]aneO4 de conformação mais estáveis e otimizadas em nível de teoria DFT são mostradas na Figura 33, apenas alguns parâmetros geométricos de distância desses macrociclos são listados.

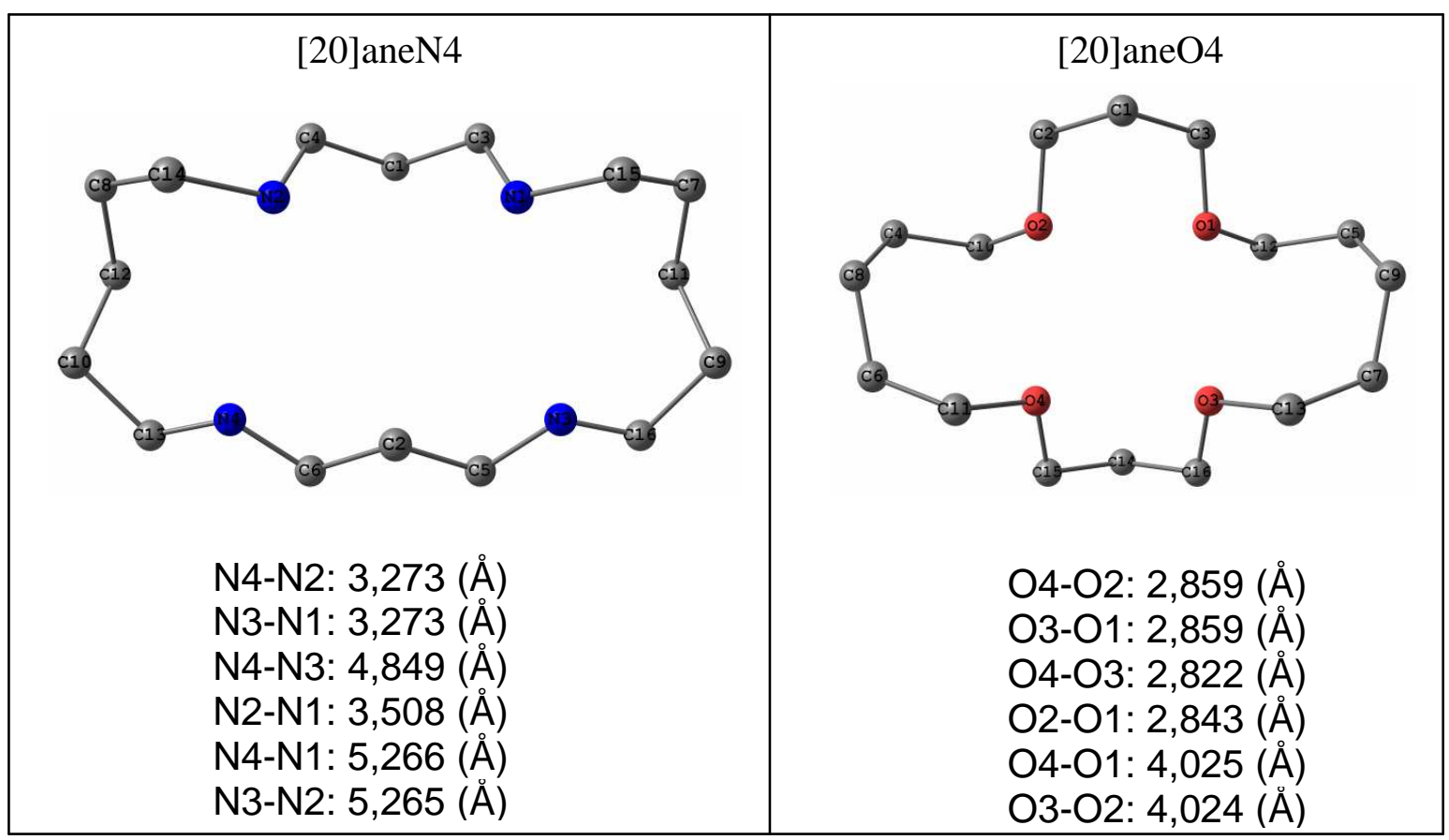

Figura 33. Estruturas otimizadas e parâmetros geométricos dos ligantes macrociclos livres [20]aneN4 e [20]aneO4 calculadas com o modelo teórico B3LYP/Lanl2DZ. Os átomos de hidrogênio foram removidos para melhor visualizar as estruturas. 
A análise da dimensão do macrociclo é um bom indicativo da sua capacidade em complexar íons metálicos. Como pode ser observado, o macrociclo [20]aneO4 mostrou-se bem mais simétrico e com menor cavidade de complexação que o macrociclo [20]aneN4. As distâncias dos átomos cruzados no macrociclo [20]aneO4, por exemplo O4-O1, foi estimada em 4,025 ̊̊; enquanto que para o macrociclo [20]aneN4, a distância N4-N1 foi calculada em 5,266 Å. Desta forma, é de se esperar que o macrociclo de menor cavidade possa complexar íons metálicos menores, e que o macrociclo de maior cavidade complexe íons maiores. Segundo Pedersen [81], prêmio Nobel de química em 1987, a razão entre o tamanho do íon metálico e a cavidade do macrociclo dá um bom indicativo sobre qual íon metálico do macrociclo se complexará melhor. Os resultados da energia de interação, que será discutido mais adiante, mostra tal evidência.

As energias eletrônicas calculadas para os macrociclos [20]aneN4 e [20]aneO4 são mostrados na Tabela 24.

Tabela 24. Energia eletrônica total calculada em nível de teoria DFT/B3LYP para os macrociclos [20]aneN4 e [20]aneO4

\begin{tabular}{lc}
\cline { 2 - 2 } & Energia (Hartree) \\
\hline [20]aneN4 & $-849,680202$ \\
[20]aneO4 & $-929,19560$ \\
\hline
\end{tabular}

Em virtude dos dois sistemas não serem isômeros, não foi feita uma comparação entre suas energias eletrônicas. As energias eletrônicas com correção ZPVE (zero point vibration energy) para os complexos octaédricos e quadrado-planares de estado de spin mais estável são mostradas nas Tabelas 25 e 26. 
Tabela 25. Energia absoluta calculadas com B3LYP/Lanl2DZ para os complexos [20]aneN4(Oct) e [20]aneO4(Oct) de arranjo octaédrico

\begin{tabular}{cccc}
\cline { 3 - 3 } & & Energia abs.(u.a.) & Energia abs. (u.a.) \\
\hline Cátion M & Multiplicidade & [20]aneN4(Oct) & [20]aneO4(Oct) \\
\hline $\mathrm{Fe}^{2+}$ & Quinteto & $-1125,552787$ & $-1205,08453$ \\
$\mathrm{Co}^{2+}$ & Quadupleto & $-1147,182523$ & $-1226,708053$ \\
$\mathrm{Ni}^{2+}$ & Tripleto & $-1171,408082$ & $-1250,926807$ \\
$\mathrm{Ru}^{2+}$ & Singleto & $-1095,961693$ & $-1175,448645$ \\
$\mathrm{Rh}^{2+}$ & Dubleto & $-1111,587378$ & $-1191,065239$ \\
$\mathrm{Pd}^{2+}$ & Singleto & $-1128,825021$ & $-1208,277565$ \\
\hline
\end{tabular}

Tabela 26. Energia absoluta calculadas com B3LYP/Lanl2DZ para os complexos [20]aneN4(qp) e [20]aneO4(qp) de arranjo quadrado-planar

\begin{tabular}{cccc} 
& & Energia abs.(u.a.) & Energia abs. (u.a.) \\
\hline Cátion $\mathrm{M}^{2+}$ & Multiplicidade & [20]aneN4(qp) & [20]aneO4(qp) \\
\hline $\mathrm{Fe}^{2+}$ & Quinteto & $-972,695668$ & $-1052,230009$ \\
$\mathrm{Co}^{2+}$ & Quadupleto & $-994,325803$ & $-1073,860409$ \\
$\mathrm{Ni}^{2+}$ & Tripleto & $-1018,534703$ & $-1098,063926$ \\
$\mathrm{Ru}^{2+}$ & Singleto & $-943,044332$ & $-1022,571338$ \\
$\mathrm{Rh}^{2+}$ & Dubleto & $-958,737159$ & $-1038,233379$ \\
$\mathrm{Pd}^{2+}$ & Singleto & $-975,989587$ & $-1055,457163$ \\
\hline
\end{tabular}

As energias eletrônicas, tanto dos macrociclos quanto dos complexos octaédrico e quadrado-planar, não serão discutidas nesta seção. A comparação entre as energias dos complexos, seja octaédrico ou quadrado-planar, é "impossível” por não se tratar de sistemas isoméricos. No entanto, podemos observar que quanto maior for o íon metálico, maior será a energia eletrônica do complexo.

As energias de interação ( $\left.\mathrm{E}_{\mathrm{INT}}\right)$ para os complexos [20]aneL4(Oct) e [20]aneL4(qp) são mostradas nas Tabela 27 e 28. Essas energias foram obtidas de acordo com a Equação 1. 
Tabela 27. Energia de interação ( $\left.\mathrm{E}_{\mathrm{INT}}\right)$ calculada para os complexos [20]aneN4(Oct) e [20]aneO4(Oct) em nível de teoria DFT/B3LYP

\begin{tabular}{ccc}
\hline Cátion $\mathrm{M}^{2+}$ & $\begin{array}{c}\text { Energia de interação (Kcal/mol) } \\
{[20] \text { aneN4(Oct) }}\end{array}$ & $\begin{array}{c}\text { Energia de interação (Kcal/mol) } \\
{[20] \text { aneO4(Oct) }}\end{array}$ \\
\hline $\mathrm{Fe}^{2+}$ & $-379,3$ & $-389,6$ \\
$\mathrm{Co}^{2+}$ & $-402,0$ & $-408,3$ \\
$\mathrm{Ni}^{2+}$ & $-415,6$ & $-417,6$ \\
$\mathrm{Ru}^{2+}$ & $-384,6$ & $-366,7$ \\
$\mathrm{Rh}^{2+}$ & $-450,3$ & $-426,8$ \\
$\mathrm{Pd}^{2+}$ & $-490,7$ & $-451,2$ \\
\hline
\end{tabular}

Tabela 28. Energia de interação $\left(\mathrm{E}_{\mathrm{INT}}\right)$ calculada para os complexos [20]aneN4(qp) e [20]aneO4(qp) em nível de teoria DFT/B3LYP

\begin{tabular}{ccc}
\hline Cátion $\mathrm{M}^{2+}$ & $\begin{array}{c}\text { Energia de interação (Kcal/mol) } \\
{[20] \text { aneN4(qp) }}\end{array}$ & $\begin{array}{c}\text { Energia de interação (Kcal/mol) } \\
{[20] \text { aneO4(qp) }}\end{array}$ \\
\hline $\mathrm{Fe}^{2+}$ & $-335,4$ & $-347,3$ \\
$\mathrm{Co}^{2+}$ & $-358,3$ & $-370,3$ \\
$\mathrm{Ni}^{2+}$ & $-361,4$ & $-370,1$ \\
$\mathrm{Ru}^{2+}$ & $-310,9$ & $-310,1$ \\
$\mathrm{Rh}^{2+}$ & $-410,7$ & $-398,7$ \\
$\mathrm{Pd}^{2+}$ & $-460,4$ & $-430,3$ \\
\hline
\end{tabular}

Os complexos octaédrico e quadrado-planar formados pelos metais de transição da primeira fila foram melhor complexados pelos macrociclos tendo como complexante os átomos de oxigênio ([20]aneO4). Essa maior estabilidade diz respeito a menor cavidade de complexação desse macrociclo. Sendo assim, os íons metálicos da primeira fila, por serem menores que os íons metálicos da segunda fila, resultaram em complexos mais estáveis. Por exemplo, a energia de interação estimada para os complexos [20]aneO4(Oct) com os íons 
$\mathrm{Fe}^{2+}, \mathrm{Co}^{2+} \mathrm{e} \mathrm{Ni}^{2+}$ foi de $-389,6,-408,3$ e $-417,6 \mathrm{Kcal}^{-\mathrm{mol}^{-1}}$, respectivamente. Nos complexos [20]aneN4(Oct) a energia de interação foi sempre menor. A diferença entre a energia de interação diminuindo, à medida que o raio do íon fica menor, ou seja, se comparamos a diferença de energia de interação entre os complexos [20]aneN4(Oct) e [20]aneO4(Oct) de $\mathrm{Fe}^{2+}$ e os complexos de $\mathrm{Ni}^{2+}$, pode-se perceber que a diferença de energia para este último é de apenas $2 \mathrm{Kcal}_{\mathrm{mol}}{ }^{-1}$, enquanto que no complexo de $\mathrm{Fe}^{2+}$, essa diferença é de aproximadamente $10 \mathrm{Kcal}^{\mathrm{mol}}{ }^{-1}$ (ver Tabela 27). Entretanto, para os complexos [20]aneO4(qp), a diferença de energia é de quase $10 \mathrm{Kcal}_{\mathrm{mol}}{ }^{-1} \mathrm{em}$ todos os casos dos íons da primeira fila.

O contrário pode ser observado para os íons da segunda fila. Aqui, o macrociclo [20]aneN4 resultou em complexos mais estáveis, tanto octaédrico ([20]aneN4(Oct)) quanto quadrado-planar ([20]aneN4(qp)). Nos complexos octaédricos, a diferença de energia de interação entre os complexos [20]aneN4(Oct) e [20]aneO4(Oct), em todos os íons estudados, foi superior a $20 \mathrm{Kcal}_{\mathrm{mol}}{ }^{-1}$; enquanto que nos complexos quadrado-planar essa diferença aumentou com o aumento do número atômico. Isto é, comparando os complexos [20]aneL4(qp) de $\mathrm{Ru}^{2+}$, pode-se perceber que essa diferença é menor que $1 \mathrm{Kcal.mol}{ }^{-1}$. Porém, para o complexo de níquel, a diferença de estabilidade é de $30 \mathrm{Kcal}_{\mathrm{mol}}{ }^{-1}$.

A preferência do macrociclo [20]aneO4 em complexar metais de transição da primeira fila e o macrociclo [20]aneN4 em complexar metais da segunda fila, pode ser explicada pelo conceito de dureza e moleza de Pearson [82,83]. Segundo este conceito, ácido duro prefere ligar-se à uma base dura e um ácido mole prefere ligar-se com uma base mole. Para melhor entendimento, base e ácido duro tendem a ser menor e ligeiramente polarizável, enquanto ácido e base mole tendem a ser maior e mais polarizável. Desta forma, comparando os ligantes oxigênio no macrociclo [20]aneO4 e os íons metálicos da primeira fila com os ligantes nitrogênio do macrociclo [20]aneN4 e os íons metálicos da segunda fila, os primeiros 
tendem a ser base e ácido duro, enquanto que os segundos tendem a ser base e ácido mole, ou seja, os átomos de oxigênio complexam melhor os íons $\mathrm{Fe}^{2+}, \mathrm{Co}^{2+} \mathrm{e} \mathrm{Ni}^{2+}$, enquanto os átomos de nitrogênio complexam mais fortemente os íons $\mathrm{Ru}^{2+}, \mathrm{Rh}^{2+}$ e $\mathrm{Pd}^{2+}$. Os íons metálicos da primeira e segunda filas são membros da classe dos ácidos e os ligantes nitrogênio e oxigênio são da classe básica. Sigel et al. [84] realizou estudos de complexação de íons metálicos bivalentes por ligante bidentado de N, O e S. Seus resultados mostraram que os íons $\mathrm{Ba}^{2+}$, $\mathrm{Sr}^{2+}, \mathrm{Ca}^{2+}, \mathrm{Mg}^{2+}$ e $\mathrm{Mn}^{2+}$ eram mais fortemente complexados pelos átomos de oxigênio no ácido oxálico, enquanto os íons $\mathrm{Co}^{2+}, \mathrm{Ni}^{2+}, \mathrm{Cu}^{2+}$ e $\mathrm{Zn}^{2+}$ preferiam ligar-se aos átomos de nitrogênio no ligante 1,2-etanodiamina [84]. Porém, nesses resultados, os ligantes são diferentes no que diz respeito às estruturas, enquanto que, no presente trabalho, as estruturas dos ligantes mudam apenas em relação aos átomos doadores oxigênio e nitrogênio. Sendo assim, o conceito de Pearson foi extremamente relevante para a compreensão das diferentes estabilidades observadas nos complexos [20]aneN4 e [20]aneO4 de arranjo octaédrico e quadrado-planar com os diferentes íons estudados.

\section{b) Energia de Perturbação de Segunda Ordem}

A energia de perturbação de segunda ordem $E(2)$ [79, 80], foi utilizada para avaliar a natureza das interações doador-receptor nos complexos [20]aneL4 de arranjos octaédrico e quadrado-planar. Essa energia está associada com a delocalização ocorrida na estabilização de dois elétrons entre os orbitais ocupados do ligante (doador, $i$ ) e os orbitais virtuais do metal (aceptor, $j$ ), em outras palavras, E(2) é um nodo alternativo de se calcular a doação de carga (ligante-metal) e a retrodoação de carga (metal-ligante). Sendo assim, nesses complexos, a análise com o método CDA [56, 57] não foi utilizada. 
A energia de perturbação de segunda ordem, $(\mathrm{E}(2))$, pode ser estimada segundo a Equação 2.

$$
\mathrm{E}(2)=\Delta \mathrm{E} i j=\mathrm{q}_{i} /\left[\mathrm{F}(i, j)^{2}\left(\mathrm{e}_{j}-\mathrm{e}_{i}\right)\right]
$$

onde $\mathrm{q}_{i}$ é o orbital ocupado do doador, $\mathrm{e}_{j}$ e $\mathrm{e}_{i}$ são os elementos da diagonal (energias dos orbitais) e F(i,j) é o elemento da matrix de Fock NBO não diagonal $[79,80]$.

Os resultados obtidos para as energias E(2) e cargas NBO sobre o metal e os ligantes são mostrados nas Tabelas 29 e 30 para os complexos octaédrico e quadrado-planar, respectivamente. 
Tabela 29. Energia de perturbação de seguanda ordem E(2), em Kcal.mol ${ }^{-1}$, e carga NBO sobre o íon metálico e os ligantes calculados para os complexos [20]aneO4(Oct) e [20]aneO4(Oct)

\begin{tabular}{|c|c|c|c|c|c|c|c|c|c|c|c|}
\hline \multicolumn{6}{|c|}{ [20]aneN4(Oct) } & \multicolumn{6}{|c|}{ [20]aneO4(Oct) } \\
\hline Doador & $\begin{array}{l}\text { Ocupação } \\
\text { (e) }\end{array}$ & Receptor & $\begin{array}{c}\text { Ocupação } \\
\text { (e) }\end{array}$ & $\mathrm{E}(2)$ & Carga (NBO) & Doador & $\begin{array}{l}\text { Ocupação } \\
\text { (e) }\end{array}$ & Receptor & $\begin{array}{l}\text { Ocupação } \\
\text { (e) }\end{array}$ & $\mathrm{E}(2)$ & Carga (NBO) \\
\hline \multicolumn{6}{|c|}{$\mathrm{Fe}\left(\Sigma^{\alpha+\beta}\right)$} & \multicolumn{6}{|c|}{$\operatorname{Fe}\left(\Sigma^{\alpha+\beta}\right)$} \\
\hline$(\mathrm{LP}) \mathrm{N} 1$ & 1,881 & $\mathrm{Fe}$ & 0,239 & 23,81 & $\mathrm{Fe}(1.548)$ & ( LP )O1 & 1,954 & $\mathrm{Fe}$ & 0,151 & 24,91 & $\mathrm{Fe}(1.607)$ \\
\hline (LP)N2 & 1,886 & $\mathrm{Fe}$ & 0,234 & 22,88 & $\mathrm{~N}(-0.829)$ & ( LP)O2 & 1,956 & $\mathrm{Fe}$ & 0,151 & 24,98 & $\mathrm{O}(-0.732)$ \\
\hline$(\mathrm{LP}) \mathrm{O}_{\mathrm{W} 1}$ & 1,958 & $\mathrm{Fe}$ & 0,165 & 19,25 & $\mathrm{O}_{\mathrm{W}}(-1.023)$ & $(\mathrm{LP}) \mathrm{O}_{\mathrm{W} 1}$ & 1,978 & $\mathrm{Fe}$ & 0,151 & 19,9 & $\mathrm{O}_{\mathrm{W}}(-1.024)$ \\
\hline$(\mathrm{LP}) \mathrm{O}_{\mathrm{W} 2}$ & 1,957 & $\mathrm{Fe}$ & 0,165 & 19,57 & & $(\mathrm{LP}) \mathrm{O}_{\mathrm{W} 2}$ & 1,958 & $\mathrm{Fe}$ & 0,151 & 18,01 & \\
\hline \multicolumn{6}{|c|}{$\operatorname{Co}\left(\Sigma^{\alpha+\beta}\right)$} & \multicolumn{6}{|c|}{$\operatorname{Co}\left(\Sigma^{\alpha+\beta}\right)$} \\
\hline$(\mathrm{LP}) \mathrm{N} 1$ & 1,928 & $\mathrm{Co}$ & 0,293 & 24,96 & $\operatorname{Co}(1,517)$ & ( LP )O1 & 1,922 & $\mathrm{Co}$ & 0,184 & 25,02 & $\operatorname{Co}(1,597)$ \\
\hline$(\mathrm{LP}) \mathrm{N} 2$ & 1,928 & $\mathrm{Co}$ & 0,293 & 23,36 & $\mathrm{~N}(-0,820)$ & $(\mathrm{LP}) \mathrm{O} 2$ & 1,922 & $\mathrm{Co}$ & 0,184 & 23,45 & $\mathrm{O}(-0.774)$ \\
\hline$(\mathrm{LP}) \mathrm{O}_{\mathrm{W} 1}$ & 1,974 & $\mathrm{Co}$ & 0,171 & 20,39 & $\mathrm{O}_{\mathrm{W}}(-1.024)$ & $(\mathrm{LP}) \mathrm{O}_{\mathrm{W} 1}$ & 1,951 & $\mathrm{Co}$ & 0,162 & 20,59 & $\mathrm{O}_{\mathrm{W}}(-1.025)$ \\
\hline$(\mathrm{LP}) \mathrm{O}_{\mathrm{W} 2}$ & 1,974 & $\mathrm{Co}$ & 0,171 & 20,61 & & ( LP ) $\mathrm{O}_{\mathrm{W} 2}$ & 1,951 & $\mathrm{Co}$ & 0,162 & 19,49 & \\
\hline \multicolumn{6}{|c|}{$\mathrm{Ni}\left(\Sigma^{\alpha+\beta}\right)$} & \multicolumn{6}{|c|}{$\operatorname{Ni}\left(\Sigma^{\alpha+\beta}\right)$} \\
\hline ( LP )N1 & 1,930 & $\mathrm{Ni}$ & 0,180 & 25,58 & $\mathrm{Ni}(1.442)$ & ( LP )O1 & 1,911 & $\mathrm{Ni}$ & 0,208 & 26,37 & $\mathrm{Ni}(1,567)$ \\
\hline ( LP )N2 & 1,930 & $\mathrm{Ni}$ & 0,180 & 24,40 & $\mathrm{~N}(-0.808)$ & ( LP )O2 & 1,911 & $\mathrm{Ni}$ & 0,208 & 25,14 & $\mathrm{O}(-0.776)$ \\
\hline$(\mathrm{LP}) \mathrm{O}_{\mathrm{W} 1}$ & 1,951 & $\mathrm{Ni}$ & 0,180 & 21,15 & $\mathrm{O}_{\mathrm{W}}(-1.020)$ & $(\mathrm{LP}) \mathrm{O}_{\mathrm{W} 1}$ & 1,066 & $\mathrm{Ni}$ & 0,173 & 21,36 & $\mathrm{O}_{\mathrm{w}}(-1.019)$ \\
\hline$(\mathrm{LP}) \mathrm{O}_{\mathrm{W} 2}$ & 1,951 & $\mathrm{Ni}$ & 0,180 & 21,58 & & $(\mathrm{LP}) \mathrm{O}_{\mathrm{W} 2}$ & 1,066 & $\mathrm{Ni}$ & 0,173 & 20,59 & \\
\hline \multicolumn{6}{|c|}{$\mathrm{Ru}$} & \multicolumn{6}{|c|}{$\mathrm{Ru}$} \\
\hline$(\mathrm{LP}) \mathrm{N} 1$ & 1,741 & $\mathrm{Ru}$ & 1,970 & 60,04 & $\mathrm{Ru}(0,745)$ & ( LP )O1 & 1,798 & $\mathrm{Ru}$ & 0,981 & 60,13 & $\mathrm{Ru}(1,006)$ \\
\hline ( LP )N2 & 1,741 & $\mathrm{Ru}$ & 1,970 & 59,73 & $\mathrm{~N}(-0.692)$ & ( LP )O2 & 1,798 & $\mathrm{Ru}$ & 0,981 & 60,03 & $\mathrm{O}(-0.636)$ \\
\hline$(\mathrm{LP}) \mathrm{O}_{\mathrm{W} 1}$ & 1,855 & $\mathrm{Ru}$ & 1,970 & 59,23 & $\mathrm{O}_{\mathrm{W}}(-0,937)$ & $(\mathrm{LP}) \mathrm{O}_{\mathrm{W} 1}$ & 1,994 & $\mathrm{Ru}$ & 0,981 & 61,01 & $\mathrm{O}_{\mathrm{W}}(-0,938)$ \\
\hline$(\mathrm{LP}) \mathrm{O}_{\mathrm{W} 2}$ & 1,994 & $\mathrm{Ru}$ & 1,970 & 60,29 & & $(\mathrm{LP}) \mathrm{O}_{\mathrm{W} 2}$ & 1,851 & $\mathrm{Ru}$ & 0,981 & 62,74 & \\
\hline \multicolumn{6}{|c|}{$\operatorname{Rh}^{2+}\left(\Sigma^{\alpha+\beta}\right)$} & \multicolumn{6}{|c|}{$\mathrm{Rh}^{2+}\left(\Sigma^{\alpha+\beta}\right)$} \\
\hline$(\mathrm{LP}) \mathrm{N} 1$ & 1,720 & $\mathrm{Rh}$ & 0,576 & 67,48 & $\operatorname{Rh}(0,921)$ & ( LP )O1 & 1,815 & $\mathrm{Rh}$ & 0.510 & 52,73 & $\operatorname{Rh}(1,180)$ \\
\hline$(\mathrm{LP}) \mathrm{N} 2$ & 1,733 & $\mathrm{Rh}$ & 0,576 & 59,67 & $\mathrm{~N}(-0,715)$ & ( LP )O2 & 1,815 & $\mathrm{Rh}$ & 0,510 & 60,08 & $\mathrm{O}(-0.651)$ \\
\hline$(\mathrm{LP}) \mathrm{O}_{\mathrm{W} 1}$ & 1,968 & $\mathrm{Rh}$ & 0,147 & 10,78 & $\mathrm{O}_{\mathrm{W}}(-0,993)$ & $(\mathrm{LP}) \mathrm{O}_{\mathrm{W} 1}$ & 1,952 & $\mathrm{Rh}$ & 0,136 & 15,29 & $\mathrm{O}_{\mathrm{W}}(-0,994)$ \\
\hline$(\mathrm{LP}) \mathrm{O}_{\mathrm{W} 2}$ & 1,956 & $\mathrm{Rh}$ & 0,147 & 13,80 & & $(\mathrm{LP}) \mathrm{O}_{\mathrm{W} 2}$ & 1,962 & $\mathrm{Rh}$ & 0,136 & 12,01 & \\
\hline \multicolumn{6}{|c|}{$\mathrm{Pd}^{2+}$} & \multicolumn{6}{|c|}{$\mathrm{Pd}^{2+}$} \\
\hline ( LP )N1 & 1,690 & $\mathrm{Pd}$ & 1,990 & 81,08 & $\operatorname{Pd}(0,797)$ & ( LP )O1 & 1,743 & $\mathrm{Pd}$ & 1,994 & 64,03 & $\operatorname{Pd}(1,075)$ \\
\hline$(\mathrm{LP}) \mathrm{N} 2$ & 1,689 & $\mathrm{Pd}$ & 1,990 & 79,48 & $\mathrm{~N}(-0,720)$ & ( LP )O2 & 1,964 & $\mathrm{Pd}$ & 1,994 & 62,30 & $\mathrm{O}(-0,655)$ \\
\hline
\end{tabular}


Tabela 30. Energia de perturbação de seguanda ordem E(2), em Kcal.mol ${ }^{-1}$, e carga NBO sobre o íon metálico e os ligantes calculados para os complexos [20]aneO4(qp) e [20]aneO4(qp)

\begin{tabular}{|c|c|c|c|c|c|c|c|c|c|c|c|}
\hline \multicolumn{6}{|c|}{ [20]AneN4(qp) } & \multicolumn{6}{|c|}{ [20]AneO4(qp) } \\
\hline Doador & $\begin{array}{l}\text { Ocupação } \\
\text { (e) }\end{array}$ & Receptor & $\begin{array}{c}\text { Ocupação } \\
\text { (e) }\end{array}$ & $\mathrm{E}(2)$ & Carga (NBO) & Doador & $\begin{array}{l}\text { Ocupação } \\
\text { (e) }\end{array}$ & Receptor & $\begin{array}{l}\text { Ocupação } \\
\text { (e) }\end{array}$ & $\mathrm{E}(2)$ & Carga (NBO) \\
\hline \multicolumn{6}{|c|}{$\mathrm{Fe}\left(\Sigma^{\alpha+\beta}\right)$} & \multicolumn{6}{|c|}{$\mathrm{Fe}\left(\Sigma^{\alpha+\beta}\right)$} \\
\hline ( LP )N1 & 1,908 & $\mathrm{Fe}$ & 0,140 & 29,58 & $\mathrm{Fe}(1,467)$ & ( LP )O1 & 0,190 & $\mathrm{Fe}$ & 0,221 & 29,50 & $\mathrm{Fe}(1,594)$ \\
\hline ( LP )N2 & 1,908 & $\mathrm{Fe}$ & 0,140 & 21,06 & $\mathrm{~N}(-0.843)$ & ( LP $) \mathrm{O} 2$ & 0,190 & $\mathrm{Fe}$ & 0,162 & 21,21 & $\mathrm{O}(-0.755)$ \\
\hline \multicolumn{6}{|c|}{$\operatorname{Co}\left(\Sigma^{\alpha+\beta}\right)$} & \multicolumn{6}{|c|}{ Co $\left(\Sigma^{\alpha+\beta}\right)$} \\
\hline ( LP )N1 & 1,928 & Co & 0,110 & 19,56 & Co $(1,436)$ & ( LP )O1 & 1,844 & Co & 0,191 & 33,98 & Co $(1,531)$ \\
\hline ( LP )N2 & 1,928 & Co & 0,110 & 18,50 & $\mathrm{~N}(-0,833)$ & ( LP $) \mathrm{O} 2$ & 1,844 & Co & 0,191 & 30,33 & $\mathrm{O}(-0.746)$ \\
\hline \multicolumn{6}{|c|}{$\left.\operatorname{Ni}\left(\Sigma^{\alpha+\beta}\right)\right)$} & \multicolumn{6}{|c|}{$\left.\mathrm{Ni}\left(\Sigma^{\alpha+\beta}\right)\right)$} \\
\hline ( LP )N1 & 1,855 & $\mathrm{Ni}$ & 0,137 & 31,28 & $\mathrm{Ni}(1,347)$ & ( LP )O1 & 1,892 & $\mathrm{Ni}$ & 0,184 & 33,07 & $\mathrm{Ni}(1,467)$ \\
\hline ( LP )N2 & 1,855 & $\mathrm{Ni}$ & 0,137 & 29,15 & $\mathrm{~N}(-0.817)$ & ( LP )O 2 & 1,892 & $\mathrm{Ni}$ & 0,184 & 31,12 & $\mathrm{O}(-0.735)$ \\
\hline \multicolumn{6}{|c|}{$\mathrm{Ru}$} & \multicolumn{6}{|c|}{$\mathrm{Ru}$} \\
\hline ( LP )N1 & 1,915 & $\mathrm{Ru}$ & 0,973 & 87,04 & $\mathrm{Ru}(0,819)$ & ( LP )O1 & 1,902 & $\mathrm{Ru}$ & 1,966 & 76,05 & $\mathrm{Ru}(0,929)$ \\
\hline ( LP )N2 & 1,915 & $\mathrm{Ru}$ & 0,973 & 86,17 & $\mathrm{~N}(-0,717)$ & ( LP $) \mathrm{O} 2$ & 1,788 & $\mathrm{Ru}$ & 1,966 & 75,72 & $\mathrm{O}(-0.620)$ \\
\hline \multicolumn{6}{|c|}{$\operatorname{Rh}\left(\Sigma^{\alpha+\beta}\right)$} & \multicolumn{6}{|c|}{$\operatorname{Rh}\left(\Sigma^{\alpha+\beta}\right)$} \\
\hline ( LP )N1 & 1,693 & $\mathrm{Rh}$ & 0,474 & 82,86 & $\mathrm{Rh}(0,869)$ & ( LP )O1 & 1,795 & $\mathrm{Rh}$ & 0,637 & 62,50 & $\mathrm{Rh}(1,126)$ \\
\hline ( LP )N2 & 1,693 & $\mathrm{Rh}$ & 0,474 & 69,82 & $N(-0,723)$ & ( LP )O2 & 1,796 & $\mathrm{Rh}$ & 0,637 & 58,85 & $\mathrm{O}(-0.606)$ \\
\hline \multicolumn{6}{|c|}{$\mathrm{Pd}$} & \multicolumn{6}{|c|}{$\mathrm{Pd}$} \\
\hline ( LP )N1 & 1,690 & $\mathrm{Pd}$ & 0,990 & 81,08 & $\operatorname{Pd}(0,797)$ & ( LP)O1 & 1,743 & $\mathrm{Pd}$ & 0,994 & 64,03 & $\mathrm{Pd}(1,075)$ \\
\hline ( LP )N2 & 1,690 & $\mathrm{Pd}$ & 0,990 & 79,48 & $\mathrm{~N}(-0,720)$ & ( LP $) \mathrm{O} 2$ & 1,964 & $\mathrm{Pd}$ & 0,994 & 62,30 & $\mathrm{O}(-0,655)$ \\
\hline
\end{tabular}


O forte caráter $\sigma$ doador dos ligantes nos complexos poliaminas e poliéteres fazem com que a transferência de carga do metal-ligante (retro-doação) seja negligenciada pela análise NBO. A mesma tendência foi observada quando utilizado o programa AOMix-CDA nos complexos anteriormente discutidos nesta tese.

A análise NBO com a energia de perturbação de segunda ordem foi desenvolvida para o melhor entendimento da natureza das interações metal-ligante nos complexos estudados. Antes de iniciarmos a discursão desses resultados, é importante relembrar que nesses complexos apenas os estados espectroscópicos mais estáveis foram considerados, por exemplo, para os complexos de ferro, em ambas as geométricos octaédrica e quadrado-planar, apenas foram realizados cálculos com o estado quinteto. Como nesse estado os spins estão desemparelhados, eles são tratados com diferença de energia gerando um sistema de camada aberta com spins alfa e beta. Já nos complexos de estado singleto, $\mathrm{Ru}^{2+}$ e $\mathrm{Pd}^{2+}$, os spins encontram-se emparelhados e o sistema e denominado de camada fechada. Ou seja, nos resultados apresentados nas Tabelas 29 e 30, para os complexos de camada aberta $\mathrm{Fe}^{2+}, \mathrm{Co}^{2+}$, $\mathrm{Ni}^{2+} \mathrm{e} \mathrm{Rh}^{2+}$, a doação de cargas é a soma das contribuições dos orbitais de spin alfa e beta.

Para os complexos octaédricos [20]aneL4, formados pelos íons metálicos da primeira fila, pode-se observar que os complexos com átomos de oxigênio como doador apresentam uma doação de carga ligeiramente maior em comparação aos complexos com os átomos de nitrogênio como doador (Tabela 29). De um modo geral, a transferência de elétrons ocorre dos pares de elétrons isolados (lone pair), nos orbitais ocupados dos ligantes, para os orbitais desocupados do metal. Em ambos os complexos [20]aneO4(Oct) e [20]aneO4(Oct), os orbitais $\left(\alpha\right.$ e $\beta$ ), do receptor, são predominantes e de caráter s e $e_{g}\left(d_{z}{ }^{2} \text { e } d_{x^{2}-y^{2}}\right)^{2}$, respectivamente. Tal caráter, garante aos complexos uma predominância da ligação sigma $(\sigma)$, como já esperado, uma vez que esses ligantes são do tipo $\sigma$. Outra observação importante é que os átomos de nitrogênio ou oxigênio, situados na cavidade de complexação do 
macrociclo, apresentam uma maior energia de perturbação $\mathrm{E}(2)$ em comparação comas moléculas de água colocadas na posição axial. Em média, o valor calculado de $E(2)$ para a doação oxigênio-metal é de 24,95 $\mathrm{Kcal} \mathrm{mol}^{-1}$, enquanto que, na doação $\mathrm{O}_{\mathrm{W}}$-metal, a energia de perturbação E(2) é de 18,96 Kcal.mol ${ }^{-1}$. Nos complexos da segunda fila dos metais de transição, com exceção do complexo de $\mathrm{Ru}^{2+}$, os átomos de nitrogênio apresentam uma maior transferência de carga (doação) que os átomos de oxigênio. Porém, devido o efeito JahnTeller observado no complexo de $\mathrm{Rh}^{2+}$ e a preferência do íon metálico $\mathrm{Pd}^{2+}$ em formar complexos quadrado-planar, a contribuição das moléculas de água para doação é significativamente pequena para os complexos de $\mathrm{Rh}^{2+}$, e sem contribuição nos complexos de $\mathrm{Pd}^{2+}$ (ver Tabela 29).

Resultados semelhantes de $\mathrm{E}(2)$ foram obtidos nos complexos quadrado-planar ([20]aneL4), que são mostrados na Tabela 29. Isto é, a diferença de energia entre a doação de cargas ligante-metal nos complexos [20]aneN4(qp) e [20]aneO4(qp) formados pelos íons metálicos da primeira fila, é relativamente pequena, sendo que este último mostra uma maior energia de perturbação $\mathrm{E}(2)$ em comparação ao complexo [20]aneN4(qp). Porém, essa diferença de energia não é superior a $4 \mathrm{Kcal}_{\mathrm{mol}}{ }^{-1}$. No entanto, no complexo de $\mathrm{Co}^{2+}$, essa diferença é acima de $20 \mathrm{Kcal}_{\mathrm{mol}}{ }^{-1}$. A doação ligante-metal, nos complexos com átomos de nitrogênio como doador, mostram-se mais forte para os íons da segunda fila, com uma diferença de energia de aproximadamente $20 \mathrm{Kcal}^{\mathrm{mol}}{ }^{-1}$, quando comparado com os complexos formado pelo macrociclo [20]aneO4 (ver Tabela 30). Essa mesma tendência foi observada na análise da energia de interação ( $\left.\mathrm{E}_{\mathrm{INT}}\right)$ desses complexos (Tabela 27).

Assim como nos complexos [20]aneN4O4 e [20]aneO4N4, as cargas NBO mostram mesma tendência para os complexos [20]aneN4 e [20]aneO4, isto é, os íons metálicos da primeira fila têm grande caráter iônico devido à grande carga calculada sobre o metal e os ligantes $(\mathrm{N}, \mathrm{O})$; enquanto que para os íons da segunda fila, predomina o caráter covalente 
(Tabelas 29 e 30), uma vez que as cargas sobre os íons metálicos e sobre os ligantes (N, O) são extremamente pequenas, quando comparadas aos íons da primeira fila. Comparando um par de íons do mesmo grupo $\mathrm{d}^{7}$, por exemplo, os íons $\mathrm{Co}^{2+} \mathrm{e} \mathrm{Rh}^{2+}$ no complexo [20]AneN4(qp) quadrado-planar, a carga estimada para o íon $\mathrm{Co}^{2+}$ é de 1,436 (e'), enquanto a carga sobre o íon $\mathrm{Rh}^{2+}$ foi estimada em $0,869\left(\mathrm{e}^{-}\right)$. As cargas sobre o ligante nitrogênio são de

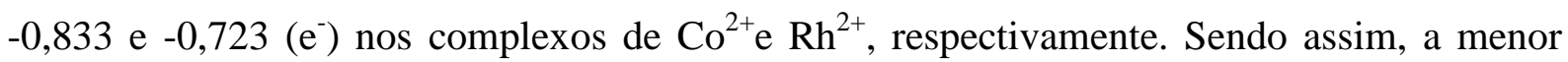
carga estimada sobre esses átomos nos complexos da segunda fila garante o maior caráter covalente nessa série. 
CAPITULO IV

CONCLUSÃO 


\section{IV - CONCLUSÃO}

Os resultados dos cálculos apresentados nesta tese mostraram que os objetivos propostos foram satisfatoriamente alcançados. A geometria molecular do macrociclo [20]aneN4O4 em fase gasosa, resultante do cálculo em nível de teoria DFT com funcianal hibrido B3LYP, com o grupo pontual $\mathrm{C}_{\mathrm{s}}$, com centro de cavidade de complexação adequado para complexação de metais, uma vez que a distância média entre os átomos cruzados N4-N1 e N3-N2 é de 4,299 ̊. Já o macrociclo [20]aneO4N4, apresentou uma geometria com alto grau de distorção do grupo pontual $\mathrm{C}_{1}$. No entanto, as energias eletrônicas calculadas para os macrociclos [20]aneN4O4 e [20]aneO4N4 mostraram que o sistema com átomos de oxigênio como doador é cerca de $7 \mathrm{Kcal}_{\mathrm{mol}}{ }^{-1}$, mais estável que o macrociclo com átomos de nitrogênio como doador. Porém, devido à sua alta distorção geométrica, a energia de reorganização quando o macrociclo [20]aneO4N4 entra em contato com um íon metálico torna-se de alto custo energético.

Nos macrociclos [20]aneN4 e [20]aneO4, as geometrias obtidas mostraram ser bem simétricas. No sistema poliamina foi observado uma maior cavidade de complexação de íons metálicos com a distância entre seus átomos cruzados N4-N1 e N3-N2 de 5,266 ̊̊. Essa maior cavidade proporciona ao macrociclo [20]aneN4 complexar melhor íons metálicos maiores como os da segunda fila. Já o macrociclo [20]aneO4, mostrou-se uma menor cavidade de complexação que favorece a complexação de íons metálicos menores com os da primeira fila. Em ambos os macrociclos, o grupo pontual $\mathrm{C}_{\mathrm{s}}$ foi observado.

Nesta tese, os complexos (1a e $\left.\mathbf{1} \mathbf{a}_{\mathbf{q}}\right)$ e $\left(\mathbf{1} \mathbf{b}\right.$ e $\left.\mathbf{1} \mathbf{b}_{\mathbf{q}}\right)$, de arranjo octaédrico e quadradoplanar, respectivamente, foram obtidos na complexação dos íons metálicos da primeira e segunda filas pelo macrociclo [20]aneN4O4 e [20]aneO4N4. Já os macrociclos [20]aneN4 e [20]aneO4 deram origem aos complexos [20]aneL4(Oct) e [20]aneL4(qp), onde L= N, O. 
Os resultados obtidos para os parâmetros geométricos no complexo (1a) 1, 7, 11, 17tetraoxa-2, 6, 12, 16-tetraazacicloicosano de níquel (II), teórico e experimental, estão em excelente grau de concordância. Esse complexo possui geometria octaédrica com grupo pontual $\mathrm{C}_{\mathrm{s}}$. A distância média N-Ni calculadas em nível de teoria DFT/B3LYP é de 2,131 Å, enquanto que o valor experimental é de 2,105 ̊. O resultado teórico superestima o valor experimental em apenas $0,026 \AA$ A. A diferença das distâncias $\mathrm{Ni}-\mathrm{O}_{\mathrm{W}}$ estão em excelente acordo. Os ângulos $\mathrm{N}-\mathrm{Ni}-\mathrm{O}_{\mathrm{W}}$ e $\mathrm{O}_{\mathrm{W}}-\mathrm{Ni}-\mathrm{O}_{\mathrm{W}}$, obtido teoricamente, são de 88,2 e $180,0^{\circ}$, respectivamente, enquanto que os ângulos experimentais são de 89,2 e $180,0^{\circ}$, respectivamente. A maior distorção entre os resultados teórico e experimental foi observada para o ângulo N1-Ni-N2. O valor calculado superestima o valor observado em aproximadamente $6^{\circ}$. Desta forma, o modelo teórico B3LYP/Land2DZ, mostrou-se adequado para realização desses cálculos. De um modo geral, os complexos (1a e $\left.\mathbf{1 a}_{\mathbf{q}}\right)$ mostraram-se mais simétricos que os complexos e (1b e $\left.\mathbf{1 b}_{\mathbf{q}}\right)$. Já os complexos derivados dos macrociclos poliaminas e poliéteres demonstraram similar distorção.

O íon metálico $\mathrm{Rh}^{2+}$ apresenta uma forte distorção tetragonal nos arranjos octaédricos em todos os sistemas estudados, com alongamento das ligações metal-água do eixo z. Já nos complexos $\mathbf{1 a}$ e $\mathbf{1 b}$ com o íon $\mathrm{Pd}^{2+}$, devido à sua preferência em forma complexo quadradoplanar, as moléculas de água estão totalmente afastadas do sítio de ligação do metal.

A análise do espectro de infravermelho na região abaixo de $600 \mathrm{~cm}^{-1}$ é importante para a verificação da formação dos complexos, uma vez que é nessa região que podem ser observados os estiramentos simétricos $\mathrm{M}-\mathrm{L}(\mathrm{L}=\mathrm{N}, \mathrm{O})$.

As energias eletrônicas calculadas para os complexos 1a e 1b (octaédrico) e os complexos $\mathbf{1 a}_{\mathbf{q}}$ e $\mathbf{1 b}_{\mathbf{q}}$ (quadrado-planar), mostraram que os íons metálicos da primeira fila preferem formar complexos de spin alto, enquanto os complexos formados por íons metálicos da segunda fila preferem formar complexos de spin baixo. Para esses últimos complexos, tal 
preferência deve-se ao grande overlap entre os orbitais do ligante e do metal e do tamanho do volume do orbital $4 \mathrm{~d}$ dos íons da segunda fila, comparado com o orbital $3 \mathrm{~d}$ dos íons da primeira fila. A comparação entre as energias relativas dos complexos 1a e 1b (octaédricos) e os complexos $1 \mathbf{a}_{\mathbf{q}}$ e $\mathbf{1} \mathbf{b}_{\mathbf{q}}$ (quadrado-planares) mostraram que os complexos $\mathbf{1 a}$ e $\mathbf{1 a}_{\mathbf{q}}$ possuem maior energia eletrônica que os complexos $\mathbf{1 b}$ e $\mathbf{1 b}_{\mathbf{q}}$. Nesta tese, as comparações entre as energias relativas foram realizadas para verificar o quanto um isômero seria mais estável que o outro.

As energias de interação calculadas para os complexos 1a e 1b (octaédricos) e os complexos $\mathbf{1} \mathbf{a}_{\mathbf{q}}$ e $\mathbf{1 b}_{\mathbf{q}}$ (quadrado-planares) mostraram que o macrociclo [20]aneN4O4 possui maior habilidade em complexar íons metálicos da primeira e segunda filas que o macrociclo [20]aneO4N4. Para os íons da primeira fila $\mathrm{Fe}^{2+}, \mathrm{Co}^{2+}$ e $\mathrm{Ni}^{2+}$, o complexo $\mathbf{1 a}$ e $\mathbf{1 a} \mathbf{q}_{\mathbf{q}}$ de $\mathrm{Ni}^{2+}$, mostraram-se mais fortemente ligados e possui uma energia de ligação de $-458,2 \mathrm{Kcal}_{\mathrm{mol}}{ }^{-1}$ (arranjo octaédrico) e de $-402,8 \mathrm{Kcal}^{\mathrm{mol}}{ }^{-1}$ (arranjo quadrado-planar) enquanto nos complexos $\mathbf{1 b}$ e $\mathbf{1} \mathbf{b}_{\mathbf{q}}$, essas energias de ligação foram estimadas em -425,9 e -369,4 $\mathrm{Kcal}^{-\mathrm{mol}^{-}}$ ${ }^{1}$, respectivamente. Nos íons da segunda fila $\mathrm{Ru}^{2+}, \mathrm{Rh}^{2+}$ e $\mathrm{Pd}^{2+}$, os complexos obtidos na complexação do íon paládio pelos macrociclos [20]aneN4O4 e [20]aneO4N4 mostraram maior energia de complexação. Desta forma, podemos concluir que a energia de interação aumenta com o aumento do número atômico em uma determinada fila.

Os complexos derivados dos macrociclos poliaminas e poliéteres demonstraram que o macrociclo [20]aneN4 complexa mais fortemente os íons metálicos da segunda fila dos metais de transição, enquanto que o macrociclo [20]aneO4 complexa mais fortemente os íons metálicos da primeira fila. O conceito de dureza e moleza de Pearson contribui significativamente para elucidação dessa preferência, uma vez que ácido duro liga-se preferencialmente a base dura, e uma base mole prefere ligar-se a um ácido mole. Sendo assim, nos complexos [20]aneO4(Oct) e [20]aneO4(qp), os átomos de oxigênio, considerados 
como base dura ligam-se mais fortemente aos íons metálicos da primeira fila que são considerados ácido duro. Já nos complexos [20]aneN4(Oct) e [20]aneN4(qp), os átomos de nitrogênio são base mole e os íons metálicos da segunda fila são ácido mole, justificando assim a preferência do macrociclo poliamina de complexar melhor os íons da segunda fila.

Para os complexos 1a e $\mathbf{1 b}$ (octaédricos) e os complexos $\mathbf{1 a}_{\mathbf{q}}$ e $\mathbf{1 b}_{\mathbf{q}}$ (quadradoplanares), a energia de interação aumenta com a diminuição da ligação metal-ligante. No entanto, para os complexos [20]aneN4(Oct) e [20]aneN4(qp) essa relação não é observada.

O método CDA usado para obter informação sobre a natureza da ligação química metal-ligante (M-L) revelou que nos complexos $\mathbf{1 a}$ e $\mathbf{1 b}$, formados por íons metálicos da primeira fila, uma relativa contribuição covalente pode ser observada. Essa evidência está na transferência de cargas (Doação) do ligante para o metal. Porém, para esses complexos, as interações químicas metal-ligante são predominantemente iônicas. Já nos complexos formados pelo os íons da segunda fila, as interações são predominante covalente. Uma relação direta com essa predominância pode ser feita com o gap de energia entre os orbitais (LUMOHOMO). Os complexos com menor gap de energia, numa dada fila, apresentaram maior caráter iônico, por exemplo, o complexo $\mathbf{1 a}$ do íon $\mathrm{Fe}^{2+}$, tem gap de energia de 5,58 eV, enquanto que o complexo do íon $\mathrm{Ni}^{2+}$ tem gap estimado em $6,10 \mathrm{eV}$. Desta forma, o complexo de $\mathrm{Fe}^{2+}$ possui um maior caráter iônico em relação ao complexo de $\mathrm{Ni}^{2+}$. Nos complexos 1b, esta relação só é valida para os íons da segunda fila. Em ambos os complexos 1a e $\mathbf{1 b}$ (octaédricos) e os complexos $\mathbf{1 a}_{\mathbf{q}}$ e $\mathbf{1 b}_{\mathbf{q}}$ (quadrado-planares) a retro-doação foi negligenciada, pois os ligantes $(\mathrm{N}, \mathrm{O})$ são do tipo $\sigma$.

Os estudos da energia de perturbação de segunda ordem E(2) para os complexos [20]aneL4(Oct) e [20]aneL4(qp) ajudaram a entender a natureza da interação desses macrociclos com os íons metálicos. Nesses sistemas, os complexos [20]aneO4(Oct) e [20]aneO4(qp) interagem mais fortemente com os íons metálicos da primeira fila, enquanto 
que os complexos [20]aneN4(Oct) e [20]aneN4(qp) interagem mais fortemente com os íons metálicos da segunda fila. Esses resultados estão em comum acordo com as energias de interação calculadas para os complexos [20]aneL4(Oct) e [20]aneL4(qp).

Em fim, este trabalho, de acordo com as conclusões delineadas acima, foi de suma importância para o entendimento da natureza das ligações nos complexos aqui estudados, uma vez que tais sistemas têm sido bastante estudados experimentalmente, apesar das dificuldades no âmbito experimental. 


\section{Referências Bibliograficas}

[1] BACON, E.; KIRCH, M. Competitive transport of the toxic heavy metals lead, mercury and cadmium by macrocyclic ligands. J. Membr. Sci., v. 32, p. 159-173, 1987.

[2] SZCZEPANIAK, W.; JUSKOWIAK, B. Spectrophotometric determination of trace amounts of lead (II) by ion-pair extraction with cryptand (2.2.2) and eosin. Anal. Chim. Acta, v. 140, p. 261-269, 1982.

[3] SZCZEPANIAK, W.; JUSKOWIAK, B.; CISZEWSLA, W. Extraction studies of metal complexes with some macrocyclic tetraaza ligands and xanthene dyes: Spectrophotometric determination of Cadmium (II) with Tetramethyltetraazacyclotetradecane and Erythrosin A. Anal. Chim. Acta, v. 156, p. 235-243, 1984.

[4] KRUPER, W. J.; RUDOLF, P. R.; LANFHOFF, C. A. Unexpected selectivity in the alkylation of polyazamacrocycles. J. Org. Chem., v. 58, p. 3869-3876, 1993.

[5] TAKENOUCHI, K.; WATANABE, K.; KATO, Y.; KOIKE, T.; KIMURA, E. Novel bifunctional macrocyclic chelating agents appended with a pendant-type carboxymethylamino ligand and nitrobenzyl group and stability of the 88YIII complexes. J. Org. Chem., v. 58, p. 1955-1958, 1993.

[6] LIANG, X.; SADLER, P. J. Cyclam complexes and their applications in medicine. Chem. Soc. Rev., v. 33, p. 246-266, 2004.

[7] SINGH, D. P.; KUMAR, R.; MALIK, V.; TYAGI, P. J. Use of selected chemical markers in combination with a multiple regression model to assess the contribution of domesticated animal sources of fecal pollution in the environment. J. Enzy. Inhib. Med. Chem., v. 22, p. 177-182, 2007.

[8] DELGADO, R.; FELIX, V.; LIMA, L. M. P.; PRICE, D. W. Metal complexes of cyclen and cyclam derivatives useful of medical applications: a discussion base on thermodynamic stability constants and structural data. Dalton Trans., v. 26, p. 2734-2745, 2007.

[9] SEVDIC, D.; MEISER, H. Macrocyclic polythiaethers as solvent extraction reagents-IV $\mathrm{Ag}(\mathrm{I})$ and $\mathrm{Hg}$ (II) complexes with 1,4,7,10,13,16-hexathiacyclooctadecane. J. Inorg. Nucl.

Chem., v. 43, p. 153-157, 1981.

[10] BAUMANN, T. F.; REYNOLDS, J. G.; FOX, G. A. Polymer pendant crown thioethers: synthesis and $\mathrm{Hg}^{\text {II }}$ extraction studies of a novel thiacrown polymer. Chem. Commun., v. 16, p. 1637-1638, 1998.

[11] KUKSA, V.; MARSHALL, C.; WARDEIL, S. M. S. V.; LIN, P. K. T. The synthesis of novel oxa-azamacrocycles. Synthesis, v. 6, 1034-1038, 1999. 
[12] KUKSA, V.; WARDEIL, S. M. S. V.; LIN, P. K. T. Synthesis and X-ray structures of Ni and $\mathrm{Zn}$ complexes of a novel oxa-azamacrocyclic system. Inorg. Chem. Commun., v. 3, p. 267-270, 2000.

[13] CARAVAN, P.; ELLISON, J. E.; MCMURRY, T. J.; LAUFFER, R. B. Gadolinium (III) chelates as MRI contrast agents: Structure, dynamics, and applications. Chem. Rev., v. 99, p. 2293-2352, 1999.

[14] HANCOCK, R. D. Macrocycles and their selectivity for metal ions on the basis of size. Pure Appl. Chem., v. 58, p. 1445-1452, 1986.

[15] FENSTERBANK, H.; ZHU, J.; RIOU, D. LANPENT, C. A tunable one-step $N, N^{\prime}$ disubstitution of 1,4,8,11-tetraazacyclotetradecane with acrylamide. J. Chem. Soc., v. 2003, p. 811-815, 1999.

[16] HANCOCK, R. D. Chelate ring size and metal ion selection: The basis of selectivity for metal ions in open-chain ligands and macrocycles. J. Chem. Educ., v . 69, p. 615-619, 1992.

[17] HUNG, Y.; MARTIN, Y. L.; JACKELS, S. C.; TAIT, A.; MARTOM, Y. L. Busch ring size effects among metal complexes with macrocyclic ligands: synthesis, stereochemistry, spectrochemistry, and electrochemistry of cobalt(III) complexes with unsubstituted, saturated tetraaza macrocycles. J. Am. Chem. Soc., v. 99, p. 4029-4039, 1977.

[18] ARCHIBALD, S. J. Macrocyclic coordination chemistry. Annu. Rep. Prog. Chem. Sect. A, v. 102, p. 332-352, 2006.

[19] PEDERSEN, C. J. Cyclic polyethers and their complexes with metal salts. J. Am. Chem. Soc., v. 89, p. 2495-2496, 1979.

[20] PEDERSEN, C. J. Cyclic polyethers and their complexes with metal salts. J. Am. Chem. Soc., v. 89, p. 7017-7036, 1979.

[21] LUCKAY, R. C.; HANCOCK, R. D. Stability of complexes of the macrocycles 1,5,9,13tetraza-cyclohexadecane and 1,4,7,11-tetraza-cyclotetradecane with metal ions. Effect of large hole size and of chelate ring sequence. J. Chem. Soc. Dalton Trans., v. 6, p. 1461-1494, 1991.

[22] ROTHERMEL, JR., G. L.; MIAO, L.; HILL, A. L.; JACKELS, S. C. Macrocyclic ligands with 18-menberer rings containing pyridine or furan groups: Preparation, protonation, and complexation by metal ions. Inorg. Chem., v. 31, p. 4854-4859, 1992.

[23] CASTRO-SOTO, D.; GUADARRAMA, P. Macrocyclic vs. dendrimeric effect. A DFT study. J. Comp. Chem., v. 25, p. 1215-1226, 2004. 
[24] BLADES, A. T.; KEBARLE, P. Gás phase ion thermochemistry of tetraaza complexes such as cyclam $\mathrm{M}^{2+}$ with $\mathrm{H}_{2} \mathrm{O}, \mathrm{CH}_{3} \mathrm{OH}, \mathrm{NH}_{3}$, and other ligands, where $\mathrm{M}^{2+}=\mathrm{Mn}^{2+}, \mathrm{Ni}^{2+}$, $\mathrm{Cu}^{2+}, \mathrm{Zn}^{2+}$. J. Phys. Chem. A, v. 110, p. 12055-12062, 2006.

[25] IZATT, R. M.; BRADSHAW, J. S.; NIELSEN, S. A.; LAMB, J. D.; CHRISTENSEN, J. J. Termodynamic and kinetic data for cation-macrocycle interaction. Chem. Rev., v. 85, p. 271-339, 1985.

[26] LAMB, J. D.; IZATT, R. M.; CHRISTENSEN, J. J.; EATOUGH, D. J. In coordination chemistry of macrocyclic compounds. New York: Plenum Press, 1979. p. 145-218.

[27] SABATINE, L.; FABBIZZI, L. Fitting of nickel(II) ion into two 14-membered tetraaza macrocycles. Blue-to-yellow conversion and the oxidation and reduction behavior Inorg. Chem., v. 18, p. 438-444, 1979.

[28] MICHELONI, M.; PAOLETTI, P. The macrocyclic effect: Thermodynamic parameters for the formation of zinc(II) complexes with macrocyclic ligands of varying ring-size. Inorg. Chim. Acta, v. 43, p. 109-102, 1980.

[29] BENETOLLO, F.; BOMBIERI, G.; CALABI, L.; AIME, S.; BOTTA M. Structural variations across the lanthanide series of macrocyclic DOTA complexes: Insights into the design of contrast agents for magnetic resonance imaging. Inorg. Chem., v. 42, p. 148-157, 2003.

[30] SHAMOV, G. A.; SCHRECKENBACH, G. Relativistic density functional theory study of dioxoactinide(VI) and -(V) complexation with alaskaphyrin and related schiff-base macrocyclic ligands. J. Phys. Chem. A, v. 110, p. 9486 - 9499, 2006.

[31] HANNONGBUA, S. V.; RODE, B. M. Quantum-Chemical investigations on the of alkaline-earth-metal íons with macrocyclic compounds. Inorg. Chem., v. 24, p. 2577-2580, 1984.

[32] AMORIN, M. T. S.; CHAVES, S.; DELGADO, R.; DA SILVA, J. J. R. F. Oxatriaza macrocyclic ligands: Studies of protonation and metal complexation. J. Chem. Soc. Dalton Trans., v. 11, p. 3065-3072, 1991.

[33] CABBINESS, D. K.; MARGERUM, D. M. Macrocyclic effect on the stability of copper(II) tetramine complexes. J. Am. Chem. Soc., v. 91, p. 6540-6541, 1969.

[34] KETTLE, S. F. A. Physical inorganic chemistry: a coordination chemistry approach. 2. ed. New York: Oxford, 1998. p. 123-129.

[35] MIESSLER, G. L.; TARR, D. A. Inorganic chemistry. New Jersey: Prentice-Hall, 1991. p. 284-285. 
[36] HUHEEY, J. E.; KEITER, E. A.; KEITER, R. L. Inorganic chemistry: principles structure and reactivity. 4. ed. New York: HaperCollins, 1993. p. 431.

[37] LEE, J. D. Química inorgânica: não tão concisa. 5. ed. São Paulo: Edgard Blücher, 1999. p. 110-111.

[38] KEATING, P.N. Effect of invariance requirements on elastic strain energy of crystals with application to diamond structure. Phys. Rev., v. 145, p. 637, 1966.

[39] PHILLIPS, J.C. Covalent bond in crystal I: Elements of a structural theory. Phys. Rev., v. 166, p. $832,1968$.

[40] OMELTCHENKO, A.; YU, J.; KALIA, R.K.; VASHISHTA, P. Crack frint propagation and fracture in a graphite sheet: A molecular-dynamics study on parallel computers. Phys.

Rev. Lett., v. 78, p. 2148-2151, 1997.

[41] MCWEENY, R.; SUTCLIFFE, B.T. Methods of molecular quantum mechanics. London: Academic Press, 1969. 690p.

[42] THOMAS, L.H. The calculation of atomic fields. Proc. Cam. Phil. Soc., v. 23, p. 542$548,1927$.

[43] FERMI, E. A statistical method for the determination of some atomic properties and application of this method to the theory of the periodic system of elements. Z. Phys., v. 48, p. 73-79, 1928.

[44] HEZENBERG, P.; KOHN, W. Inhomogeneous electron gas. Phys. Rev., v. 136, p. B864, 1964.

[45]KOHN, W.; SHAM, L. J. Self-consistent equations including exchange and correlation effects. Phys. Rev., v. 140, p. A1133-A1138, 1965.

[46] MORGON, N.H.; CUSTODIO, R. Teoria do funcional de densidade. Quim. Nova., v. 18, p. 44-54, 1995.

[47] PERDEW, J.P.; YUE, W. Accurate and simple density functional for the electronic exchange energy: Generalized gradient approximation. Phys. Rev. B., v. 33, p. 8800-8802, 1986.

[48 ] BECKE, A.D. Density-functional exchange-energy approximation with correct asymptotic behavior. Phys. Rev. A., v. 38, p. 3098-3100, 1988.

[49] BECKE, A.D. Density-functional thermochemistry 3: The role of exact exchange. J. Chem. Phys., v. 98, p. 5648-5652, 1993. 
[50] LEE, C.T.; YANG, W.T.; PARR, R.G. Development of the colle-salvetti correlation energy formula into a functional of the electron-density. Phys. Rev. B., v. 37, p. 785-789, 1988.

[51] HAY, P. J.; WADT, W. R. Ab initio effective core potentials for molecular calculations. Potentials for the transition metal atoms Sc to Hg. J. Chem. Phys., v. 82, p. 270-283, 1985.

[52] WADT, W. R.; HAY, P. J. Ab initio effective core potentials for molecular calculations. Potentials for main group elements Na to Bi. J. Chem. Phys., v. 82, p. 284-298, 1985.

[53] HAY, P. J.; WADT, W. R. Ab initio effective core potentials for molecular calculations. Potentials for K to Au including the outermost core orbitals. J. Chem. Phys., v. 82, p. 299310, 1985.

[54] FRISCH, M. J.; TRUCKS, G. W.; SCHLEGEL, H. B.; SCUSERIA, G. E.; ROBB, M. A.; CHEESEMAN, J. R.; MONTGOMERY, JR., J. A.; VREVEN, T.; KUDIN, K. N.; BURANT, J. C.; MILLAM, J. M.; IYENGAR, S. S.; TOMASI, J.; BARONE, V.; MENNUCCI, B.; COSSI, M.; SCALMANI, G.; REGA, N.; PETERSSON, G. A.; NAKATSUJI, H.; HADA, M.; EHARA, M.; TOYOTA, K.; FUKUDA, R.; HASEGAWA, J.; ISHIDA, M.; NAKAJIMA, T.; HONDA, Y.; KITAO, O.; NAKAI, H.; KLENE, M.; LI, X.; KNOX, J. E.; HRATCHIAN, H. P.; CROSS, J. B.; BAKKEN, V.; ADAMO, C.; JARAMILLO, J.; GOMPERTS, R.; STRATMANN, R. E.; YAZYEV, O.; AUSTIN, A. J.; CAMMI, R.; POMELLI, C.; OCHTERSKI, J. W.; AYALA, P. Y.; MOROKUMA, K.; VOTH, G. A.; SALVADOR, P.; DANNENBERG, J. J.; ZAKRZEWSKI, V. G.; DAPPRICH, S.; DANIELS, A. D.; STRAIN, M. C.; FARKAS, O.; MALICK, D. K.; RABUCK, A. D.; RAGHAVACHARI, K.; FORESMAN, J. B.; ORTIZ, J. V.; CUI, Q.; BABOUL, A. G.; CLIFFORD, S.; CIOSLOWSKI, J.; STEFANOV, B. B.; LIU, G.; LIASHENKO, A.; PISKORZ, P.; KOMAROMI, I.; MARTIN, R. L.; FOX, D. J.; KEITH, T.; AL-LAHAM, M. A.; PENG, C. Y.; NANAYAKKARA, A.; CHALLACOMBE, M.; GILL, P. M. W.; JOHNSON, B.; CHEN, W.; WONG, M. W.; GONZALEZ, C.; AND POPLE, J. A. Gaussian 03: revision C.02. Wallingford: Gaussian, 2004. Programa de computador.

[55] GORESLSKY, S.I.; LEVER, A.B.P. Electronic structure and spectra of ruthenium diimine complexes by density functional theory and INDO/S. Comparison of the two Methods. J. Organomet. Chem., v. 635, p. 187-196, 2001.

[56] GORESLSKY, S.I. AOMix: Program for molecular orbital analysis. Toronto: York University, 1997. Disponível em: 〈http://www.sg-chem.net〉. Acesso em: 20 nov. 2005.

[57] DAPPRICH, S.; FRENKING, G. Investigation of donor-acceptor interactions: A charge decomposition analysis using fragment molecular orbital. J. Phys. Chem., v. 99, p. 93529362, 1995. 
[58] GORESLSKY, S.I.; GHOSH, S.; SOLOMON, E. I. Mechanism of $\mathrm{N}_{2} \mathrm{O}$ reduction by the $\mathrm{m}_{4}$-Sulfide bridged tetranuclear $\mathrm{Cu}_{\mathrm{Z}}$ cluster of nitrous oxide reductase. J. Am. Chem. Soc., v. 128, p. 278-290, 2006.

[59] MAYER, I. Charge, bond order and valence in the ab initio SCF theory. Chem. Phys. Lett., v. 97, p. 270-274, 1983.

[60] MAYER, I. Bond orders and valences in the SCF theory: A comment. Theor. Chim. Acta, v. 67, p. 315-322, 1985.

[61] MAYER, I. On bond orders and valences in the ab initio quantum chemical theory. Int. J. Quantum Chem., v. 29, p. 73-84, 1986.

[62] MAYER, I. Bond orders and valences from ab initio wave functions. Int. J. Quantum Chem., v. 29, p. 477-483. 1986.

[63] GLENDENING, E. D.; BADEMHOOP, J. K.; REED, A. E.; CARPENTER, J. E.; BOHMANN, J. A.; MORAES, C. M.; WEINHOLD, F. NBO 3.0 . Madison: Theoretical Chem. Institute, 1998. Programa de computador.

[64] GORELSKY, S. I. Swizard. Toronto: York University. Department of Chemistry, 1999. Disponível em: 〈http://www.sg-chem.net〉. Acesso em: 05 fev. 2005.

[65] PANCHENKO, Y.N. Scaling of quantum-mechanical molecular force fields. Russ. Chem. Bull., v. 45, p. 753-760, 1996.

[66] SCOTT, A.P.; RADOM,L. Harmonic vibrational frequencies: An evaluation of Hartreefock, Moller-Plesset, quadratic configuration interaction, density functional theory and semiempirical scale factors. J. Chem. Phys., v. 100, p. 16502-16513, 1996.

[67] LI, W.; WANG, Y.; YANG, L.; SZEGHALMI, A.; YE, Y.; MA, J.; LUO, M.; HU, J.; KIEFER, W. Spectroscopic and computational studies on self-assembly complexes of bis(pyrrol-2-ylmethyleneamine) ligands linked by alkyl spacers with $\mathrm{Cu}(\mathrm{II})$. J. Raman Spectros., v. 38, p. 483-495, 2007.

[68] HANCOCK, R. D. Molecular mechanics calculations and metal ion recognition. Acc. Chem. Res., v. 23, p. 253-267, 1990.

[69] SCHMIEDEKAMP, A. M.; RYAN, M. D.; DEETH, R. J. Six-Coordinate $\mathrm{Co}^{2+}$ with $\mathrm{H}_{2} \mathrm{O}$ and $\mathrm{NH}_{3}$ Ligands: Which Spin State Is More Stable?. Inorg. Chem., v. 41, p. 5733-5743, 2002. 
[70] DIAZ, G. F.; CLAVIJO, C. R.; CAMPOS-VALLETTE, M. M.; SAAVEDRA, M. S., DIEZ, S.; MUÑOZ, R. Specular reflectance infrared spectra of the macrocycles cyclam and cyclamdione and their $\mathrm{Cu}$ (II) complexes deposited onto a smooth copper surface. Vibrat. Spect., v. 15, p. 201-209, 1997.

[71] CAMPOS-VALLETTE, M. M.; CLAVIJO, C. R.; COSTAMAGNA, J.; CANALES, J. C. DIAZ, G. F.; MENDIZABAL, F. E.; RAMIREZ, J. M.; SAAVEDRA, M. S. Vibrational and theoretical study of azabipiridyl macrocycle and its $\mathrm{Ni}(\mathrm{II}), \mathrm{Cu}$ (II) and $\mathrm{Zn}$ (II) complexes deposited onto a smooth copper surface. Vibrat. Spec., v. 23, p. 39-49, 2000.

[72] DIAZ, G. F.; CLAVIJO, C. R.; CAMPOS-VALLETTE, M. M.; SAAVEDRA, M. S., DIEZ, S.; MUÑOZ, R. CANALES, J. C.; COSTAMAGNA, J.; VARGAS. J. Surface vibrational study of macrocycle complexes: $\mathrm{Co}(\mathrm{II}), \mathrm{Ni}(\mathrm{II}), \mathrm{Cu}(\mathrm{II})$ and $\mathrm{Zn}$ (II) bis(phenylhydrazine)-1,10-phenanthroline. Vibrat. Spec., v. 28, p. 223-234, 2002.

[73] NAKAMOTO, K. Infrared and raman spectra of inorganic and coordination compounds. 2. ed. New York : Wiley-Interscience, 1970. p. 191-220.

[74] CHANDRA, S.; PUNDIR, M. Spectroscopic characterization of chromium(III), manganese(II) and nickel(II) complexes with a nitrogen donor tetradentate, 12-membered azamacrocyclic ligand. Spectroc. Acta A, v. 69, p. 1-7, 2008.

[75] CHANDRA, S.; VERMA, S. Spectroscopic studies of transition metal complexes with a $\mathrm{N}$-donor tetradentate $\left(\mathrm{N}_{4}\right)$ 12-membered macrocylic ligand. Spectroc. Acta A, 2008. No prelo.

[76] TABUSHI, I.; KUGIMIYA, S.; KINNAIRD, M.G.; SASAKI, T. J. Artificial allosteric system. 2. Cooperative 1-methylimidazole binding to an artificial allosteric system, zinc-gable porphyrin-dipyridylmethane complex. J. Am. Chem. Soc., v. 107, p. 4192-4199, 1985.

[77] GORELSKY, S.I.; BASUMALLICK, L.; WEIS, J.; V.; SARANGI, R.; HODGSON, K. O.; HEDMAN, B.; FUJISAWA, K.; SOLOMON, E. I. Spectroscopic and DFT investigation of $\left[\mathrm{M}\left\{\mathrm{HB}\left(3,5{ }^{i} \mathrm{Pr}_{2} \mathrm{pz}\right)_{3}\right\}\left(\mathrm{SC}_{6} \mathrm{~F}_{5}\right)\right](\mathrm{M}=\mathrm{Mn}, \mathrm{Fe}, \mathrm{Co}, \mathrm{Ni}, \mathrm{Cu}$, and $\mathrm{Zn})$ model complexes: Periodic trends in metal-thiolate bonding. Inorg. Chem., v. 44, p. 4947-4960, 2005.

[78] RUSANOVA, J.; RUSANOV, E.; GORELSKY, S.I.; CHRISTENDAT, D.; POPESCU, R.; FARAH, A.; A.; BEAULAC, R.; REBER, C.; LVER, A. B. P. The very covalent diammino(o-benzoquinonediimine) dichlororuthenium(II). An example of very strong $\pi$-backdonation. Inorg. Chem., v. 45, p. 6246-6262, 2006.

[79] REED, A. E.; CURTISS, L. A. AND WEINHOLD, F. Intermolecular interactions from a natural bond orbital, donor-acceptor viewpoint. Chem. Rev., v. 88, p. 899-926, 1988.

[80] WEINHOLD, F.; LANdis, C. L. Natural bond orbitals and extensions of localized bonding concepts. Chem. Edu., v. 2, p. 91-104, 2001.

[81] PEDERSEN, C. J. The discovery of crown ethers. Science, v. 241, p. 536-540, 1988. 
[82] PEARSON, R.G. Absolute hardness: Companion paramenter to absolute electronegativity. J. Am. Chem. Soc., v. 105, p. 7512-7516, 1983.

[83] PEARSON, R.G. Absolute electronegativity and hardness: A pplication to inorganic chemistry. Inorg. Chem., v. 27, p. 734-740, 1988.

[84] SIGEL, H.; MCCORMICK, D. B. Discriminating behavior of metal ions and ligands with regard to their biological significance. Acc. Chem. Res., v. 3, p. 201-208, 1970. 


\section{Apêndice A}

\section{ESTRUTURAS OCTAÉDRICAS DOS COMPLEXOS 1a e 1b}

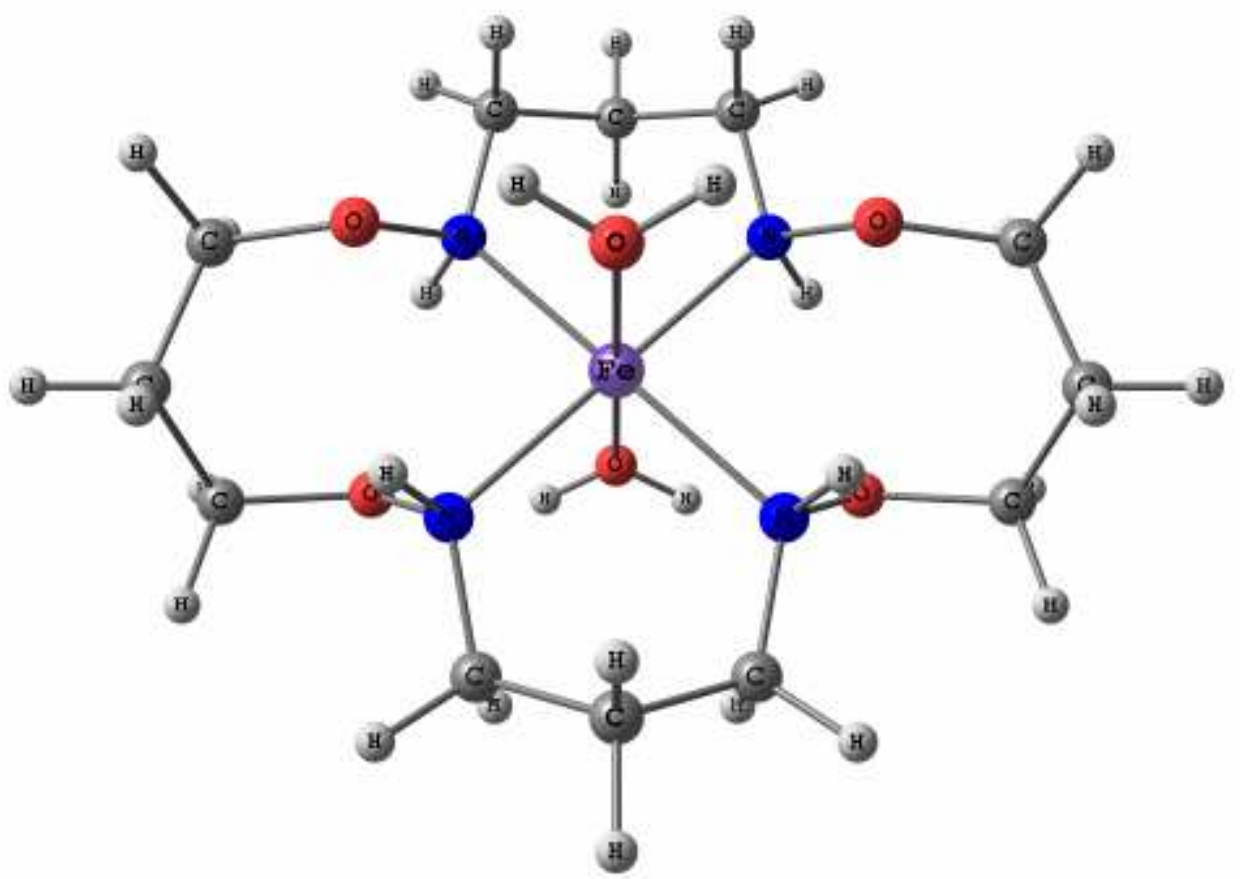

Figura 1-A. Estrutura otimizada do complexo $1 \mathbf{a}$ de $\mathrm{Fe}^{2+}$.

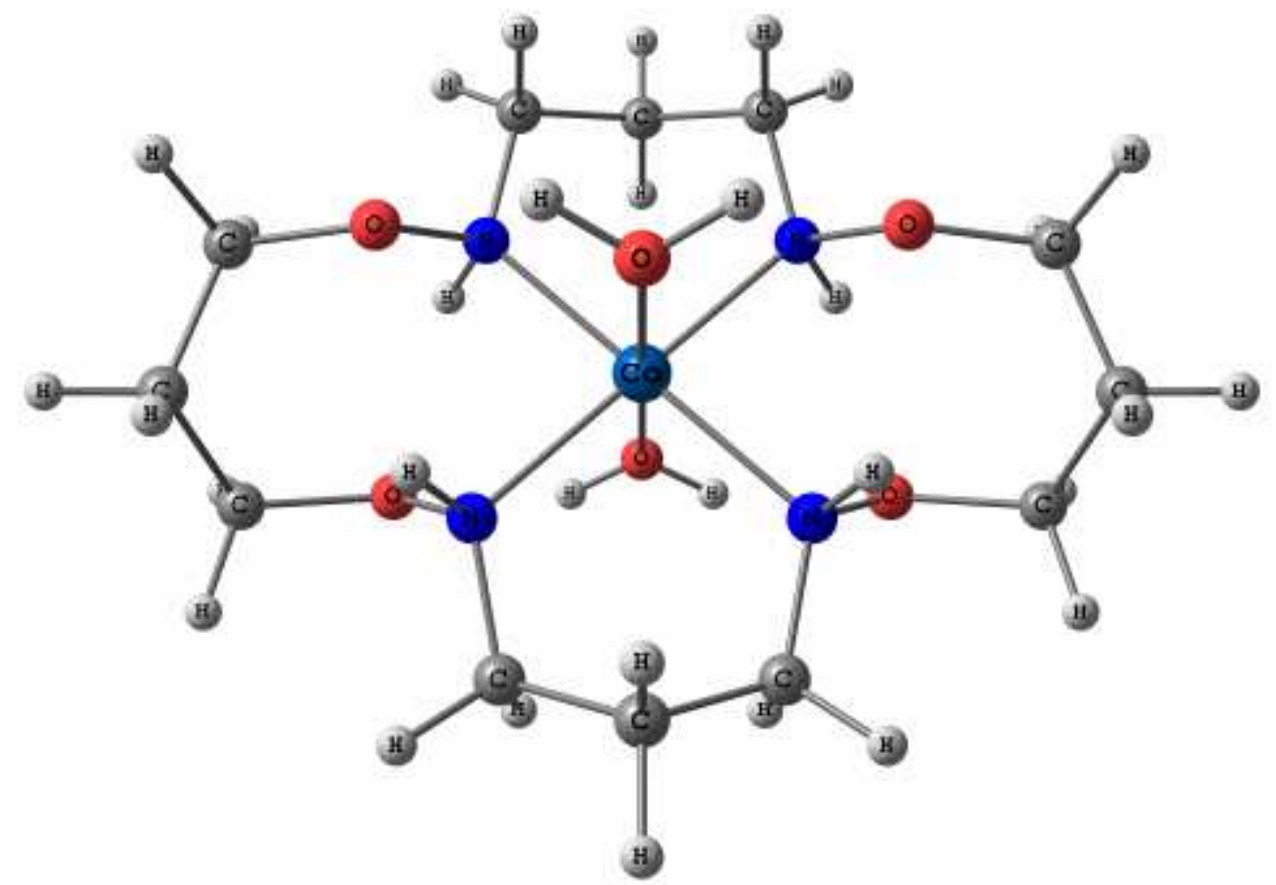

Figura 2-A. Estrutura otimizada do complexo $1 \mathbf{a}$ de $\mathrm{Co}^{2+}$. 


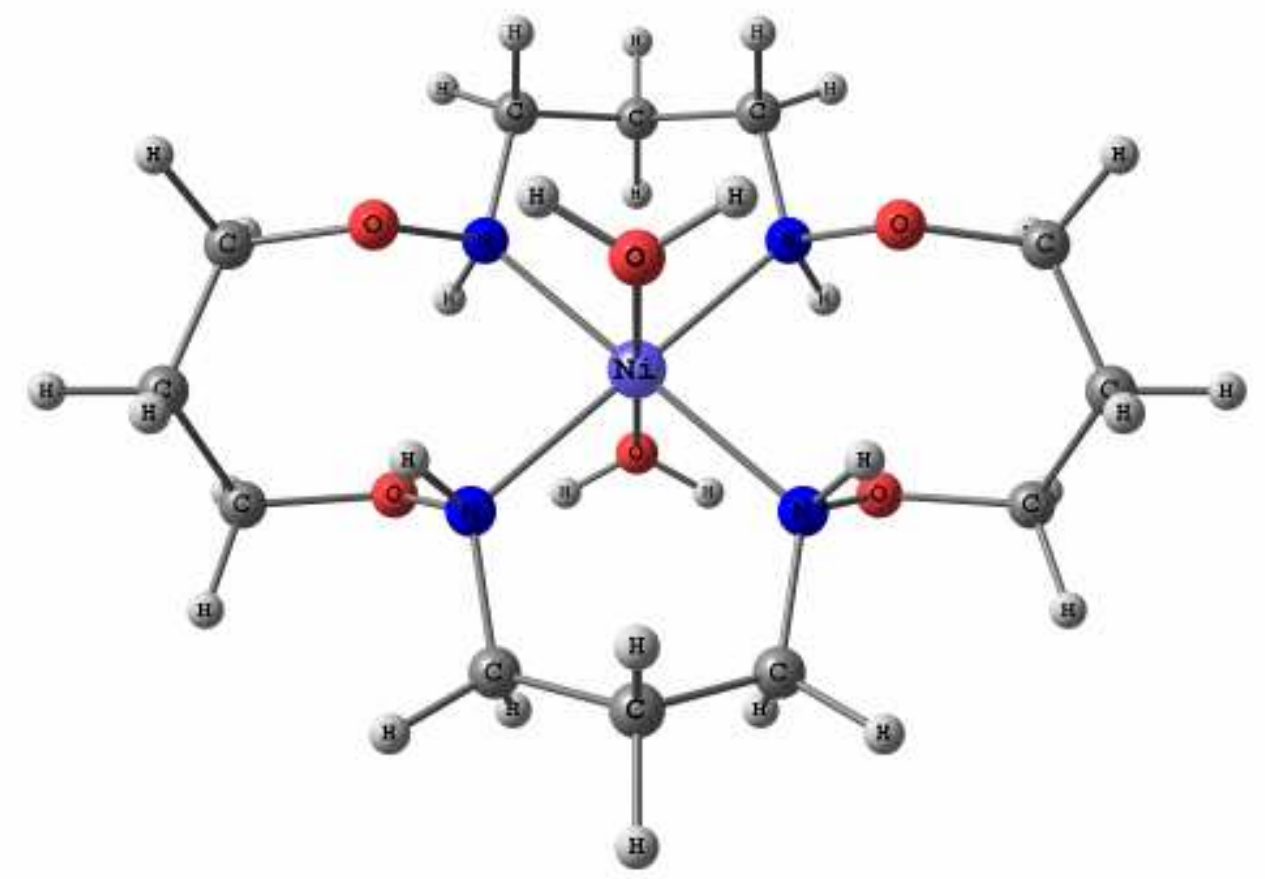

Figura 3-A. Estrutura otimizada do complexo $\mathbf{1 a}$ de $\mathrm{Ni}^{2+}$.

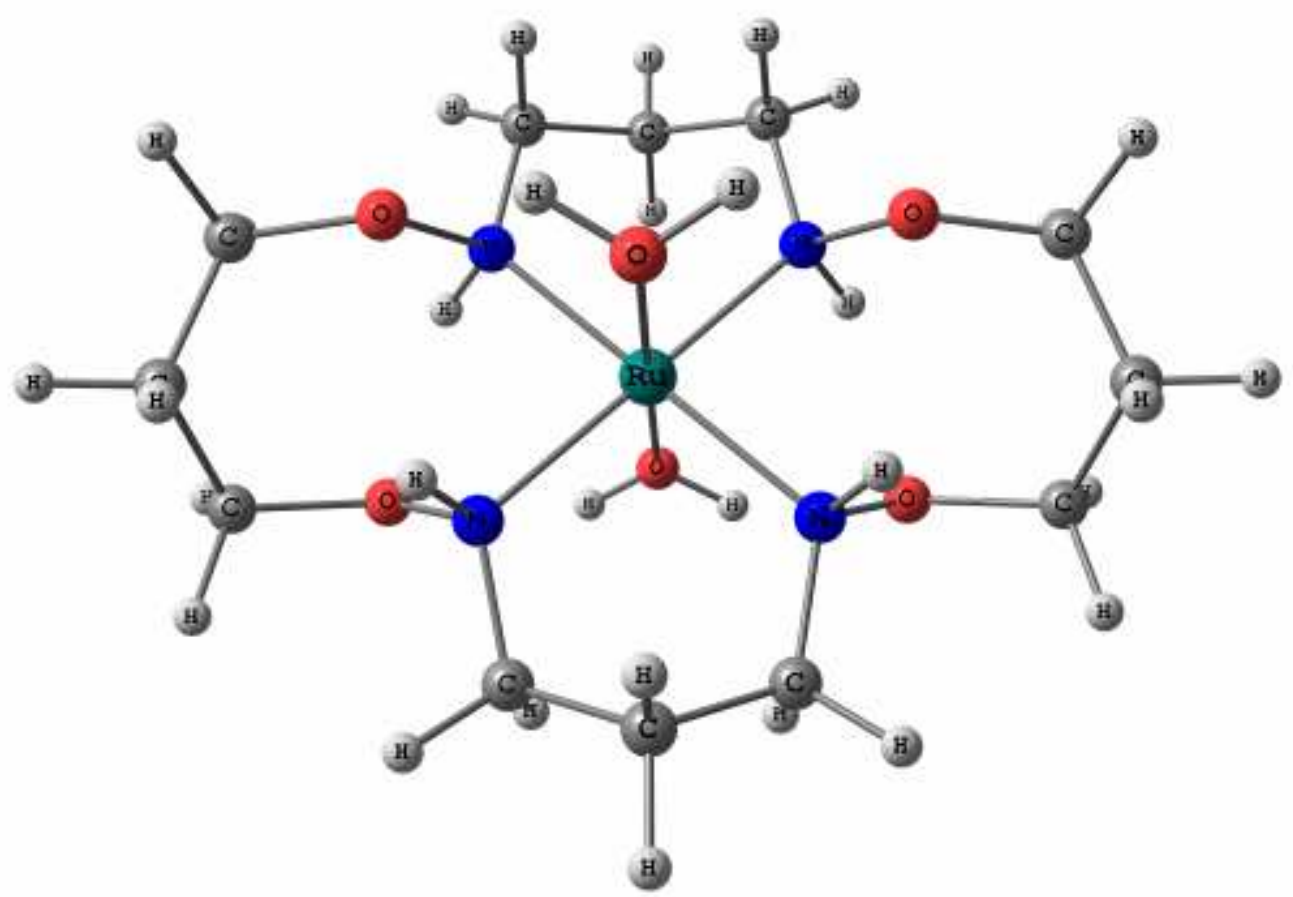

Figura 4-A. Estrutura otimizada do complexo $1 \mathbf{a}$ de $\mathrm{Ru}^{2+}$. 


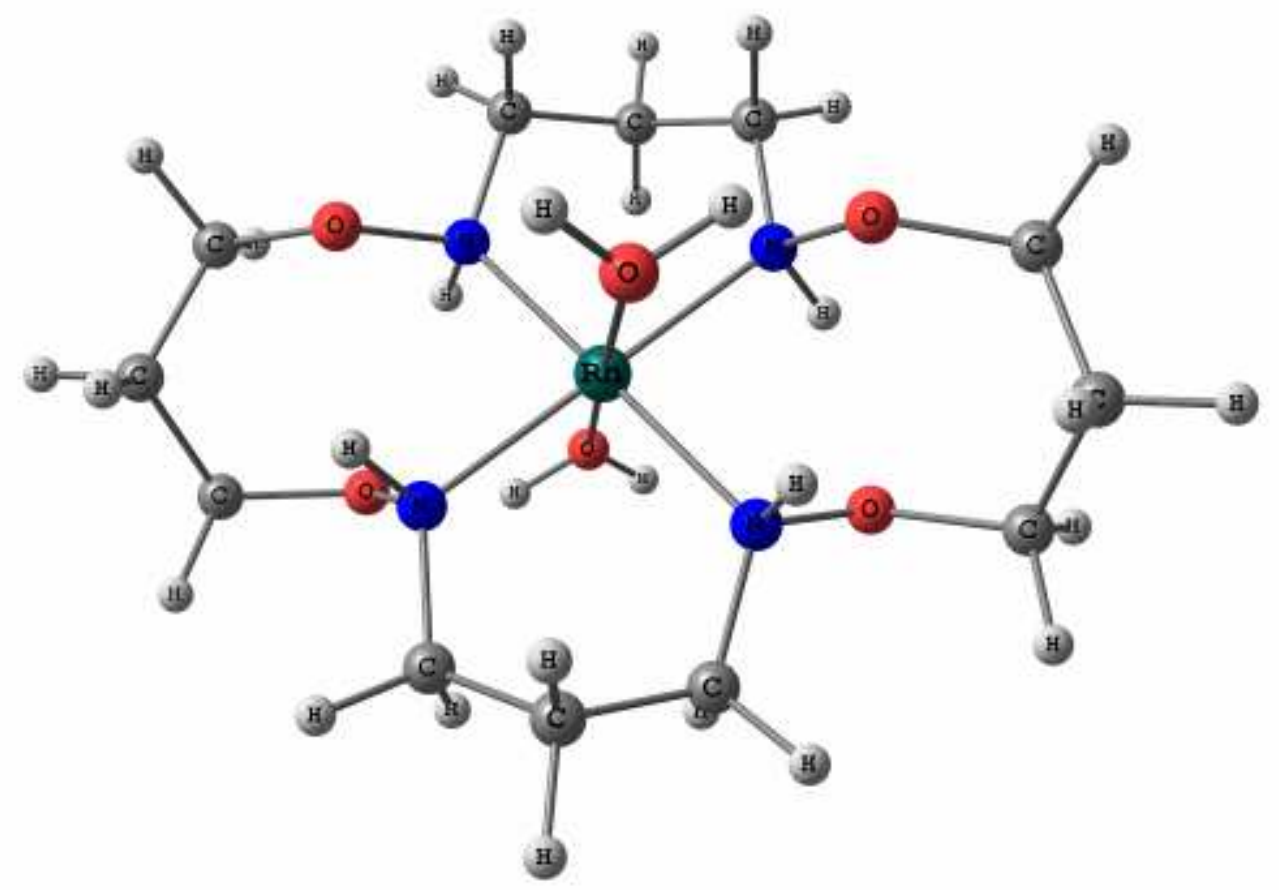

Figura 5-A. Estrutura otimizada do complexo $\mathbf{1 a}$ de $\mathrm{Rh}^{2+}$.

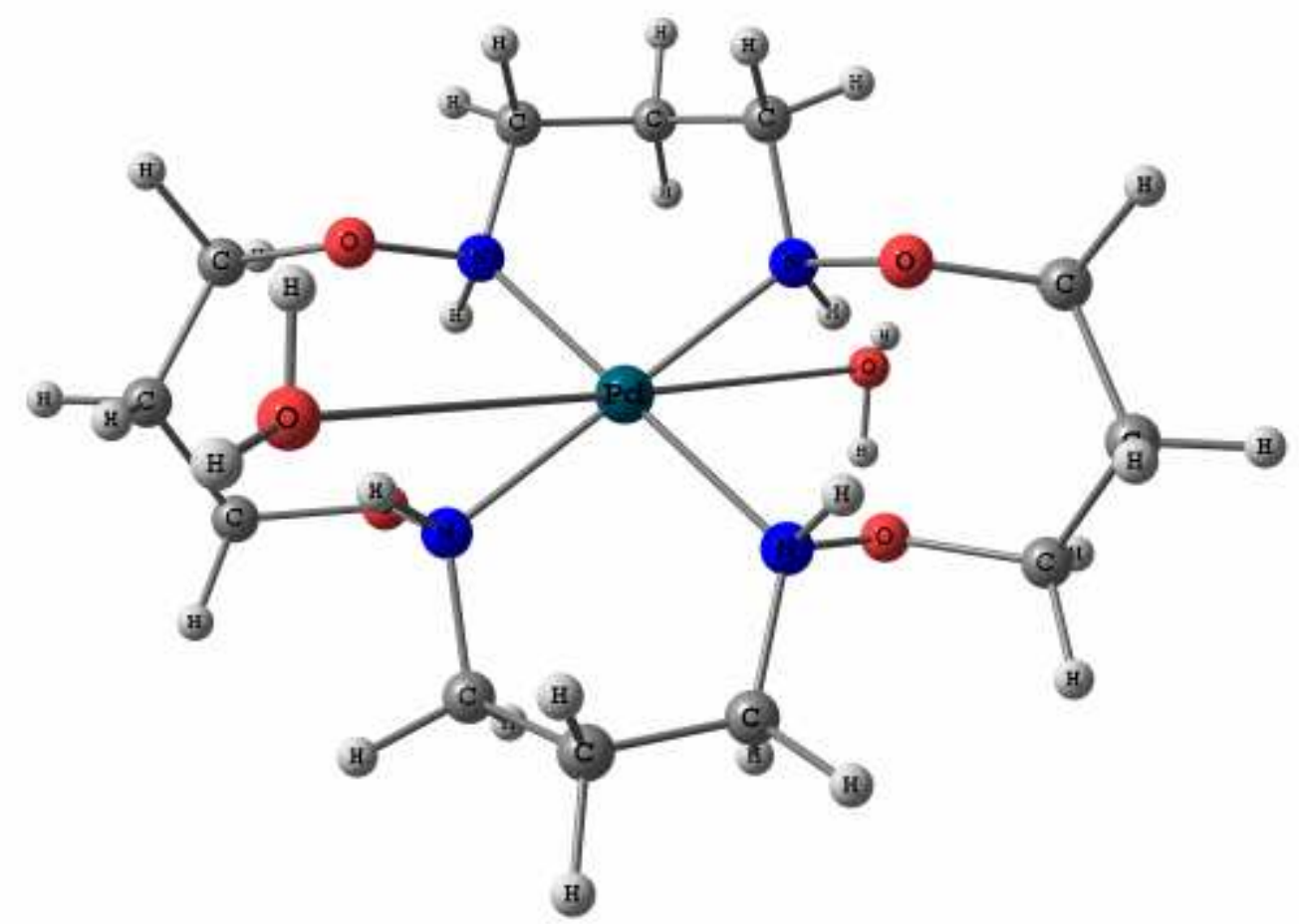

Figura 6-A. Estrutura otimizada do complexo 1a de $\mathrm{Pd}^{2+}$. 


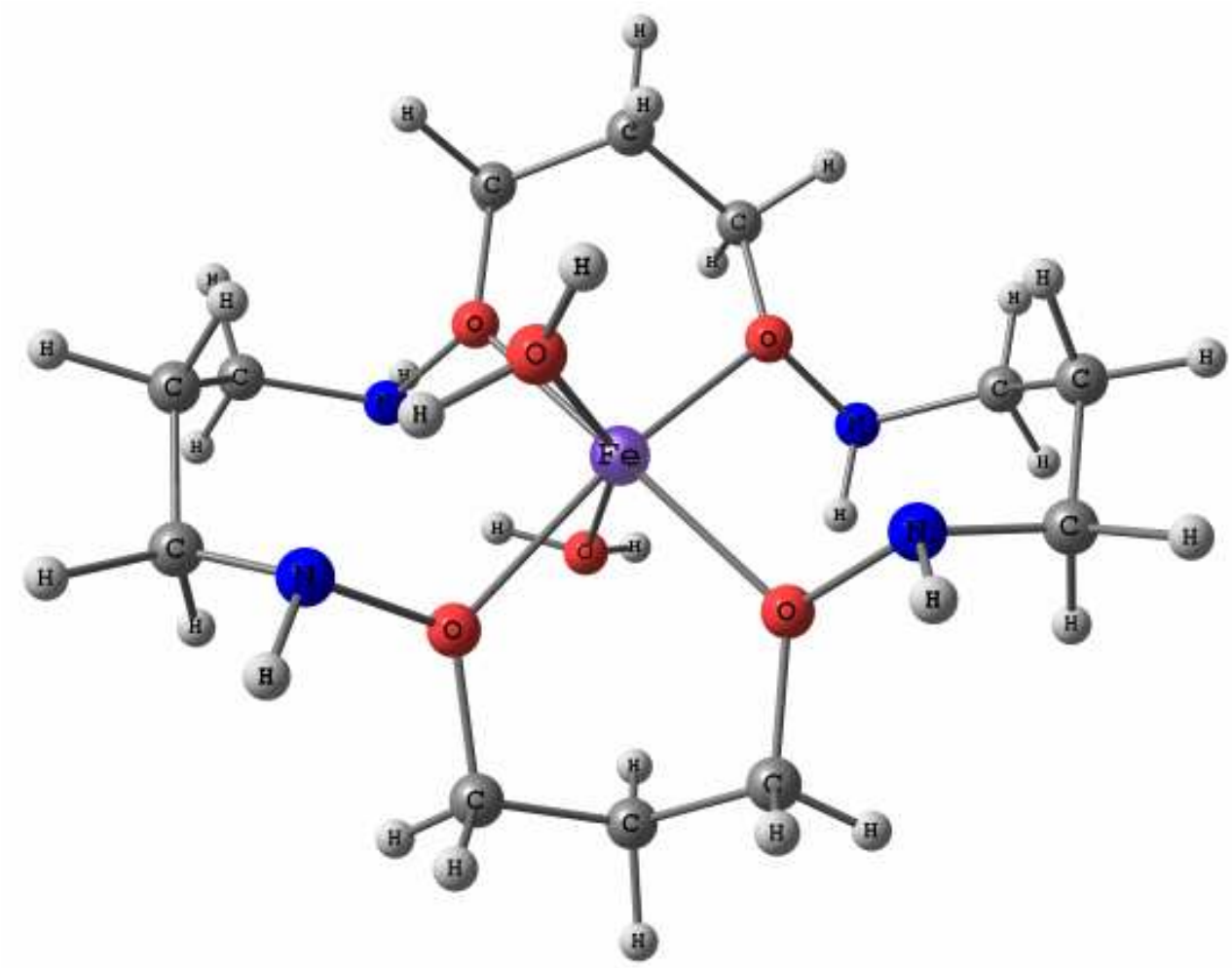

Figura 7-A. Estrutura otimizada do complexo $\mathbf{1 b}$ de $\mathrm{Fe}^{2+}$.

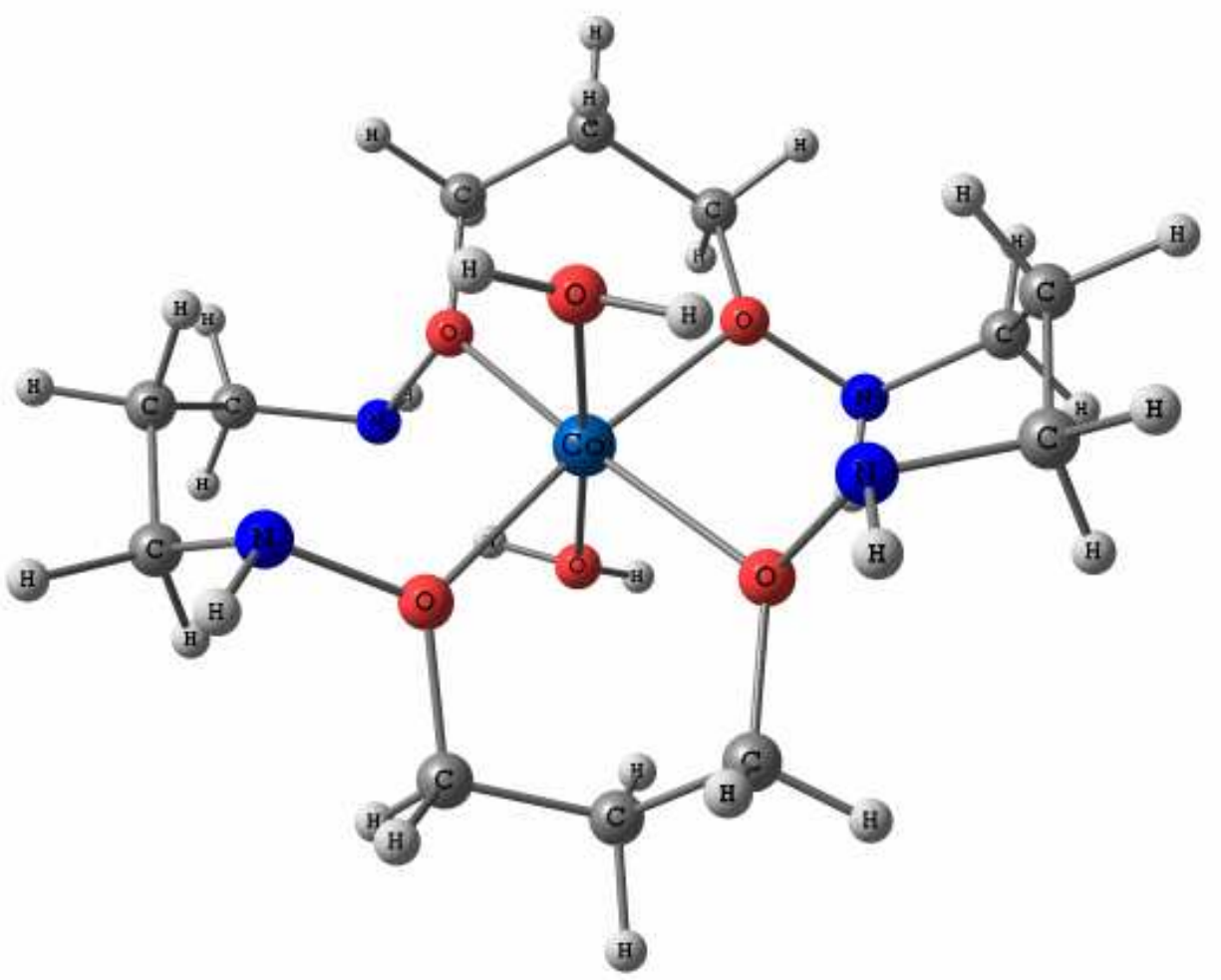

Figura 8-A. Estrutura otimizada do complexo $\mathbf{1 b}$ de $\mathrm{Co}^{2+}$. 


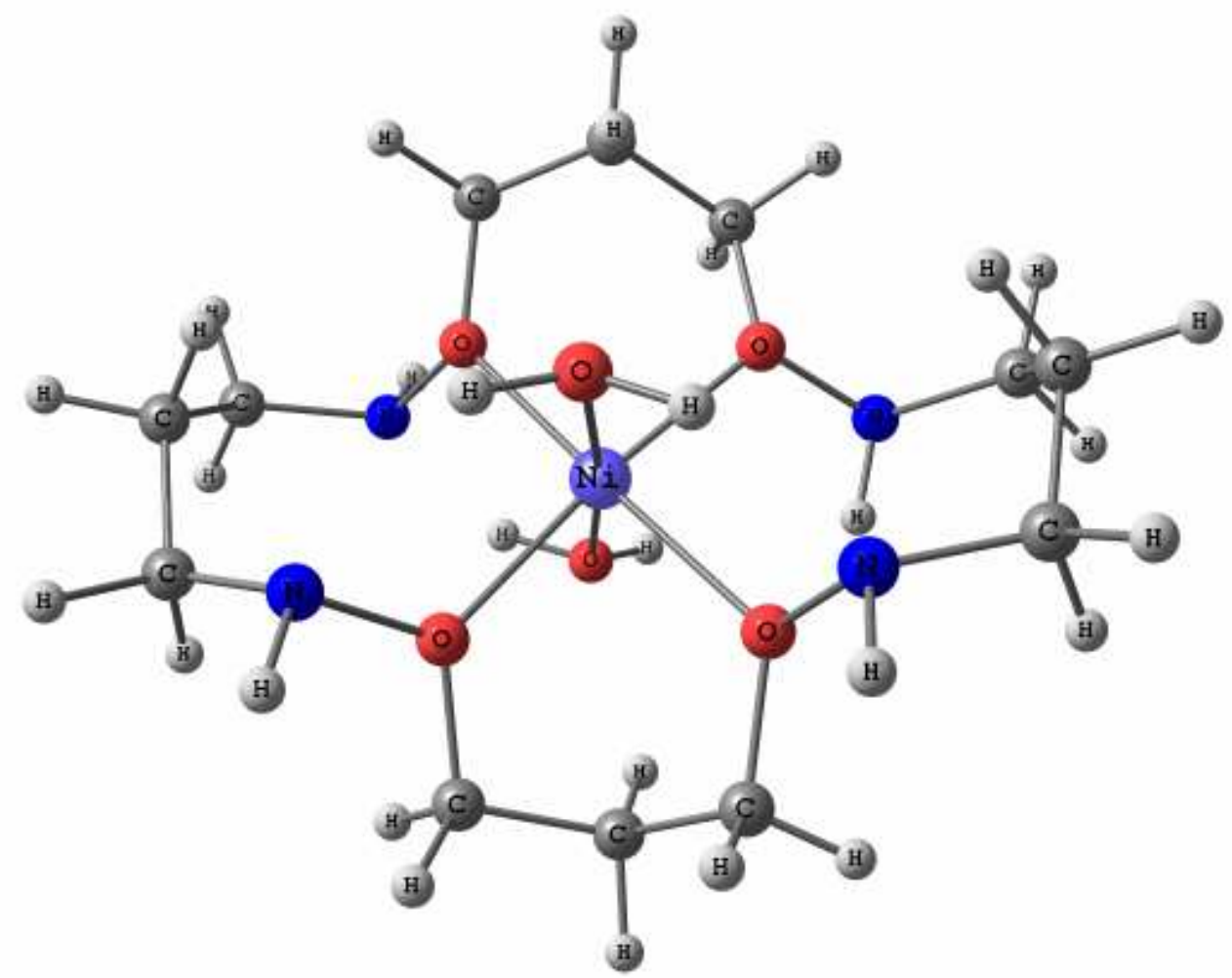

Figura 9-A. Estrutura otimizada do complexo $\mathbf{1 b}$ de $\mathrm{Ni}^{2+}$.

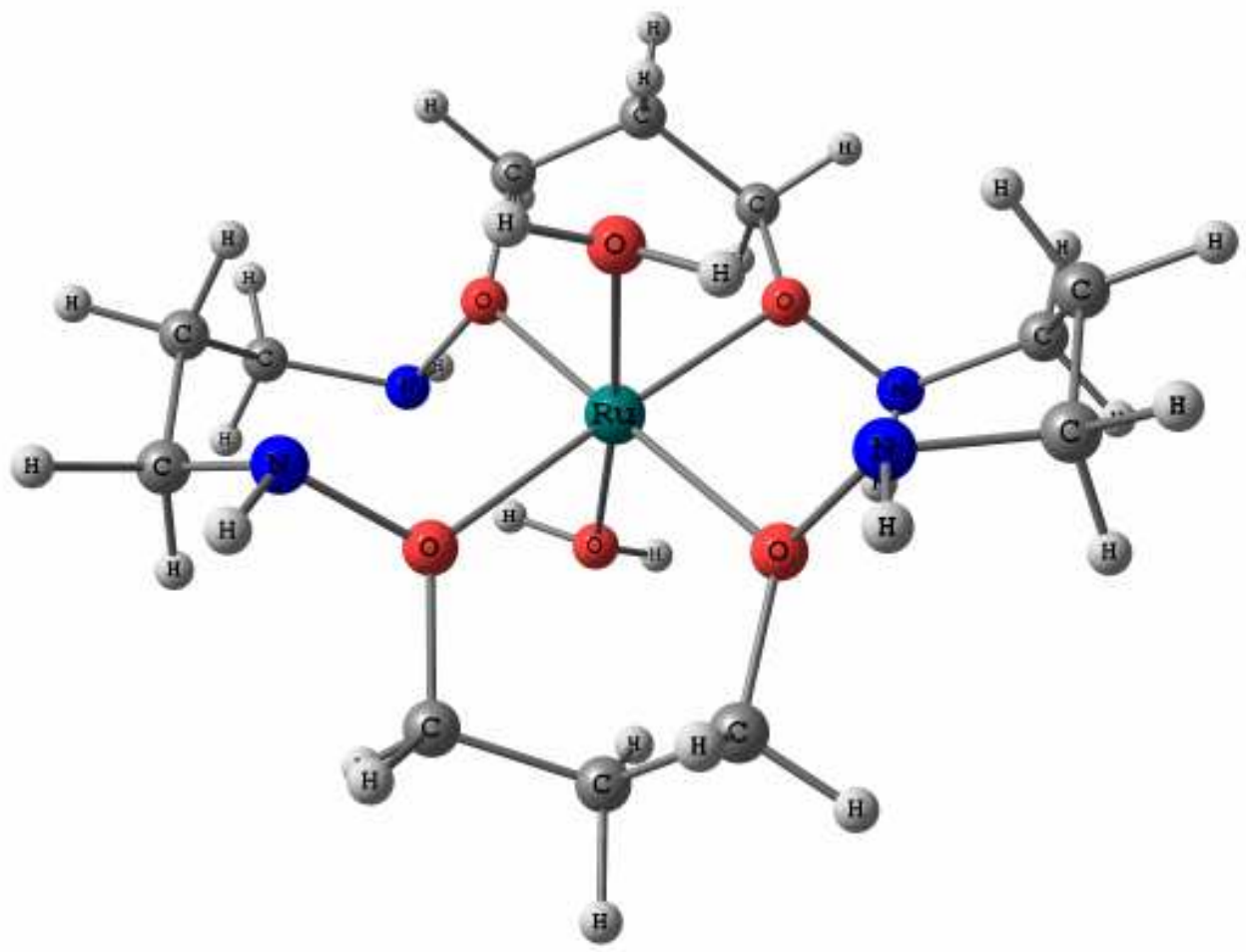

Figura 10-A. Estrutura otimizada do complexo $\mathbf{1 b}$ de $\mathrm{Ru}^{2+}$. 


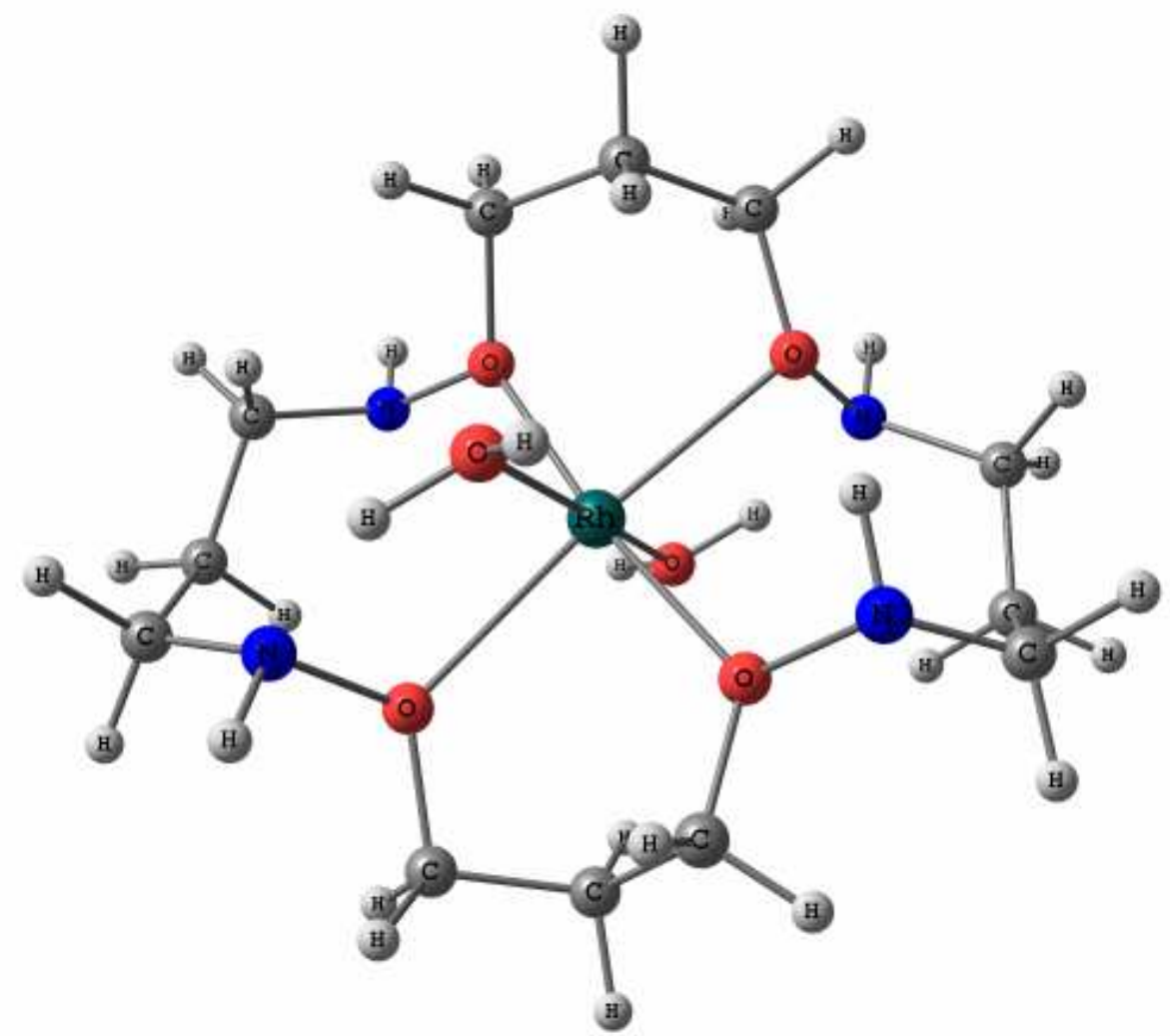

Figura 11-A. Estrutura otimizada do complexo $\mathbf{1 b}$ de $\mathrm{Rh}^{2+}$.

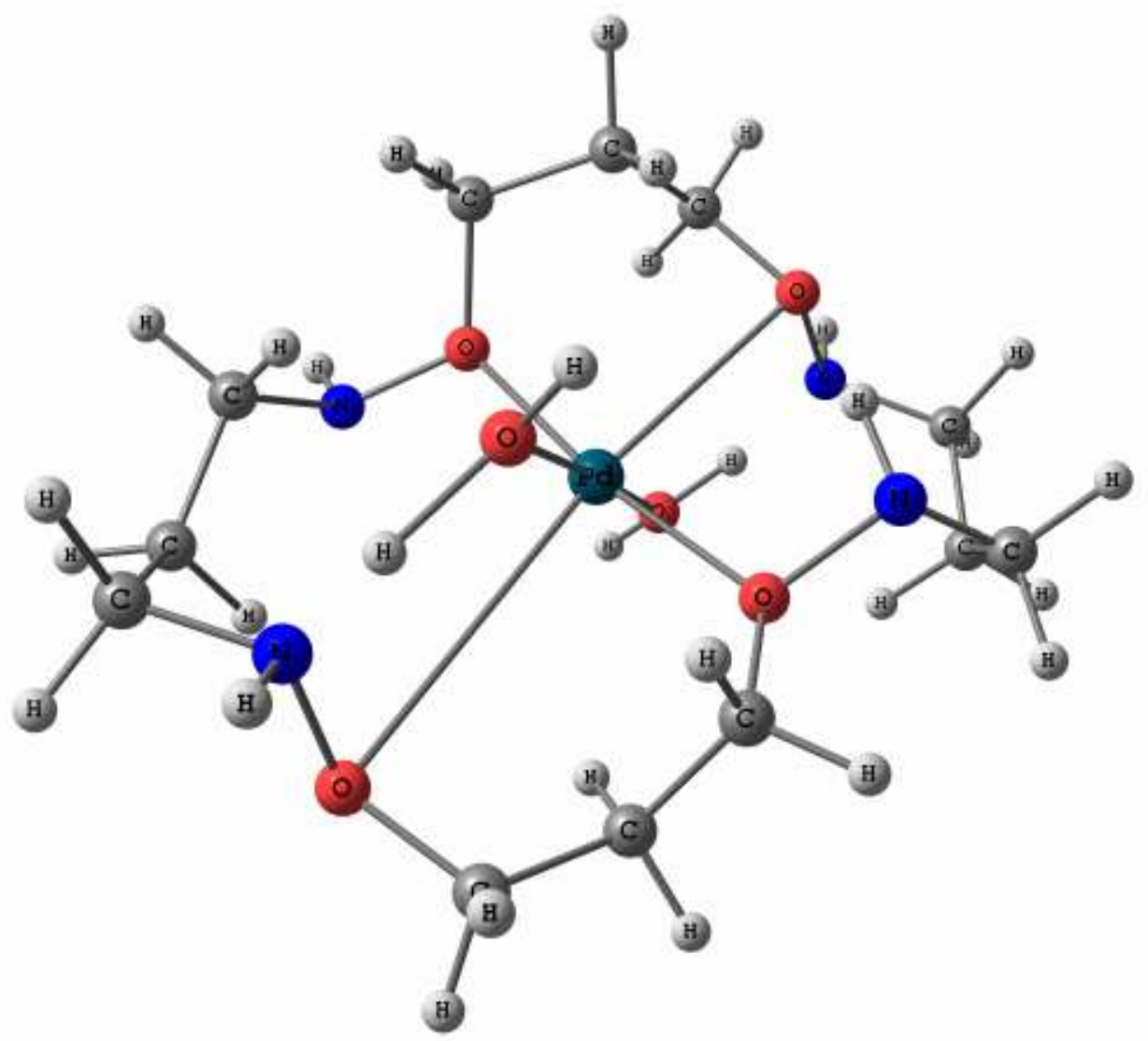

Figura 12-A. Estrutura otimizada do complexo $\mathbf{1 b} \mathrm{de} \mathrm{Pd}^{2+}$. 


\section{Apêndice B}

\section{ESTRUTURAS QUADRADO-PLANARES DOS COMPLEXOS $1 a_{q}$ e $1 b_{q}$}

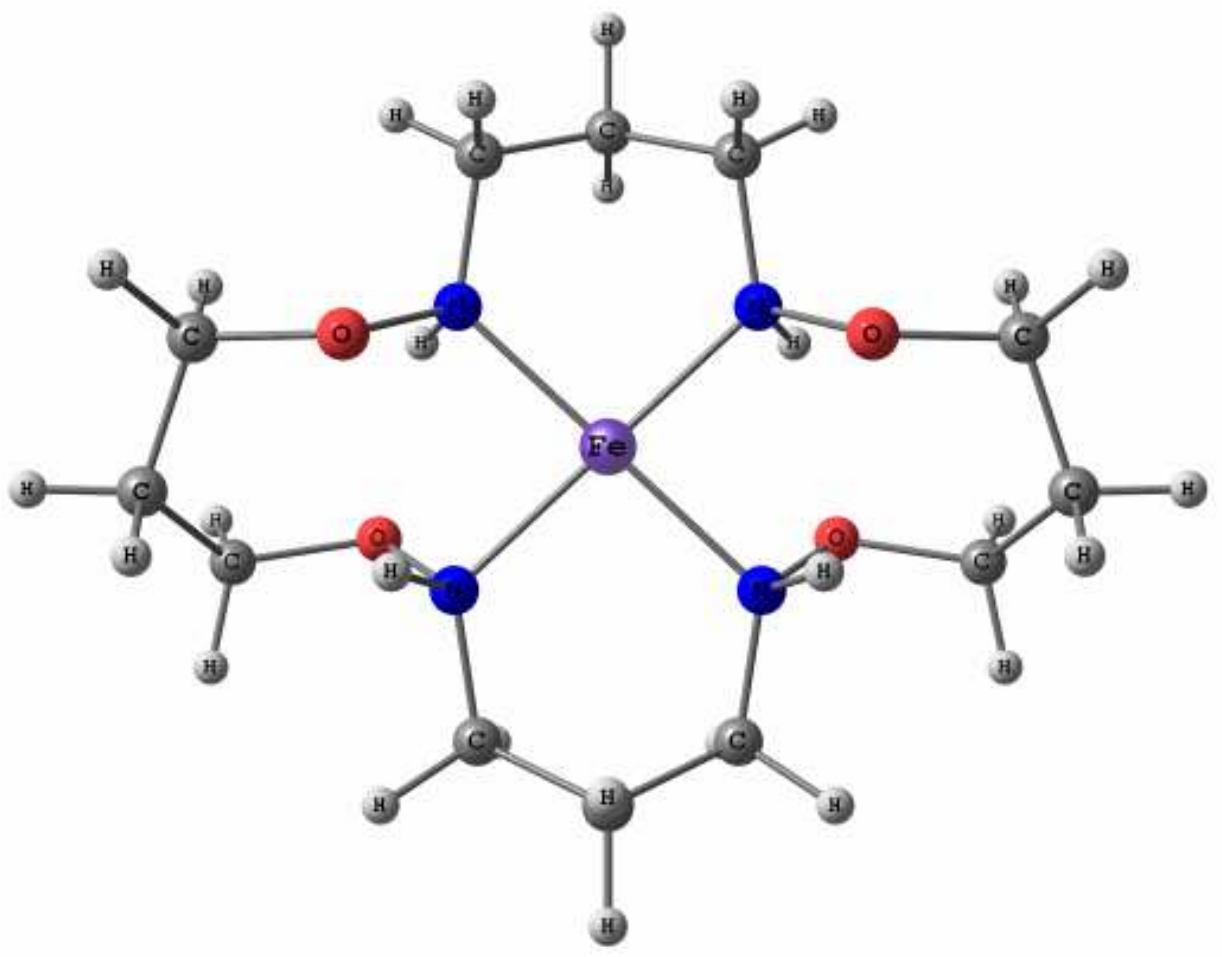

Figura 1-B. Estrutura otimizada do complexo $\mathbf{1 a}_{\mathbf{q}}$ de $\mathrm{Fe}^{2+}$.

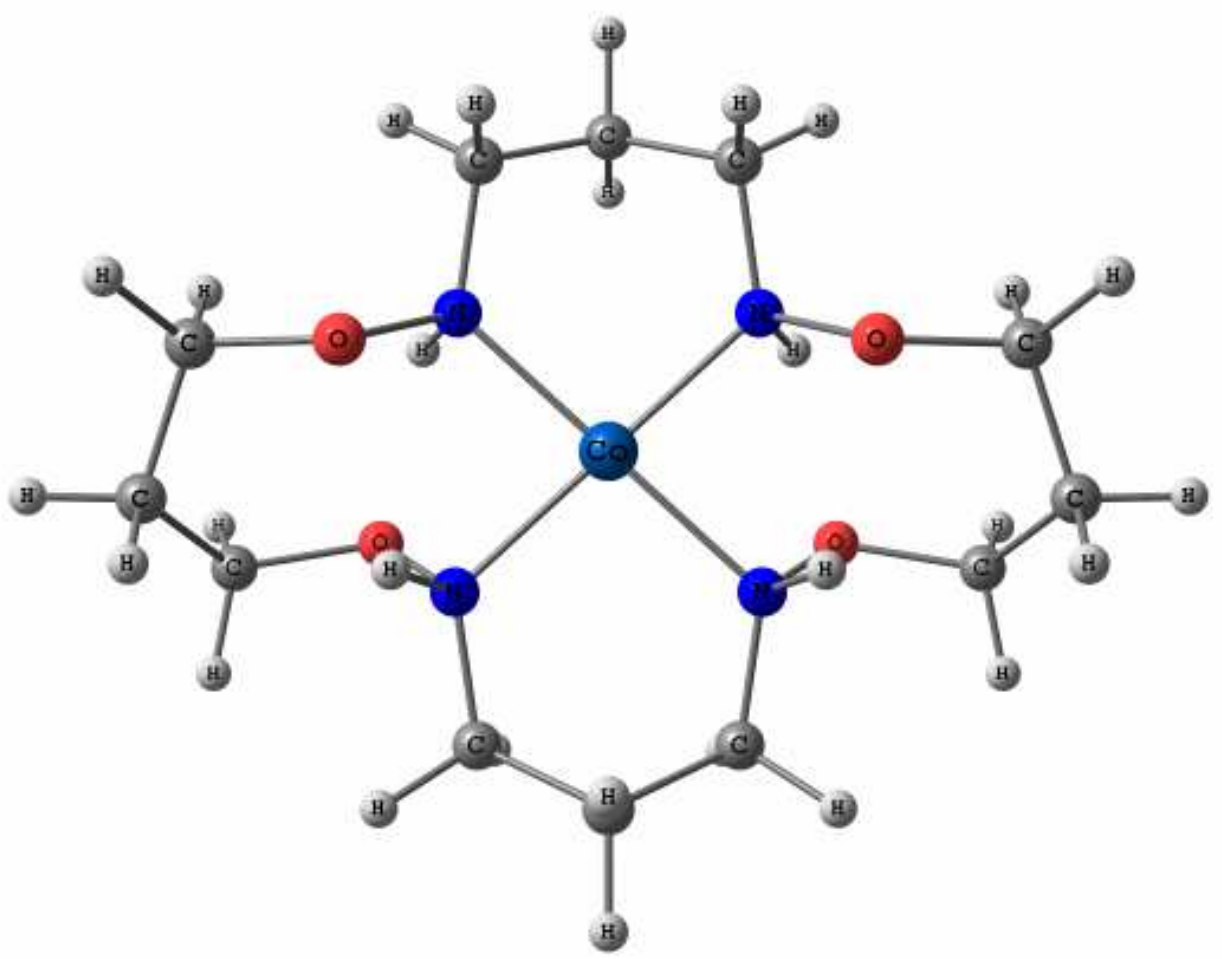

Figura 2-B. Estrutura otimizada do complexo $\mathbf{1 a}_{\mathbf{q}}$ de $\mathrm{Co}^{2+}$. 


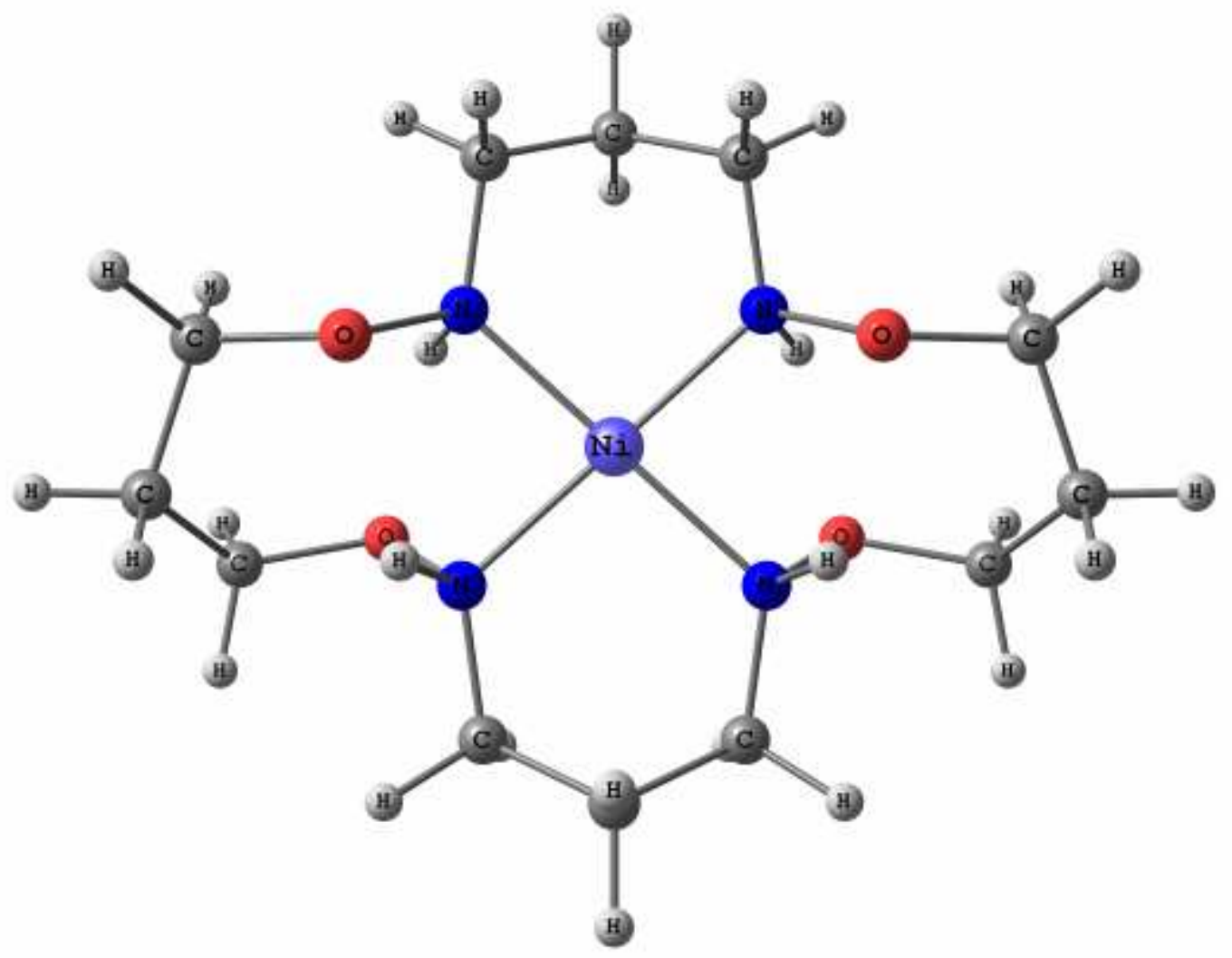

Figura 3-B. Estrutura otimizada do complexo $\mathbf{1 a}_{\mathbf{q}}$ de $\mathrm{Ni}^{2+}$.

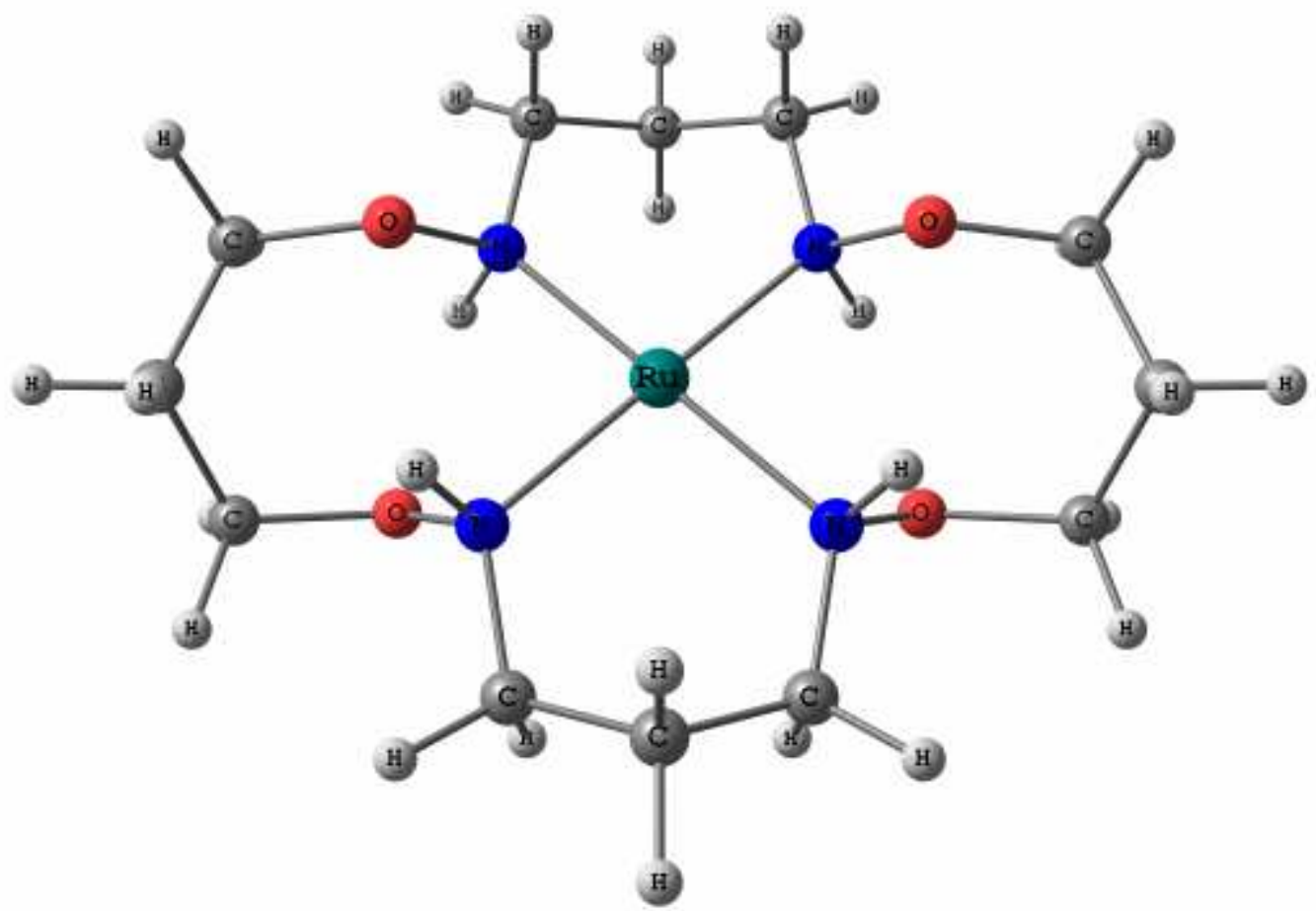

Figura 4-B. Estrutura otimizada do complexo $1 \mathbf{a}_{\mathbf{q}}$ de $\mathrm{Ru}^{2+}$. 


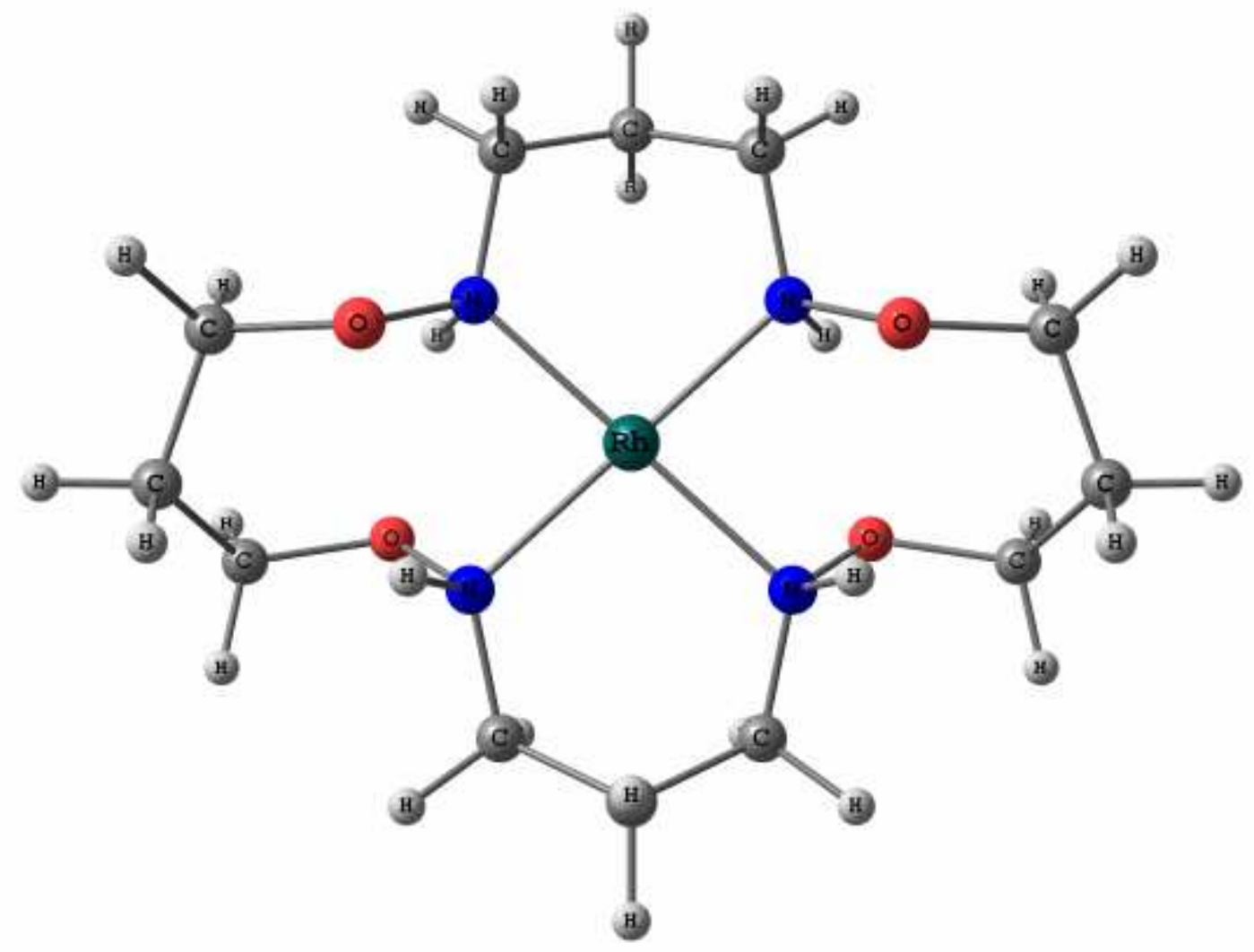

Figura 5-B. Estrutura otimizada do complexo $\mathbf{1 a}_{\mathbf{q}}$ de $\mathrm{Rh}^{2+}$.

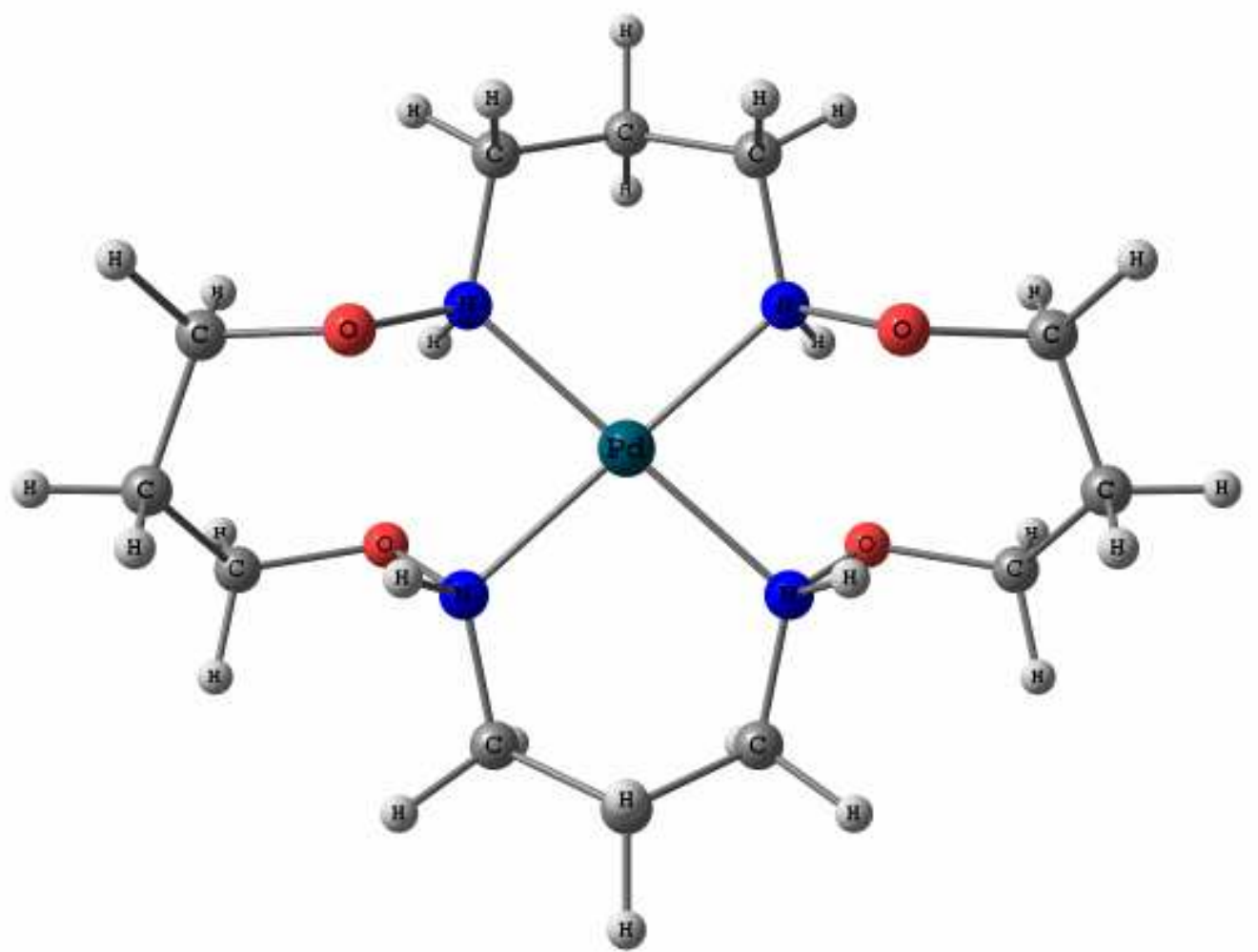

Figura 6-B. Estrutura otimizada do complexo $1 \mathbf{a}_{\mathbf{q}} \mathrm{de} \mathrm{Pd}^{2+}$. 


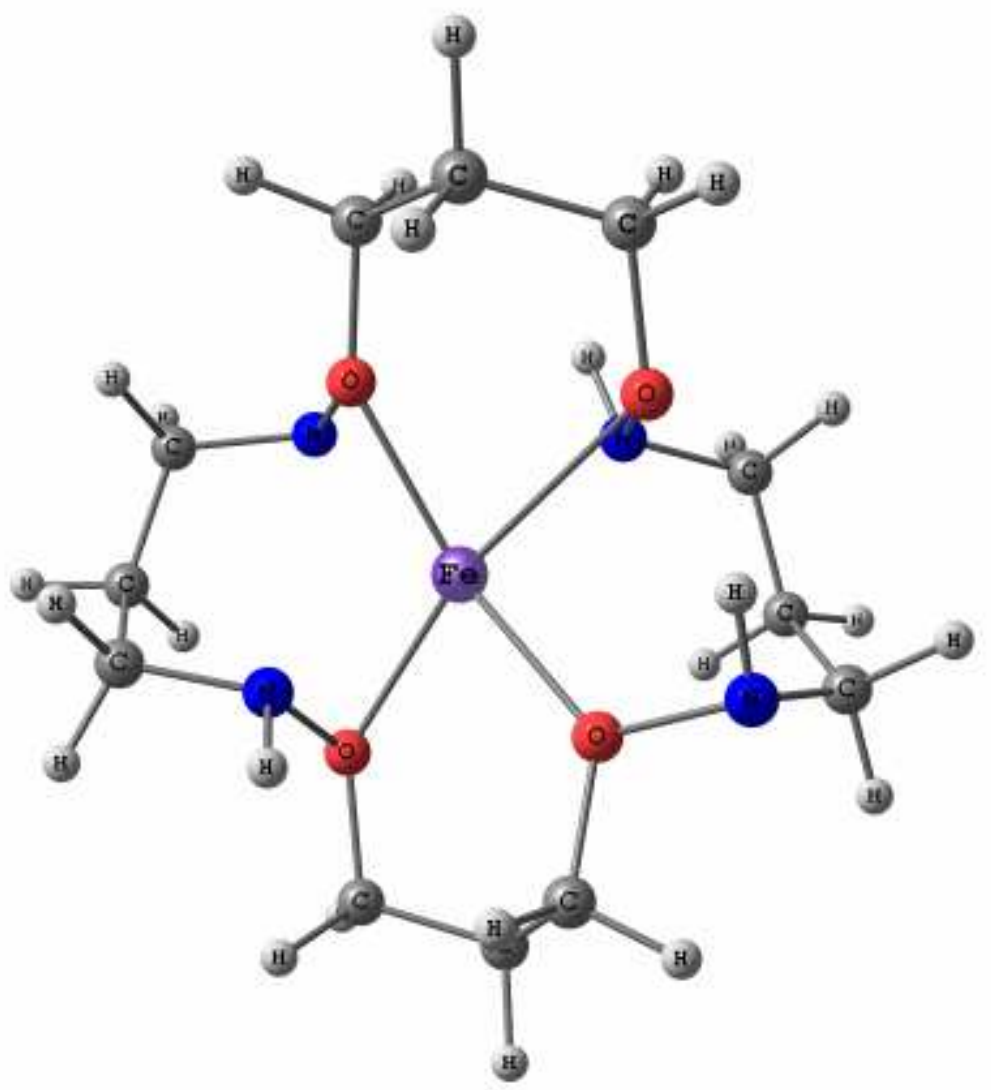

Figura 7-B. Estrutura otimizada do complexo $\mathbf{1 b}_{\mathbf{q}}$ de $\mathrm{Fe}^{2+}$.

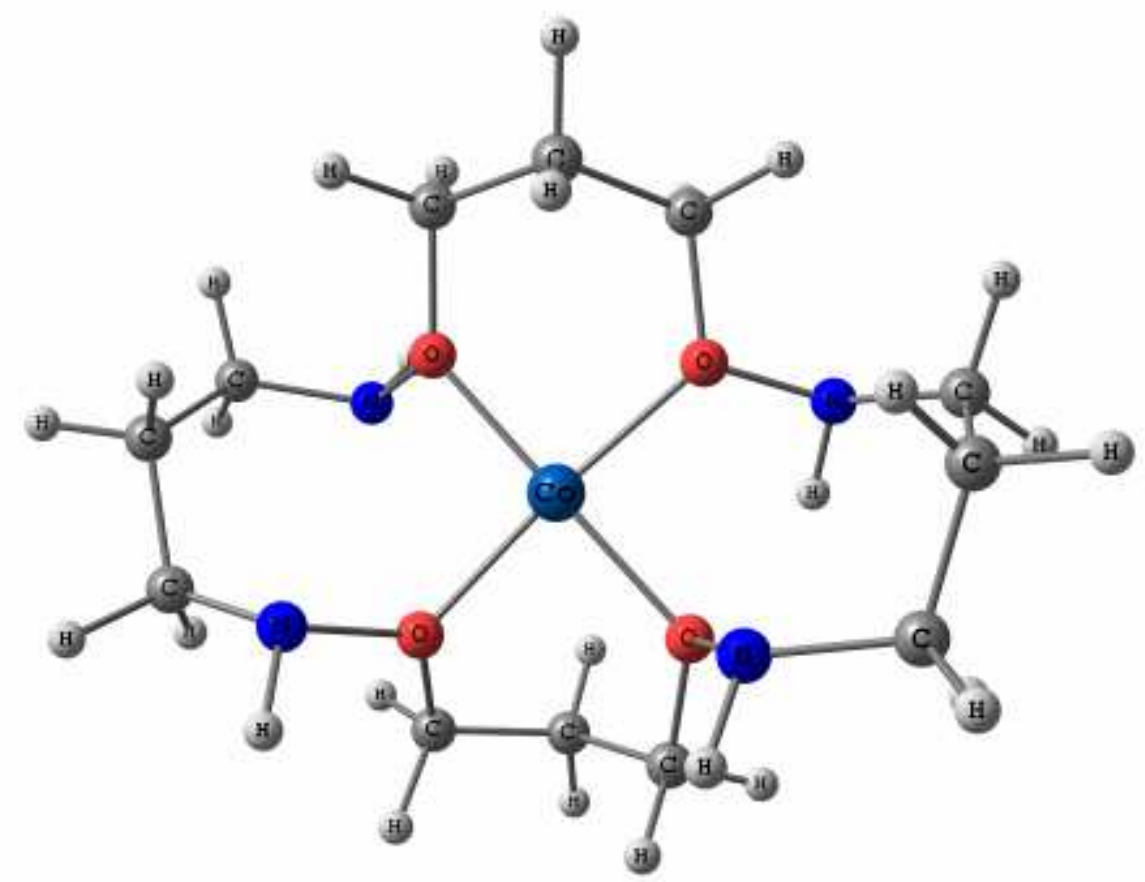

Figura 8-B. Estrutura otimizada do complexo $\mathbf{1 b}_{\mathbf{q}}$ de $\mathrm{Co}^{2+}$. 


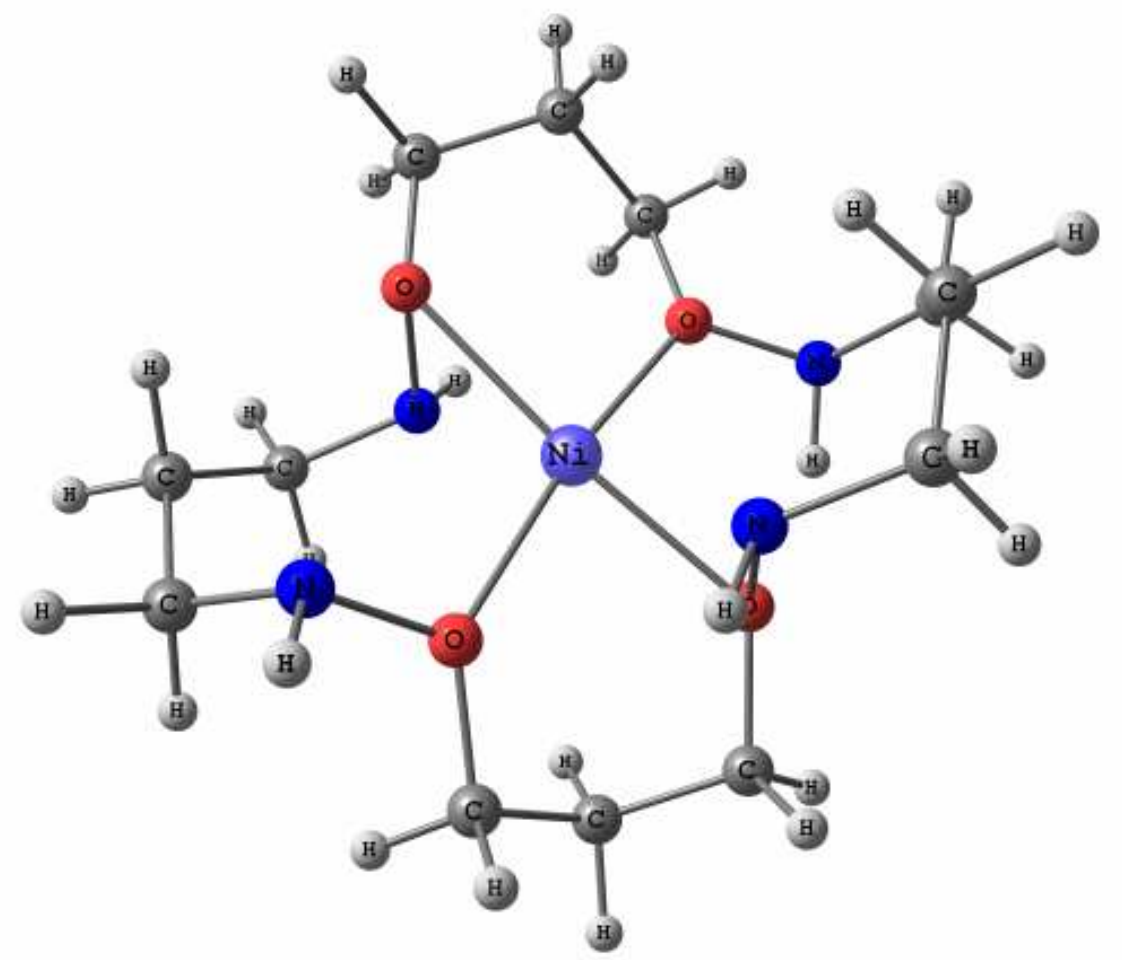

Figura 9-B. Estrutura otimizada do complexo $\mathbf{1 b}_{\mathbf{q}}$ de $\mathrm{Ni}^{2+}$.

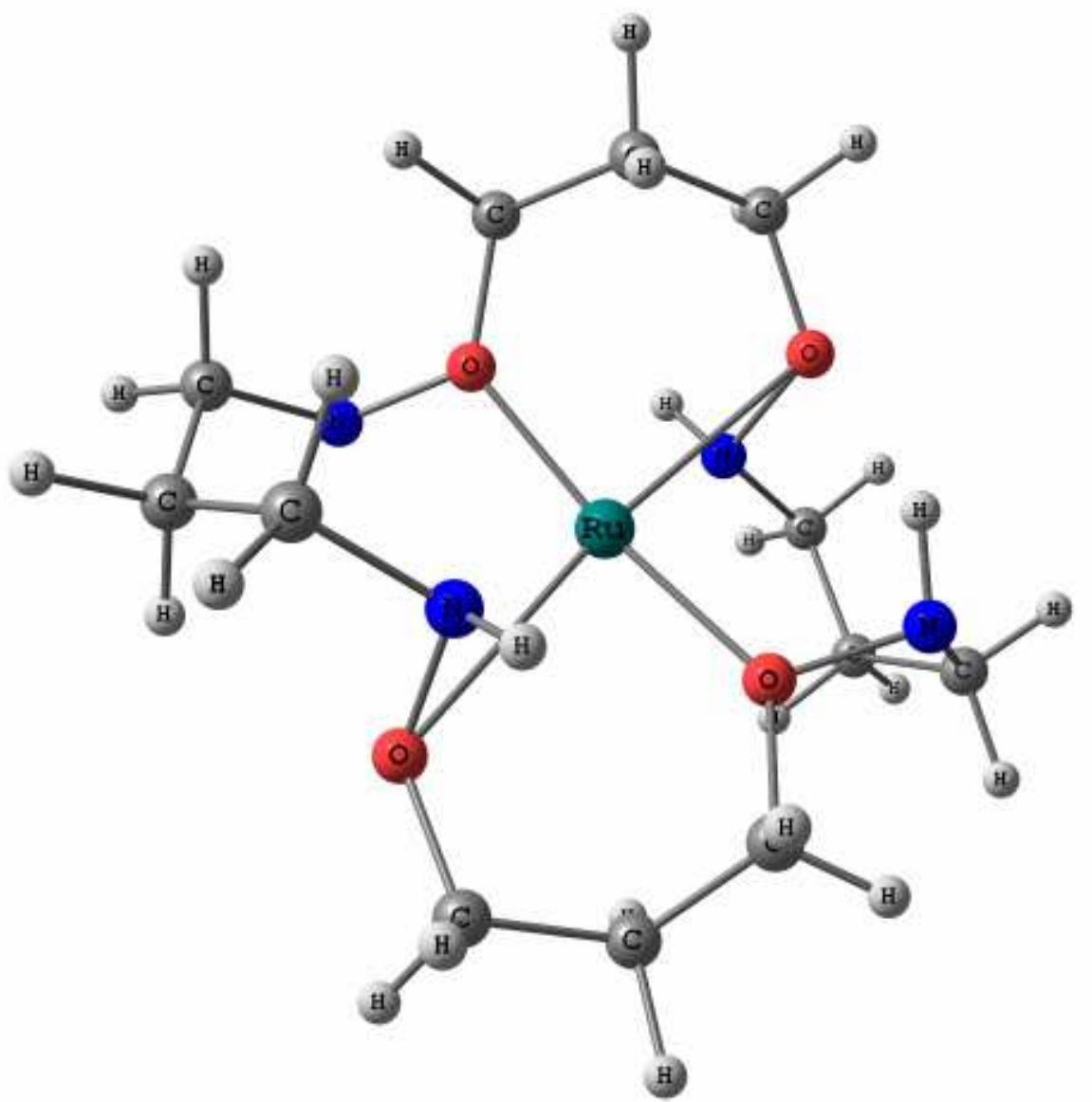

Figura 10-B. Estrutura otimizada do complexo $\mathbf{1 b}_{\mathbf{q}}$ de $\mathrm{Ru}^{2+}$. 


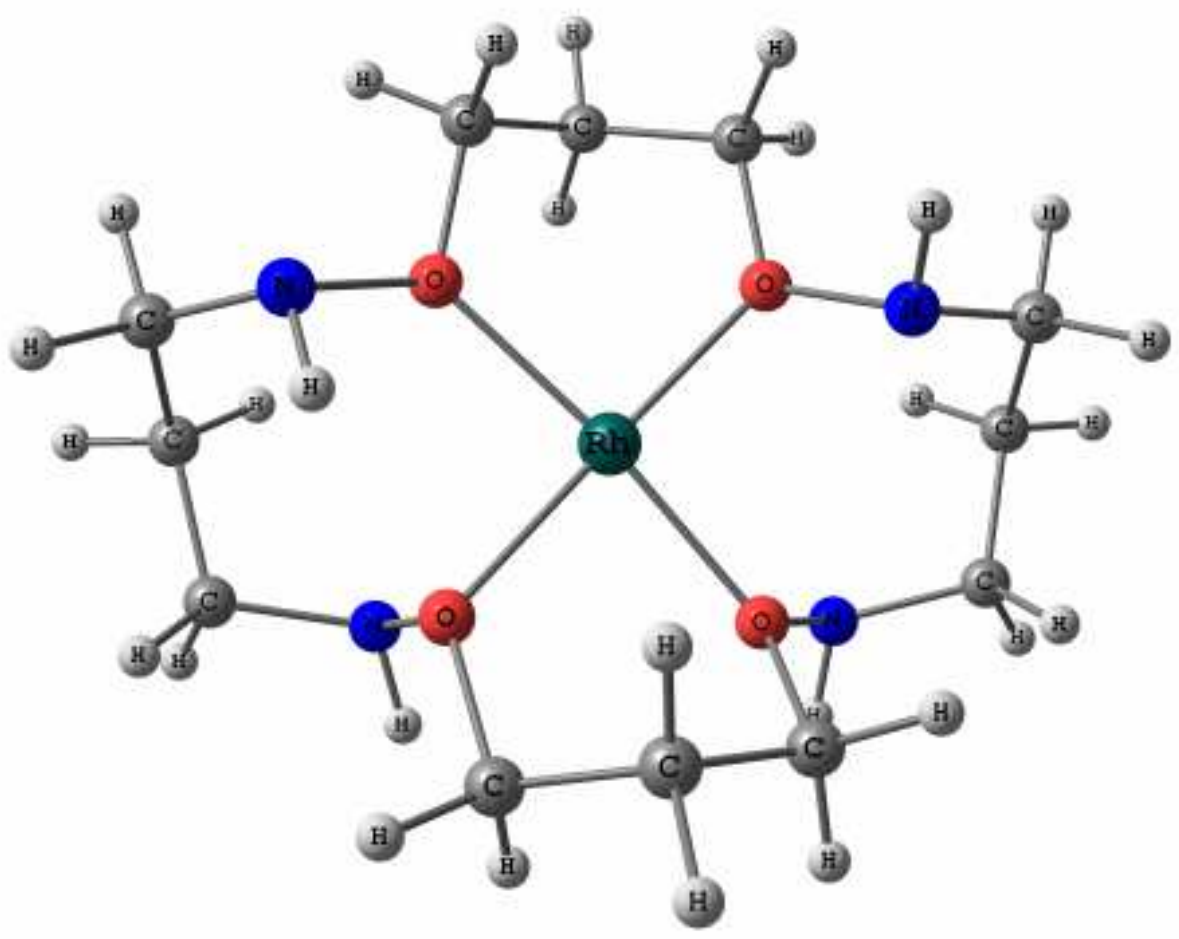

Figura 11-B. Estrutura otimizada do complexo $\mathbf{1 b}_{\mathbf{q}}$ de $\mathrm{Rh}^{2+}$.

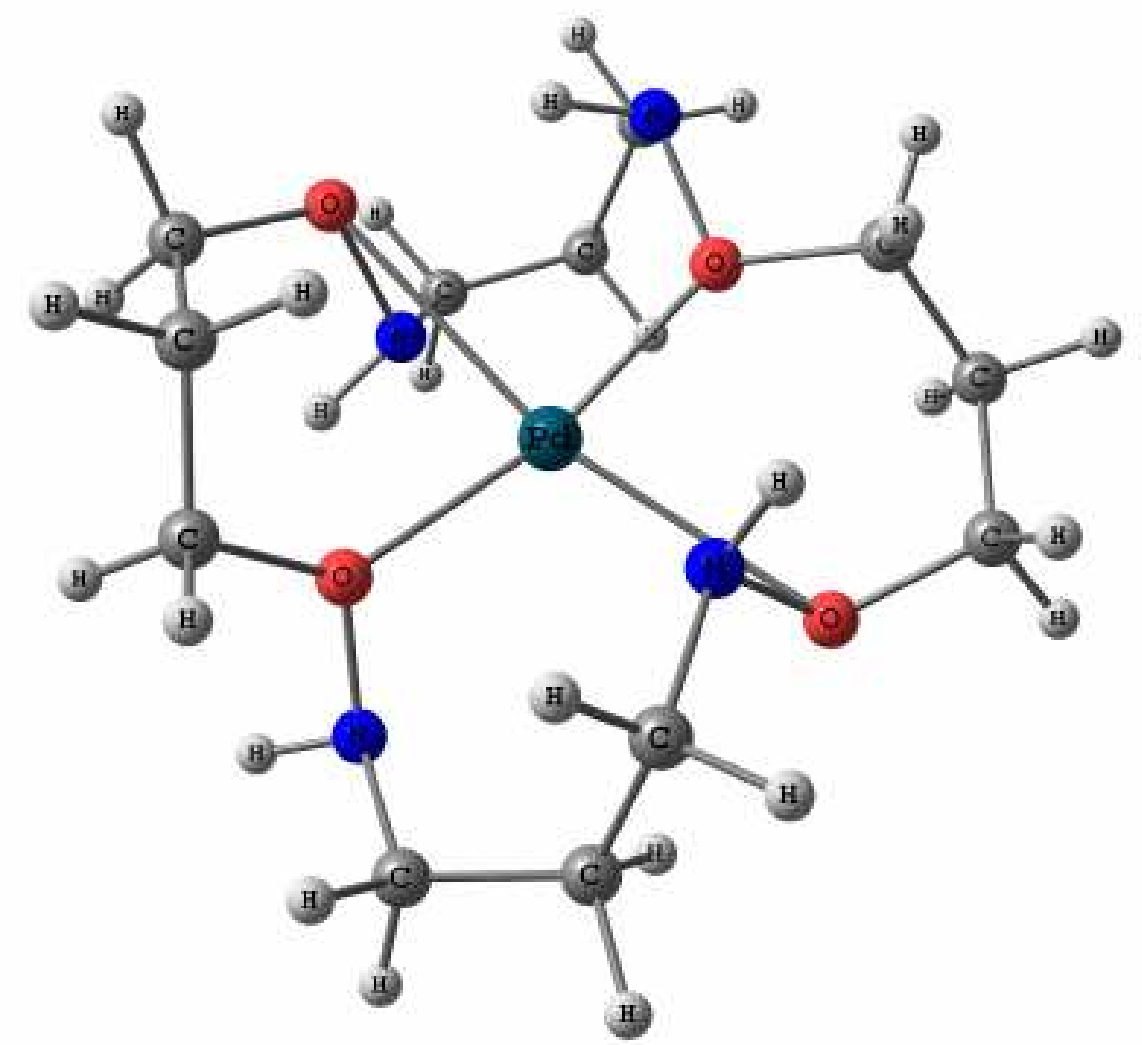

Figura 12-B. Estrutura otimizada do complexo $\mathbf{1 b}_{\mathbf{q}}$ de $\mathrm{Pd}^{2+}$. 


\section{Apêndice $C$ : Análise da população natural (NPA- Natural Population Analysis)}

\begin{tabular}{|c|c|c|c|c|c|}
\hline $\mathrm{NAO}$ & Atom & No & lang & Type (AO) & Occupancy \\
\hline 10 & $\mathrm{Fe}$ & 2 & $\mathrm{~S}$ & $\operatorname{Cor}(3 S)$ & 1.99749 \\
\hline 11 & $\mathrm{Fe}$ & 2 & $\mathrm{~S}$ & $\operatorname{Val}(4 \mathrm{~S})$ & 0.19113 \\
\hline 12 & $\mathrm{Fe}$ & 2 & S & Ryd ( 5S) & 0.00108 \\
\hline 13 & $\mathrm{Fe}$ & 2 & $\mathrm{px}$ & $\operatorname{Cor}(3 p)$ & 1.99888 \\
\hline 14 & $\mathrm{Fe}$ & 2 & $\mathrm{px}$ & Ryd ( $4 p)$ & 0.00574 \\
\hline 15 & $\mathrm{Fe}$ & 2 & $\mathrm{px}$ & Ryd ( $5 p)$ & 0.00090 \\
\hline 16 & $\mathrm{Fe}$ & 2 & py & $\operatorname{Cor}(3 p)$ & 1.99890 \\
\hline 17 & $\mathrm{Fe}$ & 2 & py & Ryd ( $4 p)$ & 0.00567 \\
\hline 18 & $\mathrm{Fe}$ & 2 & py & Ryd ( $5 p)$ & 0.00069 \\
\hline 19 & $\mathrm{Fe}$ & 2 & $\mathrm{pz}$ & $\operatorname{Cor}(3 p)$ & 1.99947 \\
\hline 20 & $\mathrm{Fe}$ & 2 & $\mathrm{pz}$ & Ryd ( $4 p)$ & 0.00461 \\
\hline 21 & $\mathrm{Fe}$ & 2 & $\mathrm{pz}$ & Ryd ( $5 p)$ & 0.00091 \\
\hline 22 & $\mathrm{Fe}$ & 2 & $d x y$ & $\operatorname{Val}(3 d)$ & 1.01844 \\
\hline 23 & $\mathrm{Fe}$ & 2 & dxy & Ryd ( 4d) & 0.00149 \\
\hline 24 & $\mathrm{Fe}$ & 2 & $d x z$ & $\operatorname{Val}(3 d)$ & 1.91152 \\
\hline 25 & $\mathrm{Fe}$ & 2 & $d x z$ & Ryd ( 4d) & 0.00259 \\
\hline 26 & $\mathrm{Fe}$ & 2 & dyz & $\operatorname{Val}(3 d)$ & 1.95231 \\
\hline 27 & $\mathrm{Fe}$ & 2 & dyz & Ryd ( 4d) & 0.00209 \\
\hline 28 & $\mathrm{Fe}$ & 2 & $d x 2 y 2$ & $\operatorname{Val}(3 d)$ & 1.14410 \\
\hline 29 & $\mathrm{Fe}$ & 2 & $d x^{2} y^{2}$ & Ryd ( 4d) & 0.00274 \\
\hline 30 & $\mathrm{Fe}$ & 2 & $\mathrm{dz} 2$ & $\operatorname{Val}(3 d)$ & 0.60083 \\
\hline 31 & $\mathrm{Fe}$ & 2 & $\mathrm{dz2}$ & Ryd ( 4d) & 0.00152 \\
\hline
\end{tabular}

WARNING: Population inversion found on atom $\mathrm{Fe} 2$

NATURAL POPULATIONS: Natural atomic orbital occupancies

$\begin{array}{llllll}\text { NAO } & \text { Atom } & \text { No } & \text { lang } & \text { Type }(\mathrm{AO}) & \text { Occupancy } \\ 10 & \mathrm{Ru} & 2 & \mathrm{~S} & \operatorname{Cor}(4 \mathrm{~S}) & 1.99625 \\ 11 & \mathrm{Ru} & 2 & \mathrm{~S} & \operatorname{Val}(5 \mathrm{~S}) & 0.13348 \\ 12 & \mathrm{Ru} & 2 & \mathrm{~S} & \operatorname{Ryd}(6 \mathrm{~S}) & 0.00240 \\ 13 & \mathrm{Ru} & 2 & \mathrm{px} & \operatorname{Cor}(4 \mathrm{p}) & 1.99831 \\ 14 & \mathrm{Ru} & 2 & \mathrm{px} & \operatorname{Ryd}(5 \mathrm{p}) & 0.00354 \\ 15 & \mathrm{Ru} & 2 & \mathrm{px} & \operatorname{Ryd}(6 \mathrm{p}) & 0.00077 \\ 16 & \mathrm{Ru} & 2 & \mathrm{py} & \operatorname{Cor}(4 \mathrm{p}) & 1.99756 \\ 17 & \mathrm{Ru} & 2 & \mathrm{py} & \operatorname{Ryd}(5 \mathrm{p}) & 0.00313 \\ 18 & \mathrm{Ru} & 2 & \mathrm{py} & \operatorname{Ryd}(6 \mathrm{p}) & 0.00098 \\ 19 & \mathrm{Ru} & 2 & \mathrm{pz} & \operatorname{Cor}(4 \mathrm{p}) & 1.99889 \\ 20 & \mathrm{Ru} & 2 & \mathrm{pz} & \operatorname{Ryd}(5 \mathrm{p}) & 0.00241 \\ 21 & \mathrm{Ru} & 2 & \mathrm{pz} & \operatorname{Ryd}(6 \mathrm{p}) & 0.00045 \\ 22 & \mathrm{Ru} & 2 & \mathrm{dxy} & \operatorname{Val}(4 \mathrm{~d}) & 0.84080 \\ 23 & \mathrm{Ru} & 2 & \mathrm{dxy} & \operatorname{Ryd}(5 \mathrm{~d}) & 0.00302 \\ 24 & \mathrm{Ru} & 2 & \mathrm{dxz} & \operatorname{Val}(4 \mathrm{~d}) & 1.91950 \\ 25 & \mathrm{Ru} & 2 & \mathrm{dxz} & \operatorname{Ryd}(5 \mathrm{~d}) & 0.00321 \\ 26 & \mathrm{Ru} & 2 & \mathrm{dyz} & \operatorname{Val}(4 \mathrm{~d}) & 1.93570 \\ 27 & \mathrm{Ru} & 2 & \mathrm{dyz} & \operatorname{Ryd}(5 \mathrm{~d}) & 0.00300 \\ 28 & \mathrm{Ru} & 2 & \mathrm{dx} 2 \mathrm{2} 2 & \operatorname{Val}(4 \mathrm{~d}) & 1.40934 \\ 29 & \mathrm{Ru} & 2 & \mathrm{dx} 2 y 2 & \operatorname{Ryd}(5 \mathrm{~d}) & 0.00483 \\ 30 & \mathrm{Ru} & 2 & \mathrm{dz} 2 & \operatorname{Val}(4 \mathrm{~d}) & 1.50957 \\ 31 & \mathrm{Ru} & 2 & \mathrm{dz} 2 & \operatorname{Ryd}(5 \mathrm{~d}) & 0.00350\end{array}$

WARNING: Population inversion found on atom Ru 2

A análise populacional natural (NPA) mostra a ocupação individual de cada orbital "d" do metal. Como pode ser observado nos íons de $\mathrm{Fe}^{2+}$ e $\mathrm{Ru}^{2+}$ ocorre uma inversão na população dos elétrons desses orbitais. Porém, como mencionado na seção dos resultados e discursão, esses íons têm configuração eletrônica $\mathrm{t}_{2 \mathrm{~g}}{ }^{5} \mathrm{e}_{\mathrm{g}}{ }^{1}$ com dois elétrons emparelhados nos orbitais $\mathrm{d}_{\mathrm{xz}}$ e $\mathrm{d}_{\mathrm{yz}}$, e um elétron desemparelhado nos orbitais $\mathrm{d}_{\mathrm{xy}} \mathrm{e} \mathrm{d}_{\mathrm{z}}^{2}$, configurando assim, um estado tripleto. 


\section{Apêndice D}

\section{ESTRUTURAS OCTAÉDRICAS DOS COMPLEXOS [20]aneL4(Oct)}

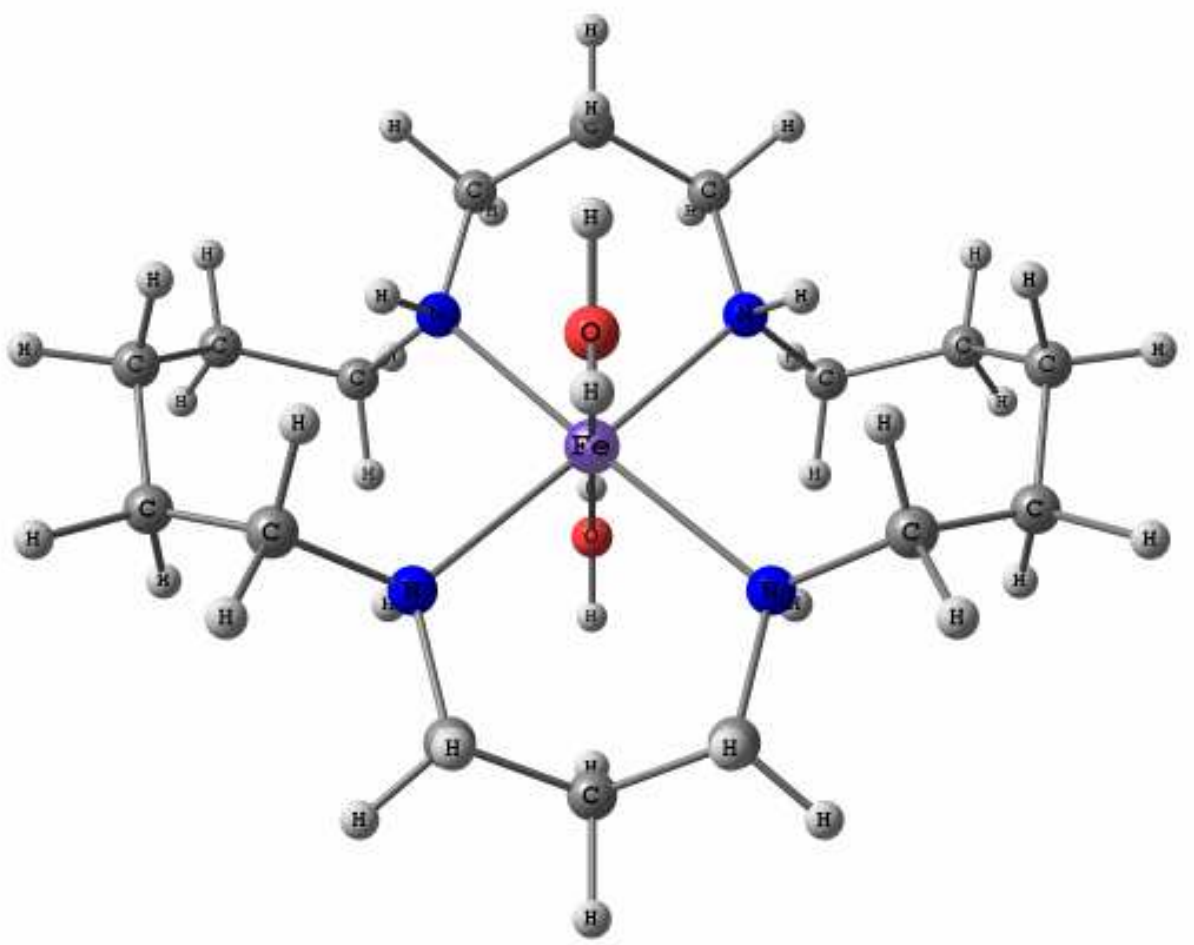

Figura 1-D. Estrutura otimizada do complexo [20]aneN4(Oct) de $\mathrm{Fe}^{2+}$.

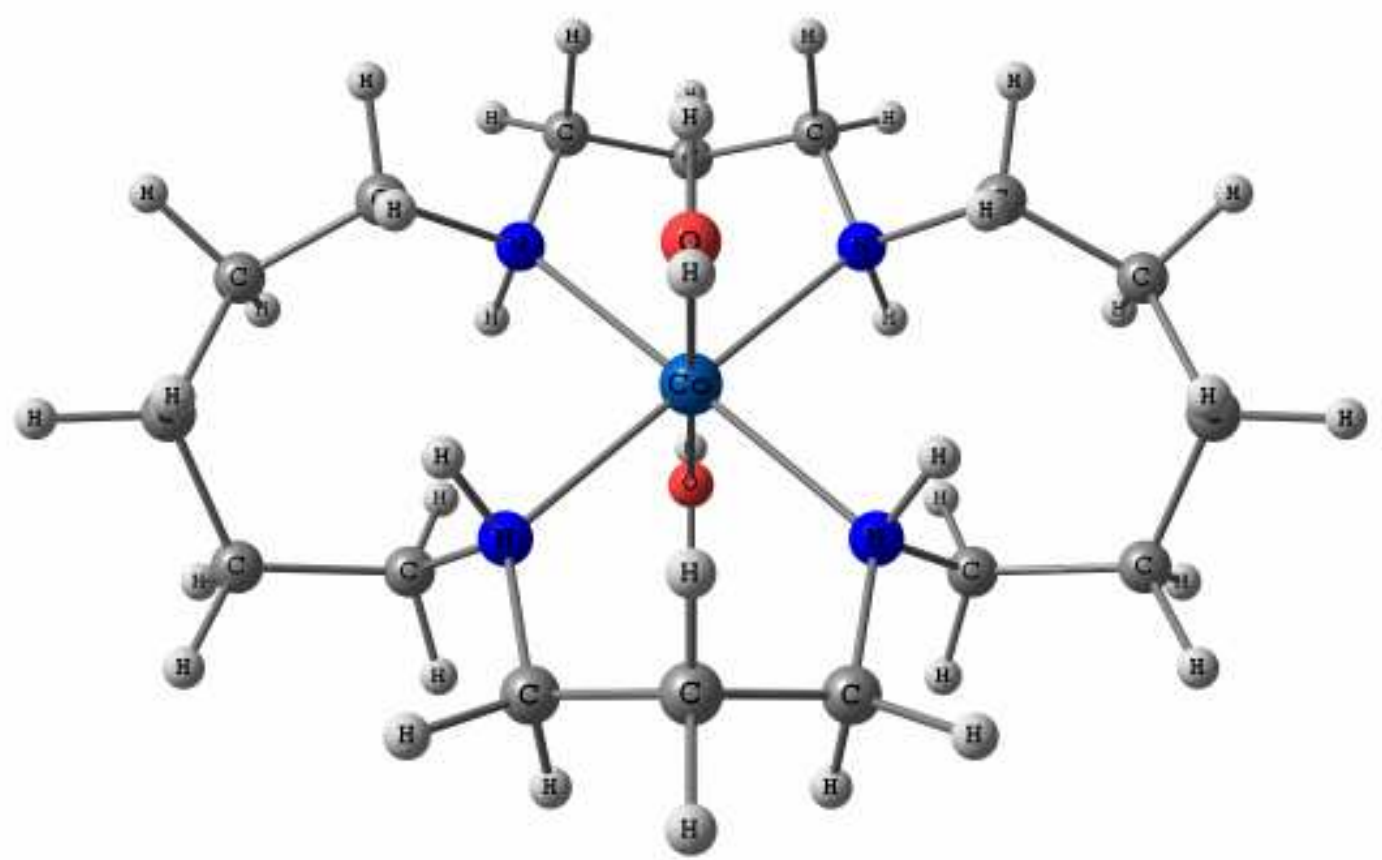

Figura 2-D. Estrutura otimizada do complexo [20]aneN4(Oct) de $\mathrm{Co}^{2+}$. 


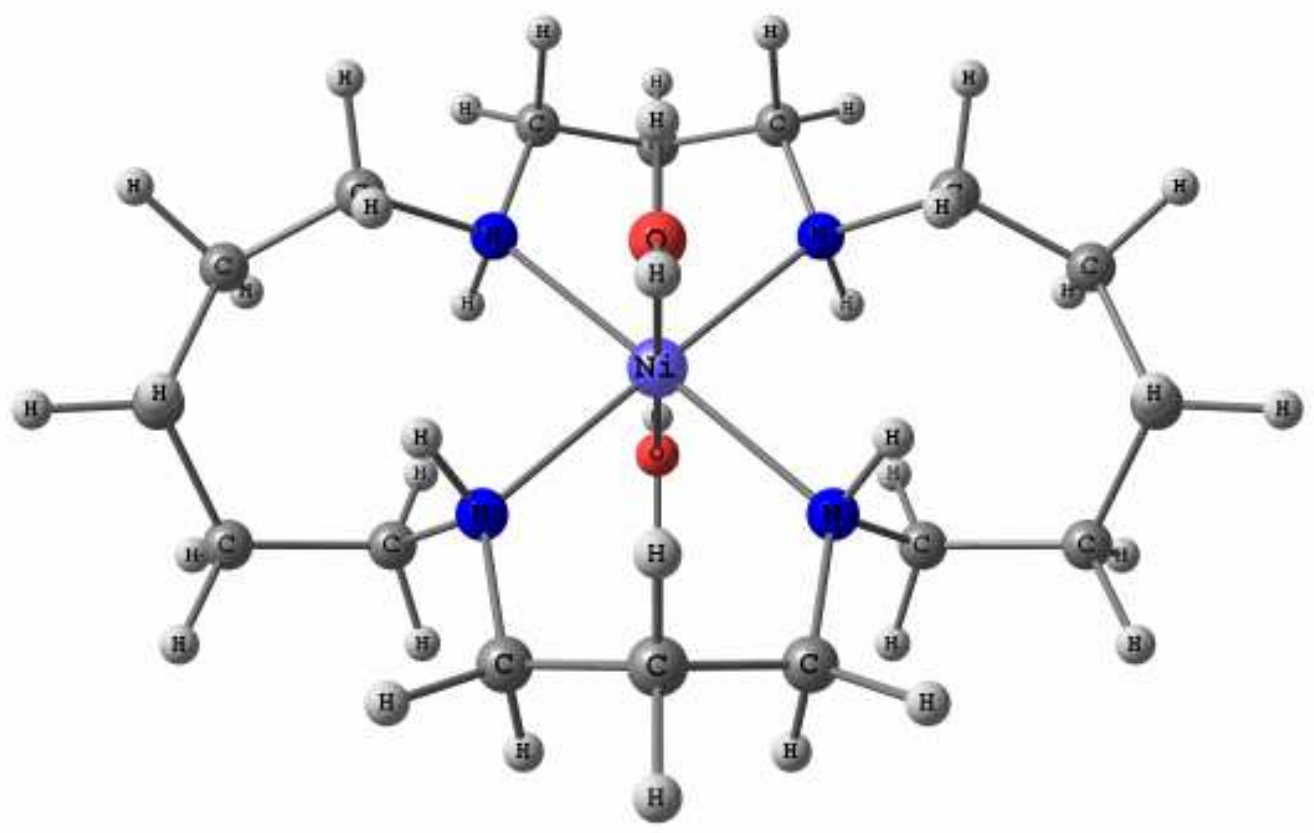

Figura 3-D. Estrutura otimizada do complexo [20]aneN4(Oct) de $\mathrm{Ni}^{2+}$.

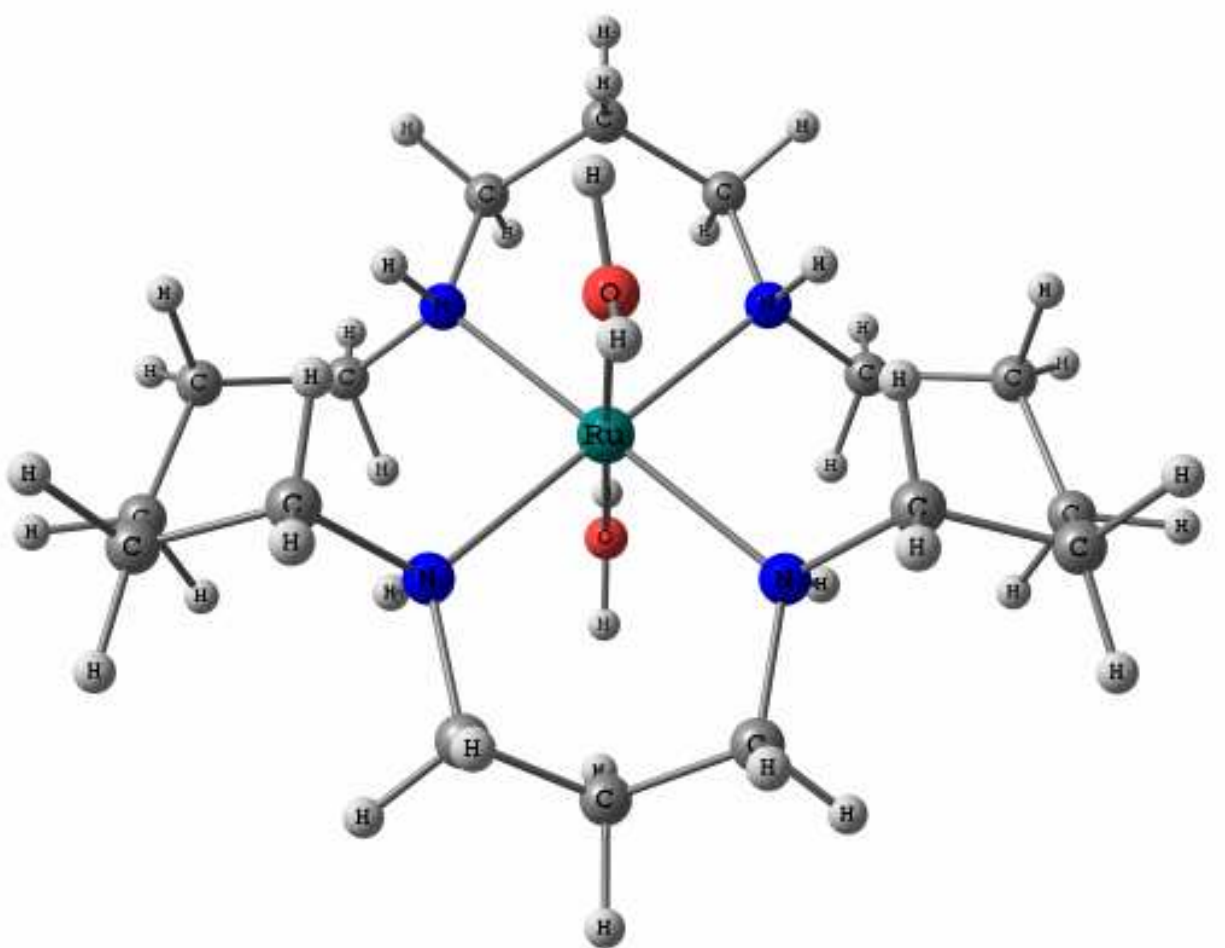

Figura 4-D. Estrutura otimizada do complexo [20]aneN4(Oct) de $\mathrm{Ru}^{2+}$. 


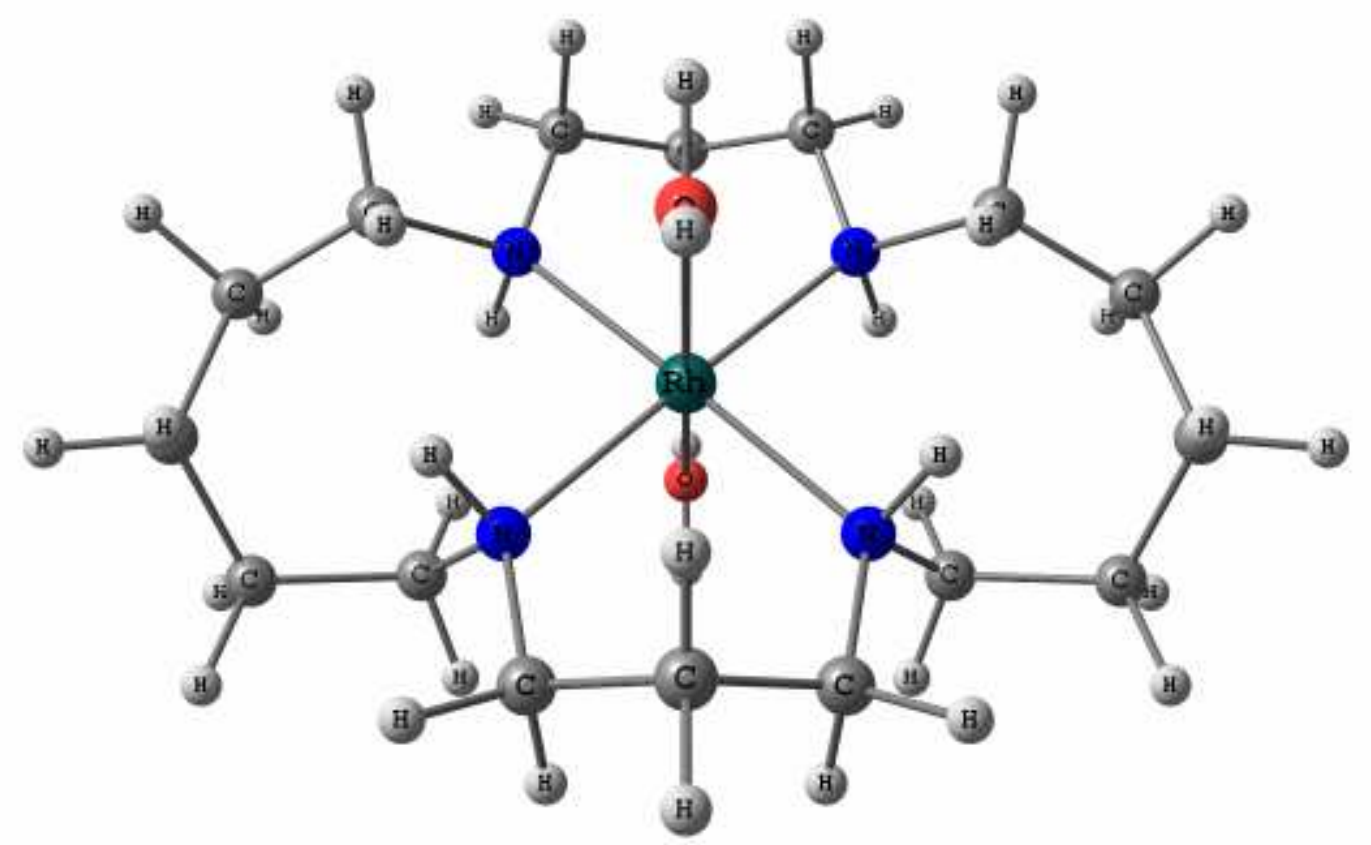

Figura 5-D. Estrutura otimizada do complexo [20]aneN4(Oct) de $\mathrm{Rh}^{2+}$.

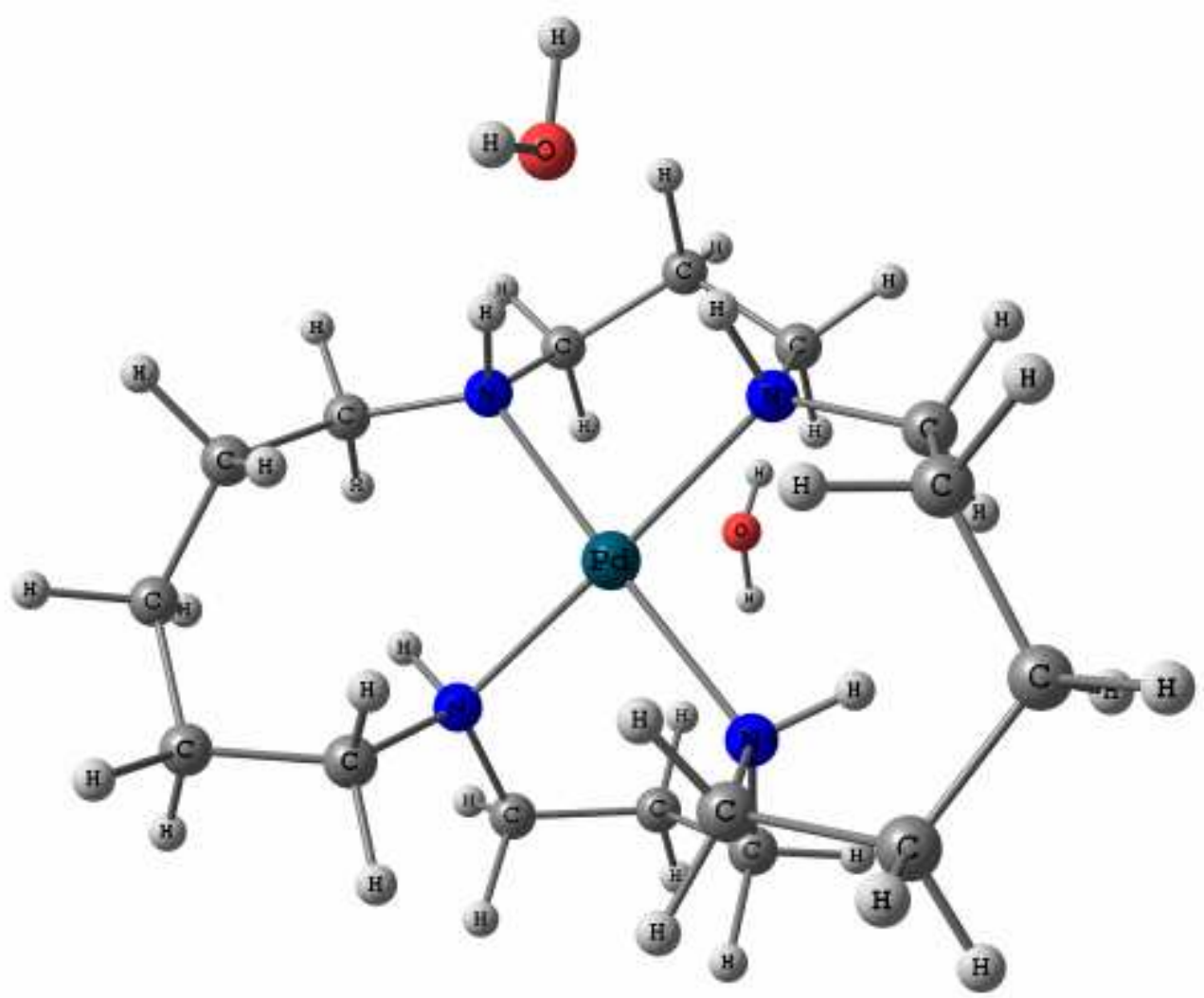

Figura 6-D. Estrutura otimizada do complexo [20]aneN4(Oct) de $\mathrm{Pd}^{2+}$. 


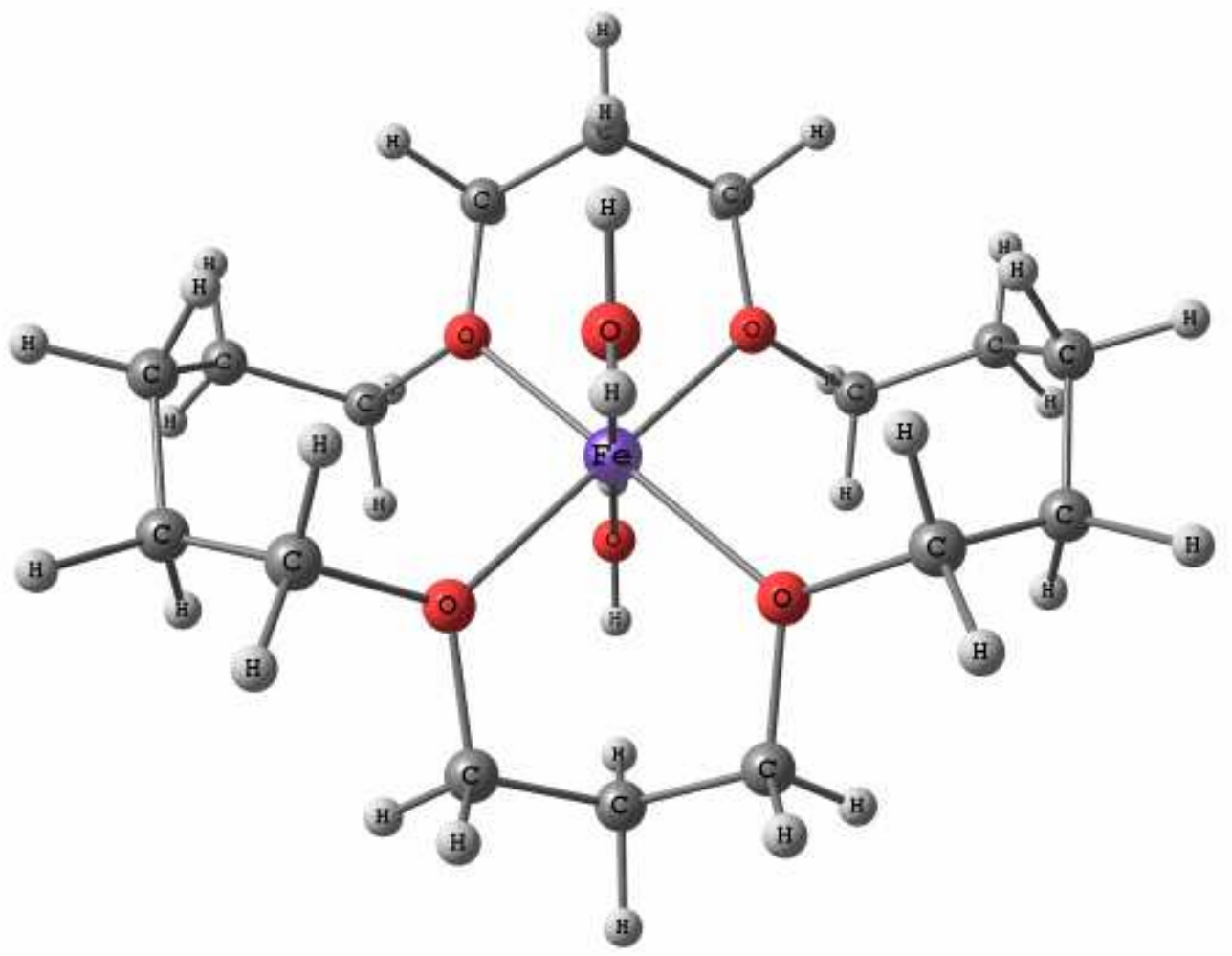

Figura 7-D. Estrutura otimizada do complexo [20]aneO4(Oct) de $\mathrm{Fe}^{2+}$.

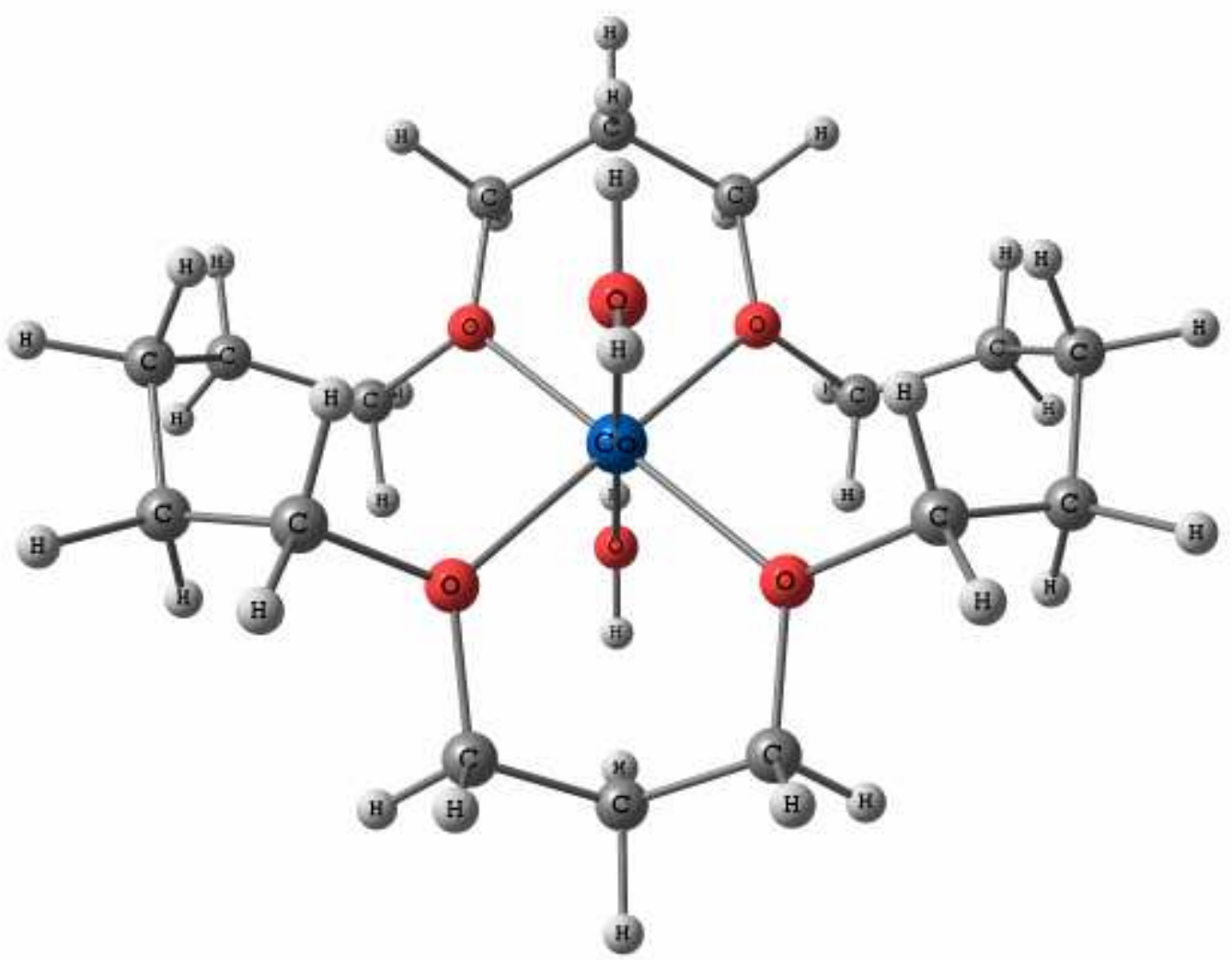

Figura 8-D. Estrutura otimizada do complexo [20]aneO4(Oct) de $\mathrm{Co}^{2+}$. 


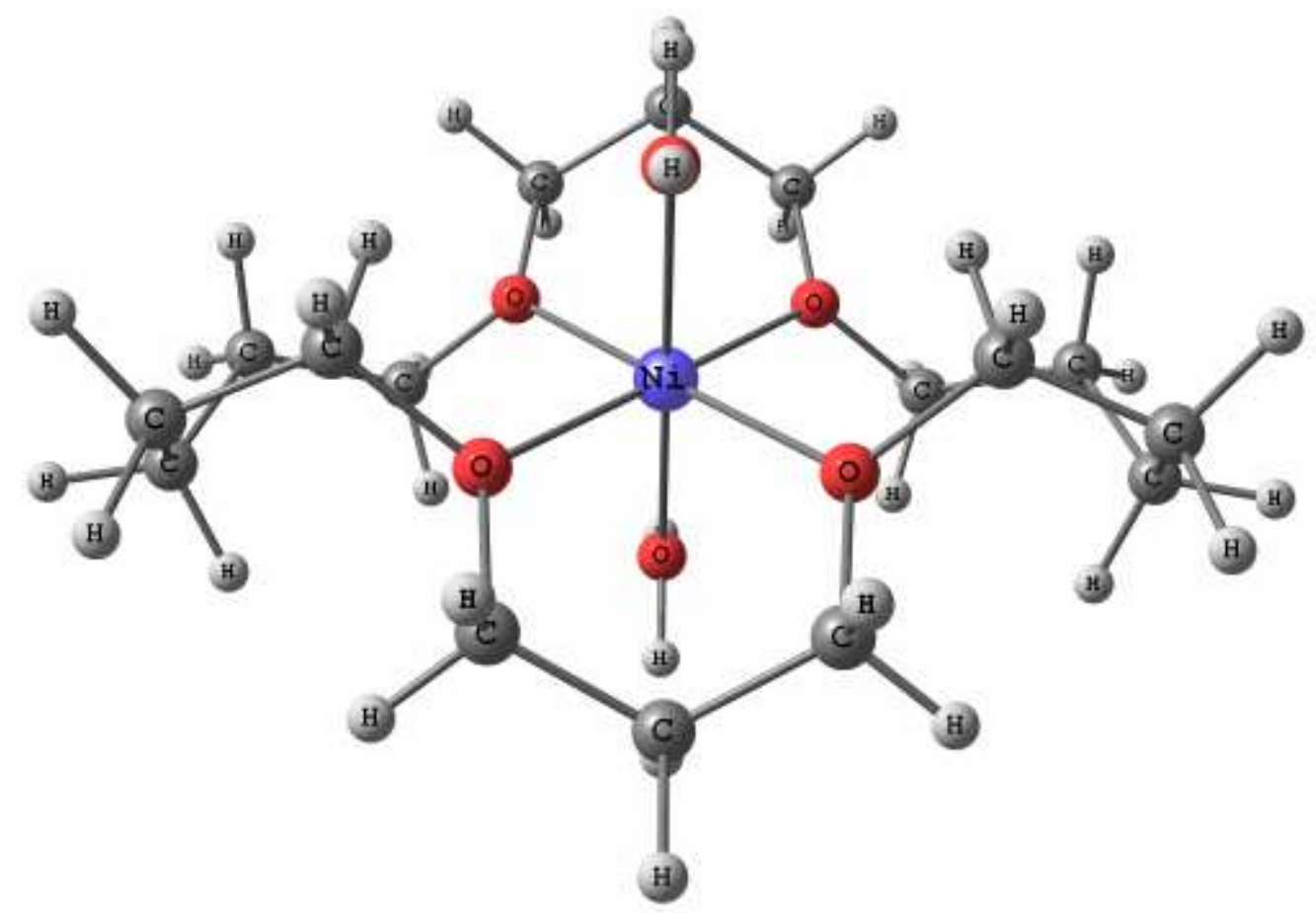

Figura 9-D. Estrutura otimizada do complexo [20]aneO4(Oct) de $\mathrm{Ni}^{2+}$.

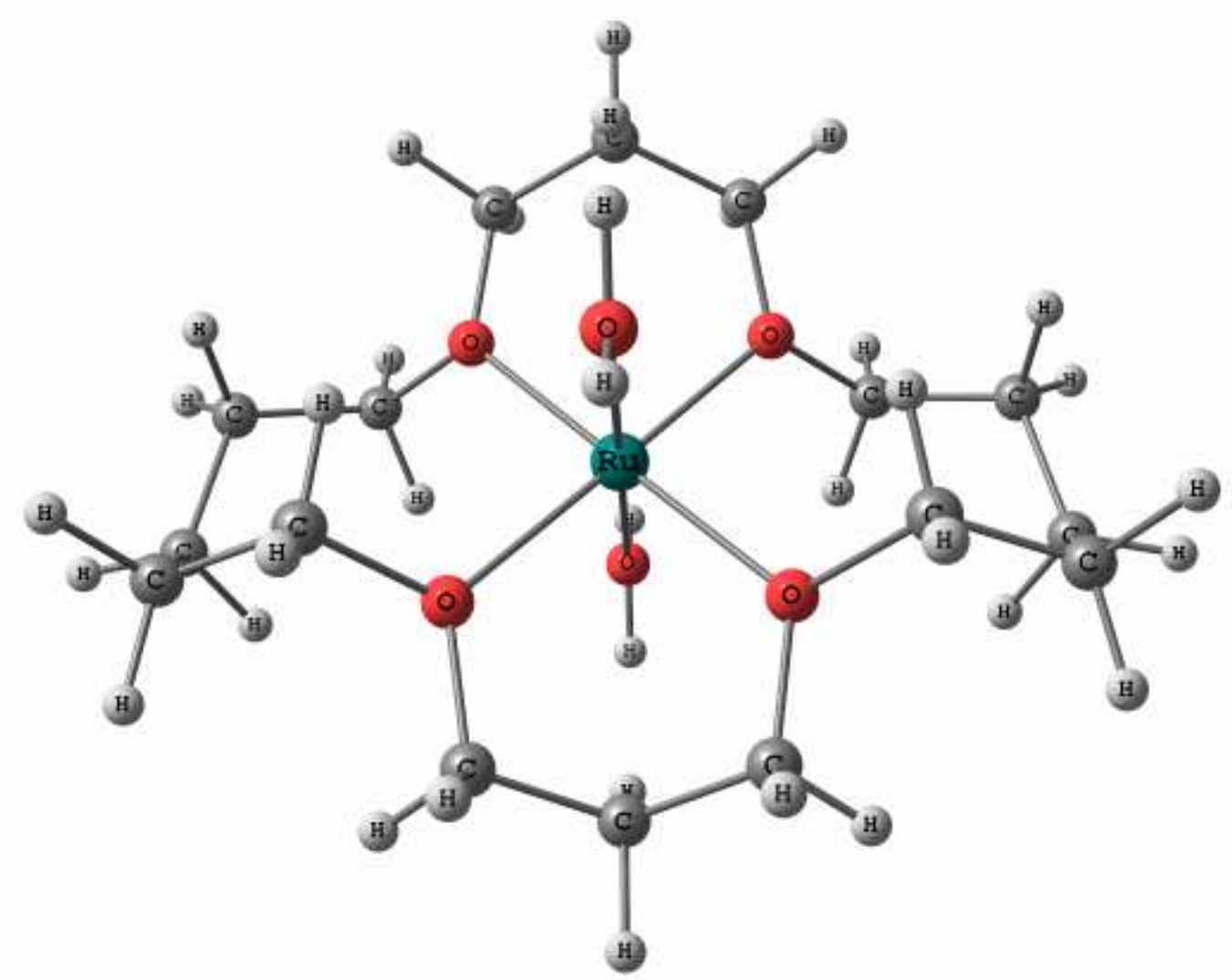

Figura 10-D. Estrutura otimizada do complexo [20]aneO4(Oct) de $\mathrm{Ru}^{2+}$. 


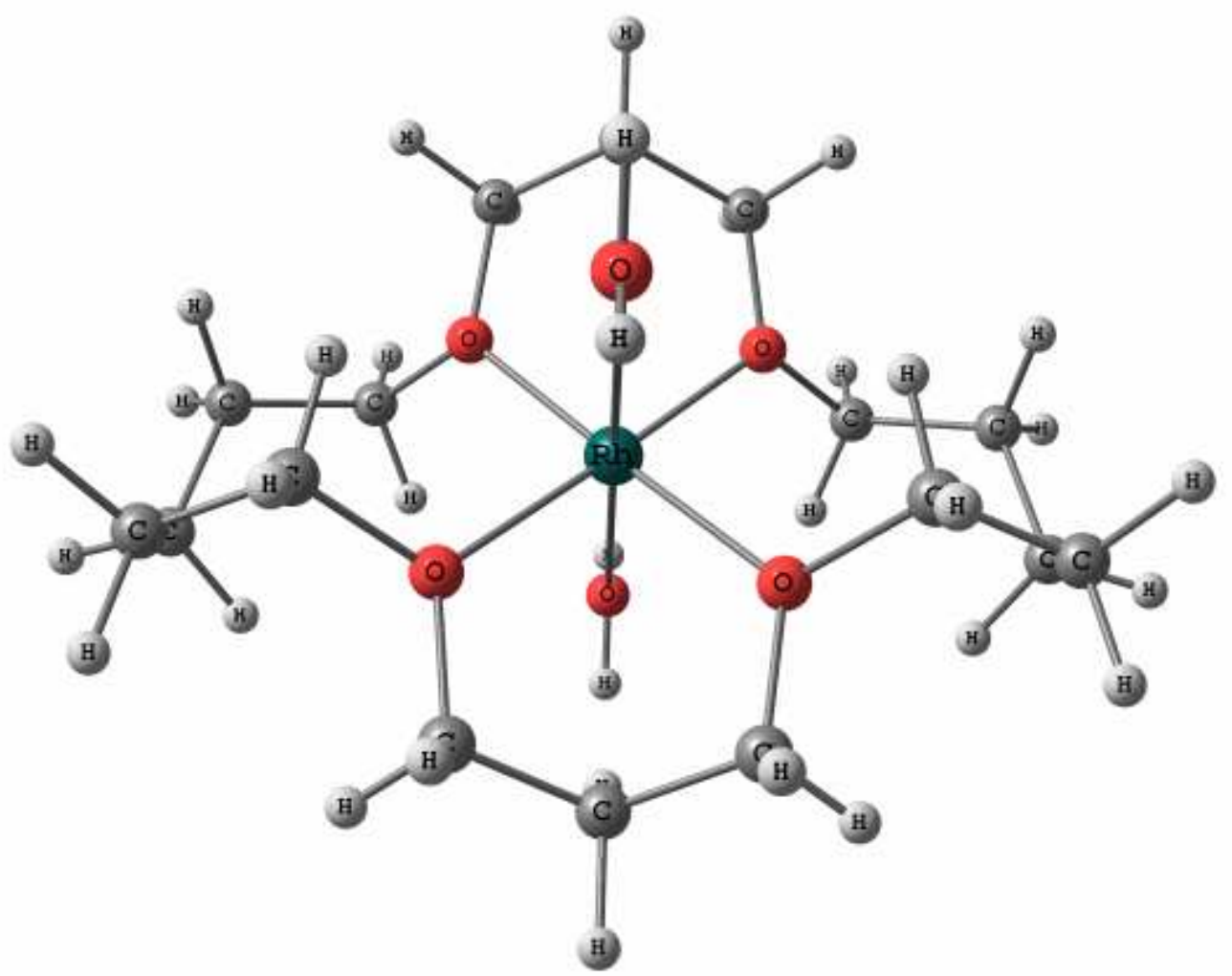

Figura 11-D. Estrutura otimizada do complexo [20]aneO4(Oct) de $\mathrm{Rh}^{2+}$.

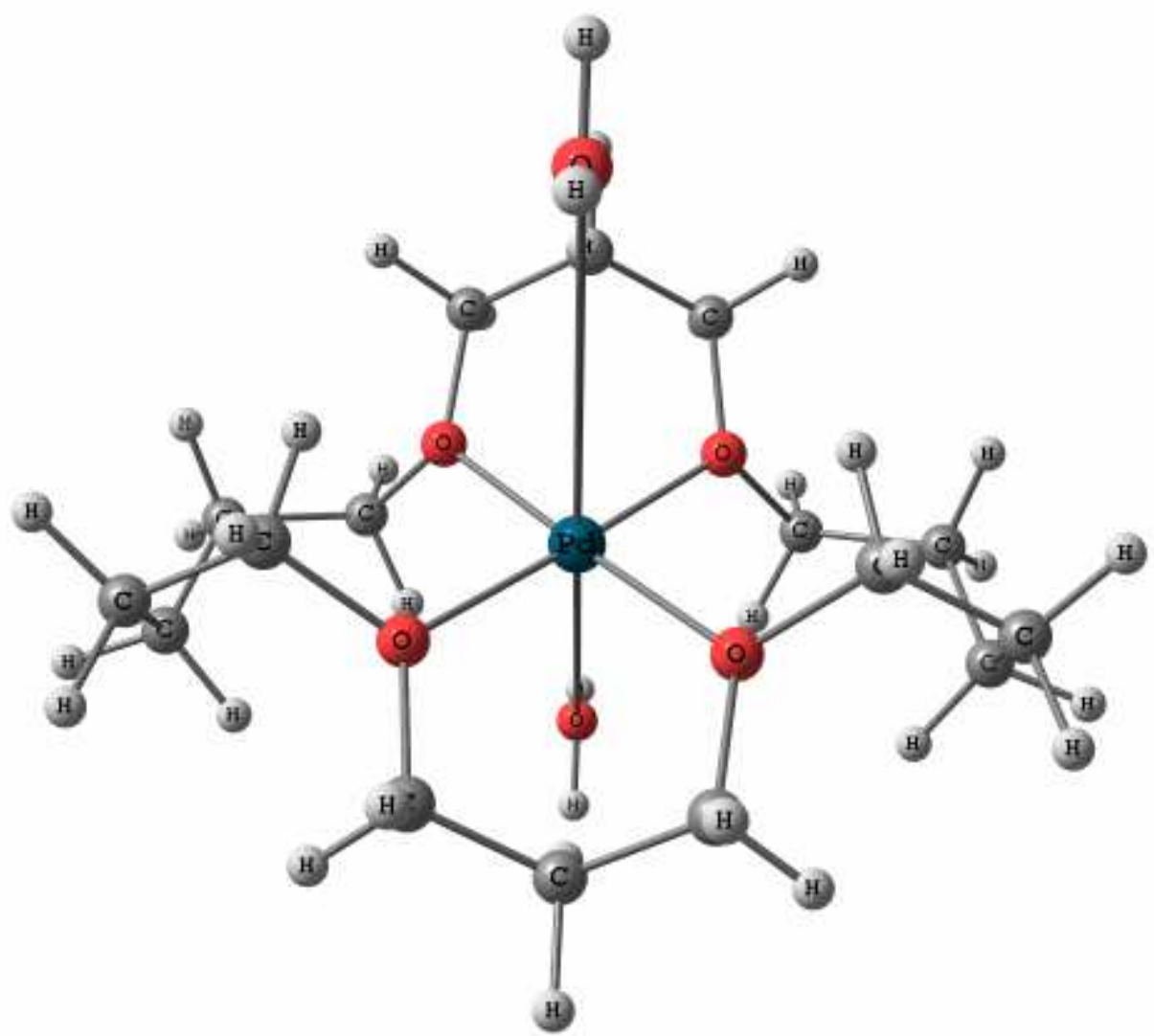

Figura 12-D. Estrutura otimizada do complexo [20]aneO4(Oct) de $\mathrm{Pd}^{2+}$. 


\section{Apêndice E}

ESTRUTURAS QUADRADO-PLANARES DOS COMPLEXOS [20]aneL4(qp)

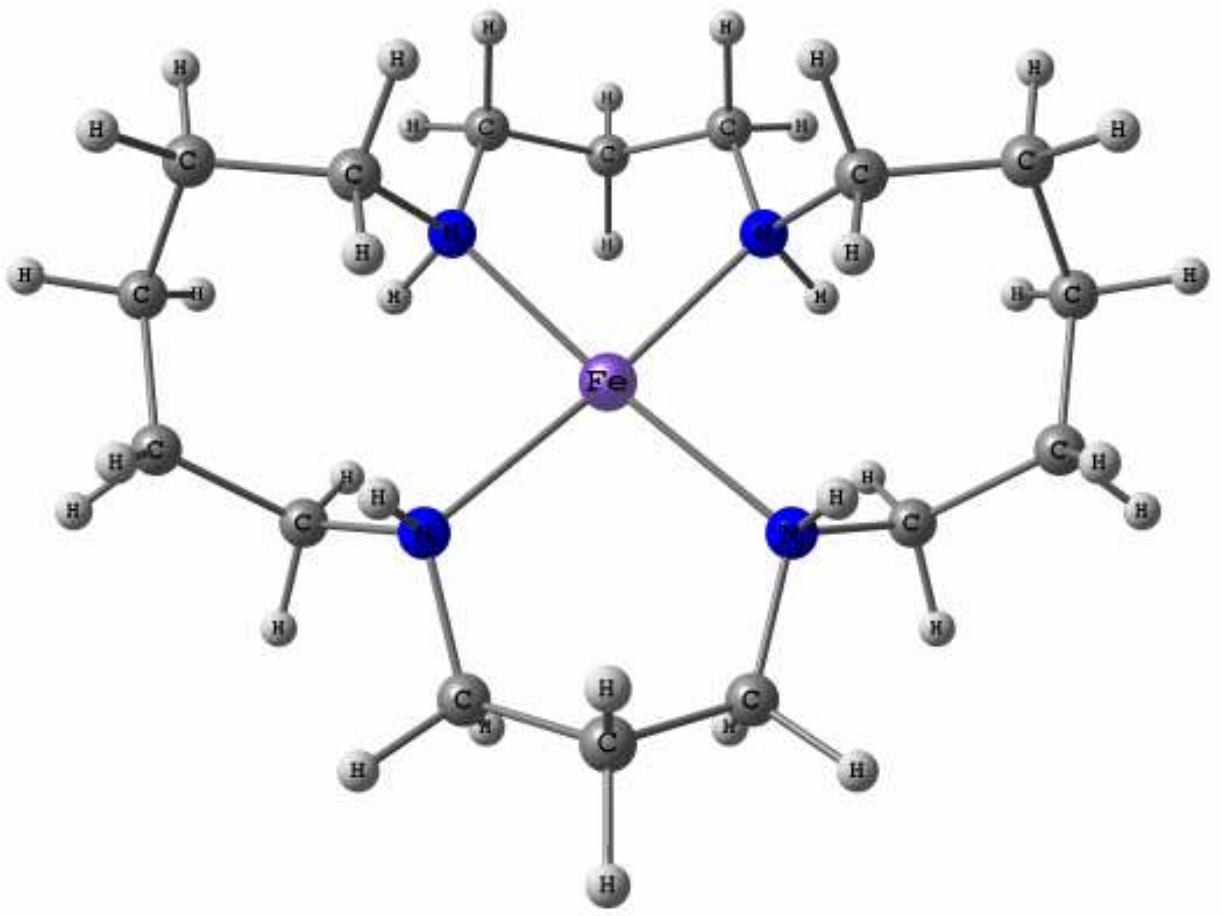

Figura 1-E. Estrutura otimizada do complexo [20]aneN4(qp) de $\mathrm{Fe}^{2+}$.

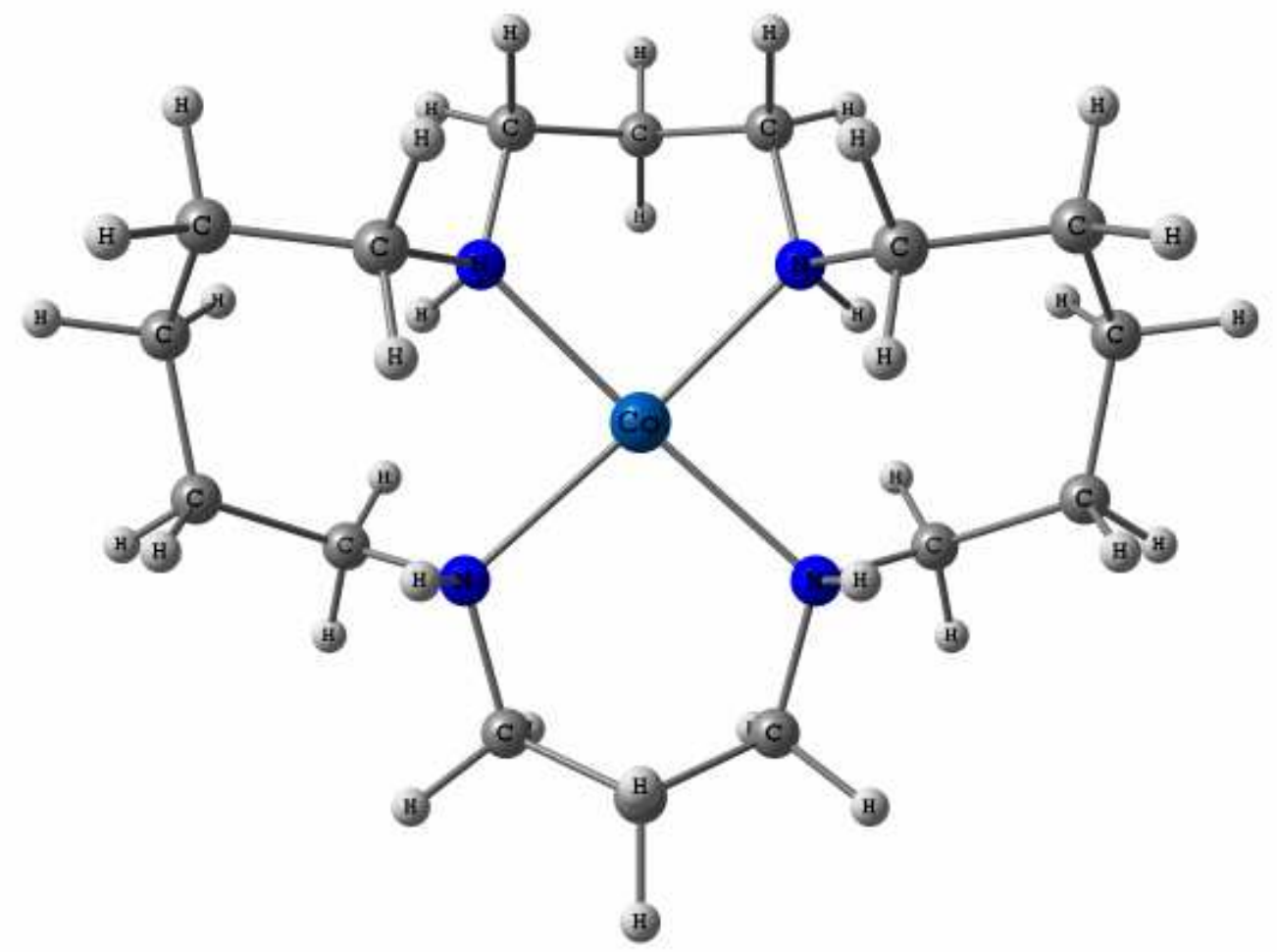

Figura 2-E. Estrutura otimizada do complexo [20]aneN4(qp) de $\mathrm{Co}^{2+}$. 


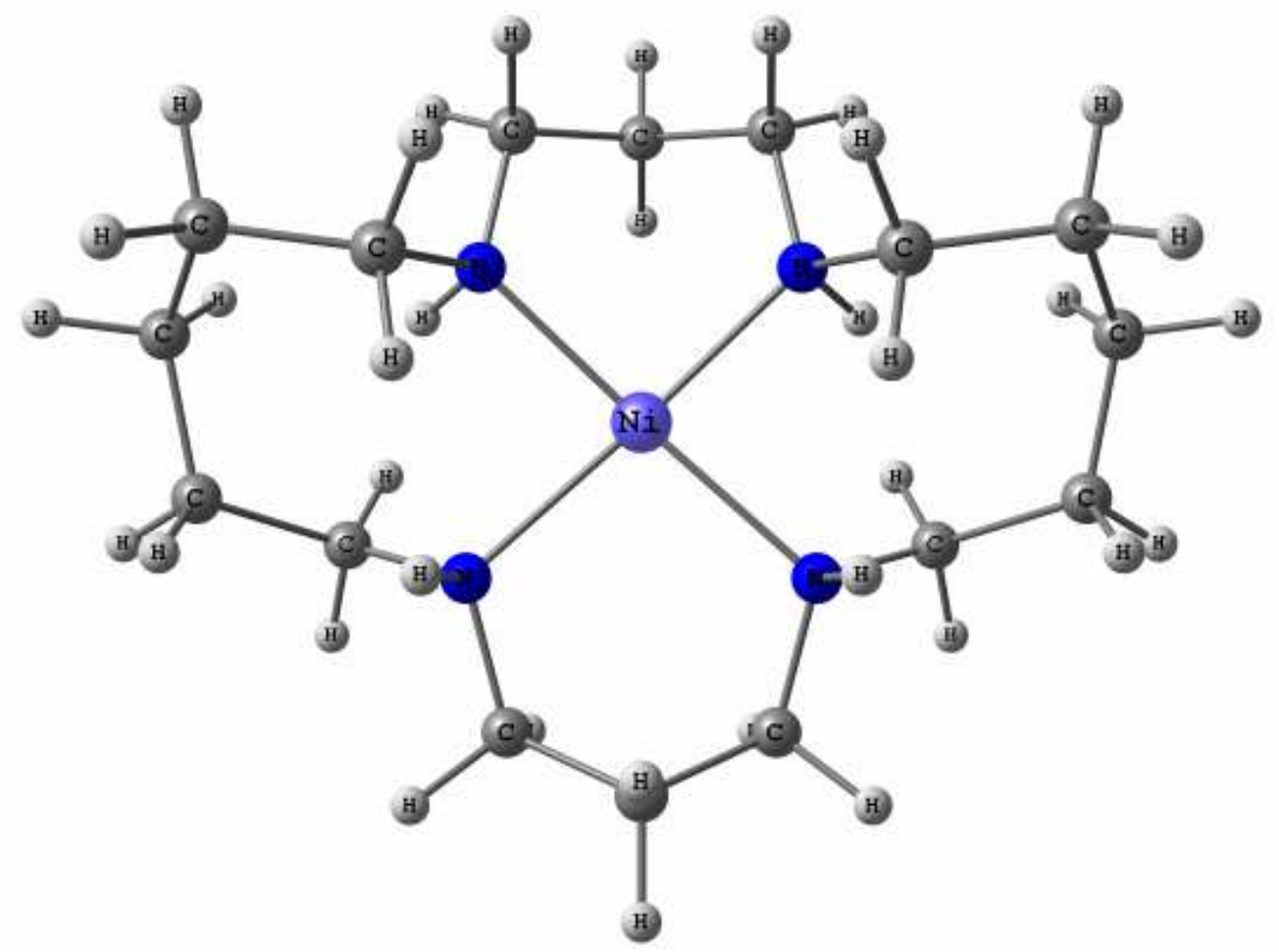

Figura 3-E. Estrutura otimizada do complexo [20]aneN4(qp) de $\mathrm{Ni}^{2+}$.

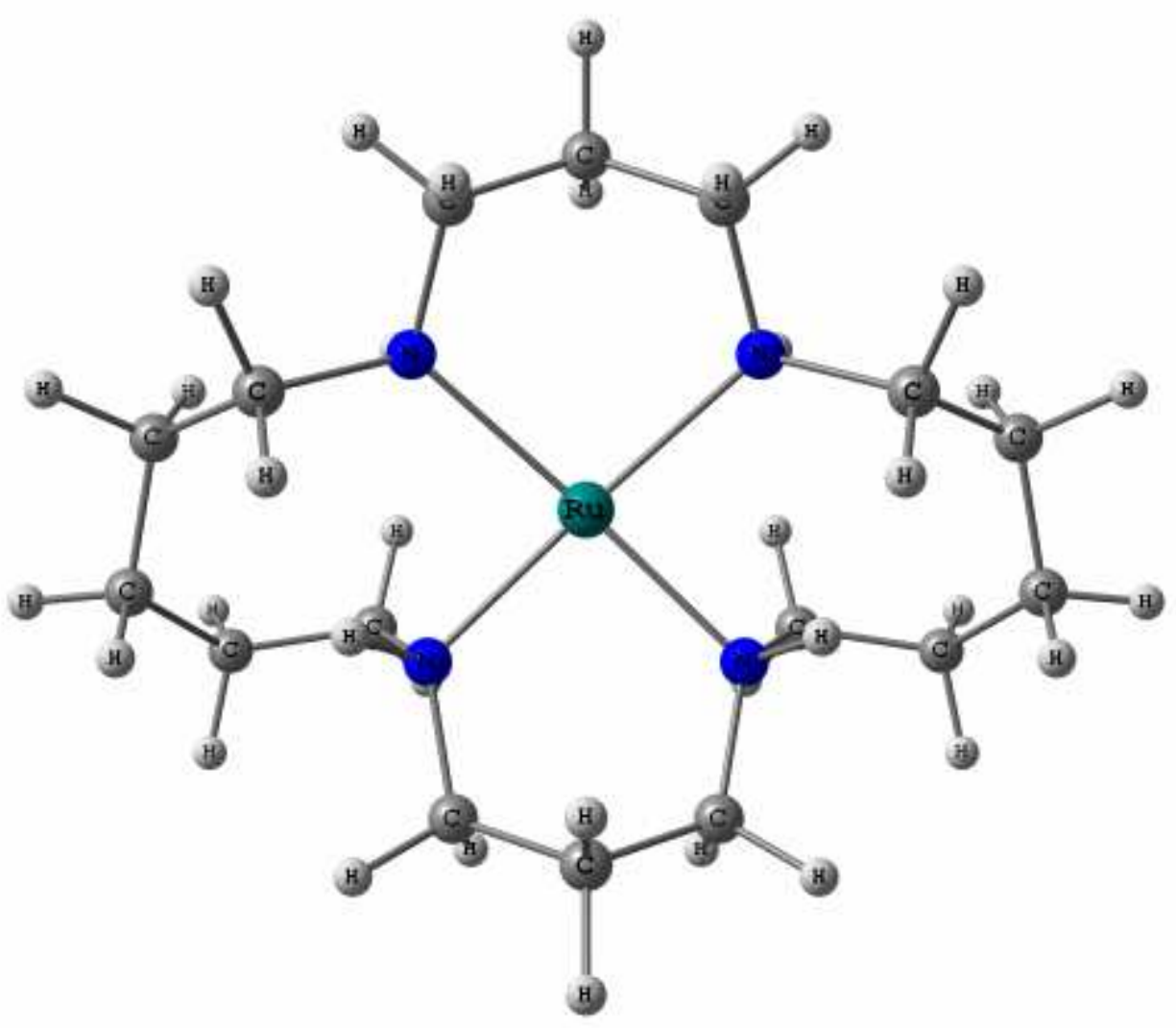

Figura 4-E. Estrutura otimizada do complexo [20]aneN4(qp) de $\mathrm{Ru}^{2+}$. 


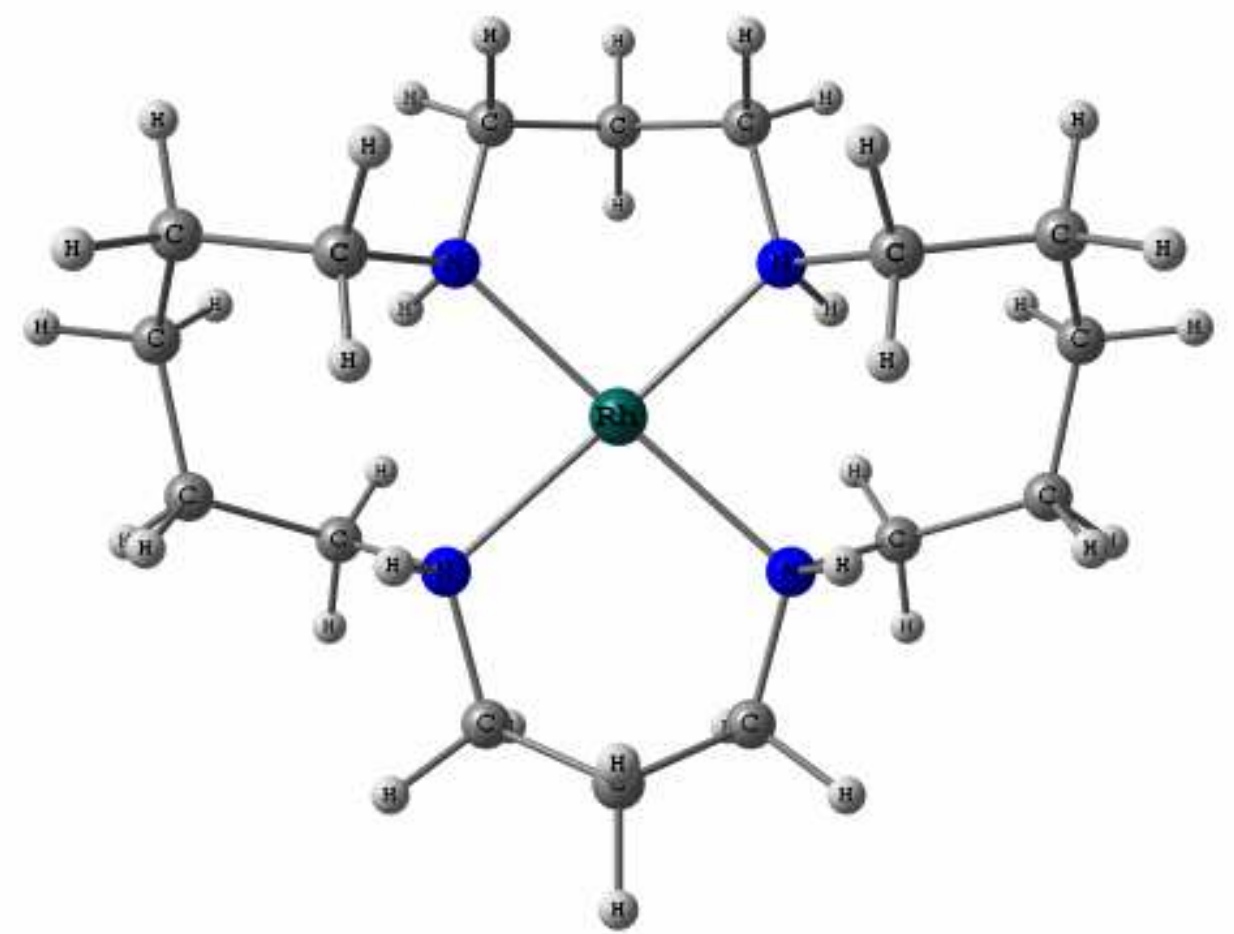

Figura 5-E. Estrutura otimizada do complexo [20]aneN4(qp) de $\mathrm{Rh}^{2+}$.

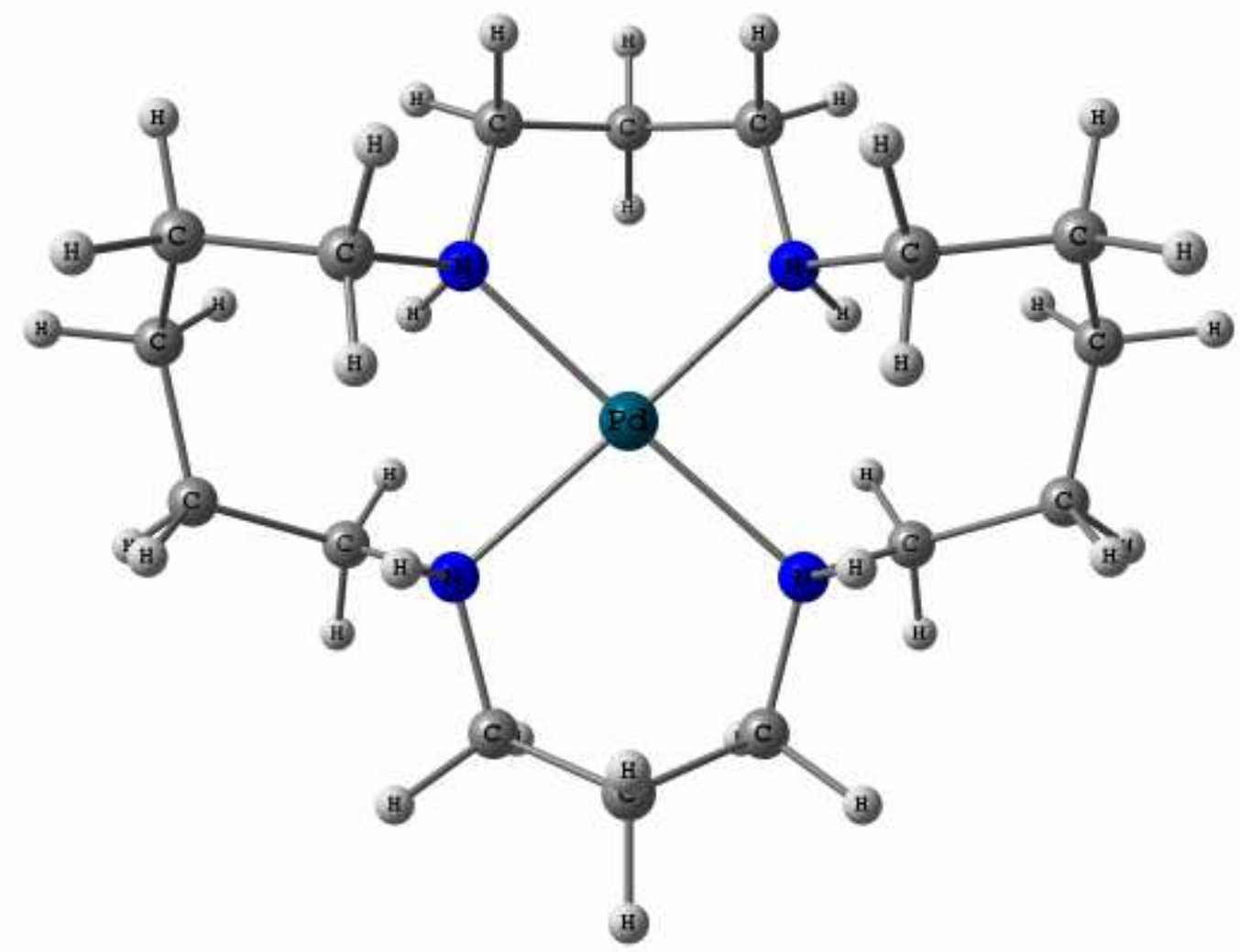

Figura 6-E. Estrutura otimizada do complexo [20]aneN4(qp) de $\mathrm{Pd}^{2+}$. 


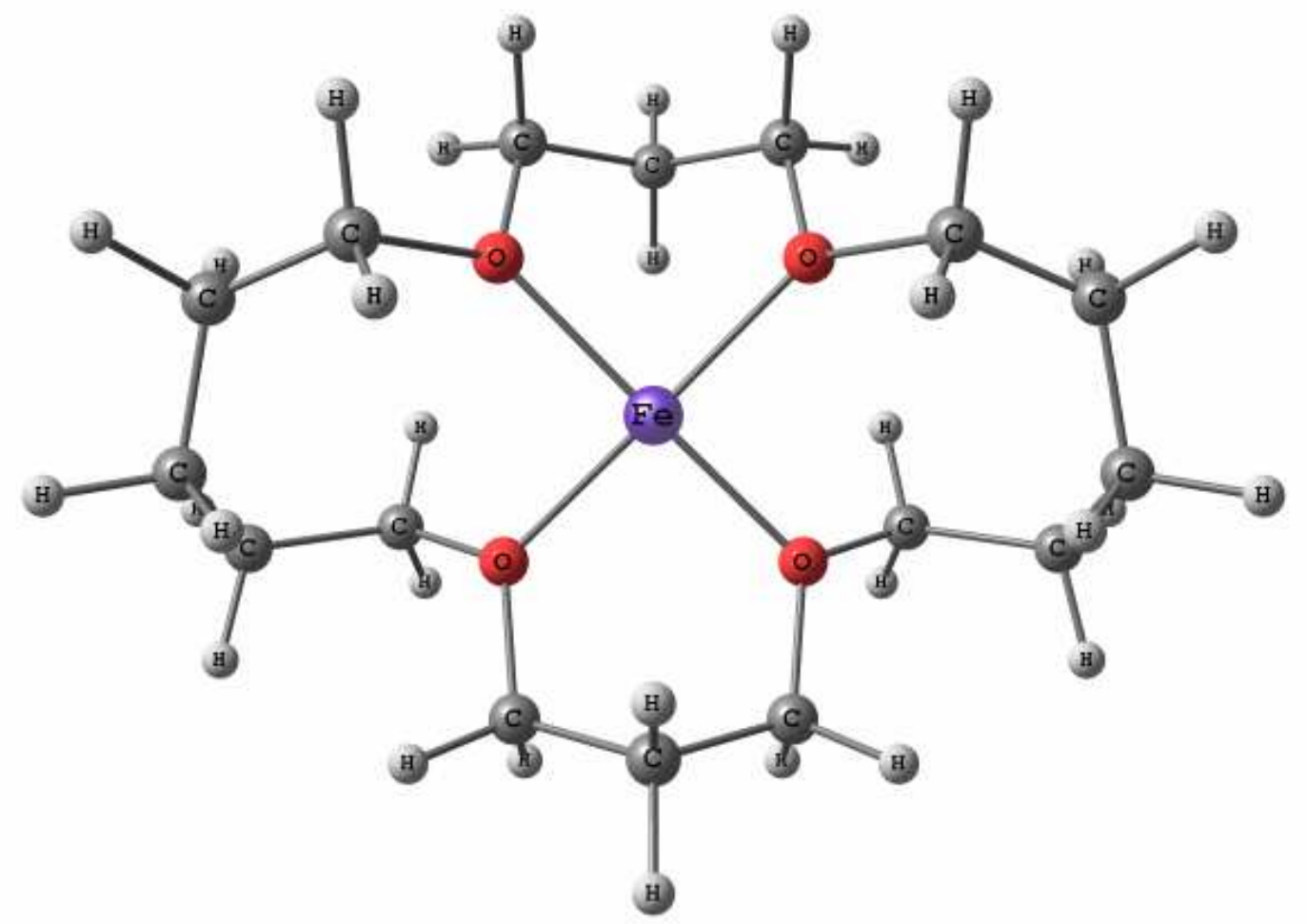

Figura 7-E. Estrutura otimizada do complexo [20]aneO4(qp) de $\mathrm{Fe}^{2+}$.

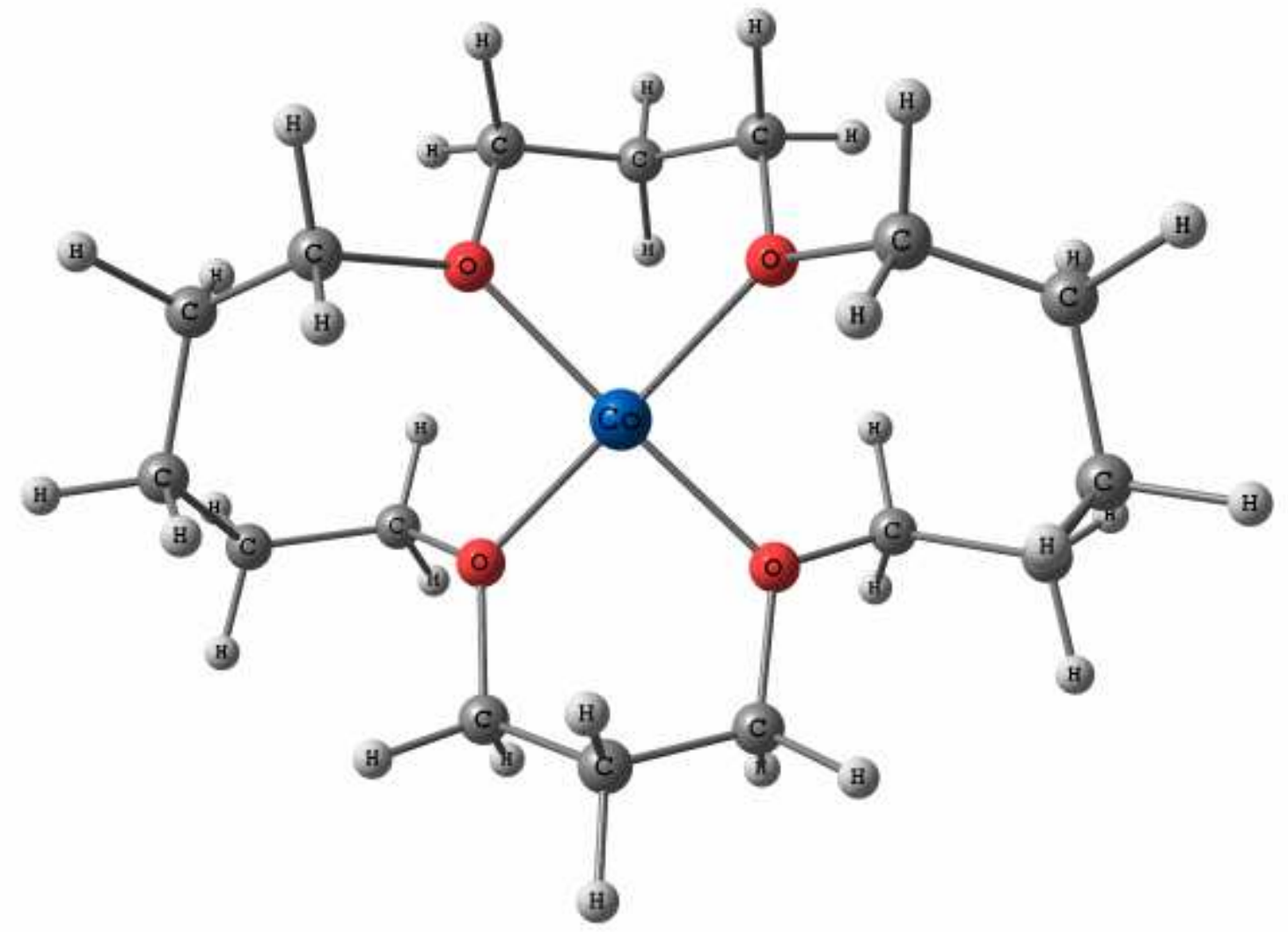

Figura 8-E. Estrutura otimizada do complexo [20]aneO4(qp) de $\mathrm{Co}^{2+}$. 


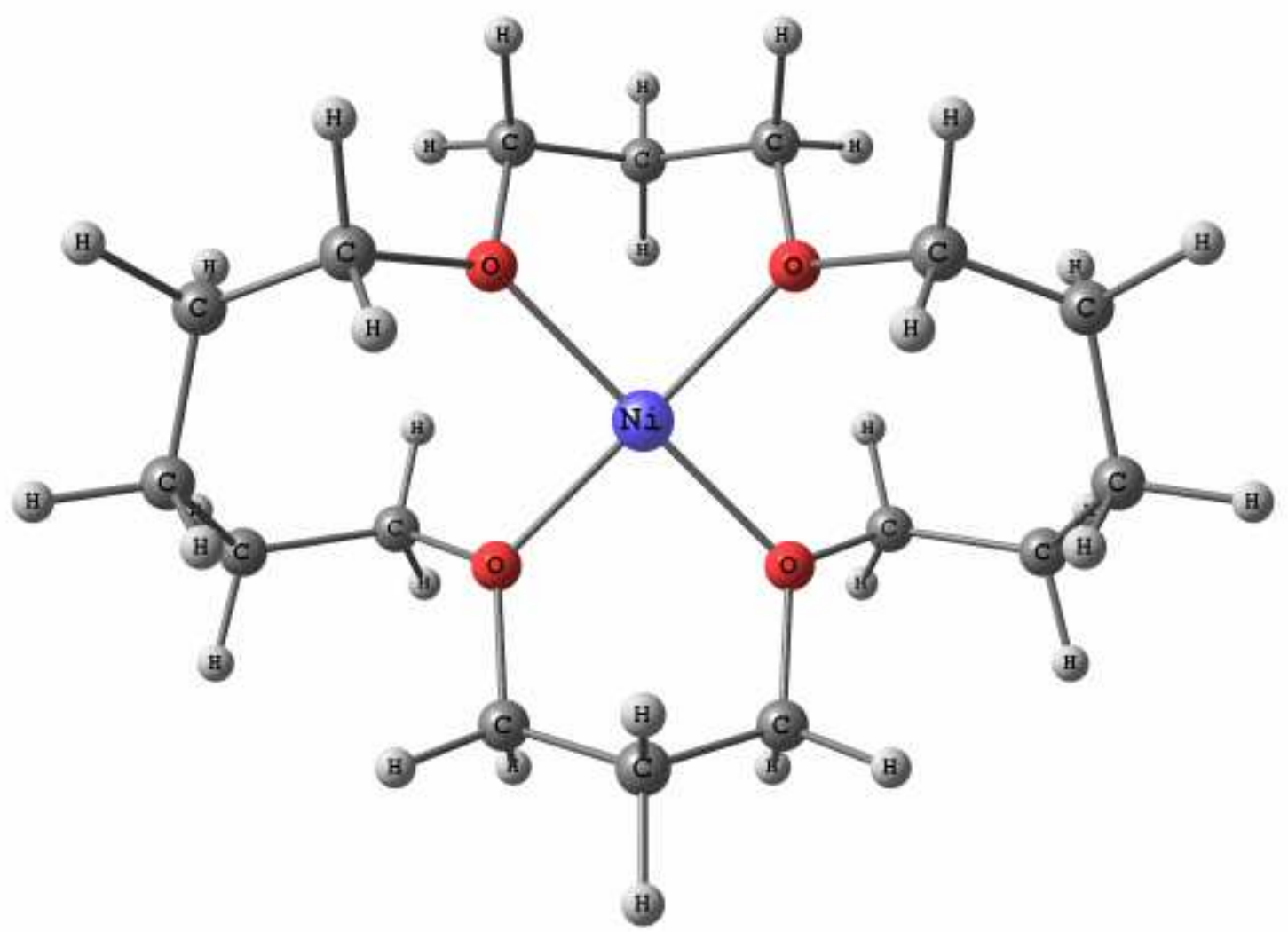

Figura 9-E. Estrutura otimizada do complexo [20]aneO4(qp) de $\mathrm{Ni}^{2+}$.

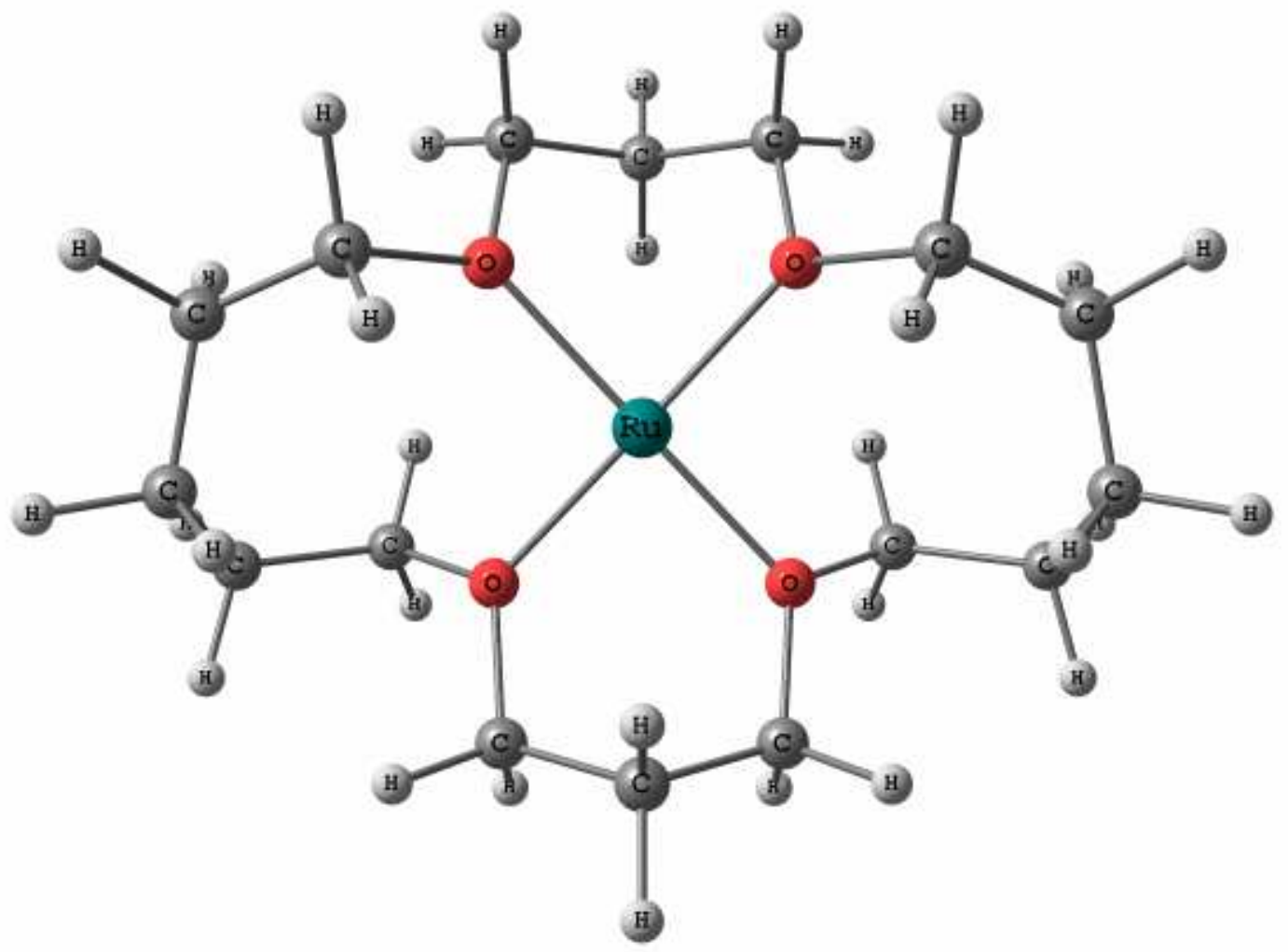

Figura 10-E. Estrutura otimizada do complexo [20]aneO4(qp) de $\mathrm{Ru}^{2+}$. 


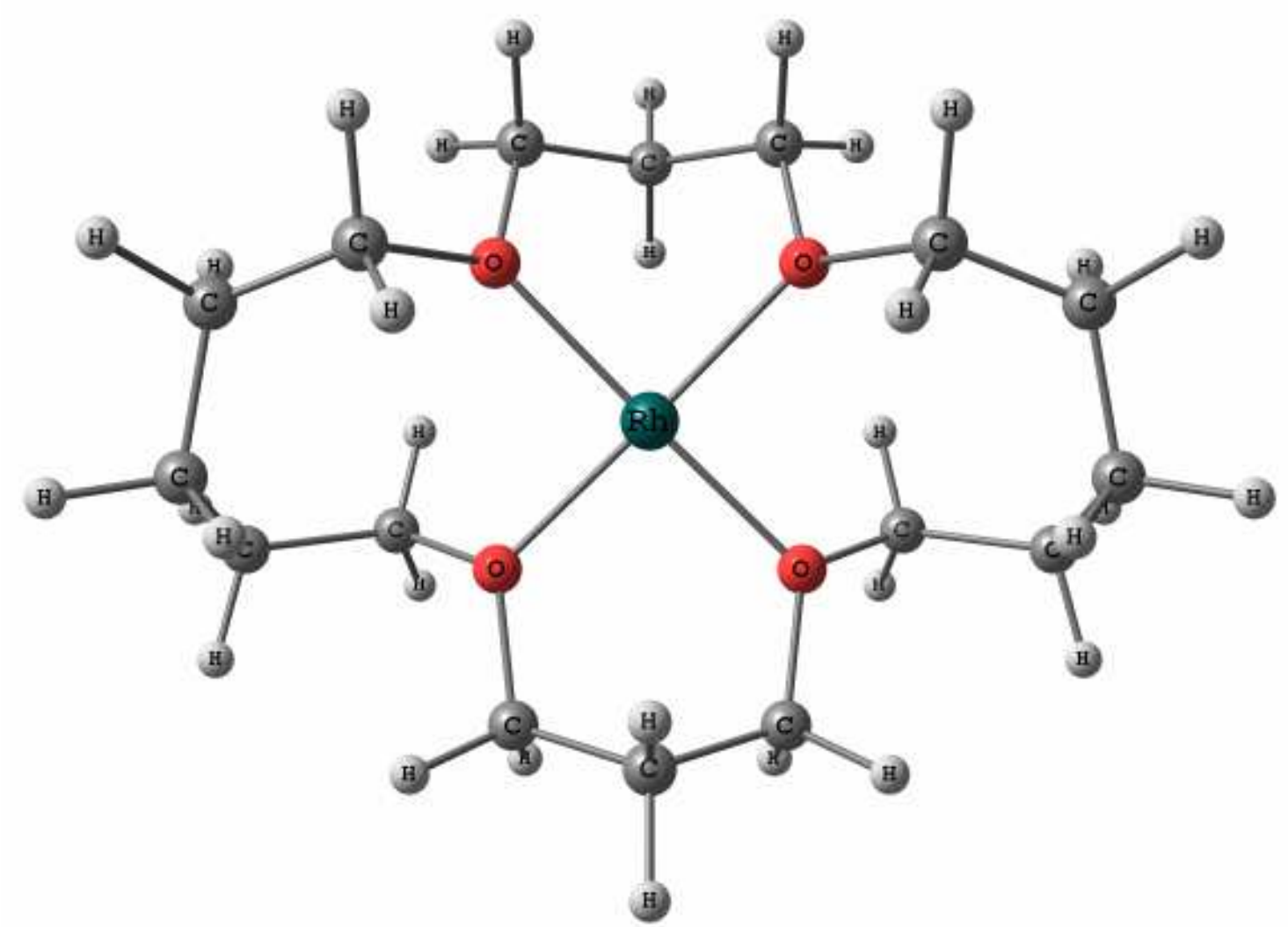

Figura 11-E. Estrutura otimizada do complexo [20]aneO4(qp) de $\mathrm{Rh}^{2+}$.

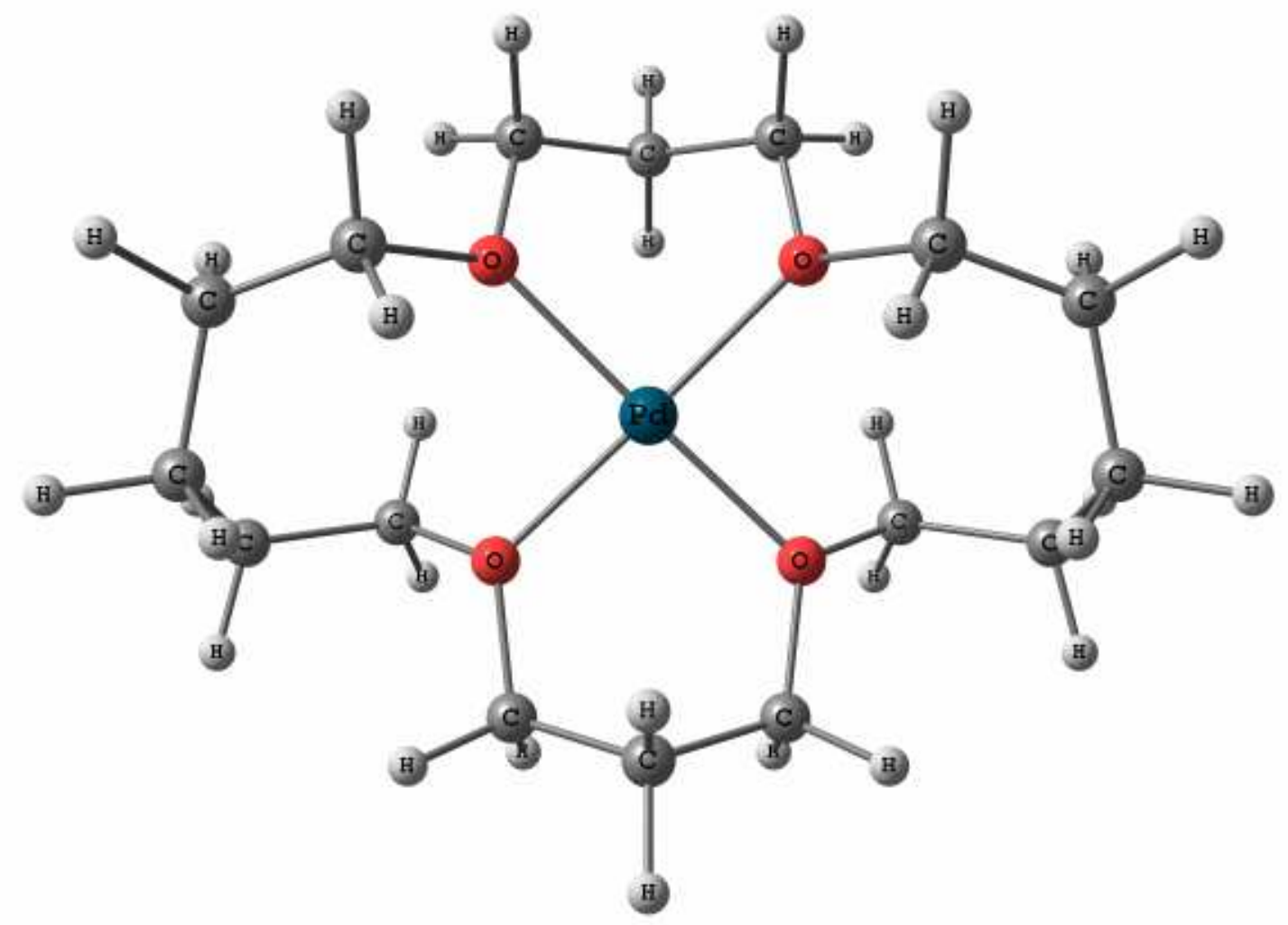

Figura 12-E. Estrutura otimizada do complexo [20]aneO4(qp) de $\mathrm{Pd}^{2+}$. 